
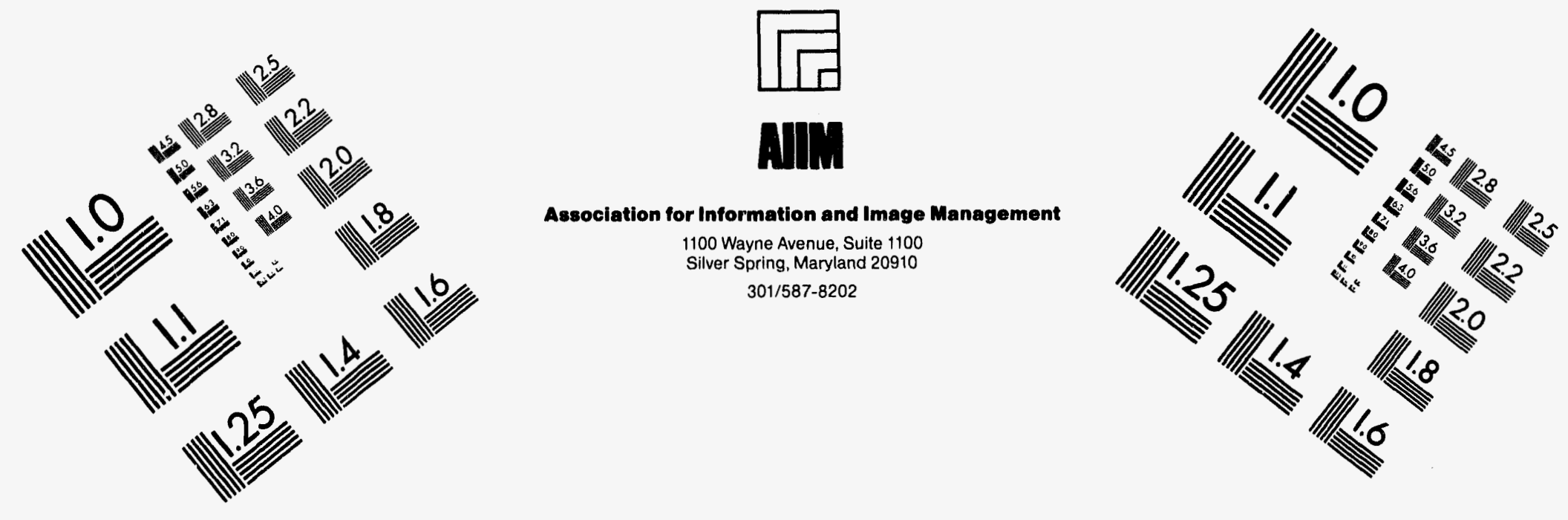

\title{
Centimeter
}

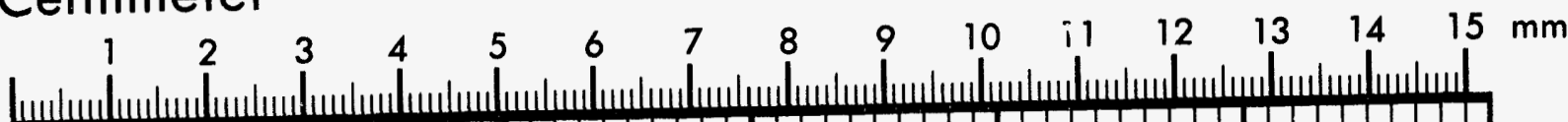

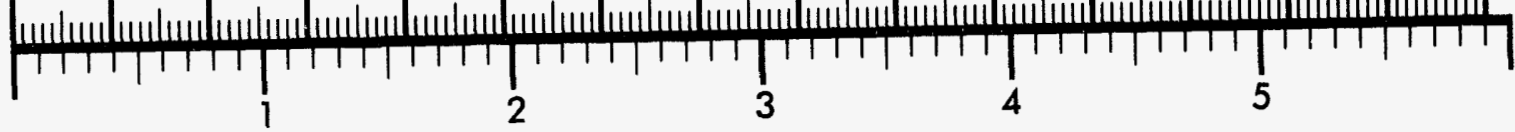
Inches
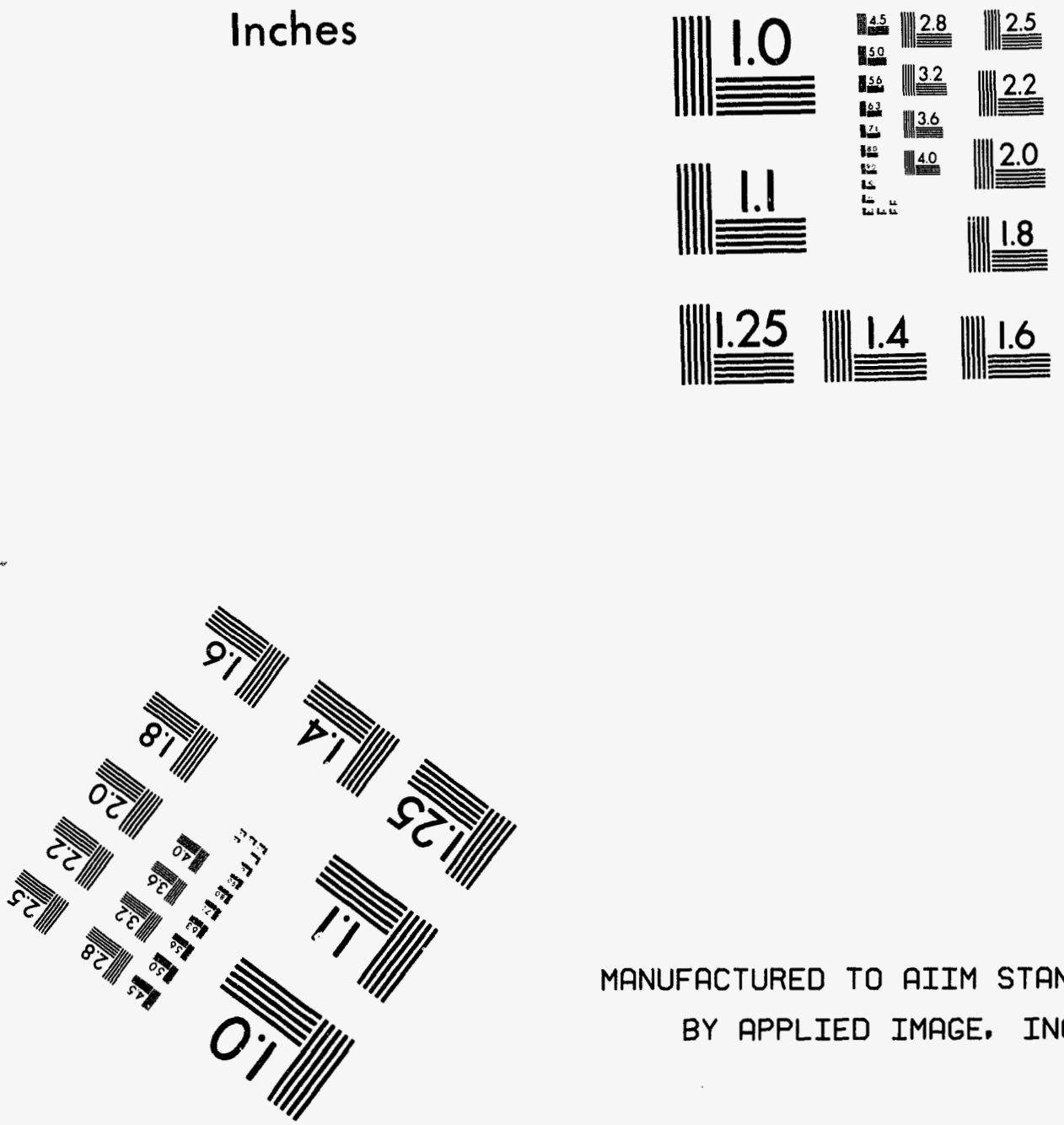

MANUFACTURED TO AIIM STANDARDS

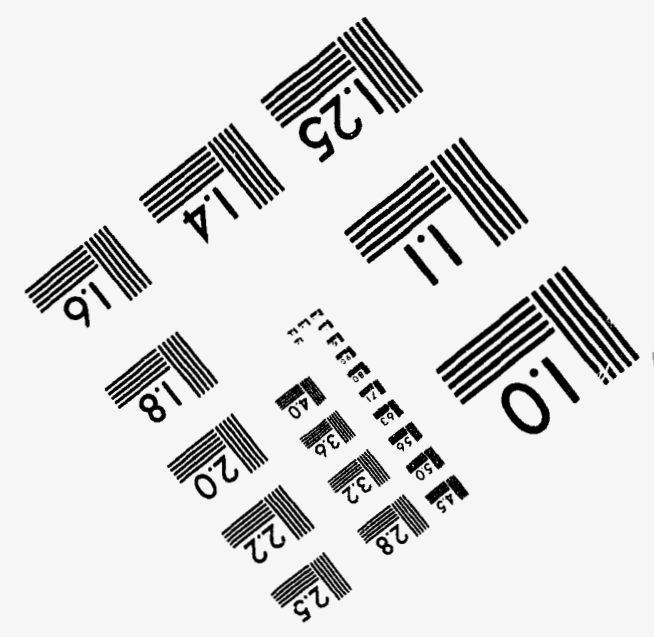



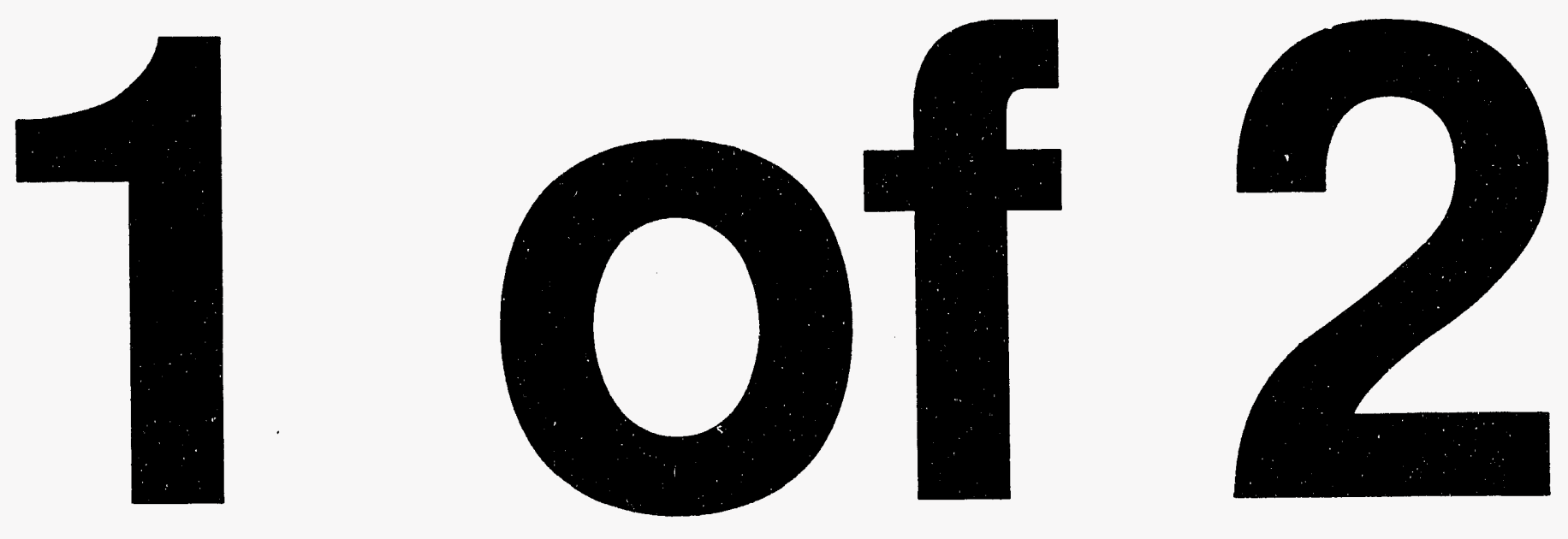
NUREG/CR-6121

EGG-2717

\section{Component Evaluation for Intersystem Loss-of-Coolant Accidents in Advanced Light Water Reactors}

Manuscript Completed: November 1993

Date Published: July 1994

Prepared by

A. G. Ware

Idaho National Engineering Laboratory

Managed by U.S. Department of Energy

EG\&G Idaho, Inc.

Idaho Falls, ID 83415

Prepared for

Division of Engineering

Office of Nuclear Regulatory Research

U.S. Nuclear Regulatory Commission

Washington, DC 20555-0001

NRC FIN L2498

Under Contract No. DE-AC07-76ID01570

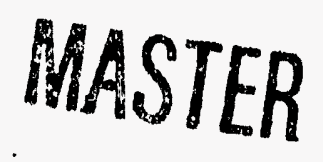




\begin{abstract}
Using the methodology outlined in NUREG/CR-5603 this report evaluates (on a probabilistic basis) design rules for components in ALWRs that could be subjected to intersystem loss-of-coolant accidents (ISLOCAs). The methodology is intended for piping elements, flange connections, on-line pumps and valves, and heat exchangers. The NRC has directed that the design rules be evaluated for BWR pressures of $7.04 \mathrm{MPa}$ (1025 psig), PWR pressures of $15.4 \mathrm{MPa}$ (2235 psig), and $177^{\circ} \mathrm{C}\left(350^{\circ} \mathrm{F}\right)$, and has established a goal of $90 \%$ probability that system rupture will not occur during an ISLOCA event. The results of the calculations in this report show that components designed for a pressure of 0.4 of the reactor coolant system operating pressure will satisfy the NRC survival goal in most cases. Specific recommendations for component strengths for BWR and PWR applications are made in the report. A peer review panel of nationally recognized experts was selected to review and critique the initial results of this program.
\end{abstract}

FIN L2498-Design Criteria for ISLOCA 


\section{CONTENTS}

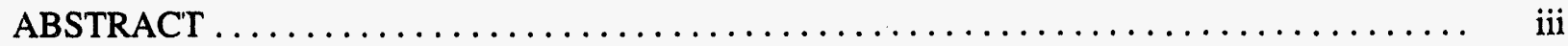

EXECUTIVE SUMMARY $\ldots \ldots \ldots \ldots \ldots \ldots \ldots \ldots \ldots \ldots \ldots \ldots \ldots \ldots \ldots \ldots \ldots \ldots \ldots \ldots$

ACKNOWLEDGMENTS $\ldots \ldots \ldots \ldots \ldots \ldots \ldots \ldots \ldots \ldots \ldots \ldots \ldots \ldots \ldots \ldots \ldots \ldots \ldots$

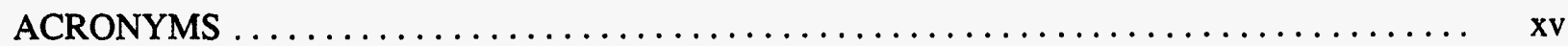

NOMENCLATURE $\ldots \ldots \ldots \ldots \ldots \ldots \ldots \ldots \ldots \ldots \ldots \ldots \ldots \ldots \ldots \ldots \ldots \ldots \ldots \ldots$

1. INTRODUCTION $\ldots \ldots \ldots \ldots \ldots \ldots \ldots \ldots \ldots \ldots \ldots \ldots \ldots \ldots \ldots \ldots \ldots$

$1.1 \quad$ Background $\ldots \ldots \ldots \ldots \ldots \ldots \ldots \ldots \ldots \ldots \ldots \ldots \ldots \ldots \ldots \ldots \ldots \ldots \ldots \ldots \ldots \ldots \ldots$

1.2 INEL ISLOCA Research Programs $\ldots \ldots \ldots \ldots \ldots \ldots \ldots \ldots \ldots \ldots \ldots \ldots \ldots$

2. METHODOLOGY DEVELOPMENT $\ldots \ldots \ldots \ldots \ldots \ldots \ldots \ldots \ldots \ldots \ldots \ldots \ldots \ldots$

2.1 Methodology Outline for Allowable Stresses $\ldots \ldots \ldots \ldots \ldots \ldots \ldots \ldots \ldots \ldots$

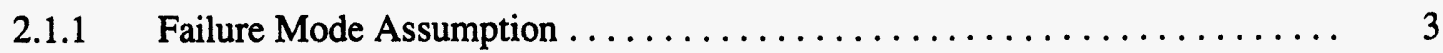

2.1.2 Ultimate Tensile Strength Curve $\ldots \ldots \ldots \ldots \ldots \ldots \ldots \ldots \ldots \ldots \ldots \ldots \ldots$

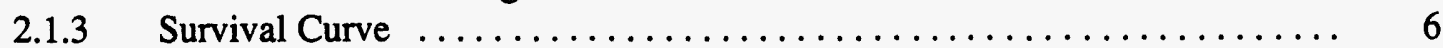

2.2 Methodology for Leak Rate Assumptions $\ldots \ldots \ldots \ldots \ldots \ldots \ldots \ldots \ldots \ldots \ldots$

2.3 Investigations of Other Possible Assumptions $\ldots \ldots \ldots \ldots \ldots \ldots \ldots \ldots \ldots \ldots$

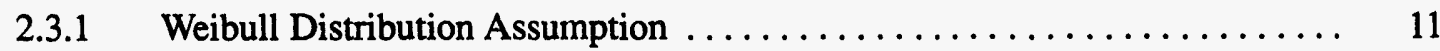

2.3.2 Alternate Uncertainty Assumption $\ldots \ldots \ldots \ldots \ldots \ldots \ldots \ldots \ldots \ldots \ldots$

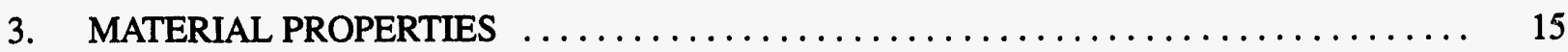

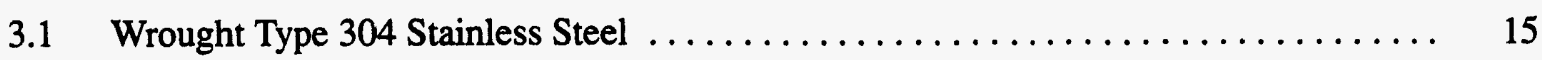

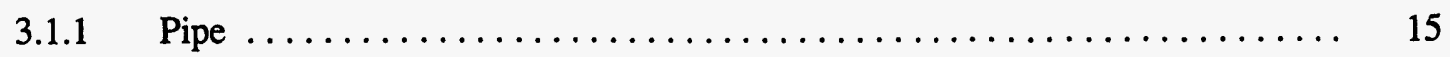

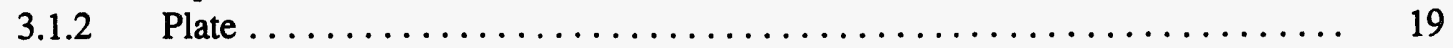

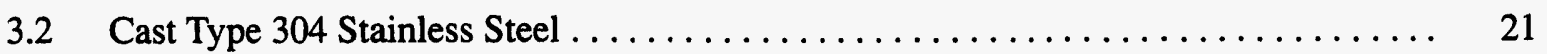

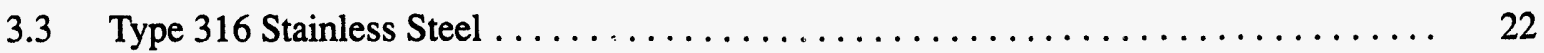

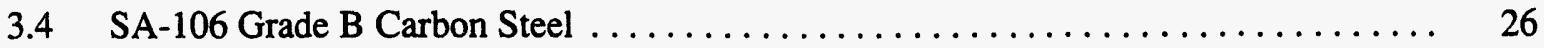

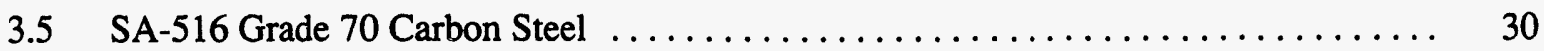

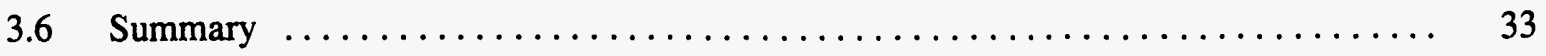

4. COMPONENT EVALUATIONS $\ldots \ldots \ldots \ldots \ldots \ldots \ldots \ldots \ldots \ldots \ldots \ldots \ldots \ldots$ 


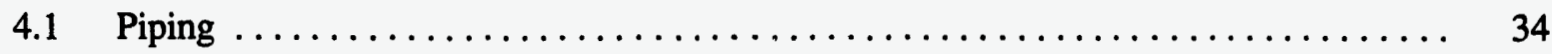

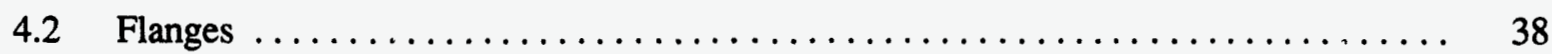

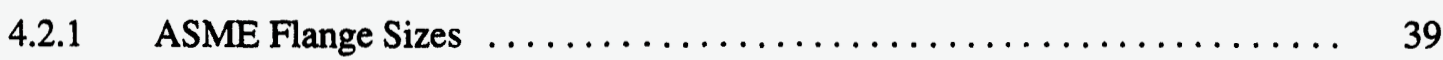

4.2.2 Methodology to Determine the GLP ................... 39

4.2.3 Flange Size and Bolt Preload Verification Calculations ............ 42

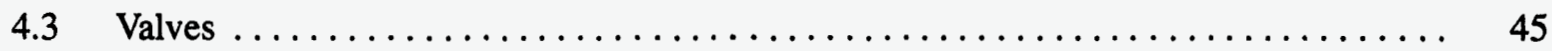

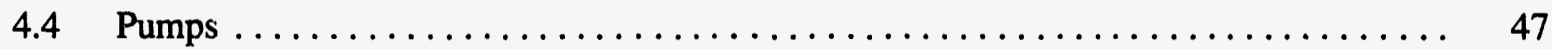

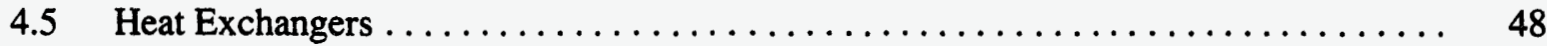

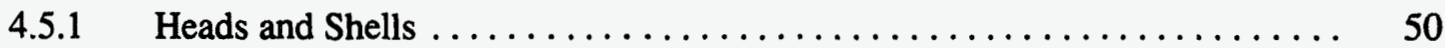

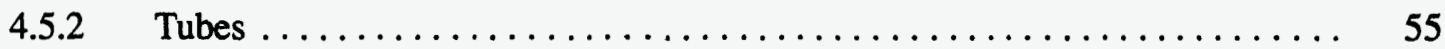

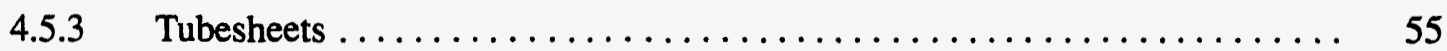

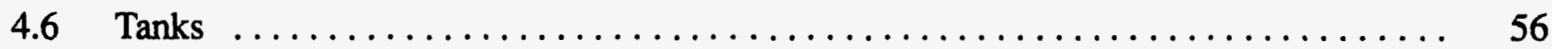

5. CONCLUSIONS AND RECOMMENDATIONS $\ldots \ldots \ldots \ldots \ldots \ldots \ldots \ldots \ldots \ldots \ldots$

6. REFERENCES $\ldots \ldots \ldots \ldots \ldots \ldots \ldots \ldots \ldots \ldots \ldots \ldots \ldots \ldots \ldots \ldots \ldots \ldots$

Attachment 1 Peer Review Panel Report $\ldots \ldots \ldots \ldots \ldots \ldots \ldots \ldots \ldots \ldots \ldots \ldots \ldots \ldots \ldots \ldots \ldots$

Attachment 2 -Survival Confidence Tables $\ldots \ldots \ldots \ldots \ldots \ldots \ldots \ldots \ldots \ldots \ldots \ldots \ldots \ldots \ldots$ 


\section{LIST OF FIGURES}

1. Engineering stress-strain curve for stainless steel (data from Boyer, 1987) $\ldots \ldots \ldots \ldots \ldots$

2. Engineering stress-strain curve for carbon steel (data from Boyer, 1987) $\ldots \ldots \ldots \ldots \ldots$

3. Assumed ultimate tensile strength distribution for Type 304 stainless steel

(a) $10^{-3}$ (b) $10^{-4}$ probability of failure at yield stress $\ldots \ldots \ldots \ldots \ldots \ldots \ldots \ldots \ldots \ldots$

4. Assumed ultimate tensile strength distribution for SA-106 Grade B carbon steel

(a) $10^{-3}$ (b) $10^{-4}$ probability of failure at yield stress $\ldots \ldots \ldots \ldots \ldots \ldots \ldots \ldots \ldots \ldots \ldots$

5. Comparisons of allowable stress limits for Type 304 stainless steel pipe: ASME

Code Levels $2.5 \mathrm{~A}$ and $\mathrm{D}$ and probability-based confidence limits $\left(10^{-3}\right.$ probability

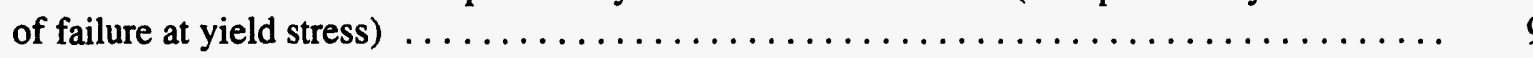

6. Comparisons of allowable stress limits for Type 304 stainless steel pipe: ASME

Code Levels $2.5 \mathrm{~A}$ and $\mathrm{D}$ and probability-based confidence limits $\left(10^{-4}\right.$ probability

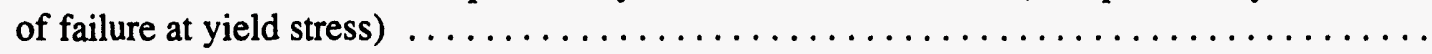

7. Comparisons of allowable stress limits for SA-106 Grade B carbon steel pipe:

ASME Code Levels $2.5 \mathrm{~A}$ and $\mathrm{D}$ and probability-based confidence limits

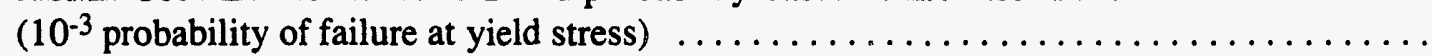

8. Comparison of lognormal and Weibull representations of the ultimate failure

stress for SA-106 Grade B carbon steel at $400^{\circ} \mathrm{F}$

9. Survival confidences at 2.5 times the Level A stress for various probabilities of

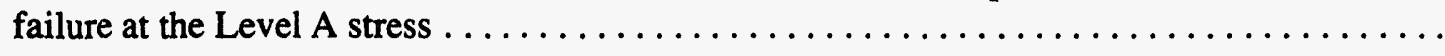

10. Ultimate tensile strength data for wrought Type 304 stainless steel pipe $\ldots \ldots \ldots \ldots \ldots$

11. Yield stress data for wrought Type 304 stainless steel pipe $\ldots \ldots \ldots \ldots \ldots \ldots \ldots \ldots \ldots$

12. Ultimate tensile strength curve fit for wrought Type 304 stainless steel pipe $\ldots \ldots \ldots \ldots \ldots$

13. Yield stress curve fit for wrought Type 304 stainless steel pipe $\ldots \ldots \ldots \ldots \ldots \ldots \ldots \ldots$

14. Comparison of ultimate tensile strength data for wrought Type 304 stainless steel plate $\ldots \ldots \quad 19$

15. Comparison of yield stress data for wrought Type 304 stainless steel plate $\ldots \ldots \ldots \ldots \ldots \ldots$

16. Curve fit for wrought Type 304 stainless steel plate ultimate tensile strength data $\ldots \ldots \ldots 20$

17. Curve fit for wrought Type 304 stainless steel plate yield stress data $\ldots \ldots \ldots \ldots \ldots \ldots$

18. Comparison of ultimate tensile strength data for cast Type 304 stainless steel $\ldots \ldots \ldots \ldots 22$

19. Comparison of yield stress data for cast Type 304 stainless steel $\ldots \ldots \ldots \ldots \ldots \ldots \ldots$

20. Curve fit for cast Type 304 stainless steel ultimate tensile strength data $\ldots \ldots \ldots \ldots \ldots$ 
21. Curve fit for cast Type 304 stainless steel yield stress data $\ldots \ldots \ldots \ldots \ldots \ldots \ldots \ldots$

22. Comparison of ultimate tensile strength data for Type 316 stainless steel $\ldots \ldots \ldots \ldots \ldots$

23. Comparison of yield stress data for Type 316 stainless steel $\ldots \ldots \ldots \ldots \ldots \ldots \ldots \ldots$

24. Curve fit for Type 316 stainless steel ultimate tensile strength data $\ldots \ldots \ldots \ldots \ldots \ldots \ldots$

25. Curve fit for Type 316 stainless steel yield stress data $\ldots \ldots \ldots \ldots \ldots \ldots \ldots \ldots \ldots$

26. Curve fit comparison of Types 304 and 316 stainless steel ultimate tensile strength data . ... 28

27. Curve fit comparison of Types 304 and 316 stainless steel yield stress data ......... 29

28. Normal and lognormal representations of SA-106 Grade B carbon steel ultimate tensile strength data from NUREG/CR-2137 (room temperature) $\ldots \ldots \ldots \ldots \ldots \ldots \ldots$

29. Normal and lognormal representations of SA-106 Grade B carbon steel yield stress data from NUREG/CR-2137 (room temperature) $\ldots \ldots \ldots \ldots \ldots \ldots \ldots \ldots \ldots \ldots$

30. Ultimate tensile strength data for SA-106 Grade B carbon steel $\ldots \ldots \ldots \ldots \ldots \ldots \ldots \ldots$

31. Yield stress data for SA-106 Grade B carbon steel $\ldots \ldots \ldots \ldots \ldots \ldots \ldots \ldots \ldots \ldots$

32. Ultimate tensile strength data for SA-516 Grade 70 carbon steel $\ldots \ldots \ldots \ldots \ldots \ldots \ldots$

33. Yield stress data for SA-516 Grade 70 carbon steel $\ldots \ldots \ldots \ldots \ldots \ldots \ldots \ldots \ldots$

34. Raised-face flange with Style CG gasket $\ldots \ldots \ldots \ldots \ldots \ldots \ldots \ldots \ldots \ldots \ldots \ldots \ldots$

35. Fraction of pressure load transferred to gasket (Figure $3-1$ of NUREG/CR-5603) $\ldots \ldots \ldots 41$

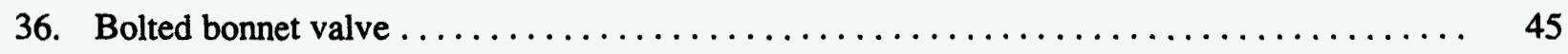

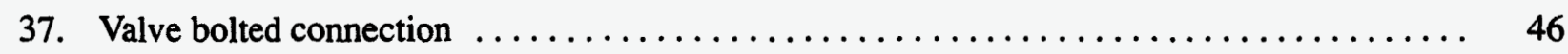

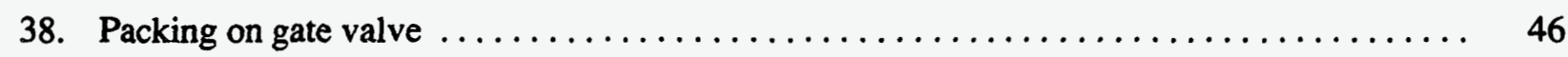

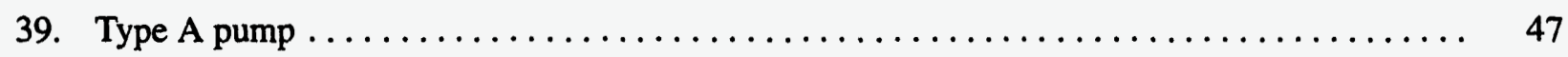

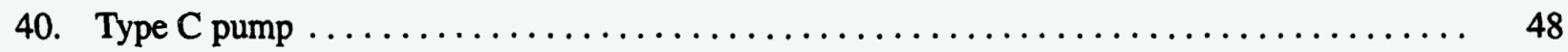

41. PWR RHR heat exchanger $\ldots \ldots \ldots \ldots \ldots \ldots \ldots \ldots \ldots \ldots \ldots \ldots \ldots \ldots \ldots \ldots \ldots \ldots \ldots$

\section{LIST OF TABLES}

1. Failure stress probability curve parameters with failure probability of $10^{-3}$

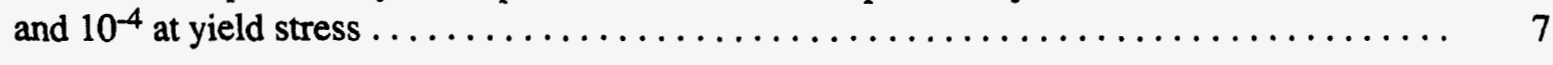

2. Comparison of allowable stresses computed using Weibull and lognormal distributions .... 12

3. Computation of ASME Code allowable stress for SA-106 Grade B carbon steel

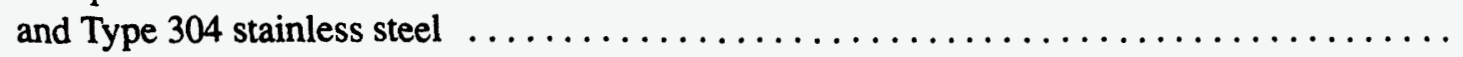


4. Curve fit constants for Type 304 wrought stainless steel $\ldots \ldots \ldots \ldots \ldots \ldots \ldots \ldots$

5. Comparison of survival confidence stress values for wrought Type 304 stainless

steel pipe $\left(10^{-3}\right.$ probability of failure at yield stress $) \ldots \ldots \ldots \ldots \ldots \ldots \ldots \ldots \ldots \ldots \ldots \ldots \ldots \ldots \ldots \ldots$

6. Comparison of survival confidence stress values for wrought Type 304 stainless

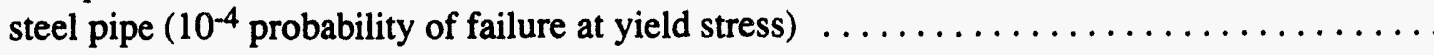

7. Comparison of survival confidence stress values for Type 304 stainless steel

plate at $350^{\circ} \mathrm{F}\left(10^{-3}\right.$ and $10^{-4}$ probabilities of failure at yield stress $) \ldots \ldots \ldots \ldots \ldots \ldots \ldots 21$

8. Curve fit constants for Type 304 cast stainless steel pipe ................... 23

9. Comparison of survival confidence stress values for cast Type 304 stainless steel

pipe at $350^{\circ} \mathrm{F}\left(10^{-3}\right.$ and $10^{-4}$ probabilities of failure at yield stress $) \ldots \ldots \ldots \ldots \ldots \ldots \ldots 25$

10. Curve fit constants for Type 316 stainless steel $\ldots \ldots \ldots \ldots \ldots \ldots \ldots \ldots \ldots \ldots \ldots$

11. Comparison of survival confidence stress values for Type 316 stainless steel at $350^{\circ} \mathrm{F}\left(10^{-3}\right.$ and $10^{-4}$ probabilities of failure at yield stress $) \ldots \ldots \ldots \ldots \ldots \ldots \ldots \ldots \ldots$

12. Survival confidences for Type 304 stainless steel BWR pipe $\ldots \ldots \ldots \ldots \ldots \ldots \ldots \ldots$

13. Survival confidences for Type 316 stainless steel BWR pipe $\ldots \ldots \ldots \ldots \ldots \ldots \ldots \ldots$

14. Survival confidences for SA-106 Grade B carbon steel BWR pipe $\ldots \ldots \ldots \ldots \ldots \ldots$

15. Survival confidences for Type 304 stainless steel PWR pipe $\ldots \ldots \ldots \ldots \ldots \ldots \ldots \ldots$

16. Survival confidences for Type 316 stainless steel PWR pipe $\ldots \ldots \ldots \ldots \ldots \ldots \ldots \ldots \ldots$

17. Survival confidences for SA-106 Grade B carbon steel PWR pipe $\ldots \ldots \ldots \ldots \ldots \ldots$

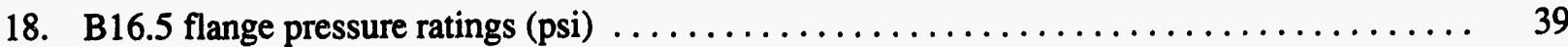

19. BWR flange calculations for 40,000 psi bolt preload $\ldots \ldots \ldots \ldots \ldots \ldots \ldots \ldots \ldots \ldots$

20. PWR flange calculations for 40,000 psi bolt preload $\ldots \ldots \ldots \ldots \ldots \ldots \ldots \ldots \ldots \ldots$

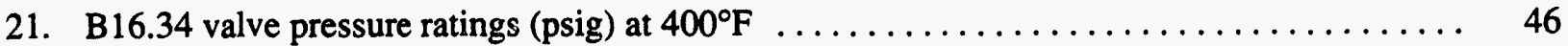

22. Survival confidences for Type 304 stainless steel cylindrical shells at $350^{\circ} \mathrm{F} \ldots \ldots \ldots \ldots 2$

23. Survival confidences for Type $\mathbf{3 0 4}$ stainless steel shells at BWR conditions constructed of plates of thicknesses divisible by $1 / 8$ in. . . . . . . . . . 52

24. Knuckle buckling pressures for torispherical heads at $350^{\circ} \mathrm{F} \ldots \ldots \ldots \ldots \ldots \ldots \ldots \ldots$

25. Survival confidences for ellipsoidal heads at $350^{\circ} \mathrm{F} \ldots \ldots \ldots \ldots \ldots \ldots \ldots \ldots \ldots$

26. Survival confidences for Type 304 BWR heat exchanger tubes subject to internal pressure designed to TEMA standards $\ldots \ldots \ldots \ldots \ldots \ldots \ldots \ldots \ldots \ldots \ldots \ldots \ldots \ldots$ 
27. Survival confidences for Type 304 PWR heat exchanger tubes subject to internal pressure designed to TEMA standards 


\section{EXECUTIVE SUMMARY}

Low-pressure piping systems that branch to the reactor coolant systems (RCSs) of light water reactors (LWRs) are normally protected by multiple valves from the reactor coolant. Failure or misalignment of these isolation valves leads to an intersystem (sometimes called interfacing system) loss-of-coolant accident (ISLOCA), and to the potential leak or rupture of low-pressure systems.

SECY-90-016 (NRC, 1990) and the associated Staff Requirements Memorandum from the Nuclear Regulatory Commission (NRC) Commissioners require evolutionary advanced light water reactor (ALWR) plant designers to include ISLOCA in the design basis; this requirement has been extended to passive plant designers as well. However, the NRC did not initially provide design stress allowables or uniform criteria for ISLOCA design. Subsequently, it was decided to use Service Level A design stresses and a fraction of the RCS design pressure to achieve an acceptable overall system failure probability.

Four ALWRs are presently under review by the NRC staff: ABWR, SBWR, AP600, and System $80+$. The piping systems of these plants that may be affected by ISLOCAs include, for example, the residual heat removal system, the safety injection system, the makeup and purification system, and other low-pressure lines that branch to the RCS. While the chief safety concern deals with low-pressure lines that bypass containment, piping that remains entirely within the containment is of concern as well.

To date, no full ISLOCAs have occurred in U.S. nuclear plants, though there have been several instances of leakage past valves from the RCS to connecting systems. These instances have been benign and correctable by the plant staff. The total ISLOCA core damage frequency for existing LWRs was estimated to be in the range of $2 \times 10^{-6}$ events per reactor per year. Thus, it is a low-probability event. Since the maintenance procedures and operator training on ALWRs are expected to be similar to that at present LWRs, the
ISLOCA probability for ALWRs is expected to be in the same range as for current LWRs.

The NRC has established an objective that evolutionary ALWRs (and by extension, passive ALWRs) provide some protection against ISLOCA sequences. The NRC position is that ISLOCA, for purposes of design, can be treated as a severe accident with a very low frequency of occurrence, thereby allowing relatively high conditional failure probabilities given an ISLOCA. The present NRC goal (but not a requirement) is to ensure that each connecting system (including piping, flanges, valves, etc.) has at least a $90 \%$ chance of surviving an ISLOCA event.

A comprehensive research program to investigate ISLOCAs was carried out in a previous research program at the Idaho National Engineering Laboratory (INEL). Part of that overall program concentrated on the failure probabilities of mechanical components in currently operating LWRs. That portion of the program is documented in NUREG/CR-5603 and NUREG/ CR-5862. The purpose of this report is to use the methodology outlined in NUREG/CR-5603 to evaluate design rules for ISLOCA systems in ALWRs on a probabilistic basis. The methodology is intended for piping elements, flange connections, on-line pumps and valves, heat exchangers, and tanks. The NRC has directed that the design rules be evaluated for BWR pressures of $1025 \mathrm{psig}$, PWR pressures of $2235 \mathrm{psig}$, and $350^{\circ} \mathrm{F}$. The goal of this report is to demonstrate that each type of component in the system achieves a $98 \%$ survival confidence, so that the overall system survival confidence would be in the range of $90 \%$.

The basic methodology is to compute failure stresses that can be used with an ISLOCA survival curve to calculate the probability of component survival at a given system pressure. The curves were developed by estimating the median and the uncertainty of the failure stress, and are material and temperature dependent. For other components (e.g., flanges), the methodology is 
based on limiting the leak rate for gasketed connections below the makeup capability of the plant.

The methodology assumes that the only cause of failure is overpressure, and includes the effect of the other stresses in determining the failure stresses and the uncertainty. The hoop stress caused by the pressure loading is set equal to a failure stress. However, this failure stress is reduced from the median ultimate tensile strength by a factor of 0.9 for carbon steel and 0.85 for stainless steel to account for the difference in gage length and for the effect of triaxial stresses, part of which arise from stresses other than pressure stresses. Moreover, a wide uncertainty has been assigned by selecting the $99.9 \%$ survival confidence as the median yield stress. This accounts for the probability of a large crack existing in the material, and also provides margin for the additional stresses such as thermal and deadweight stresses present in the pipe. Thus, the design stresses based on high confidences of survival are much closer to the yield stress than to the median ultimate tensile stress.

Available yield stress and ultimate tensile strength data were used in an attempt to better define the material properties that were used in NUREG/CR-5603. The comparison of the NUREG/CR-5603 values to the material property data obtained from alternate sources indicate that the NUREG/CR-5603 values are conservative or representative for most types of materials. However, there are two cases where the NUREG/ CR-5603 values appear to be nonconservative. These are for Type 316 stainless steel and SA-516 Grade 70 carbon steel. Alternate curves were developed and used in this report for stainless steels and SA-516 Grade 70 carbon steel.

A pressure ratio of 0.4 (the design pressure divided by the RCS operating pressure) was investigated. The conclusions are that this pressure ratio is a suitable design value for most cases. Based on the calculations in this report, the recommended sizes for components in ALWR systems to be designed for ISLOCA conditions are as follows:
- $\quad$ Pipe and pipe fittings

BWR-STD for all materials

PWR - STD up to 10 in. for all materials

SA-106 Grade B-12 in., STD; 14,16 , 20 in., Sch. 40; 18 in.., XS

Type $316-12$ in., Sch. 40 ; 14 to 20 in., Sch. 60

Type $304-12$ and 14 in., XS; 16 to 20 in., Sch. 60

- Flanges

BWR-Class 300

PWR-Class 600

Bolts-High strength with $40 \mathrm{ksi}$ preload

- $\quad$ Valves

BWR-Class 300

PWR-Class 600

- Pumps

Design for 0.4 pressure ratio

Seals-Need not design for ISLOCA but allow minimal loakage

- Heat exchangers

Cylindrical shell-Design for pressure ratio of 0.40 (SA-516 Grade 70 carbon steel), 0.45 (Type 304 stainless steel)

Heads-Design for 0.4 pressure ratio

Tubes and tubesheets-Design to TEMA standards (except 20 gage for 1 -in. and 18 gage for 1-1/4-in. PWR tubes).

These recommendations will satisfy the goal of $90 \%$ confidence that gross leakage will not occur to the system during an ISLOCA, but the scope of this project did not include any evaluations to assure that components such as pumps and valves will remain operable during, or fit for service after, an ISLOCA event.

An expert peer review panel reviewed the methodology. Their report is included as Attachment 1 to this report. 


\section{ACKNOWLEDGMENTS}

I express appreciation to Dr. John O'Brien, NRC Program Manager, for his guidance and support. D. F. Landers, E. C. Rodabaugh, and D. A. Wesley served on the peer review panel and offered many helpful suggestions and comments. W. J. Galyean and D. L. Kelly of the INEL staff assisted with details of a previous INEL study on ISLOCA. G. M. Wilkowski of Battelle Columbus Laboratories and A. L. Hiser of the NRC helped to identify material property data sources. D. R. Pack provided editorial assistance in preparing the manuscript. 


\section{ACRONYMS}

ABWR advanced boiling water reactor

ALWR advanced light water reactor

BWR boiling water reactor

GE General Electric

GLP gross leak pressure

INEL Idaho National Engineering Laboratory

ISLOCA intersystem loss-of-coolant accident

LWR light water reactor

NPS nominal pipe size

NRC Nuclear Regulatory Commission
ORNL Oak Ridge National Laboratory

PWR pressurized water reactor

RCS reactor coolant system

RHR residual heat removal

SBWR simplified boiling water reactor

SR $\quad$ stress relieved

STD standard schedule pipe

UTS ultimate tensile strength

XS extra-strong schedule pipe

XXS double extra-strong schedule pipe 


\section{NOMENCLATURE}

$a, b, c, d \quad$ curve fit constants

A pump scroll dimension

$A_{b} \quad$ individual bolt area

$\mathrm{A}_{\mathrm{g}} \quad$ gasket area

$A_{p} \quad$ pressure area

D inside diameter

E elastic modulus

$f_{L} \quad$ flange and ring contact factor

$\Delta \mathrm{G}_{\mathrm{L}} \quad$ change in gasket load

JR joint relaxation

$\mathrm{K}_{\mathrm{g}} \quad$ gasket initial stiffness

$\mathrm{K}_{\mathrm{gr}} \quad$ gasket unloading/reloading stiffness

L hemispherical head crown radius

m mean of probability distribution

M median of probability distribution

$\mathrm{N}_{\mathrm{b}} \quad$ number of bolts

p primary system design pressure

P pressure

$\mathrm{P}_{\mathrm{cr}} \quad$ critical buckling pressure

$\Delta \mathrm{P} \quad$ change in system pressure

r inside radius

$r_{n} \quad$ knuckle radius of torispherical head

$\mathrm{R} \quad$ correction factor for plastic strain

$\mathrm{R}_{\mathrm{o}} \quad$ outside radius

S
S

$\mathrm{S}_{\mathrm{f}}$

$\mathrm{S}_{\mathrm{u}}$

$\mathrm{S}_{\mathrm{y}}$

t

$\mathrm{T}$

$\mathrm{U}_{\mathrm{g}}$

$\mathbf{X}$

$\alpha$

$\beta$

$\beta_{b p}$

$\beta_{\mathrm{jr}}$

$\delta_{\text {gi }}$

$\delta_{\mathrm{gr}}$

$\varepsilon$

$\varepsilon_{\mathrm{f}}$

$\theta$

$\sigma$

$\sigma_{\mathrm{bp}}$

$\sigma_{\mathrm{c}}$

$\sigma_{\mathrm{f}}$

$\sigma_{\mathrm{gi}}$

$\sigma_{\mathrm{gr}}$

$\sigma_{\text {sc }}$

$\sigma_{\mathrm{y}}$
ASME Code design stress limit

flange size

ASME Code ultimate tensile strength

ASME Code yield stress

wall thickness

temperature

factor for change in gasket load with pressure

value from normal probability tables for given survival probability

Weibull distribution parameter

logarithmic uncertainty

bolt preload uncertainty

joint relaxation uncertainty

initial gasket deflection

relaxed gasket deflection

strain

strain at $\sigma_{\mathrm{f}}$

Weibull distribution parameter

stress

bolt preload stress

failure stress at survival confidence c

failure stress

initial gasket stress (psi)

relaxed gasket stress (psi)

$\sigma_{\mathrm{c}}$ corrected for plastic strain

yield stress 


\section{Component Evaluation for ISLOCAs in ALWRS}

\section{INTRODUCTION}

Low-pressure piping systems that branch to the reactor coolant systems (RCSs) of light water reactors (LWRs) are normally protected by multiple valves from the reactor coolant. Failure or misalignment of these isolation valves leads to an intersystem (sometimes called interfacing system) loss-of-coolant accident (ISLOCA), and to the potential leak or rupture of low-pressure systems.

SECY-90-016 (NRC, 1990) and the associated Staff Requirements Memorandum from the Nuclear Regulatory Commission (NRC) Commissioners require evolutionary advanced light water reactor (ALWR) plant designers to include ISLOCAs in the design basis; this requirement has been extended to passive plant designers as well. However, the NRC did not initially provide design stress allowables or uniform criteria for ISLOCA design. Subsequently, it was decided to use Service Level A design stresses and a fraction of the RCS design pressure to achieve an acceptable overall system failure probability. The purpose of this report is to evaluate design rules for ISLOCAs on a probabilistic basis.

\subsection{Background}

Four ALWRs are presently under review by the NRC staff: ABWR, SBWR, AP600, and System $80+$. The piping systems of these plants that may be affected by ISLOCAs include, for example, the residual heat removal system, the safety injection system, the makeup and purification system, and other low-pressure lines that branch to the RCS. While the chief safety concern deals with low-pressure lines that bypass containment, piping that remains entirely within the containment is of concern as well.

To date, no full ISLOCAs have occurred in U.S. nuclear plants, though there have been several instances of leakage past valves from the RCS to connecting systems. These instances have been benign and correctable by the plant staff. The total ISLOCA core damage frequency for existing LWRs was estimated to be in the range of $2 \times 10^{-6}$ events per reactor per year (Galyean et al., 1993). Thus, it is a low-probability event. Since the maintenance procedures and operator training ${ }^{a}$ on ALWRs are expected to be similar to that at present LWRs, the ISLOCA probability for ALWRs is expected to be in the same range as for current LWRs.

The NRC has established an objective that evolutionary ALWRs (and by extension, passive ALWRs) provide some protection against ISLOCA sequences. The NRC position is that an ISLOCA, for purposes of design, can be treated as a severe accident with a very low frequency of occurrence, thereby allowing relatively high conditional failure probabilities given an ISLOCA. The present NRC goal (but not a requirement) is to ensure that each connecting system (including piping, flanges, valves, etc.) has at least a $90 \%$ chance of surviving an ISLOCA event.

It appears that European nuclear safety authorities are considering similar actions. The French and Germans released their safety goals in Common Safety Approach for Future Pressurized Water Reactors, in which they state that "containment bypass is to be practically eliminated by such measures as adequate piping design pressure" (Inside NRC, 1993).

\subsection{INEL ISLOCA Research Programs}

A comprehensive research program to investigate ISLOCAs was carried out at the Idaho National Engineering Laboratory (INEL). The results are summarized by Galyean et al. (1993). A part of that overall program concentrated on the

a. Plant personnel actions are the leading cause of ISLOCAs. 
failure probabilities of mechanical components in currently operating LWRs, which is documented in NUREG/CR-5603 (Wesley et al., 1990) and NUREG/CR-5862 (Wesley, 1992).

The purpose of the current program is to use the methodology outlined in NUREG/CR-5603 to evaluate design rules for ISLOCA systems in ALWRs on a probabilistic basis. Design of systems for ISLOCA pressures of $40 \%$ of the primary system operating pressure was the base case evaluated. The methodology is intended to include piping elements, flange connections, online pumps and valves, heat exchangers, and tanks. The NRC has directed that the design rules be evaluated for BWR pressures of 1025 psig, PWR pressures of $2235 \mathrm{psig}$, and $350^{\circ} \mathrm{F}$. A peer review panel of nationally recognized experts was selected to review and critique the initial results of this program. Their conclusions are included as Attachment 1 of this report. The author has addressed their comments in the body of this report. 


\section{METHODOLOGY DEVELOPMENT}

A methodology for evaluating probabilistic pressure capacities for selected components in systems potentially susceptible to ISLOCA events was developed and reported in NURJEG/CR-5603 (Wesley et al., 1990). For some components (e.g., pipes, tanks) the methodology for evaluating design rules is based on an allowable stress concept. The basic methodology is to compute failure stresses that can be used with an ISLOCA survival curve to calculate the probability of component survival at a given system pressure. The curves were developed by estimating the median and the uncertainty of the failure stress, and are material and temperature dependent. For other components (e.g., flanges), the methodology is based on limiting the leak rate for gasketed connections below the makeup capability of the plant (a 200-gpm leak rate will be assumed). In the methodology described below, the original NUREG/CR-5603 methodology has been slightly modified in places by the author based on his own and the peer review panel's recommendations, but remains basically the same as descritied in NUREG/CR-5603.

\subsection{Methodology Outline for Allowable Stresses}

The major steps and assumptions associated with the allowable stress methodology are as follows:

Step 1. Determine the stress induced in the pipe cluring ISLOCA conditions.

- The ISLOCA failure mode is assumed to be from a statically applied pressure alone (this assumption is discussed in Section 2.1.1).

- The stress in the pipe wall can be calculated using the equation for hoop stress (pr/t).

Step 2. Estimate the median failure stress.

- The median ultimate tensile strength of the piping materials can be obtained using material property data.
- The median value can be reduced to account for triaxial stresses and the differences in the gage length of the tensile specimens and the actual piping.

- A further reduction can be applied to account for the increase in pipe diameter caused by the plastic strain in the pipe wall.

Step 3. Estimate the uncertainty of the failure stress.

- The failure stress curve is assumed to have a lognormal distribution.

- The uncertainty of the failure stress curve can be estimated by assuming that the failure probability at the yield stress is $10^{-3}$ (or some smaller value) to account for cracking (original or induced).

- Attention can be given to the manufacturer's tolerance and the corrosion allowance.

The following sections discuss these assumptions.

2.1.1 Failure Mode Assumption. To establish design rules based on the failure probability of piping during an ISLOCA event, it is desirable to have a simple, general methodology that will apply to all ALWR piping systems rather than factor in the specific operating stresses for each individual design. However, the magnitudes of piping stresses (other than the ISLOCA pressure stress that can be assumed to be the full primary system pressure) are design-specific, small compared to the ISLOCA pressure stresses, and depend on the plant conditions at the time of the ISLOCA event. Thermal and deadweight stresses will be present to some degree, while there is a very low probability that seismic or water hammer stresses will occur during the ISLOCA event. These stresses represent only a portion of the overall design stresses (they do not include the pressure stress), which have already been limited according to ASME Code rules for A through D Service Levels, and these stresses would not 
increase significantly during the ISLOCA event as does the pressure stress.

The methodology simply assumes that the only cause of failure is overpressure, and includes the effect of the other stresses in the determination of the failure stresses and the uncertainty, as follows. The hoop stress caused by the pressure loading is set equal to a failure stress. However, this failure stress will be reduced from the median ultimate tensile strength (Section 2.1.2). Moreover, a wide uncertainty has been assigned by selecting the 99.9\% survival confidence as the median yield stress. This accounts for the probability of a large crack existing in the material, and also provides margin for the additional stresses such as thermal and deadweight stresses present in the pipe. Thus, as shown in later sections, the design stresses based on high confidences of survival are much closer to the yield stress than to the median ultimate tensile stress.

\subsubsection{Ultimate Tensile Strength Curve. In} NUREG/CR-5603, the median ${ }^{b}$ ultimate tensile strengths for carbon and stainless steels were obtained from the open literature (Harvey, 1985; Weiss and Sessler, 1963). (Section 3 evaluates NUREG/CR-5603 material properties). The median ultimate tensile strength values were reduced by factors of 0.85 for stainless steel and 0.9 for carbon steel to account for the following differences between the specimens from which the strength data were generated and nuclear piping:

1. The material property data were based on testing uniaxial tensile specimens, whereas a state of triaxial stress will exist in the actual piping (however, only two of the three stress components are significant)

2. The uniaxial tensile specimen gage length was very small compared to that of the actual piping, which is assumed to be the pipe circumference.

These reduction factors were based on Manjoine's (1975) work. Wesley (1990) esti-

b. The median is the stress at which the failure probability is $50 \%$. mated that the reduction factor is 1.73 for pressure alone and 2 when bending is included. A further reduction of the order of 1.5 to 2 was estimated for the gage length effect. By multiplying the means of the two ranges $(1.865 \times 1.75)$, the estimated reduction factor is 3.264. Figures 1 and 2 show engineering stress-strain curves for stainless and carbon steels, respectively (Boyer, 1987). (However, these curves were not used in NUREG/ CR-5603 to arrive at the 0.85 and 0.9 stress reduction factors). The strains (room temperature) at the ultimate tensile strengths are 0.575 and 0.183 in./in., respectively. Applying the mean reduction factors results in estimated failure strains of 0.177 and $0.056 \mathrm{in}$./in. The stresses at these strains are 63 and $55 \mathrm{ksi}$, which are 78 and $86 \%$ of the ultimate tensile strength and approximately equal to NUREG/CR-5603 values of 0.85 and 0.90 . As further verification of the appropriateness of the NUREG/CR-5603 stress reduction values, Chu et al. (1989) reported that General Electric conducted burst tests on seamless A106 carbon steel pipes and found that "the average burst hoop stress of unflawed pipe specimens was found to be at approximately $90 \%$ of the ultimate stress independent of the pipe size." Unfortunately, there were no corresponding data for stainless steel. Appendix B of the peer review panel report (Attachment 1 of this report) estimates that the evaluating criteria may underestimate the median burst pressure by about $30 \%$.

After stress reduction factors are applied, the resulting stress is called the median failure stress $\left(\sigma_{f}\right)$. The lognormal curve results in the following equation for the failure stress $\left(\sigma_{c}\right)$ at a given percent confidence of survival $\mathrm{c}$ :

$\sigma_{c}=\sigma_{f} e^{-\beta x}$.

The logarithmic uncertainty of the failure stress $(\beta)$ is determined by using the following values of $\sigma_{\mathrm{c}}$ and $\mathrm{x}$ :

$$
\begin{aligned}
& \sigma_{\mathrm{c}}=\sigma_{\mathrm{y}} \\
& \mathrm{x}=\begin{array}{l}
\text { the value from the normal proba- } \\
\text { bility tables for a survival proba- } \\
\text { bility of } 10^{-3} \text { (that is, 3.09) }
\end{array}
\end{aligned}
$$




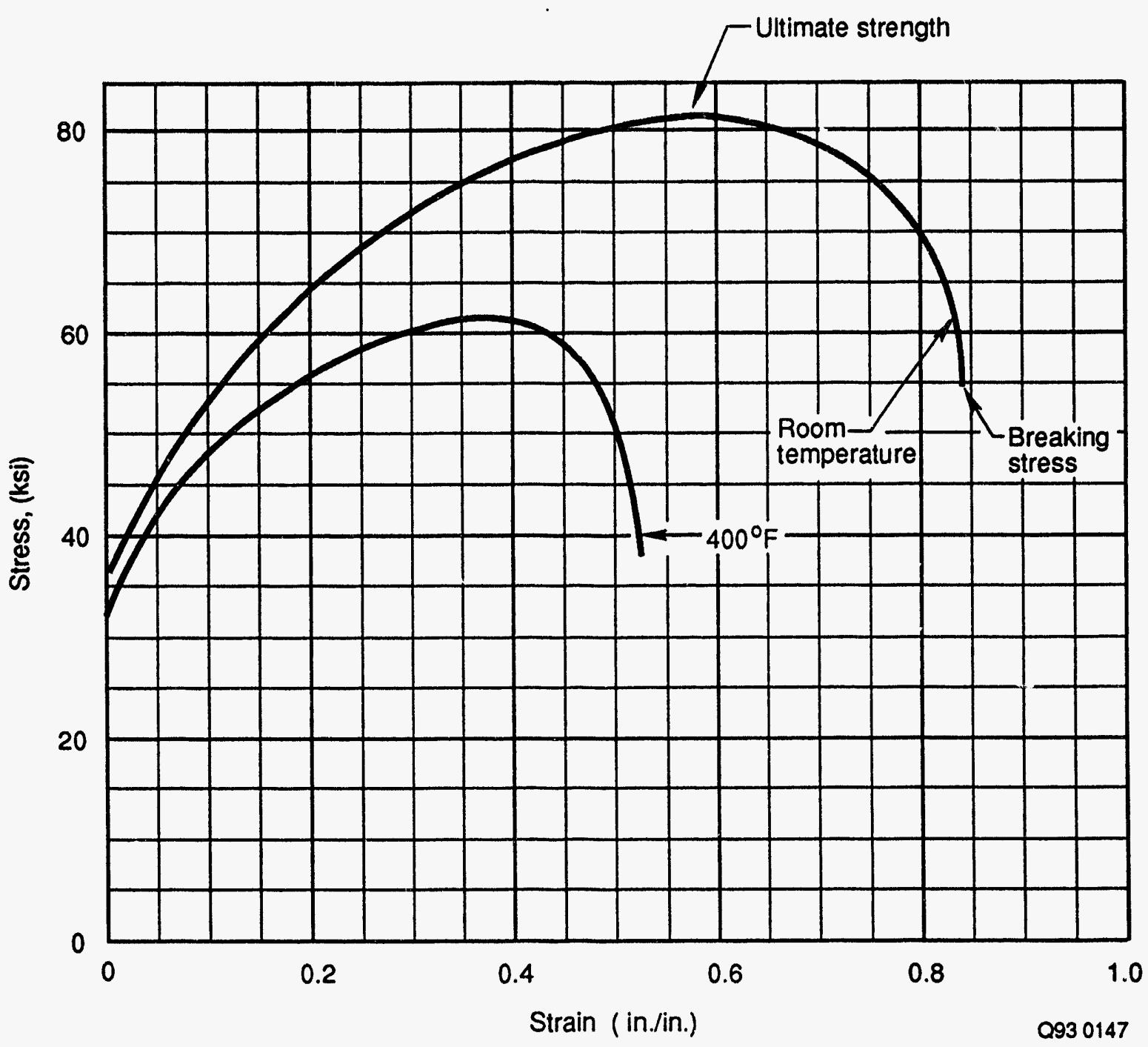

Figure 1. Engineering stress-strain curve for stainless steel (data from Boyer, 1987).

and solving Equation 1 for $\beta$. A sensitivity study also was conducted for a survival probability of $10^{-4}$ at $\sigma_{y}$. Table 1 lists the resulting probability curve parameters for Type 304 stainless and SA-106 Grade B carbon steel pipe failure stresses at several temperatures (using NUREG/CR-5603 and NUREG/CR-5862 material property values),

where

$$
\begin{aligned}
& \beta \quad=\text { logarithmic uncertainty } \\
& \varepsilon_{\mathrm{f}}=\text { strain at } \sigma_{\mathrm{f}} \\
& \sigma_{\mathrm{c}}=\begin{array}{l}
\text { failure stress at survival confi- } \\
\text { dence } c
\end{array}
\end{aligned}
$$

$$
\begin{aligned}
& \sigma_{\mathrm{f}}=\text { failure stress } \\
& \sigma_{\mathrm{y}}=\text { yield stress. }
\end{aligned}
$$

Plots of the resulting failure curves can be made by using the values of the lognormal distribution parameters from Table 1 and the assumed probabilities of failure at the yield stress of $10^{-3}$ and $10^{-4}$. As an example, the lognormal curves at $400^{\circ} \mathrm{F}$ for Type 304 stainless and SA-106 Grade B carbon steel are plotted in Figures 3 and 4 for yield-stress failure probabilities of $10^{-3}$ and $10^{-4}$. These curves may be considered reasonable for failure stresses of the order of plus 


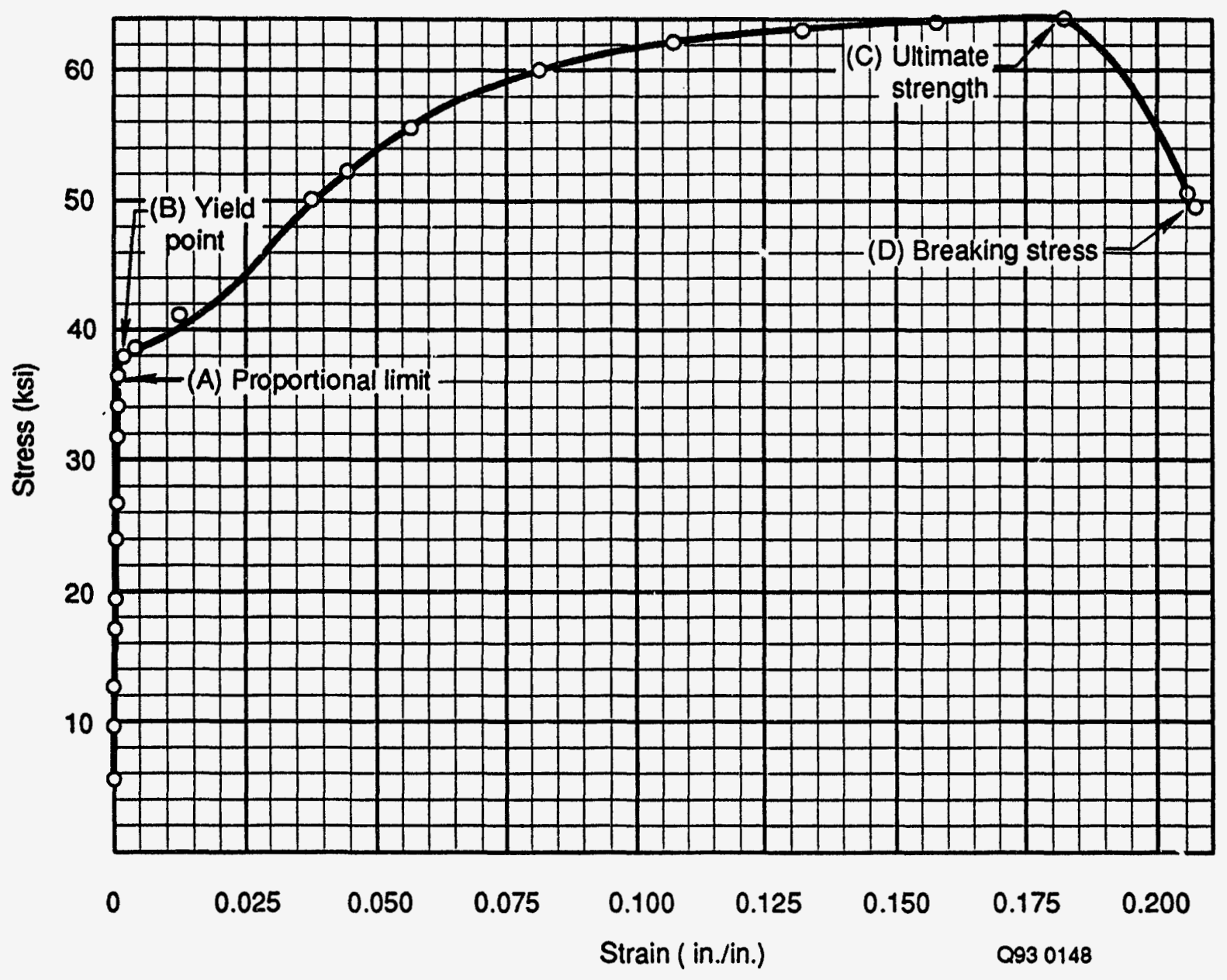

Figure 2. Engineering stress-strain curve for carbon steel (data from Boyer, 1987).

one standard deviation and below; consequently, they have been truncated at $+1 \beta$. At failure stresses in the high end of the distribution, some upper bound cutoff is required. Although flaws can reduce the failure stress significantly below the median value, the absence of flaws cannot strengthen the material such that the upper bound is greater than the failure stress of unflawed material. Since we will be working with the high confidence of survival area at the low end of the curve, selection of an upper bound cutoff is unnecessary.

2.1.3 Survival Curve. Once the failure probability curves have been determined, the survival probability (which is 1 minus the failure probability) for any stress can be determined and corrected for the expansion caused by plastic stress.
This correction is applied because the hoop stress in the piping is computed based on the original surface area that the pressure acts upon on the inside wall of the pipe. However, the pipe radius expands as the pressure causes plastic deformation in the wall; consequently, the surface area on which the pressure acts increases with strain [the increased radius is $r(1+\varepsilon)$ ]. To apply such a correction for the plastic strain, we assume that the stress-strain relation is bilinear with the break point at the yield stress $\sigma_{y} .{ }^{c}$ Then the strain $\varepsilon_{\mathrm{f}}$

c. Actually, the stress-strain curve is not linear between the yield strength and the ultimate tensile strength, as seen in Figures 1 and 2. A straight line between the two points results in a higher strain and, therefore, a lower allowable stress than would the actual curve; thus, the assumption is slightly conservative. 
Table 1. Failure stress probability curve parameters with failure probability of $10^{-3}$ and $10^{-4}$ at yield stress.

\begin{tabular}{|c|c|c|c|c|c|}
\hline \multirow[b]{2}{*}{$\begin{array}{c}\text { Temperature } \\
\left({ }^{\circ} \mathrm{F}\right)\end{array}$} & \multicolumn{5}{|c|}{ Type 304 stainless steel pipe } \\
\hline & $\begin{array}{c}\sigma_{\mathrm{f}} \\
(\mathbf{k s i})\end{array}$ & $\begin{array}{c}\varepsilon_{\mathrm{f}} \\
\text { (in./in.) }\end{array}$ & $\begin{array}{c}\sigma_{\mathrm{y}} \\
(\mathrm{ksi})\end{array}$ & $\begin{array}{c}\beta \\
\left(10^{-3}\right) \\
\end{array}$ & $\begin{array}{c}\beta \\
\left(10^{-4}\right) \\
\end{array}$ \\
\hline Room temperature & 73.1 & 0.283 & 37 & 0.22 & 0.18 \\
\hline 400 & 62.9 & 0.179 & 23 & 0.33 & 0.27 \\
\hline 600 & 59.5 & 0.165 & 19.5 & 0.36 & 0.30 \\
\hline \multirow[t]{2}{*}{800} & 55.7 & 0.161 & 16.5 & 0.39 & 0.32 \\
\hline & \multicolumn{5}{|c|}{ Type 304 stainless steel plate } \\
\hline $\begin{array}{c}\text { Temperature } \\
\left({ }^{\circ} \mathrm{F}\right)\end{array}$ & $\begin{array}{c}\sigma_{\mathrm{f}} \\
(\mathrm{ksi})\end{array}$ & $\begin{array}{c}\varepsilon_{\mathrm{f}} \\
\text { (in./in.) }\end{array}$ & $\begin{array}{c}\sigma_{\mathrm{y}} \\
(\mathrm{ksi})\end{array}$ & $\begin{array}{c}\beta \\
\left(10^{-3}\right) \\
\end{array}$ & $\begin{array}{c}\beta \\
\left(10^{-4}\right) \\
\end{array}$ \\
\hline Room temperature & 67 & 0.20 & 37 & 0.19 & 0.16 \\
\hline 400 & 57.9 & 0.13 & 23 & 0.30 & 0.25 \\
\hline 600 & 54.6 & 0.12 & 19.5 & 0.33 & 0.28 \\
\hline \multirow[t]{2}{*}{800} & 51.2 & 0.11 & 16.5 & 0.37 & 0.30 \\
\hline & \multicolumn{5}{|c|}{ Type 316 stainless steel } \\
\hline $\begin{array}{c}\text { Temperature } \\
\left({ }^{\circ} \mathrm{F}\right)\end{array}$ & $\begin{array}{c}\sigma_{\mathrm{f}} \\
(\mathrm{ksi})\end{array}$ & $\begin{array}{c}\varepsilon_{\mathrm{f}} \\
\text { (in./in.) }\end{array}$ & $\begin{array}{c}\sigma_{\mathrm{y}} \\
(\mathrm{ksi})\end{array}$ & $\begin{array}{c}\beta \\
\left(10^{-3}\right) \\
\end{array}$ & $\begin{array}{c}\beta \\
\left(10^{-4}\right) \\
\end{array}$ \\
\hline Room temperature & 73.5 & 0.162 & 42 & 0.18 & 0.15 \\
\hline 400 & 69.3 & 0.152 & 35 & 0.22 & 0.18 \\
\hline 600 & 65.9 & 0.151 & 31 & 0.24 & 0.20 \\
\hline \multirow[t]{2}{*}{800} & 62.1 & 0.147 & 28 & 0.26 & 0.21 \\
\hline & \multicolumn{5}{|c|}{ SA-106 Grade B carbon steel } \\
\hline $\begin{array}{c}\text { Temperature } \\
\left({ }^{\circ} \mathrm{F}\right)\end{array}$ & $\begin{array}{c}\sigma_{\mathrm{f}} \\
(\mathrm{ksi})\end{array}$ & $\begin{array}{c}\varepsilon_{\mathrm{f}} \\
\text { (in./in.) }\end{array}$ & $\begin{array}{c}\sigma_{\mathrm{y}} \\
(\mathrm{ksi})\end{array}$ & $\underset{\left(10^{-3}\right)}{\beta}$ & $\underset{\left(10^{-4}\right)}{\beta}$ \\
\hline Room temperature & 61.2 & 0.119 & 36 & 0.17 & 0.14 \\
\hline 400 & 64.8 & 0.083 & 31 & 0.24 & 0.20 \\
\hline 600 & 62.1 & 0.109 & 27 & 0.27 & 0.22 \\
\hline 800 & 49.5 & 0.163 & 24 & 0.23 & 0.19 \\
\hline
\end{tabular}


Methodology Development

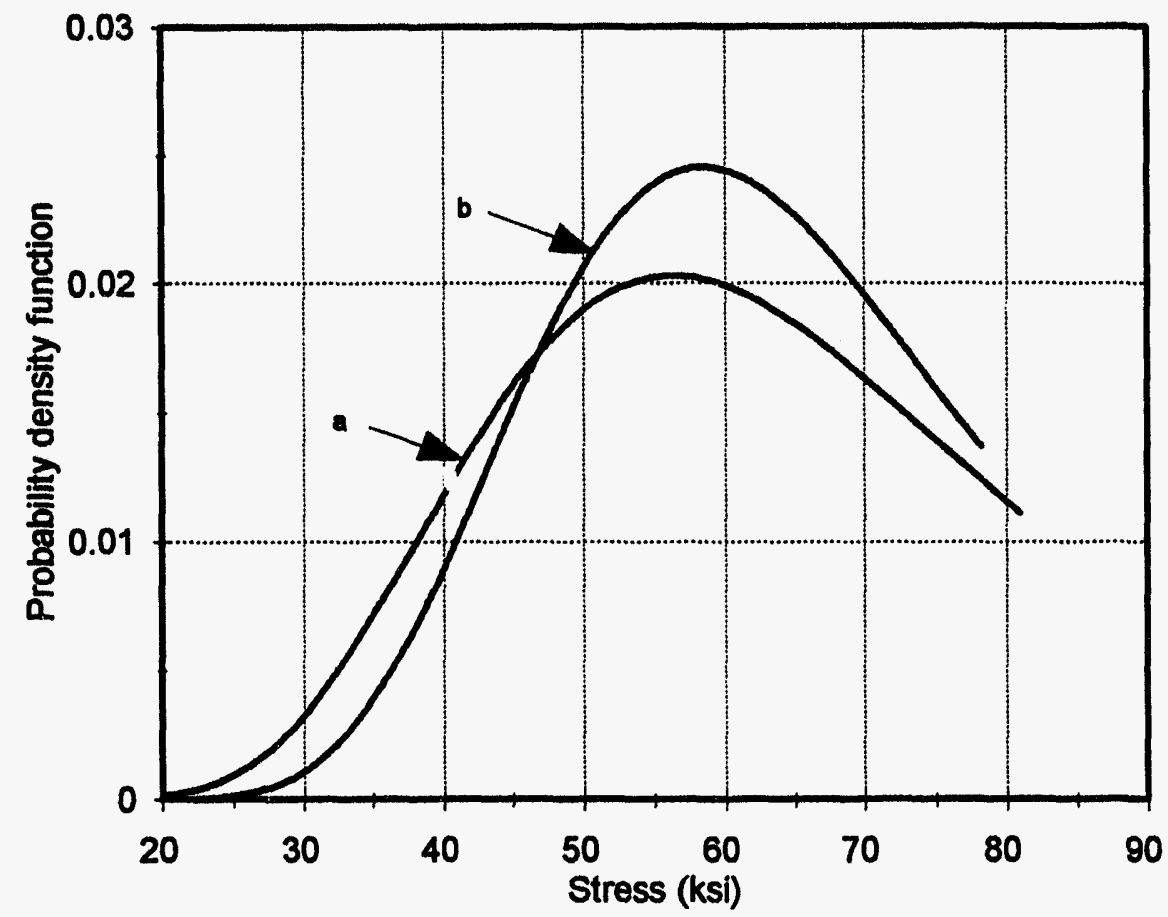

Figure 3. Assumed ultimate tensile strength distribution for Type 304 stainless steel (a) $10^{-3}$ (b) $10^{-4}$ probability of failure at yield stress.

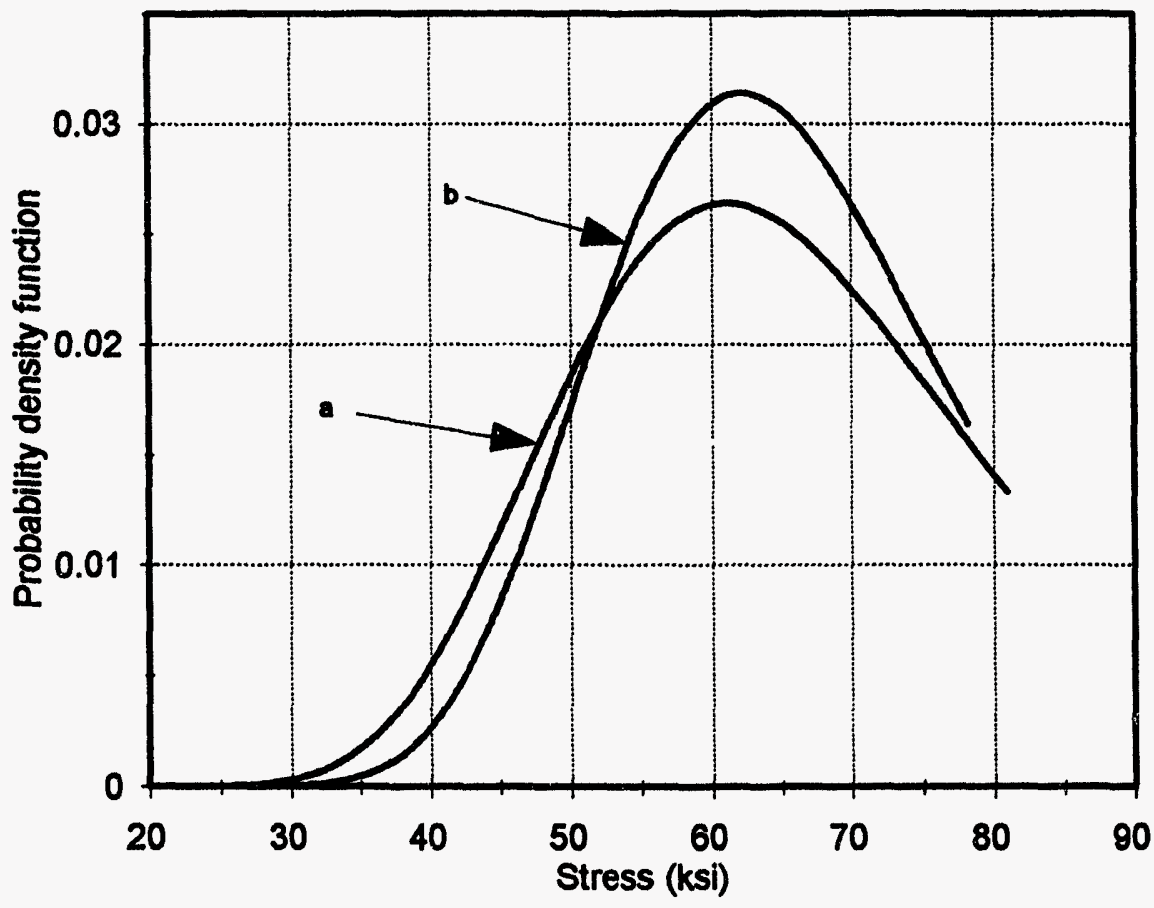

Figure 4. Assumed ultimate tensile strength distribution for SA-106 Grade B carbon steel (a) $10^{-3}$ (b) $10^{-4}$ probability of failure at yield stress. 
corresponding to the median ( $50 \%$ confidence) failure stress $\left(\sigma_{f}\right)$ can be adjusted by the following ratio to estimate the corresponding strain at the failure stress $\left(\sigma_{\mathrm{c}}\right)$ :

$R=\frac{\sigma_{c}-\sigma_{y}}{\sigma_{f}-\sigma_{y}}$

where $\sigma_{\mathrm{y}}, \sigma_{\mathrm{f}}$, and $\sigma_{\mathrm{c}}$ are defined above.

The corrected value of $\sigma_{c}{ }^{d}$ is calculated by dividing $\sigma_{\mathrm{c}}$ by $\left(1+R \varepsilon_{\mathrm{f}}\right)$.

$\sigma_{s c}=\frac{\sigma_{f} e^{-\beta_{x}}}{\left(1+R \varepsilon_{f}\right)}$

where

d. It would be more logical to apply the correction for plastic strain as a multiplier to $r$ in the $\mathrm{pr} / \mathrm{t}$ stress calculations, but, in practice, when performing sensitivity studies using several $\mathrm{pr} / \mathrm{t}$ values, it is easier to apply the correction only once to the allowable stress, and, thereby, not have to perform the correction for each $\mathrm{pr} / \mathrm{t}$ that is calculated.

$$
\begin{aligned}
& \sigma_{\mathrm{sc}}=\sigma_{\mathrm{c}} \text { corrected for plastic strain } \\
& R \varepsilon_{\mathrm{f}}=\text { strain at } \sigma_{\mathrm{c}} .
\end{aligned}
$$

Hoop stress $(\mathrm{pr} / \mathrm{t})$ versus temperature curves for several survival probabilities are plotted in Figures 5 through 7. The ASME Section III Classes 2 and 3 Levels 2.5A and D stress limits (for an ABWR pressure of 1025 psig and no corrosion allowance) also are included, with the hoop stress computed as follows:

$$
\frac{p r}{t}=S-0.6 p
$$

where

$$
\begin{aligned}
& \mathbf{p}=\text { primary system design pressure } \\
& \mathbf{r}=\text { inside radius } \\
& \mathbf{t}=\text { wall thickness } \\
& \mathbf{S}=\text { ASME Code design stress limit. }
\end{aligned}
$$

The Level D limit allows a factor of 2 increase in pressure over the normal primary system operating pressure, so piping designed for $50 \%$ of the

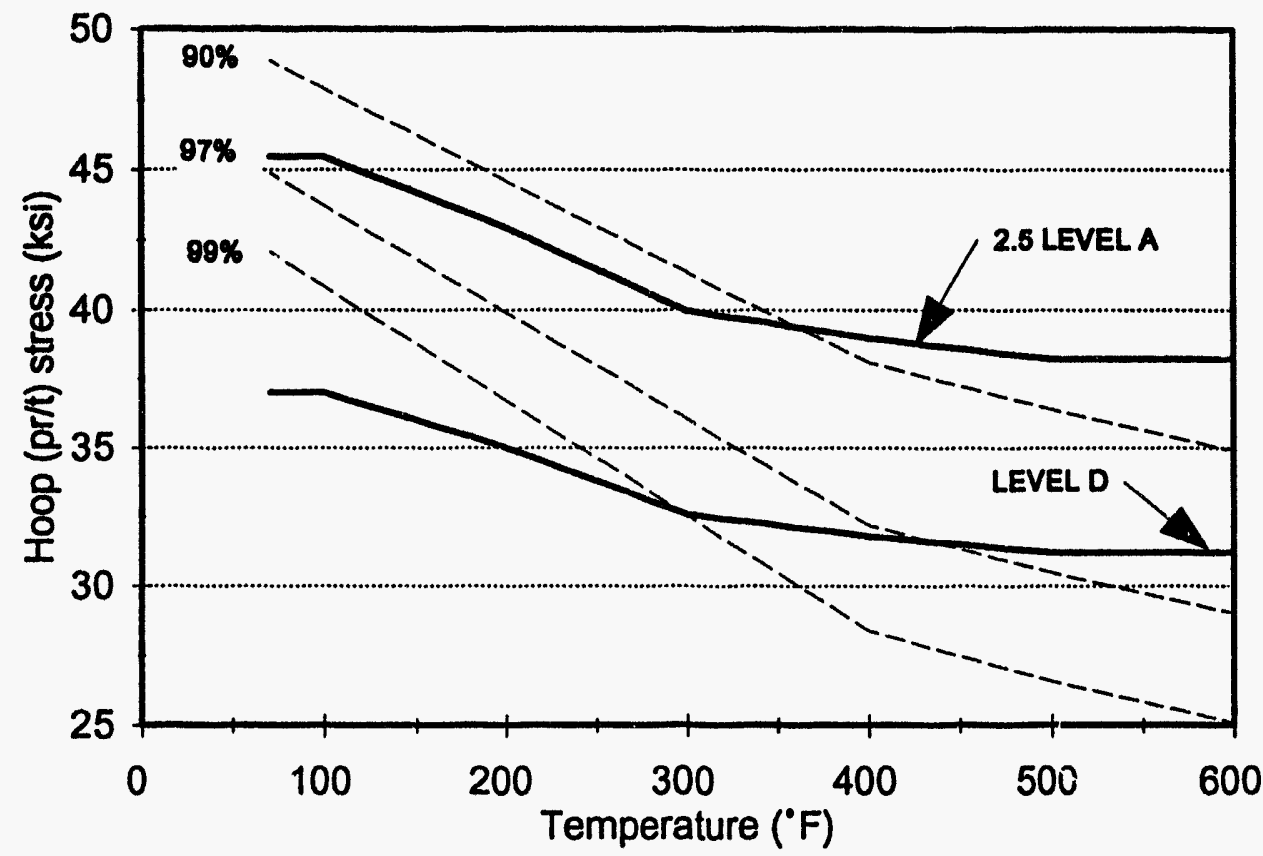

Figure 5. Comparisons of allowable stress limits for Type 304 stainless steel pipe: ASME Code Levels $2.5 \mathrm{~A}$ and $\mathrm{D}$ and probability-based confidence limits $\left(10^{-3}\right.$ probability of failure at yield stress). 


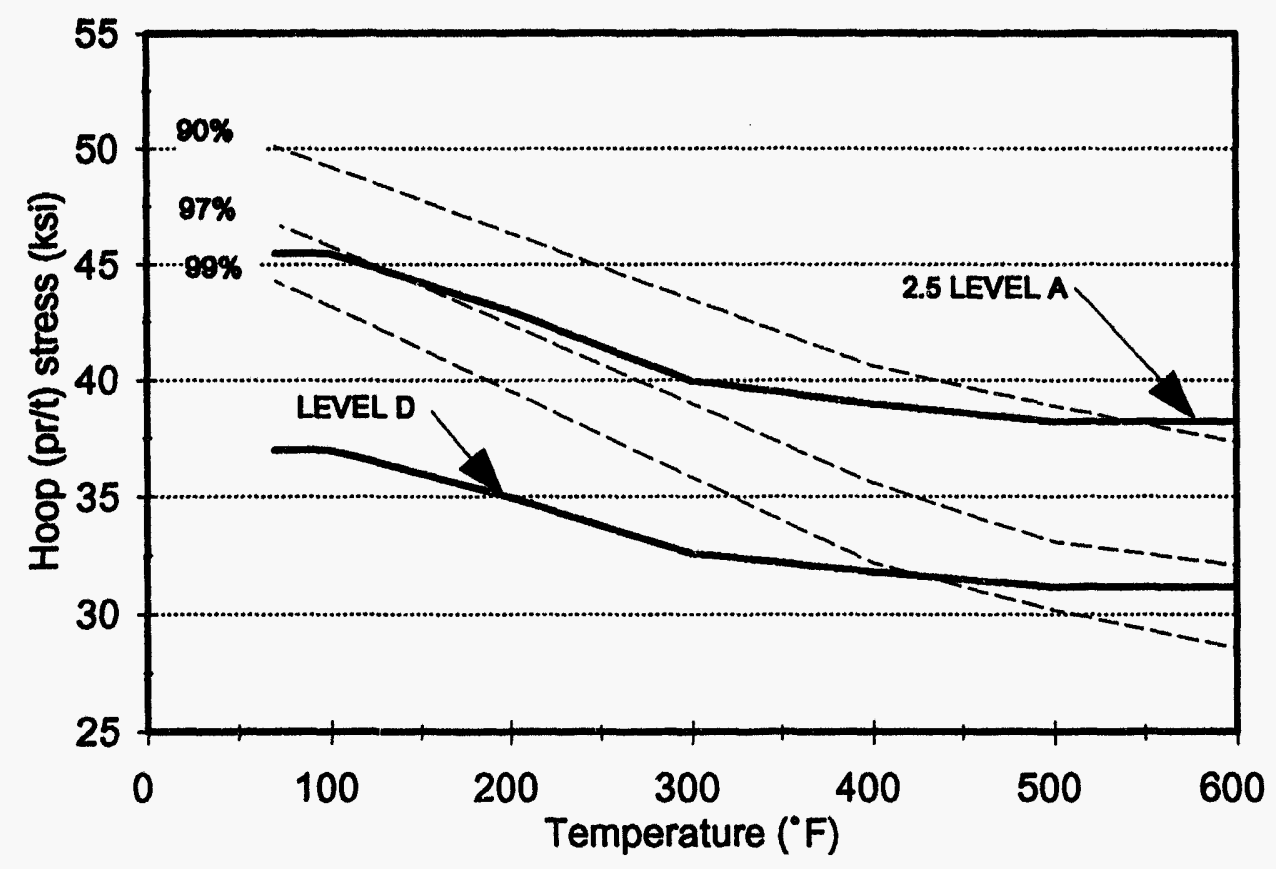

Figure 6. Comparisons of allowable stress limits for Type 304 stainless steel pipe: ASME Cocie Levels $2.5 \mathrm{~A}$ and $\mathrm{D}$ and probability-based confidence limits $\left(10^{-4}\right.$ probability of failure at yield stress).

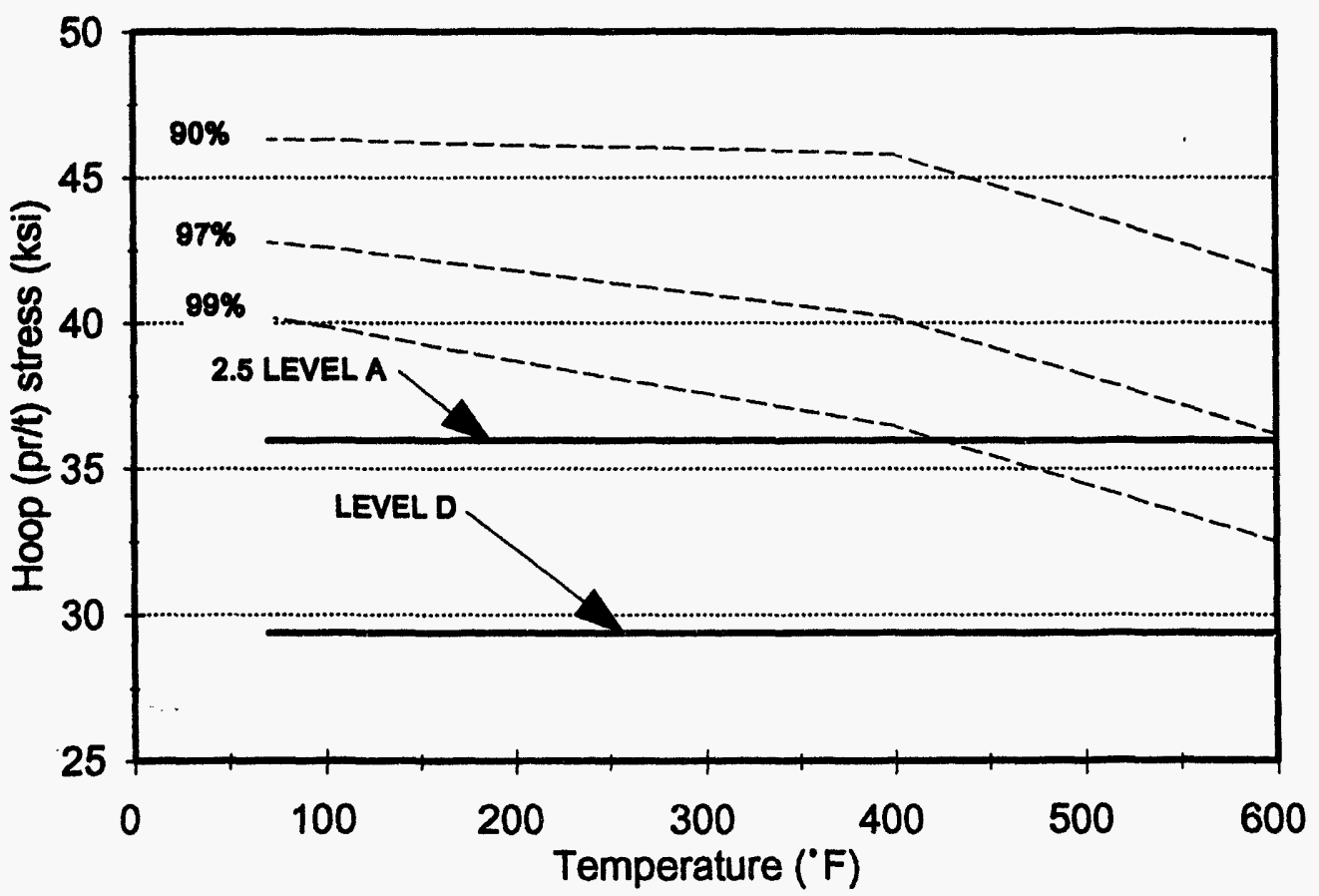

Figure 7. Comparisons of allowable stress limits for SA-106 Grade B carbon steel pipe: ASME Code Levels $2.5 \mathrm{~A}$ and $\mathrm{D}$ and probability-based confidence limits $\left(10^{-3}\right.$ probability of failure at yield stress). 
expected ISLOCA pressure would meet the Level $D$ stress limit. The Level $D$ limit provides about a $98 \%$ confidence of survival at $350^{\circ} \mathrm{F}$ for Type 304 stainless steel with an assumed $10^{-3}$ failure probability at yield stress (Figure 5).

Piping designed for $40 \%$ of the primary system operating pressure would meet a 2.5 Level A stress limit. The 2.5 Level A confidence level is about $90 \%$. The Level D confidence level at $350^{\circ} \mathrm{F}$ would increase to greater than $99 \%$ for an assumed $10^{-4}$ failure probability at yield stress (Figure 6), while the 2.5 Level A confidence level is about $93 \%$. Both the Level D and 2.5 Level A limits provide greater than $99 \%$ confidence of survival at $350^{\circ} \mathrm{F}$ for carbon steel with an assumed $10^{-3}$ failure probability at yield stress (Figure 7).

\subsection{Methodology for Leak Rate Assumptions}

For nonmetallic components such as gaskets and seals (where leakage will occur before rupture), the basic assumption will be to limit the leakage to a small amount that is within the capability of the plant's coolant makeup system. The details for affected components such as flanges are included in Section 4.

A related question that is not within the scope of the present study, but which is planned to be addressed later, is whether small lines under a certain diameter (as yet to be determined) that branch from the main system, may be excluded from consideration because the leakage from a ruptured line in the system will be within the capacity of the plant's coolant makeup system.

\subsection{Investigations of Other Possible Assumptions}

A number of assumptions were made in the previous section to obtain survival probability curves. Two alternatives were investigated to determine how different assumptions would affect the results. The first was to use another probability distribution for the failure stress curve, and the second was to use a different assumption for the failure strength uncertainty.

\subsubsection{Weibull Distribution Assumption.}

The lognormal distribution represents a cistribution that is appropriate when the variable is the product of a number of factors. Other probability distributions (such as Weibull or beta distributions) also could be used. Consequently, the lognormal distribution and the Weibull distribution, a distribution that was conceived for failure data, were compared. The Weibull probability distribution function is defined as

$$
f(x ; \theta, a)=\frac{a}{\theta^{\alpha}} x^{a-1} e^{-\left(\frac{x}{\theta}\right)^{a}} \text { for } x>0
$$

and the corresponding cumulative density function is

$$
F(x ; \theta, a)=1-e^{-\left(\frac{x}{\theta}\right)^{a}} \text { for } x>0 .
$$

We can solve for $\theta$ and $\alpha$ by choosing the $50 \%$ confidence level as the median of the ultimate tensile strength data corrected for the effects of triaxial stress and gage length $\left(\sigma_{f}\right)$, and the $99.9 \%$ confidence level as $\sigma_{y}$. For SA-106 Grade B carbon steel at $400^{\circ} \mathrm{F}\left(\sigma_{\mathrm{f}}=64.8 \mathrm{ksi}, \sigma_{\mathrm{y}}=31 \mathrm{ksi}\right)$, the Weibull parameters are $\theta=67.5$ and $\alpha=8.87$.

The Weibull distribution is plotted versus the comparable lognormal curve (uncorrected for strain) in Figure 8. Next, the $90 \%, 97 \%$, and $99 \%$ survival probability stresses for the Weibull and lognormal distributions were computed, including the adjustment to correct for the increased pipe diameter caused by plastic strain. The results are presented in the Table 2.

The Weibull distribution results in about a 3 to $4 \mathrm{ksi}$ increase in allowable stress levels over the lognormal curve. Thus, the lognormal curve provides more conservative stress values than does the Weibull curve.

2.3.2 Alternate Uncertainty Assumption. Figures 5 and 7 show that using the failure assumptions in Section 2.1, carbon steel has a higher probability of survival than does stainless steel. This does not mean, however, that carbon 


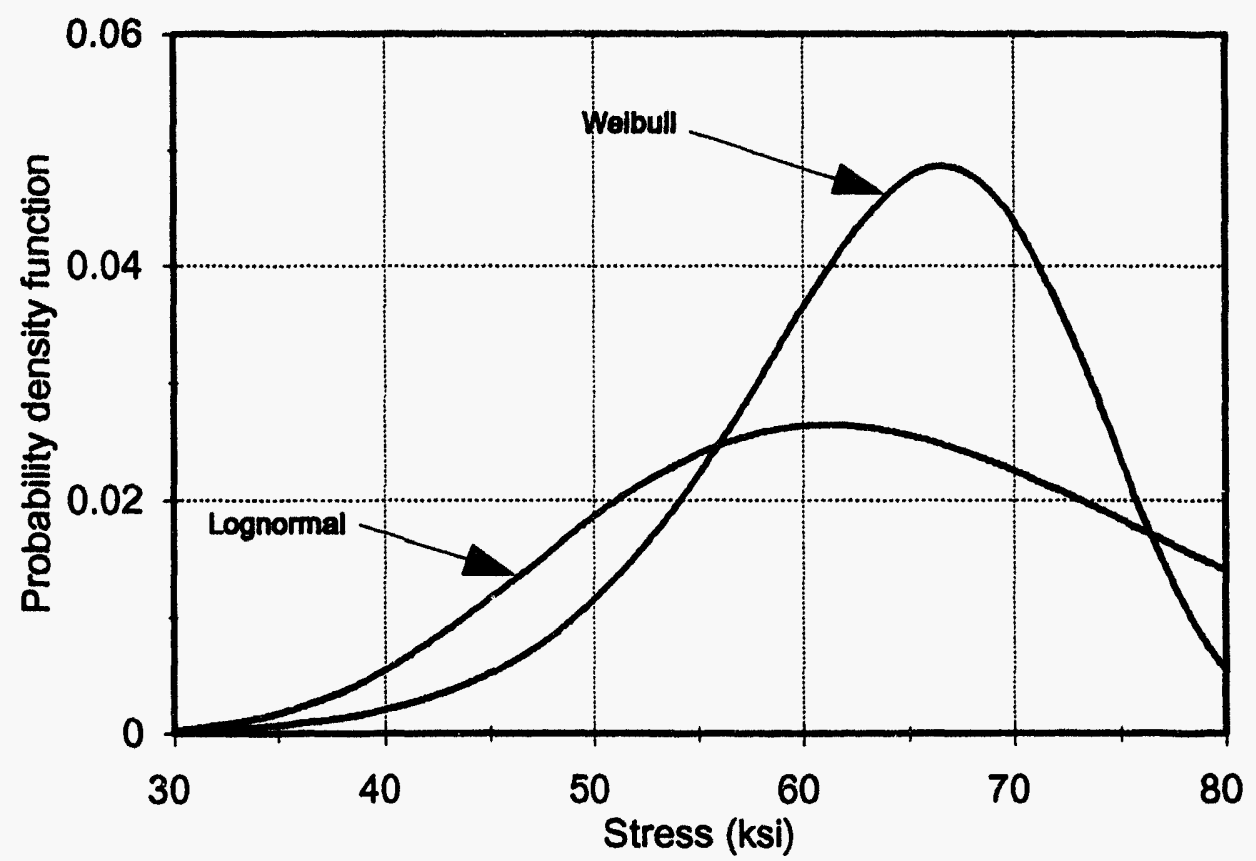

Figure 8. Comparison of lognormal and Weibull representations of the ultimate failure stress for SA-106 Grade B carbon steel at $400^{\circ} \mathrm{F}$.

Table 2. Comparison of allowable stresses computed using Weibull and lognormal distributions.

\begin{tabular}{cccccc}
\hline & \multicolumn{2}{c}{ Weibull distribution } & & \multicolumn{2}{c}{ Lognormal distribution } \\
\cline { 2 - 3 } $\begin{array}{c}\text { Survival } \\
\text { confidence } \\
(\%)\end{array}$ & $\begin{array}{c}\text { Stress from curve } \\
(\mathrm{ksi})\end{array}$ & $\begin{array}{c}\text { Corrected stress } \\
(\mathrm{ksi})\end{array}$ & & $\begin{array}{c}\text { Stress from curve } \\
(\mathrm{ksi})\end{array}$ & $\begin{array}{c}\text { Corrected stress } \\
(\mathrm{ksi})\end{array}$ \\
\hline 90 & 52.4 & 49.8 & & 47.6 & 45.8 \\
97 & 45.6 & 44.9 & & 41.3 & 40.2 \\
99 & 40.2 & 39.3 & & 37.1 & 36.5 \\
\hline
\end{tabular}

steel is a preferred material; the higher failure probability for carbon steel is a result of the ratios of the yield and ultimate strengths of carbon and stainless steels, and the basis that is used in the ASME Boiler and Pressure Vessel Code for selecting allowable stresses. The ASME Code uses the lesser of one-fourth of the ultimate tensile strength or two-thirds of the yield stress as the allowable stress for Class 2 piping.

Table 3 shows that the allowable stress is based on one-fourth of the tensile strength for SA-106
Grade B carbon steel, but on two-thirds of the yield stress for Type 304 stainless steel at $400^{\circ} \mathrm{F}$ (ASME, 1992a). ${ }^{\text {e }}$ For carbon steel, the ratio of the yield to the design stress is 2 , while the ratio is only 1.5 for stainless steel. Th 1 s, the $99 \%$ survival confidence stress (the yield stress) is twice the design stress (the Level D limit) for carbon

e. S is used throughout the text to indicate ASME Code stresses (e.g., $S_{y}$ is the Code yield stress and $S_{u}$ is the Code ultimate tensile strength), whereas $\sigma$ is used in the text to denote computed stresses. 
Table 3. Computation of ASME Code allowable stress for SA-106 Grade B carbon steel and Type 304 stainless steel.

\begin{tabular}{lcc}
\hline & $\begin{array}{c}\text { Carbon steel } \\
(\mathrm{ksi})\end{array}$ & $\begin{array}{c}\text { Stainless steel } \\
(\mathrm{ksi})\end{array}$ \\
\cline { 2 - 3 } $\mathrm{S}_{\mathrm{u}}$ & 60.0 & 64.4 \\
$1 / 4 \mathrm{~S}_{\mathrm{u}}$ & 15.0 & 16.1 \\
$\mathrm{~S}_{\mathrm{y}}$ & 30.0 & 20.7 \\
$2 / 3 \mathrm{~S}_{\mathrm{y}}$ & 20.0 & 13.8 \\
$\mathrm{~S}$ & 15.0 & 13.8 \\
\hline
\end{tabular}

steel, but twice the design stress for stainless steel is greater than the yield stress, so the survival confidence at the Level D limit is less than $99 \%$.

Brookhaven National Laboratory has attempted to define the failure uncertainty by assigning the average ultimate tensile strength as the $99 \%$ failure limit to the failure curve, and $90 \%$ of the average ultimate tensile strength as the median of the curve (Chu, 1989). The basis for the $90 \%$ value as the median of the curve was from the GE pipe burst test results previously mentioned in which the hoop stress at burst was $90 \%$ of the ultimate tensile strength. The resulting failure probability at the yield stress ranged from $2 \times 10^{-3}$ to $8 \times 10^{-3}$, which is about the same order of magnitude as the failure probability of $1 \times 10^{-3}$ assumed in NUREG/CR-5603. While the Brookhaven study has a defensible basis for the median and upper confidence level, the lower confidence level was not based on anything physical and did not take into account the possibility of cracking but was decided by the parameters of the upper portion of the curve. Yet the lower region of the curve is of interest since we need to determine stress limits for high probabilities of survival.

The difficulties in establishing the lower survival confidence limit in the Brookliaven and
NUREG/CR-5603 studies show that there is no straightforward way to define the lower limit, as pointed out in the peer review panel report (Attachment 1). We have no data for overpressure failures of nuclear piping that has been designed to ASME Code stress limits. However, we do know that for piping designed to ASME Code requirements, there have been no overpressure failures (excluding piping thinned by erosion/ corrosion), so the failure probability must be "low." If we assign various failure probabilities to represent this "low" number at the Level A design stress and the failure stress in Table 1 as the median stress, the survival probabilities at 2.5 times the Level A stress for $350^{\circ} \mathrm{F}$ are as shown in Figure 9. Using this argument, the lower confidence limit is now based on something physical for which we have data, namely the design stress value for which we have experience at operating pressures. However, we have no operating data at higher pressures, nor do we have any precise knowledge of the magnitude of the failure probability at the design stress.

Based on operating experience of LWRs worldwide, the failure probability at the design stress is estimated to be less than $10^{-4}$ events per reactor per year, so the survival confidence from Figure 9 at 2.5 times the Level A stress is about $92 \%$ or greater. The survival confidences in Figure 9 are approximately the same for carbon and stainless steels; whereas, using the assumption of $10^{-3}$ failure probability of failure at the yield stress, the survival confidence is substantially greater for carbon than for stainless steels.

The alternate method of developing an uncertainty for the failure curves leads to basically the same conclusion as does the method in NUREG,'CR-5603, that is, the minimum survival confidence at 2.5 times the Level A design stress is greater than $90 \%$. This argument is based on actual operating data, and shows a better balance between the carbon and stainless steel survival probabilities than does the NUREG/CR-5603 method. 


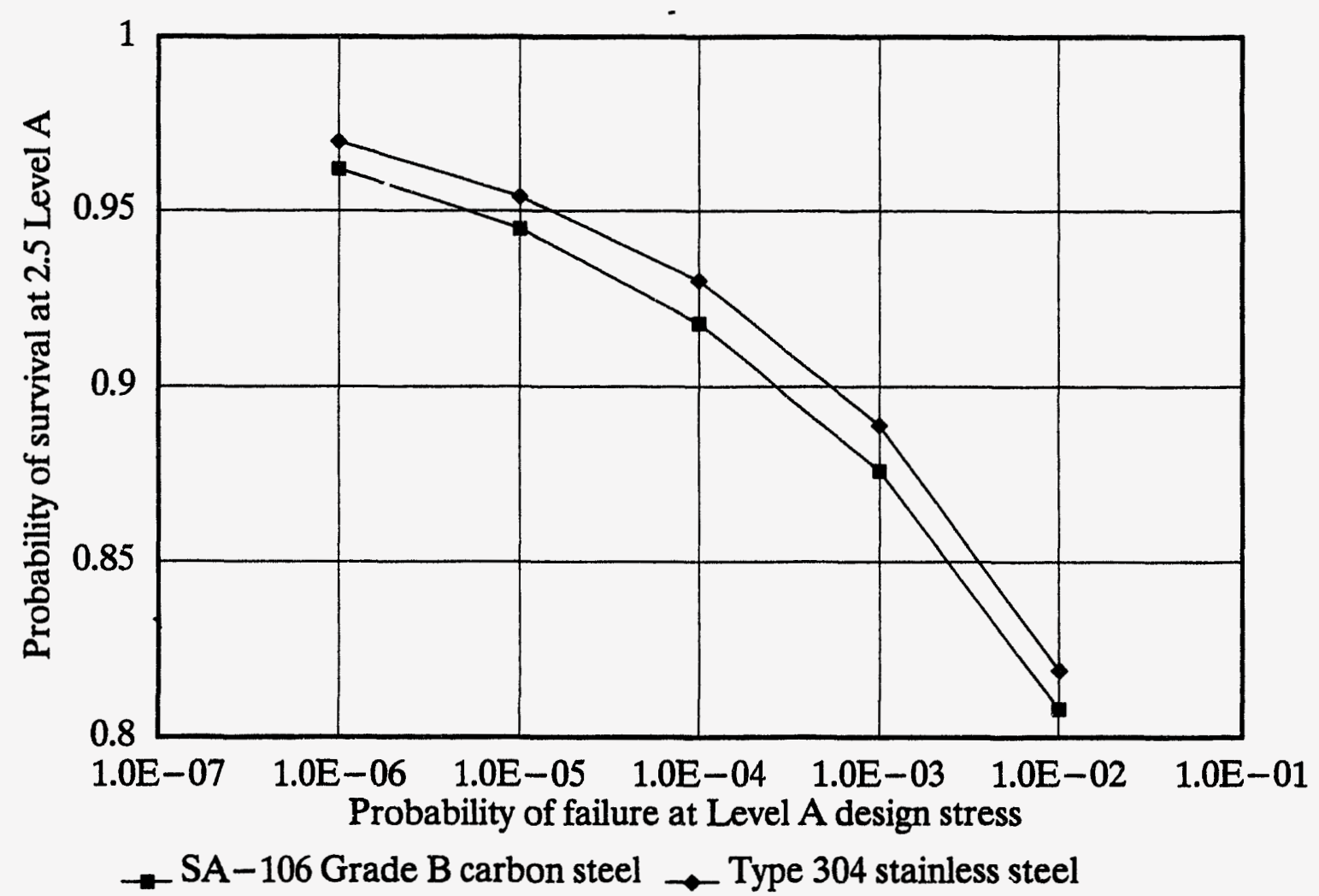

Figure 9. Survival confidences at 2.5 times the Level A stress for various probabilities of failure at the Level A stress. 


\section{MATERIAL PROPERTIES}

In NUREG/CR-5603, the median ultimate tensile strengths for carbon and stainless steels were obtained from Harvey (1985) and Weiss and Sessler (1963). In a September 1992 presentation by the author to the ASME Subgroup on Design in New York, the question was asked whether the NUREG/CR-5603 data had been compared to the data used in generating the ASME Code material property values. In response, material property data were obtained from alternate sources and compared to the NUREG/CR-5603 data. The ASME staff stated that the original data are found in some old ASTM publications, designated DS5 (stainless steel) and DS11 (carbon steel) and their supplements (Simmons and Van Echo, 1965; Simmons and Cross, 1952 and 1955; Smith, 1969 and 1972). The data in the five ASTM publications are carefully referenced (in almost all cases) to the source, the product form (bar, plate, pipe/ tube, etc.), and the test temperature. Individual data points (as opposed to averages) are tabulated. Therefore, these publications make excellent sources to which the NUREG/CR-5603 median values can be compared.

Data from several other sources also were used to supplement the ASME/ASTM data, where applicable. Dr. Gery Wilkowski of Battelle Columbus Laboratories was particularly helpful in identifying material property data sources.

From discussions with ALWR vendors and a review of the materials in operating plants, the following materials are believed to be those that will likely be used in systems subject to ISLOCA in ALWRs:

- Type 304 stainless steel pipe (wrought and cast) and plate

- Type 316 stainless steel pipe (wrought and cast)

- SA-106 Grade B carbon steel pipe

- SA-516 Grade 70 carbon steel plate.
The median ultimate isnsile strengths and the yield stresses of the alternate data can be compared directly with the NUREG/CR-5603 values, though in some cases the mean (m) and the standard deviation (s) need to be converted to the lognormal uncertainty $(\beta)$ and the median $(\mathrm{M})$, using the following formulas:

$$
\begin{aligned}
& M=e^{\ln (m)-\frac{\beta^{2}}{2}}=m e^{-\frac{\beta^{2}}{2}} \\
& \beta=\sqrt{\ln \left[\left(\frac{s}{m}\right)^{2}+1\right]} .
\end{aligned}
$$

Some further adjustments need to be made for the survival confidences. To obtain the survival confidences for the alternate data, the median failure stresses $\left[\sigma_{u}(\right.$ data $) \times 0.85$ (stainless steel) and 0.9 (carbon steel)] were adjusted by dividing by the $1+R \varepsilon_{f}$ factor to account for the increased diameter caused by the plastic strain. To obtain $\varepsilon_{\mathrm{f}}$ for the alternate data, the corresponding strains from NUREG/CR-5603 were multiplied by the ratio of the differences in median failure and yield stresses of the alternate data and the NUREG/CR-5603 values.

\subsection{Wrought Type 304 Stainless Steel}

Wrought Type 304 stainless steel data are available in two product forms applicable to systems to be designed for ISLOCA: pipe and plate.

3.1.1 Pipe. The oldest Type 304 stainless steel data sets are from Simmons and Cross (1952). This ASTM special publication had two supplements (Simmons and Van Echo, 1965; Smith, 1969). The 1952 data series contain values for three forms of 18-8 steel (although Type 304 stainless steel is not specially referred to in this reference, its composition is $18 \mathrm{Cr}-8 \mathrm{Ni}$ ): bar stock, sheet, and other (cast). There is no specific mention of the wrought pipe/tube product form. Supplement 1 , published in 1965 , specifically lists wrought Type 304 stainless steel as a separate product form, whereas Supplement 2, published in 1969, lists Type 304-304H pipe/tube as a separate product form. Other sources of data are 
Hiser (1989), Wilkowski et al. (1989), Hays et al. (1986), Kanninen (1982), and Yagawa et al. (1984).

The ultimate tensile strength (UTS) and yield stress data are plotted in Figures 10 and 11 with the NUREG/CR-5603 values. Since the ASME/ ASTM 1969 supplement does not present the data sources, some of the data in the two supplements may be duplicated. For the range of temperatures at which we are interested for ISLOCA (350 to $550^{\circ} \mathrm{F}$ ), the NUREG/CR-5603 median values are slightly higher than the ASTM data for the ultimate tensile strength, but slightly lower than the ASTM data for the yield stress. To obtain bestestimate values for the material parameters, leastsquares curve fits were calculated from the material property data and are shown in Figures 12 and 13. The curve fits are of the form:

$\sigma=a+b T+c T^{2}+d T^{3}$ where $T$ is the temperature and a through $d$ are constants (shown in Table 4).

What is really important is how the confidence level stresses compare. Table 5 compares the 90 , 97, and 99\% NLREG/CR-5603 confidence levels for a $10^{-3}$ probability of failure at the yield stress to the other data at 350 and $500^{\circ} \mathrm{F}$. The NUREG/CR-5603 confidence levels are within $1 \mathrm{ksi}$ of the confidence levels calculated using the other data, except for the $90 \%$ confidence level at $350^{\circ} \mathrm{F}$, where the NUREG/CR-5603 values are about 2.5 ksi nonconservative.

Table 6 summarizes the confidence levels assuming a $10^{-4}$ probability of failure at the yield stress. At this failure probability, the NUREG/CR-5603 values are within about $1 \mathrm{ksi}$ of the survival probabilities calculated using the other data at $500^{\circ} \mathrm{F}$, and about 1 to $3 \mathrm{ksi}$ nonconservative with respect to the other data at $350^{\circ} \mathrm{F}$. The overall conclusion is that the survival confidences calculated using the NUREG/CR-5603 and other data differ by, at most, about $6 \%$.

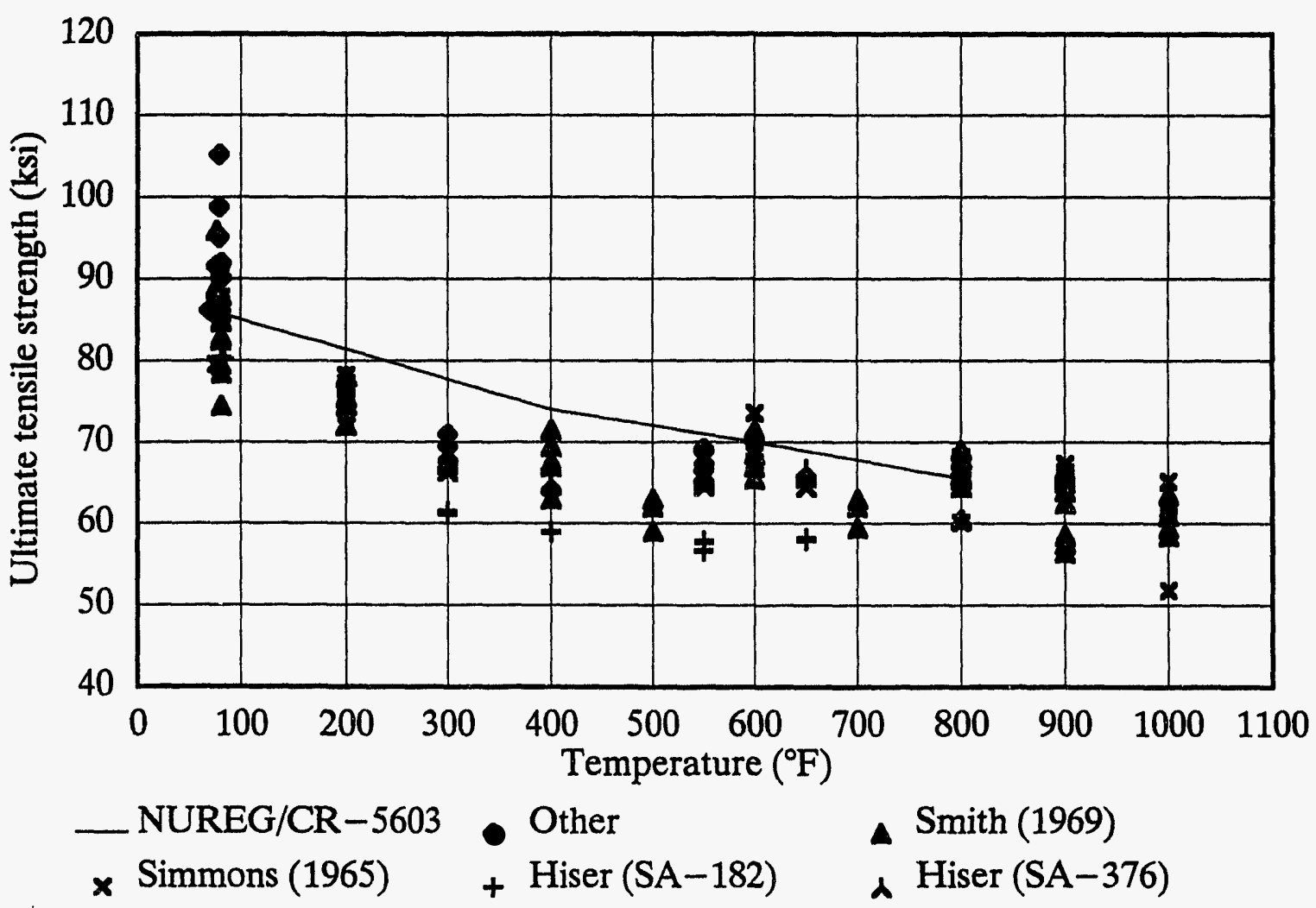

Figure 10. Ultimate tensile strength data for wrought Type 304 stainless steel pipe. 


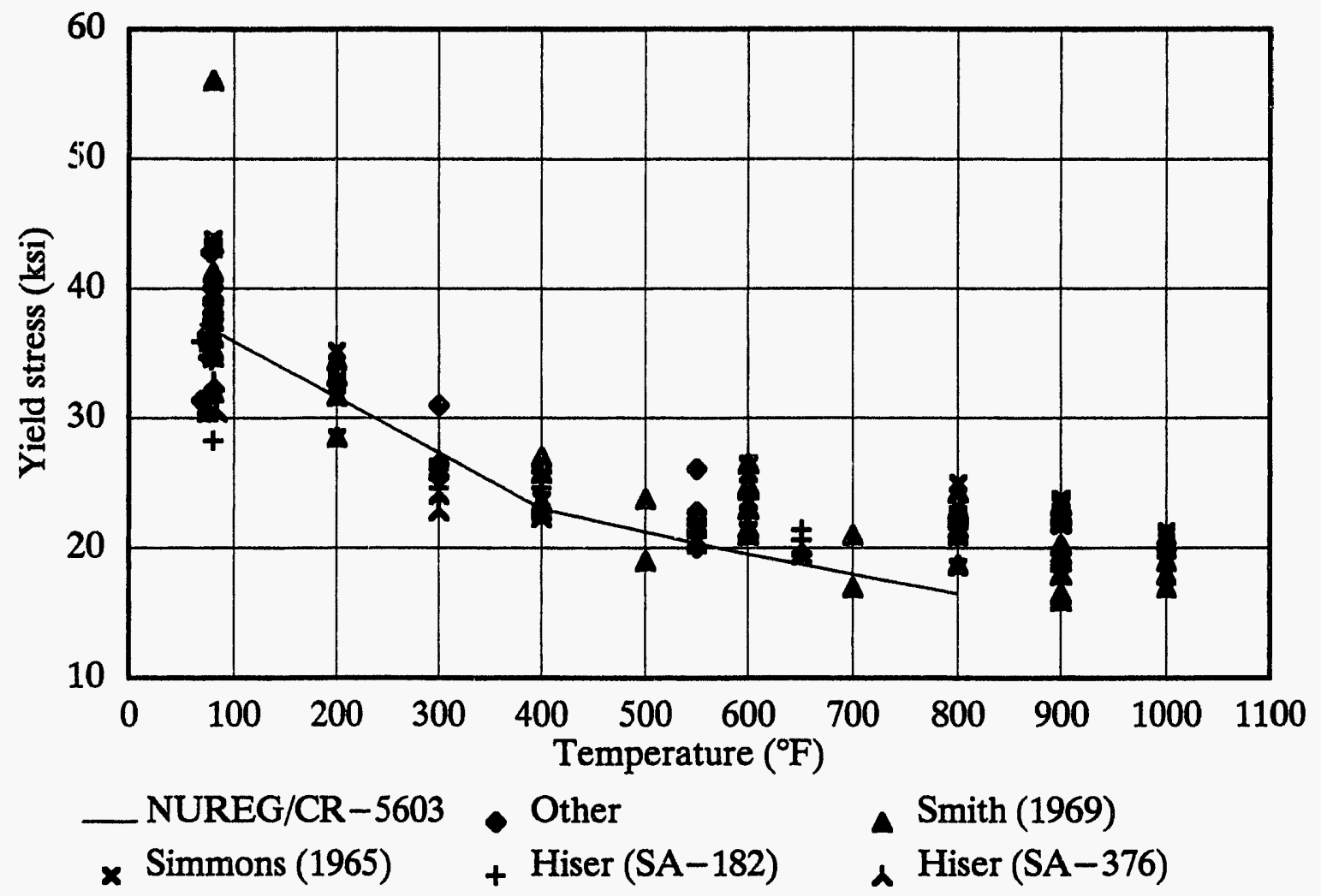

Figure 11. Yield stress data for wrought Type 304 stainless steel pipe.

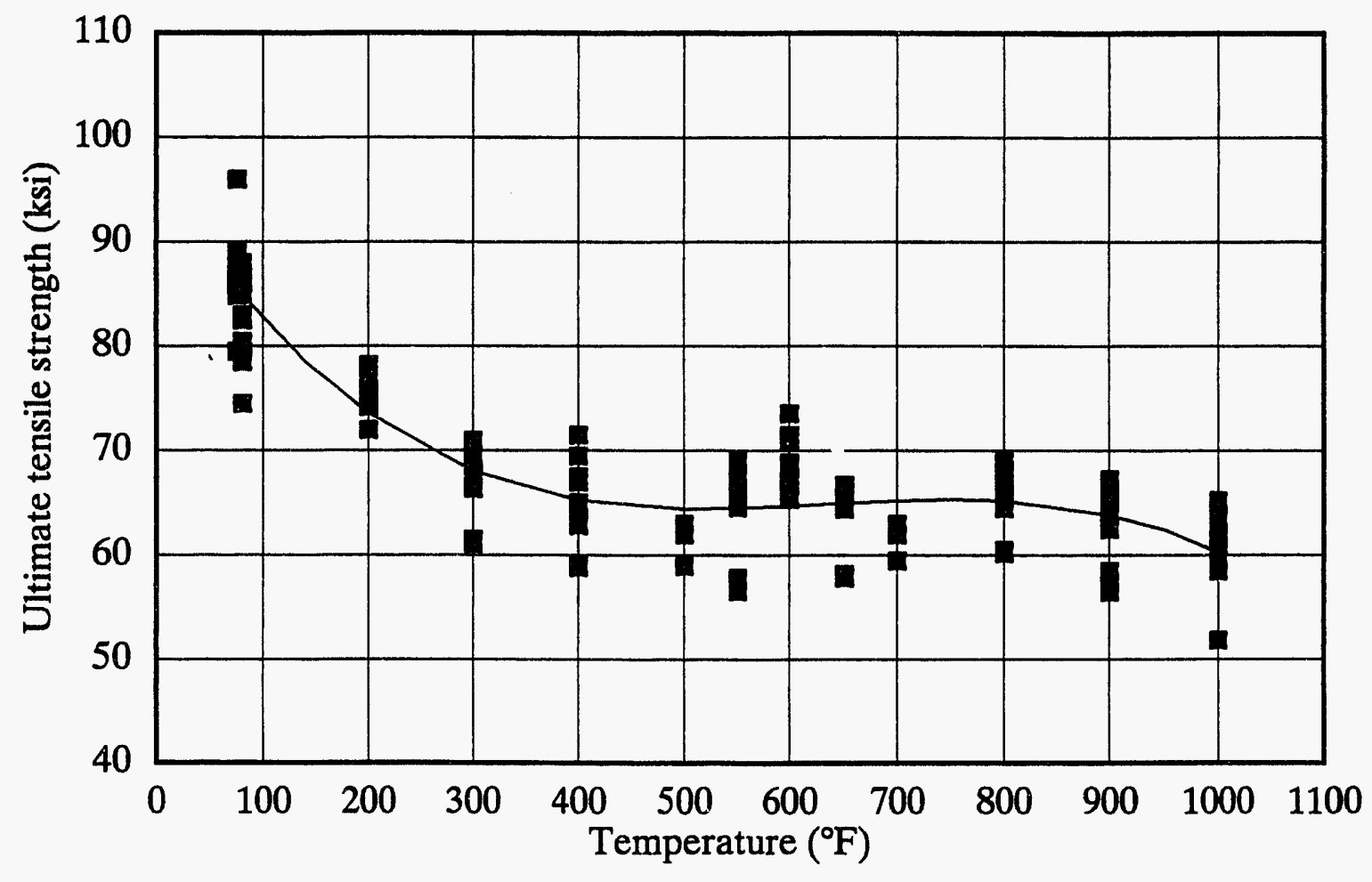

Figure 12. Ultimate tensile strength curve fit for wrought Type 304 stainless steel pipe. 


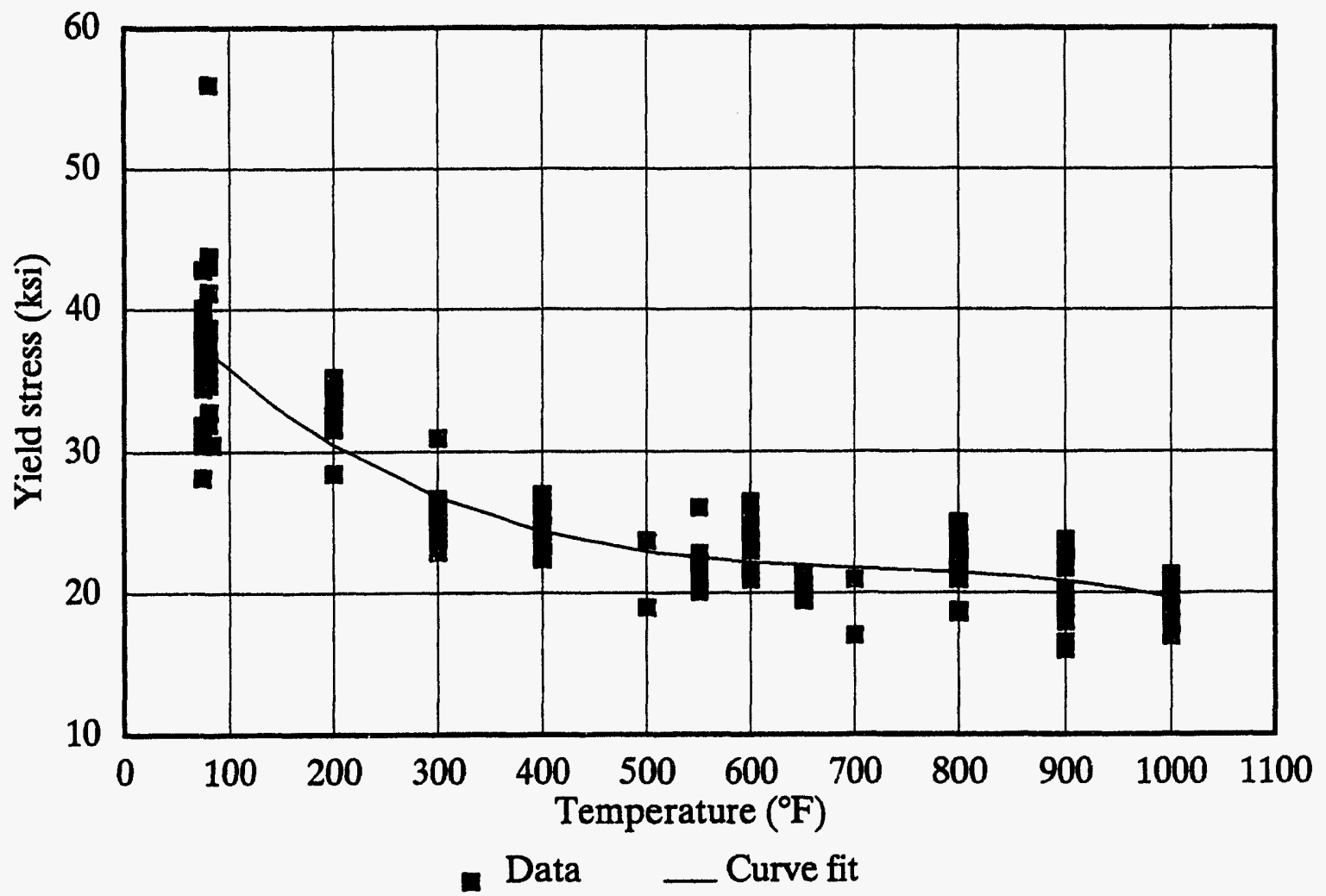

Figure 13. Yield stress curve fit for wrought Type 304 stainless steel pipe.

Table 4. Curve fit constants for Type 304 wrought stainless steel.

\begin{tabular}{ccccc}
\hline Pipe & a & b & c & d \\
\hline$S_{y}$ & 42.94 & -0.08229 & 0.000110 & $-5.1 \times 10^{-8}$ \\
$S_{u}$ & 96.0938 & -0.1593 & 0.000260 & $-1.4 \times 10^{-7}$ \\
\hline Plate & a & b & c & d \\
\hline$S_{y}$ & 42.82 & -0.07195 & $9.02 \times 10^{-5}$ & $-4.3 \times 10^{-8}$ \\
$S_{u}$ & 98.32 & -0.1720 & 0.000279 & $-1.5 \times 10^{-7}$ \\
\hline
\end{tabular}

Table 5. Comparison of survival confidence stress values for wrought Type 304 stainless steel pipe $\left(10^{-3}\right.$ probability of failure at yield stress).

\begin{tabular}{cccccc}
\multirow{2}{*}{$\begin{array}{c}\text { Survival } \\
\text { confidence } \\
(\%)\end{array}$} & \multicolumn{2}{c}{ Temperature $=500^{\circ} \mathrm{F}$} & & \multicolumn{2}{c}{ Temperature $=350^{\circ} \mathrm{F}$} \\
\cline { 2 - 3 } \cline { 5 - 6 } \cline { 5 - 6 } & NUREG/CR-5603 & Other data & & NUREG/CR-5603 & Other data \\
\hline 99 & 26.71 & 27.79 & & 30.72 & 30.15 \\
97 & 30.55 & 31.01 & & 34.44 & 33.22 \\
90 & 36.45 & 35.83 & & 40.00 & 37.73 \\
\hline
\end{tabular}


Table 6. Comparison of survival confidence stress values for wrought Type 304 stainless steel pipe (10-4 probability of failure at yield stress).

Stress

(ksi)

\begin{tabular}{cccccc}
\multirow{2}{*}{$\begin{array}{c}\text { Survival } \\
\text { confidence } \\
(\%)\end{array}$} & \multicolumn{2}{c}{ Temperature $=500^{\circ} \mathrm{F}$} & & \multicolumn{2}{c}{ Temperature $=350^{\circ} \mathrm{F}$} \\
\cline { 2 - 3 } \cline { 5 - 6 } & NUREG/CR-5603 & Other data & & NUREG/CR-5603 & Other data \\
\hline & 30.35 & 30.61 & & 33.99 & 32.84 \\
99 & 33.69 & 33.49 & & 37.31 & 35.55 \\
97 & 38.85 & 37.72 & & 42.16 & 39.47 \\
90 & &
\end{tabular}

3.1.2 Plate. The ASTM data by Simmons and Van Echo (1965) and Smith (1969), and other data from Wilkowski et al. (1989) and Kanninen et al. (1976 and 1982) contain a few material property values for Type 304 stainless steel plate. Figures 14 and 15 show the NUREG/CR-5603 Type 304 stainless steel values plotted with the data points for Type 304 plate material from other sources. From inspection, some of the data from the two ASME/ASTM sources may be dupli- cated. The NUREG/CR-5603 ultimate tensile strength values trend higher than the other data, whereas the NUREG/CR-5603 yield stress values trend lower than the other data points.

Table 4 lists the Equation 9 curve fit coefficients and Figures 16 and 17 show the curve fits. The curve coefficients for the pipe and plate forms do not differ greatly. Table 7 compares the survival confidences at $350^{\circ} \mathrm{F}$.

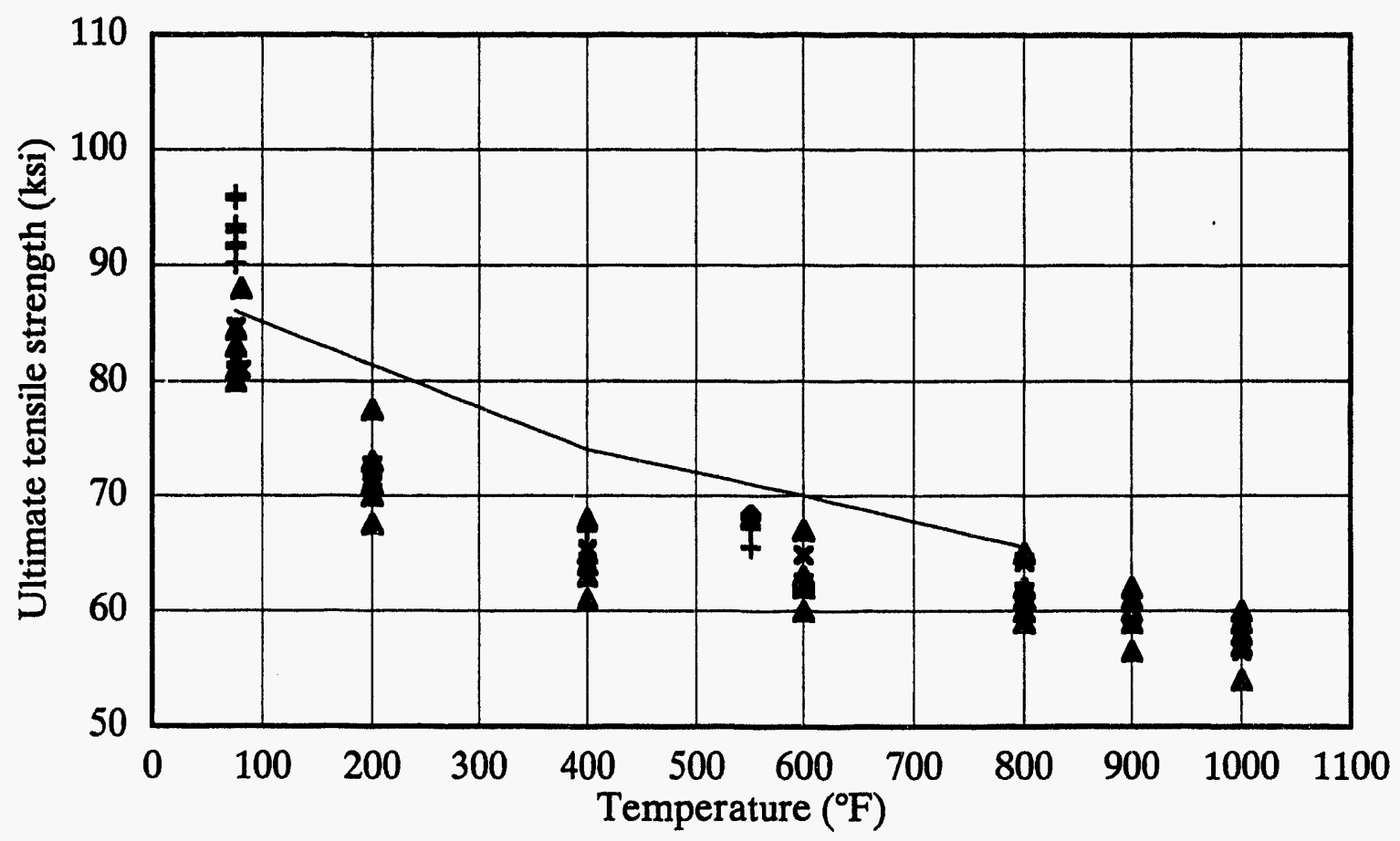
_ NUREG/CR-5603
× Simmons (1965)
- Wilkowski (1989)
+ Kanninen $(1976,1982)$
^ Smith (1969)

Figure 14. Comparison of ultimate tensile strength data for wrought Type 304 stainless steel plate. 
Material Properties

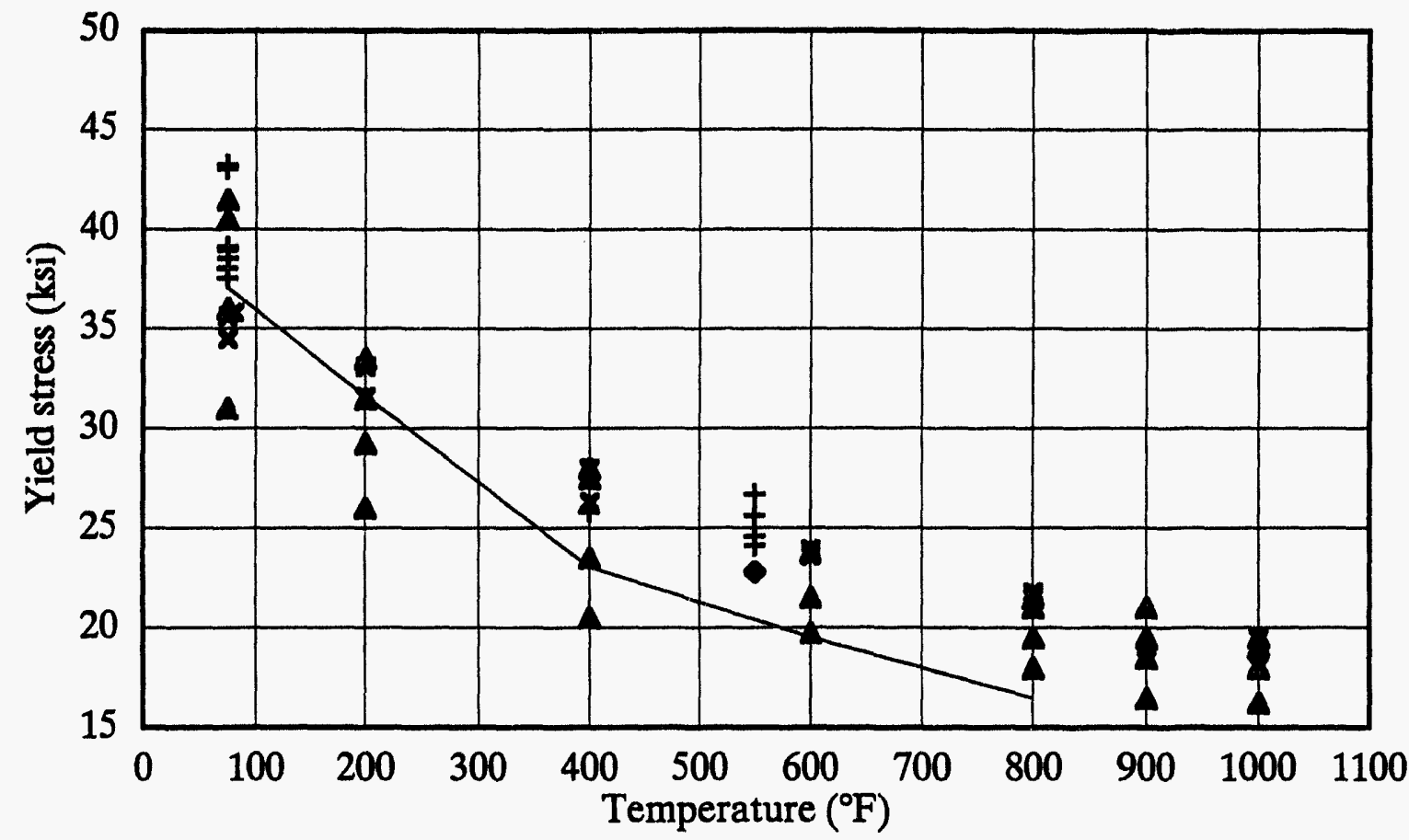
_ NUREG/CR-5603
- Wilkowski (1989)
A Smith (1969)
x Simmons (1965)
+ Kanninen (1976,1982)

Figure 15. Comparison of yield stress data for wrought Type 304 stainless steel plate.

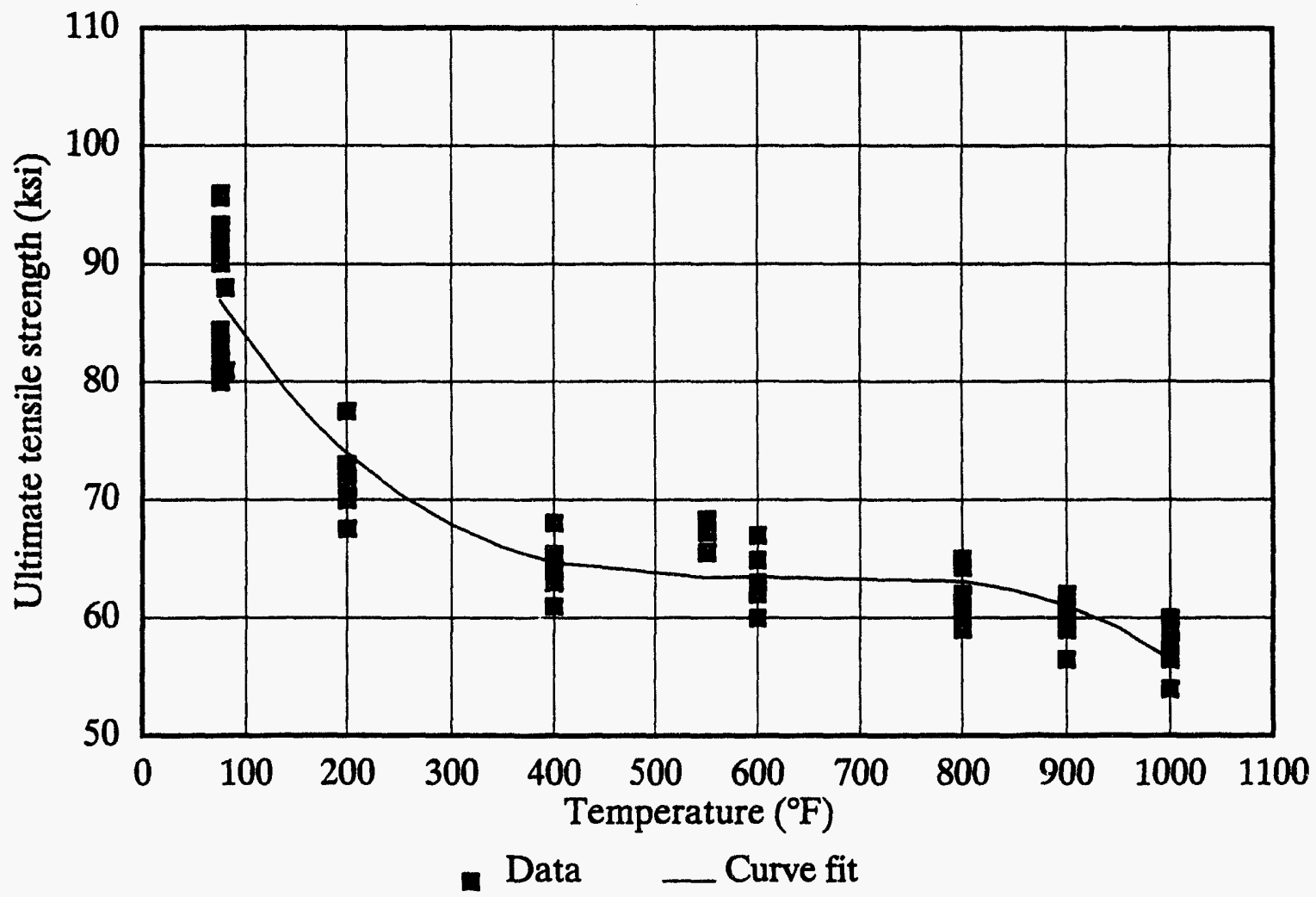

Figure 16. Curve fit for wrought Type 304 stainless steel plate ultimate tensile strength data. 


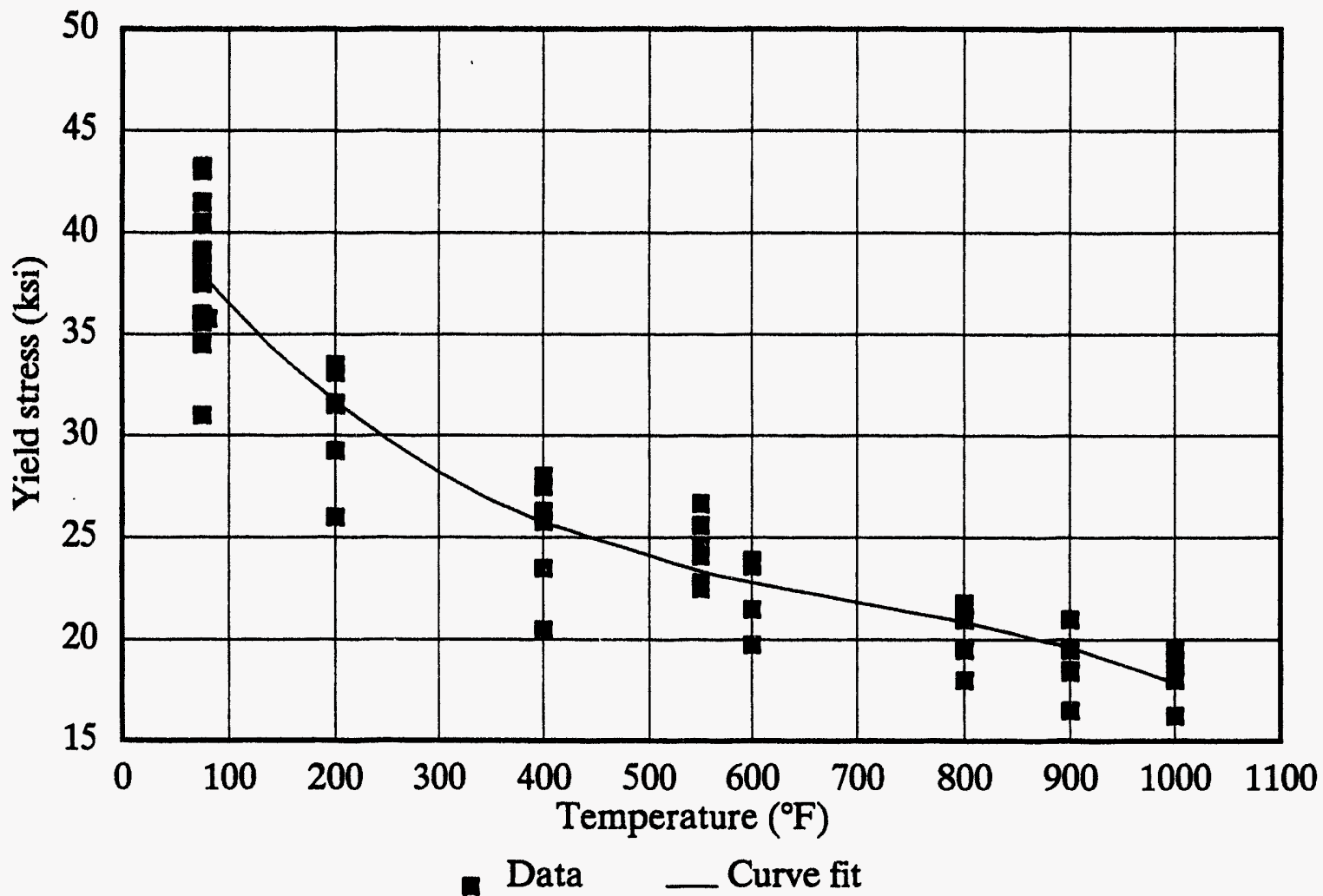

Figure 17. Curve fit for wrought Type 304 stainless steel plate yield stress data.

Table 7. Comparison of survival confidence stress values for Type 304 stainless steel plate at $350^{\circ} \mathrm{F}$ $\left(10^{-3}\right.$ and $10^{-4}$ probabilities of failure at yield stress).

\begin{tabular}{cccccc} 
& \multicolumn{2}{c}{$10^{-3}$ failure probability at $\sigma_{\mathrm{y}}$} & & \multicolumn{2}{c}{$10^{-4}$ failure probability at $\sigma_{\mathrm{y}}$} \\
\cline { 2 - 3 } $\begin{array}{c}\text { Survival confidence } \\
(\%)\end{array}$ & NUREG/CR-5603 & Curve fit & & NUREG/CR-5603 & Curve fit \\
\hline 99 & 30.32 & 31.49 & & 32.02 & 34.15 \\
97 & 33.76 & 34.52 & & 35.19 & 36.82 \\
90 & 38.90 & 38.97 & & 39.92 & 40.69 \\
\hline
\end{tabular}

The NUREG/CR-5603 survival confidences are within $2 \mathrm{ksi}$ of the corresponding survival confidences calculated from the other data. NUREG/CR-5603 recommends lower failure stress values for vessels than for piping; consequently, the survival confidence levels for the NUREG/CR-5603 values in Table 7 are lower than those in Tables 5 and 6.

\subsection{Cast Type 304 Stainless Steel}

Most of the data in the ASTM reports are for wrought stainless steel. The 1969 report deliberately excludes data for cast stainless steel, whereas the 1952 and 1965 reports contain only a 
few points for cast material at several temperatures. The data in the 1965 report are for cast stainless steel pipe that had been bored and cold expanded. Figures 18 and 19 plot this data with data from Brown (1992) [which were obtained from Allegheny Ludlum (1958)], Hiser (1988), and Chopra et al. (1991). The overall conclusions are that the NUREG/CR-5603 ultimate tensile strength values trend higher than the other data, and that the NUREG/CR-5603 yield stress values are approximately the same as the additional data.

Table 8 lists the Equation 9 curve fit coefficients, and Figures 20 and 21 show the curve fits. The curve coefficients for the cast and wrought forms do not differ greatly. Table 9 compares the survival confidences at $350^{\circ} \mathrm{F}$. The NUREG/ CR-5603 survival confidences are within 0 to $3 \mathrm{ksi}$ of the curve fit values obtained from the other data. The ASTM (1952) data were from tests of cast cylinders and cast keel blocks (navy pattern). The ASTM (1965) data were from tests of material that was cast, rough-turned and bored, cold expanded, and annealed. Based on the graphs in Figures 18 through 21 and the survival confidences in Table 9, it appears that the NUREG/CR-5603 values are representative for cast Type 304 stainless steel.

\subsection{Type 316 Stainless Steel}

The Type 316 stainless steel data in NUREG/CR-5603 were taken from the 1963 version of the Aerospace Structural Metals Handbook (Brown, 1992). These data were in turn taken from tests conducted by the Timken Roller Bearing Company (1962). Unfortunately, there were no data reported between room temperature and $1000^{\circ} \mathrm{F}$, so essentially a straight-line curve was fit between the room temperature and the $1000^{\circ} \mathrm{F}$ data in the Aerospace Structural Metals Handbook. From review of the same data reported in Simmons and Van Echo (1965), the type of stainless steel tested was wrought, 6-5/8-in. diameter by $1-5 / 16$-in. wall, seamless, rotary-pierced, inside-and-outside-surfacesmachined material.

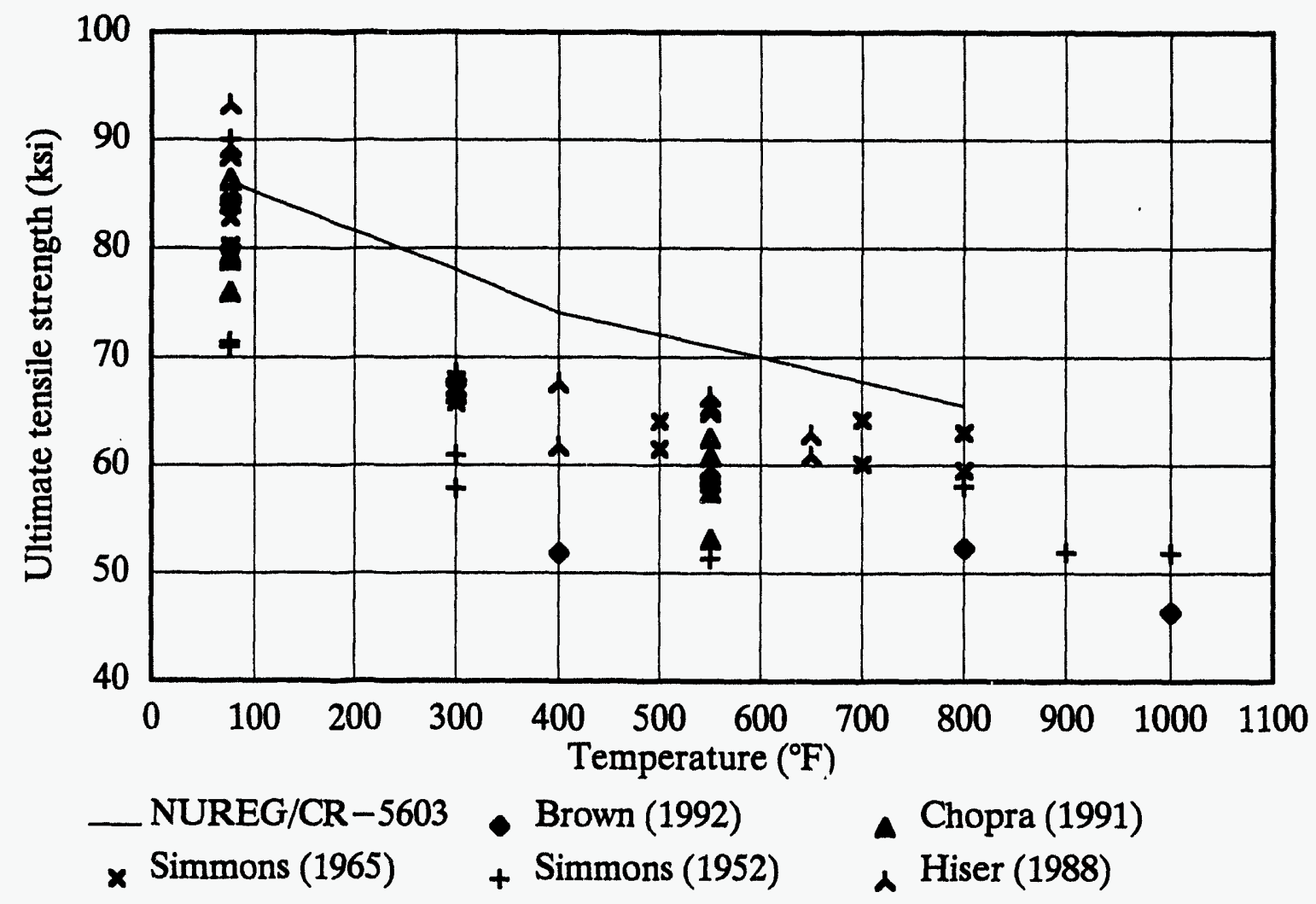

Figure 18. Comparison of ultimate tensile strength data for cast Type 304 stainless steel. 


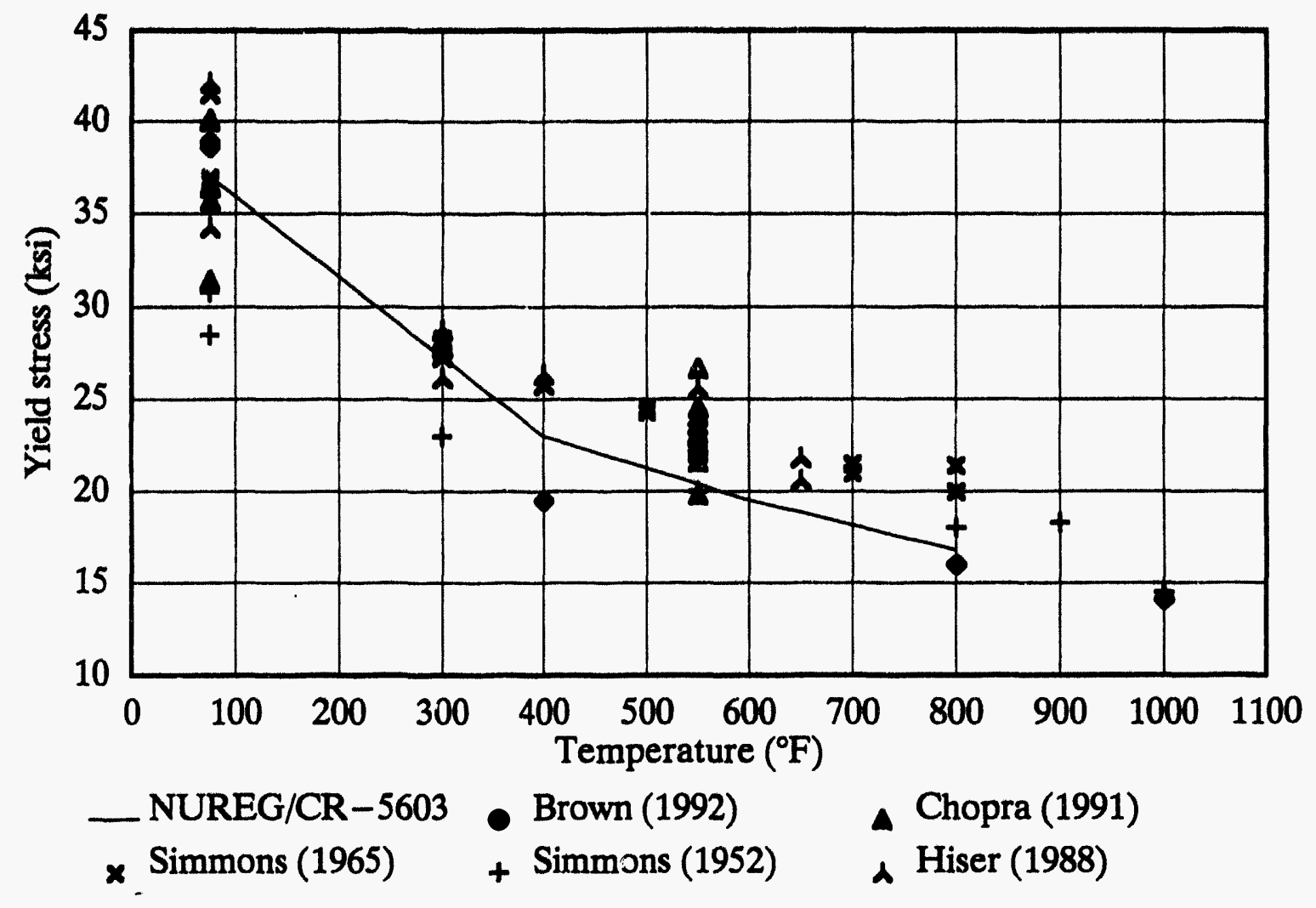

Figure 19. Comparison of yield stress data for cast Type 304 stainless steel.

Table 8. Curve fit constants for Type 304 cast stainless steel pipe.

\begin{tabular}{ccccc} 
& $\mathrm{a}$ & \multicolumn{1}{c}{$\mathrm{b}$} & $\mathrm{c}$ & $\mathrm{d}$ \\
\cline { 2 - 5 } $\mathrm{S}_{\mathrm{y}}$ & 41.94 & -0.07655 & 0.000109 & $-6.0 \times 10^{-8}$ \\
$\mathrm{~S}_{\mathrm{u}}$ & 93.67 & -0.165 & 0.000278 & $-1.6 \times 10^{-7}$ \\
\hline
\end{tabular}

There are far less available data for Type 316 stainless steel than for Type 304 stainless steel. A comparison of the wrought and cast properties of Type 304 stainless steel pipe show that the cast yield and ultimate tensile strength values are less than the wrought values by 5.3 and $3.3 \%$, respectively. From plots of the corresponding values for Type 316 stainless steel, it appears that there also is not a great difference between the wrought and cast values; therefore, no differentiation will be made between the forms of Type 316 stainless steel.

The NUREG/CR-5603 Type 316 stainless steel ultimate tensile strength and the yield strength data are plotted with wrought and cast
Type 316 from Simmons and Van Echo (1965), Smith (1969), and CF8M (the cast form of Type 316 stainless steel) from Bamford and Swamy (1984), Chopra et al. (1991), Hiser (1988), Wilkowski et al. (1989), and Wilkowski (1984) in Figures 22 and 23 . The other data are clearly lower than the NUREG/CR-5603 values in the ISLOCA temperature range. The shape of the Type 316 stainless steel data curve follows the general trend for stainless steels (e.g., Type 304) in the room temperature to $1000^{\circ} \mathrm{F}$ range.

Table 10 lists Equation 9 curve fit coefficients, and Figures 24 and 25 show the curve fits. Table 11 presents the survival confidences for the Type 316 data. The curve fit values are about 
Material Properties

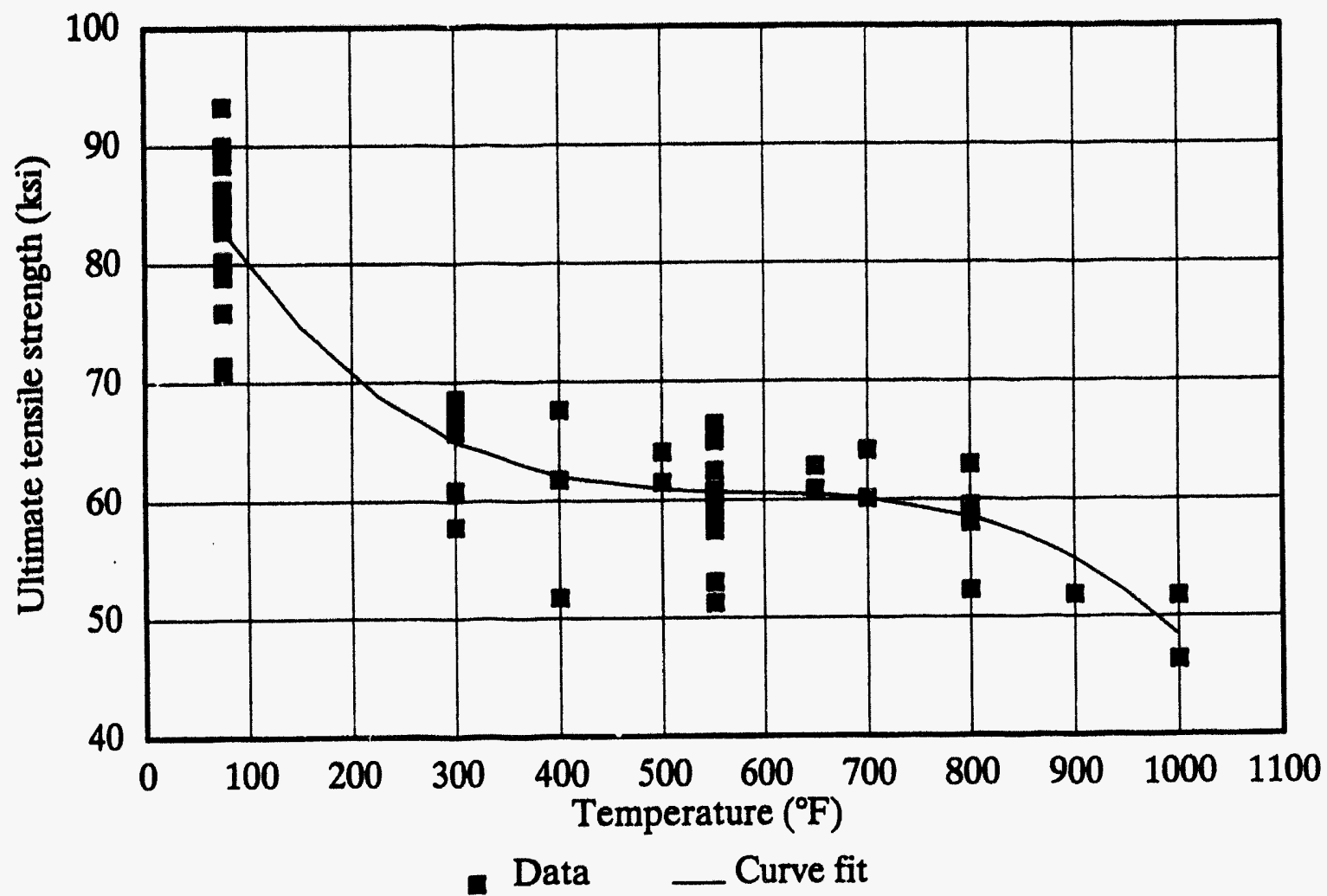

Figure 20. Curve fit for cast Type 304 stainless steel ultimate tensile strength data.

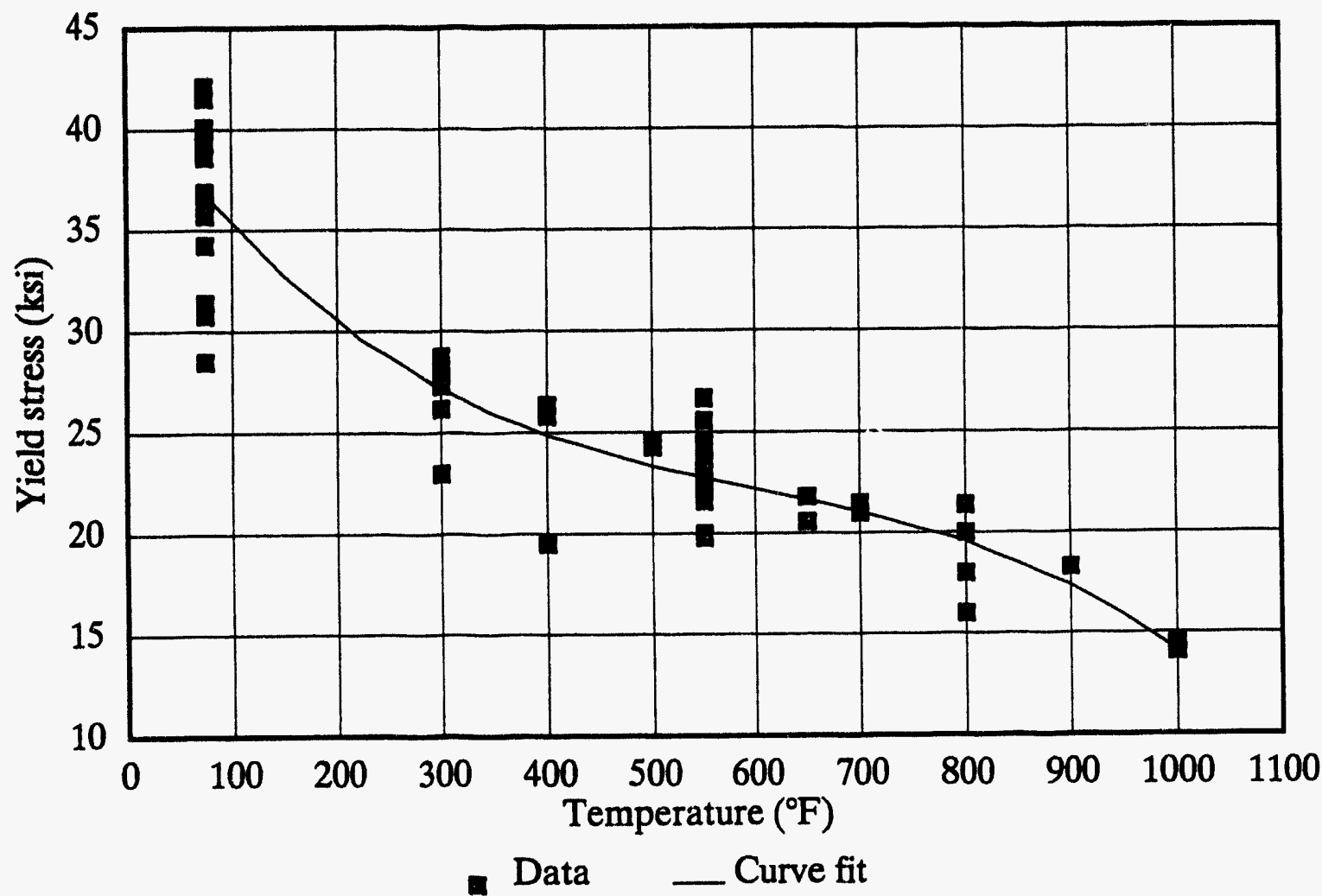

Figure 21. Curve fit for cast Type 304 stainless steel yield stress data. 
Table 9. Comparison of survival confidence stress values for cast Type 304 stainless steel pipe at $350^{\circ} \mathrm{F}$ $\left(10^{-3}\right.$ and $10^{-4}$ probabilities of failure at yield stress).

\section{Stress}

(ksi)

\begin{tabular}{|c|c|c|c|c|}
\hline \multirow{2}{*}{$\begin{array}{c}\text { Survival confidence } \\
(\%)\end{array}$} & \multicolumn{2}{|c|}{$10^{-3}$ failure probability at $\sigma_{y}$} & \multicolumn{2}{|c|}{$10^{-4}$ failure probability at $\sigma_{y}$} \\
\hline & NUREG/CR-5603 & Curve fit & NUREG/CR-5603 & Curve fit \\
\hline 99 & 30.72 & 30.25 & 33.99 & 32.71 \\
\hline 97 & 34.44 & 33.05 & 37.31 & 35.18 \\
\hline 90 & 40.00 & 37.16 & 42.16 & 38.73 \\
\hline
\end{tabular}

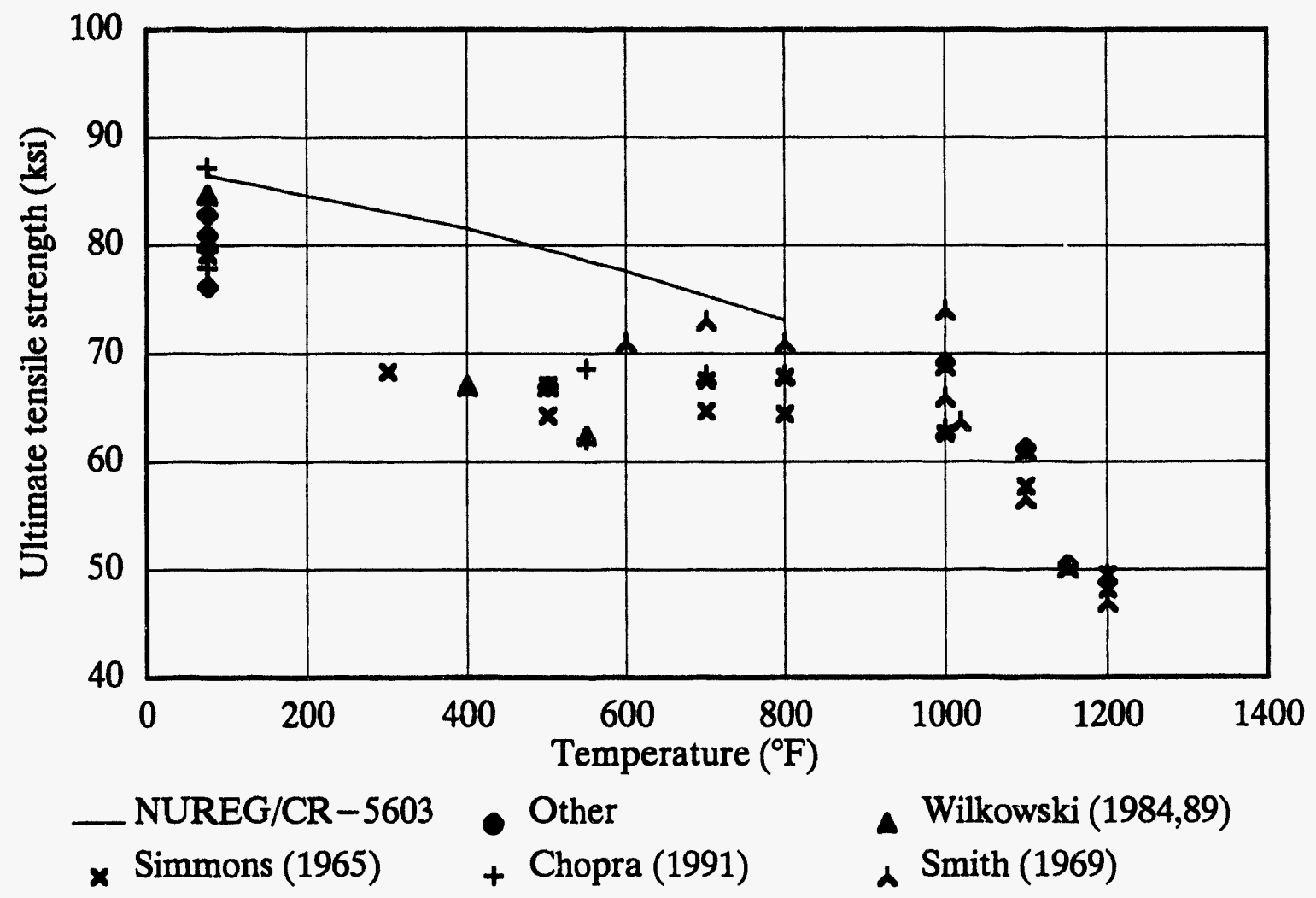

Figure 22. Comparison of ultimate tensile strength data for Type 316 stainless steel.

7 to $10 \mathrm{ksi}$ lower than the NUREG/CR-5603 values. This is mainly a result of the yield stress from the curve fit being $27.4 \mathrm{ksi}$ at $350^{\circ} \mathrm{F}$, compared to the NUREG/CR-5603 value of 36.1 . Therefore, it appears that the NUREG/CR-5603 values are nonconservative for Type 316 stainless steel.

Figures 26 and 27 compare the curves fits for the three forms of Type 304 stainless steel with the curve fit for Type 316 stainless steel. The material property values appear about the same in the region of interest $\left(350\right.$ to $\left.550^{\circ} \mathrm{F}\right)$.

The best-estimate ultimate tensile strength value at $350^{\circ} \mathrm{F}$ from the curve fit of the available data is $65.8 \mathrm{ksi}$, whereas the ASME Code values for cast and wrought Type 316 stainless steel are 


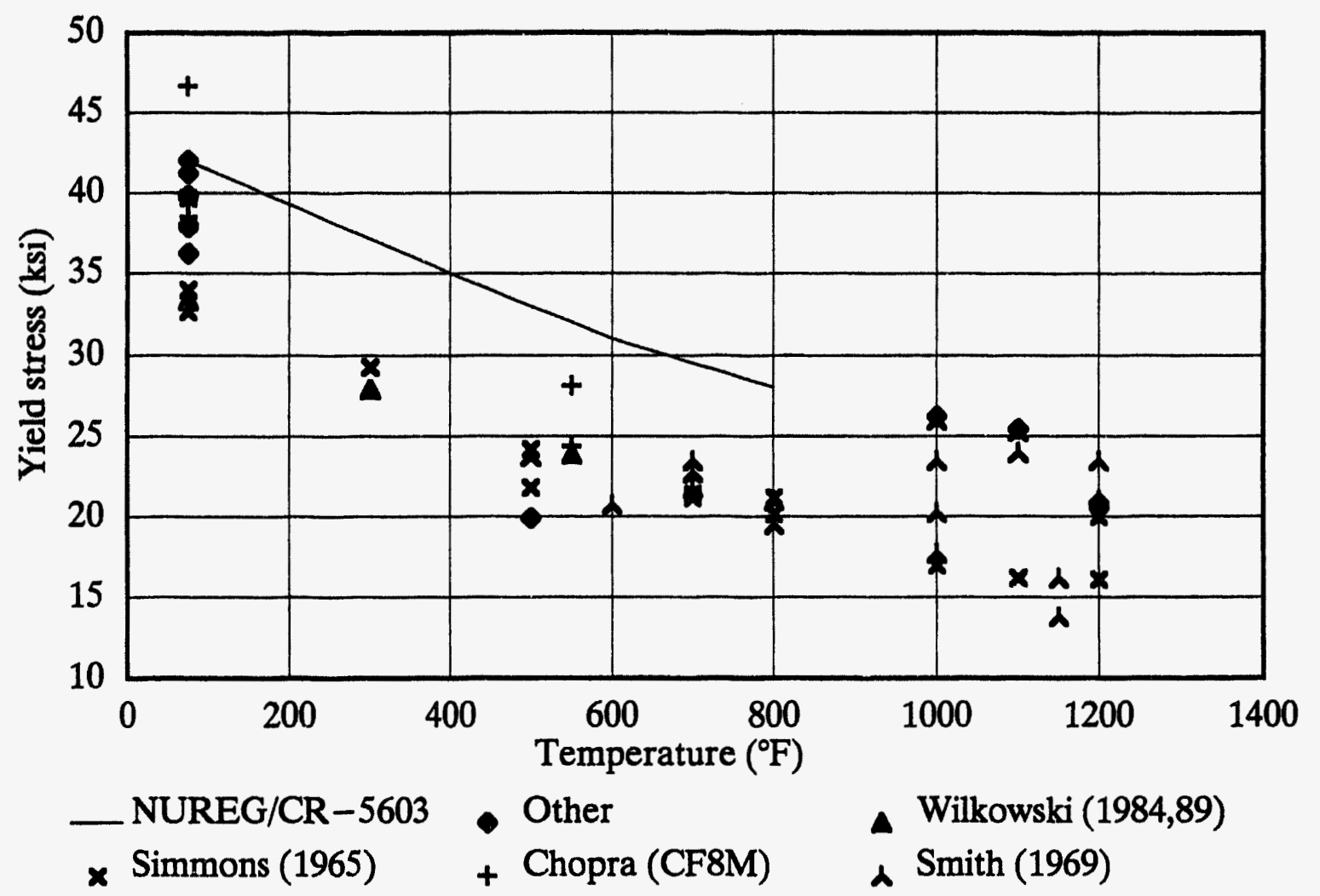

Figure 23. Comparison of yield stress data for Type 316 stainless steel.

Table 10. Curve fit constants for Type 316 stainless steel.

\begin{tabular}{ccccc} 
& $\mathrm{a}$ & \multicolumn{1}{c}{$\mathrm{b}$} & $\mathrm{c}$ & $\mathrm{d}$ \\
\cline { 2 - 5 } & & & & \\
$\mathrm{S}_{\mathrm{y}}$ & 43.47 & -0.07495 & 0.000088 & $-3.5 \times 10^{-8}$ \\
$\mathrm{~S}_{\mathrm{u}}$ & 91.58 & -0.152 & 0.000274 & $-1.5 \times 10^{-7}$ \\
\hline
\end{tabular}

67.75 and $72.6 \mathrm{ksi}$, respectively. The ASME ultimate tensile strength values also are not supported by the data in Simmons and Van Echo (1965).

\subsection{SA-106 Grade B Carbon Steel}

NUREG/CR-2137 (Rodabaugh and Desai, 1980) presents data for carbon steel at room temperature. Although there are no elevated temperature data, the report does have the advantage that a relatively large number of data are presented for each material, and, thus, the shape of the probability distribution can be estimated. However, there are insufficient data samples to produce an extremely smooth curve. Figures 28 and 29 plot the ultimate tensile strength and yield stress normal and lognormal distributions for SA-106 Grade B carbon steel with the distribution of the 102 data points in NUREG/CR-2137. Equations 10 and 11 are the forms of the normal and lognormal distribution functions used, respectively. The traces of the normal and lognormal distributions are very similar, and both fit the data reasonably well. 

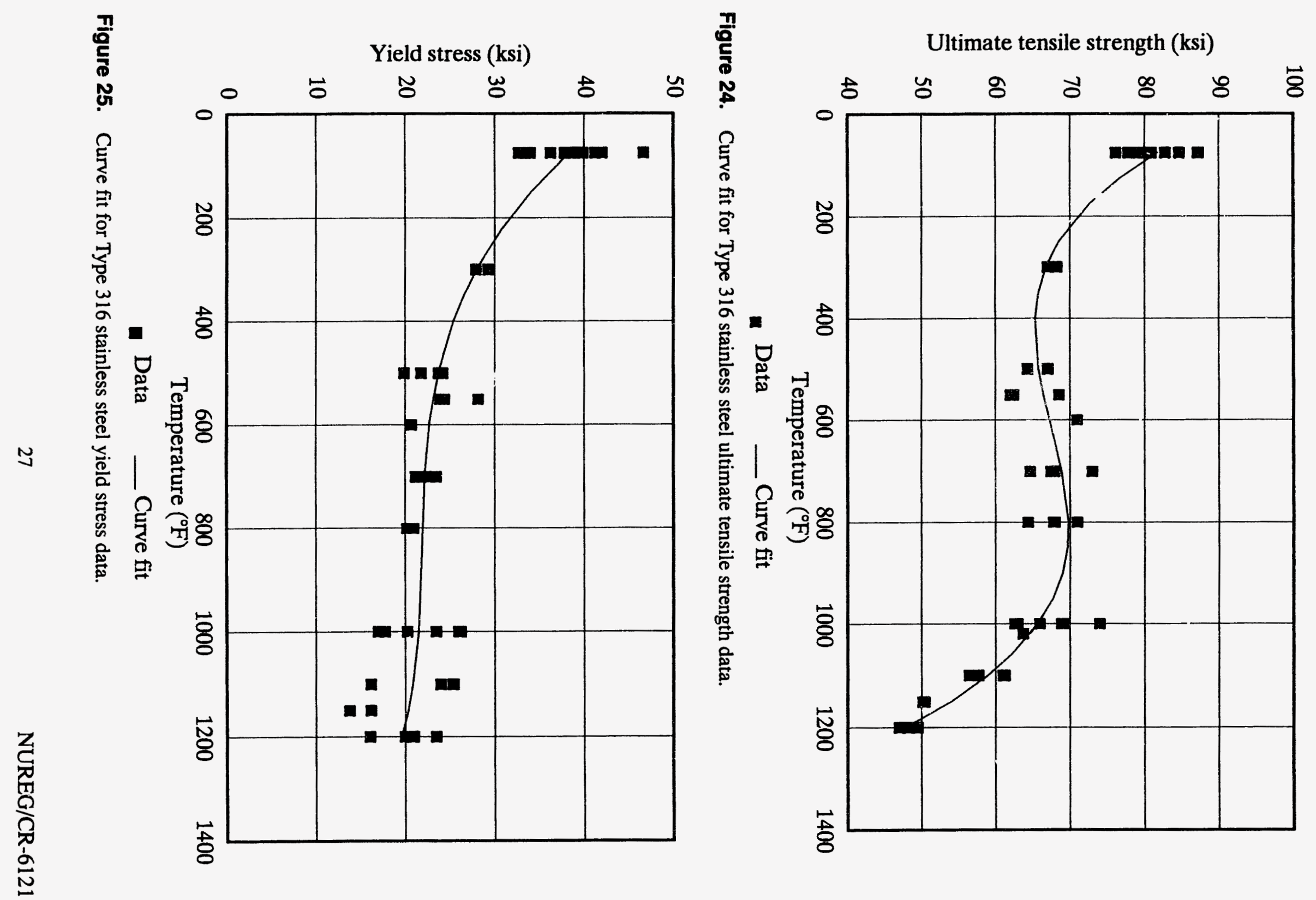
Table 11. Comparison of survival confidence stress values for Type 316 stainless steel at $350^{\circ} \mathrm{F}\left(10^{-3}\right.$ and $10^{-4}$ probabilities of failure at yield stress).

\begin{tabular}{|c|c|c|c|c|}
\hline \multirow{3}{*}{$\begin{array}{l}\text { Survival confidence } \\
(\%) \\
\end{array}$} & \multicolumn{4}{|c|}{$\begin{array}{c}\text { Stress } \\
(\mathrm{ksi})\end{array}$} \\
\hline & \multicolumn{2}{|c|}{$10^{-3}$ failure probability at $\sigma_{y}$} & \multicolumn{2}{|c|}{$10^{-4}$ failure probability at $\sigma_{y}$} \\
\hline & NUREG/CR-5603 & Curve fit & NUREG/CR-5603 & Curve fit \\
\hline 99 & 40.94 & 31.00 & 43.63 & 33.52 \\
\hline 97 & 43.99 & 33.87 & 46.26 & 36.03 \\
\hline 90 & 48.36 & 38.03 & 49.95 & 39.63 \\
\hline
\end{tabular}

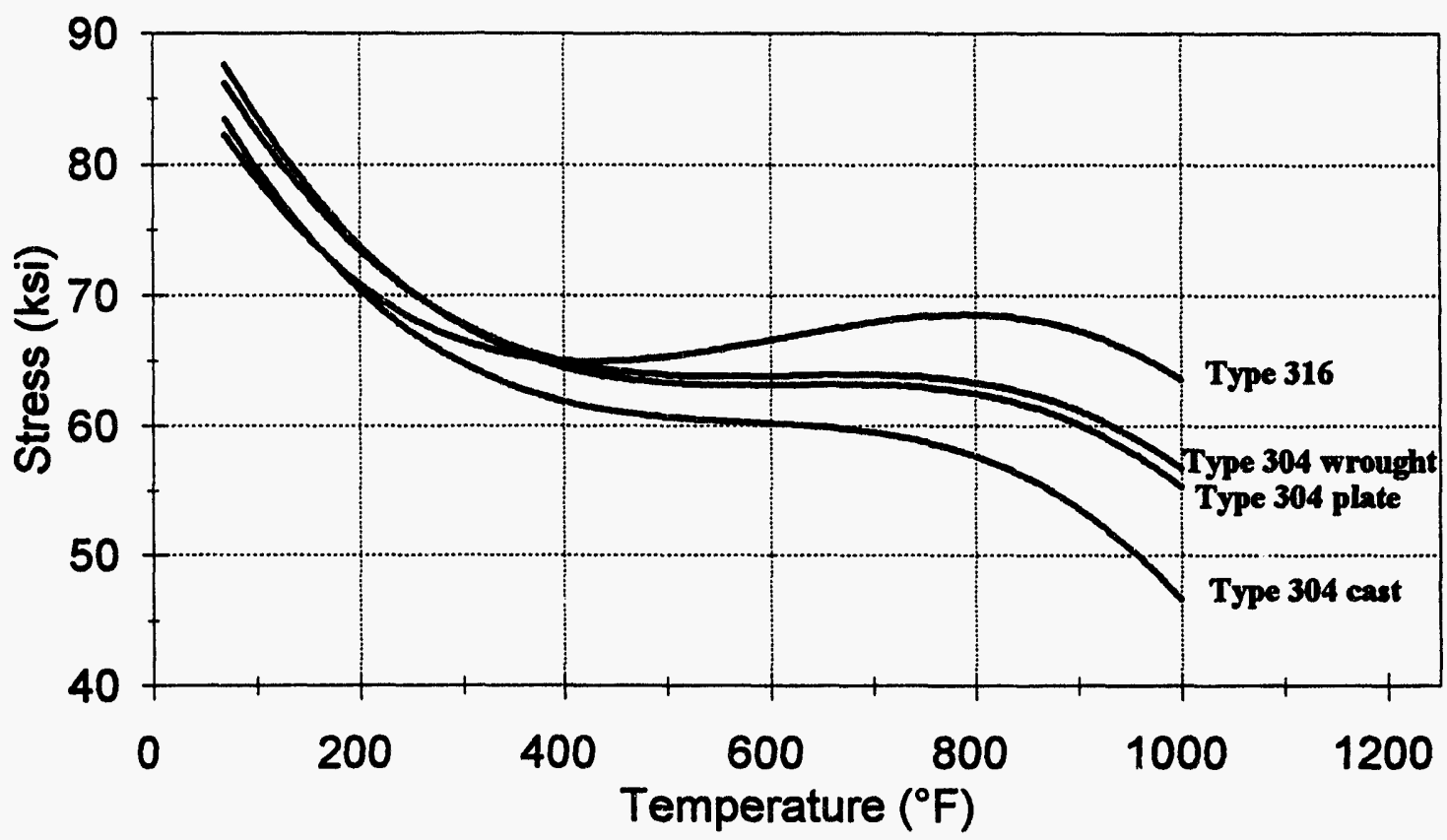

Figure 26. Curve fit comparison of Types 304 and 316 stainless steel ultimate tensile strength data.

$f($ sigms $)=\frac{1}{s \sqrt{2 \pi}} e^{-\frac{(0-m)^{2}}{2 s^{2}}}$

$f(\sigma)=\frac{1}{\sigma \beta \sqrt{2 \pi}} e^{\frac{-1}{2}\left[\frac{1}{\beta} \ln \left(\frac{\sigma}{M}\right)\right]^{2}}$.

The NUREG/CR-5603 ultimate tensile strength of $68 \mathrm{ksi}$ at room temperature is very close to the median in Figure 28 , but the NUREG/CR-5603 yield stress of $36 \mathrm{ksi}$ is located on the extreme lower tail of the curve in Figure 29. Thus, we would expect that the stress values for high survival confidences based on the NUREG/CR-5603 values would be conservative.
Simmons and Cross (1955) have a few data points at several temperatures for SA-106 Grade $B$ carbon steel. There are three data points at each temperature for the as-rolled material and an additional three values where the material had been stress relieved for 2 hours at $1150^{\circ} \mathrm{F}$. The ASTM Standards (1982) state that “... A-106 Grade B material shall be killed steel; pipe sizes of NPS 2 and over shall be furnished hot finished (cold-drawn pipe may be furnished if agreed upon between the manufacturer and purchaser); hotfinished pipe need not be heat treated, but colddrawn pipe shall be heat treated at a temperature 


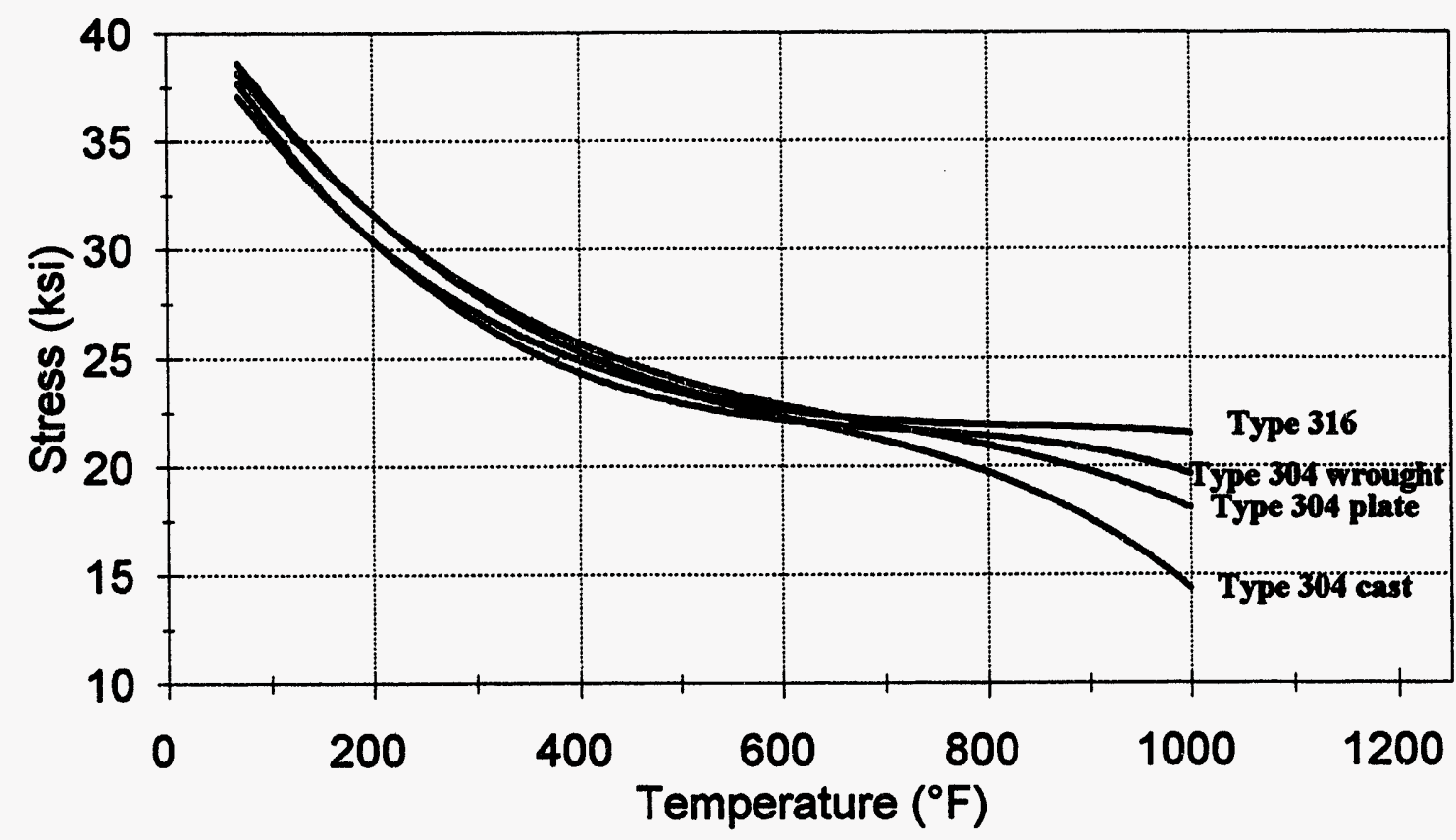

Figure 27. Curve fit comparison of Types 304 and 316 stainless steel yield stress data.

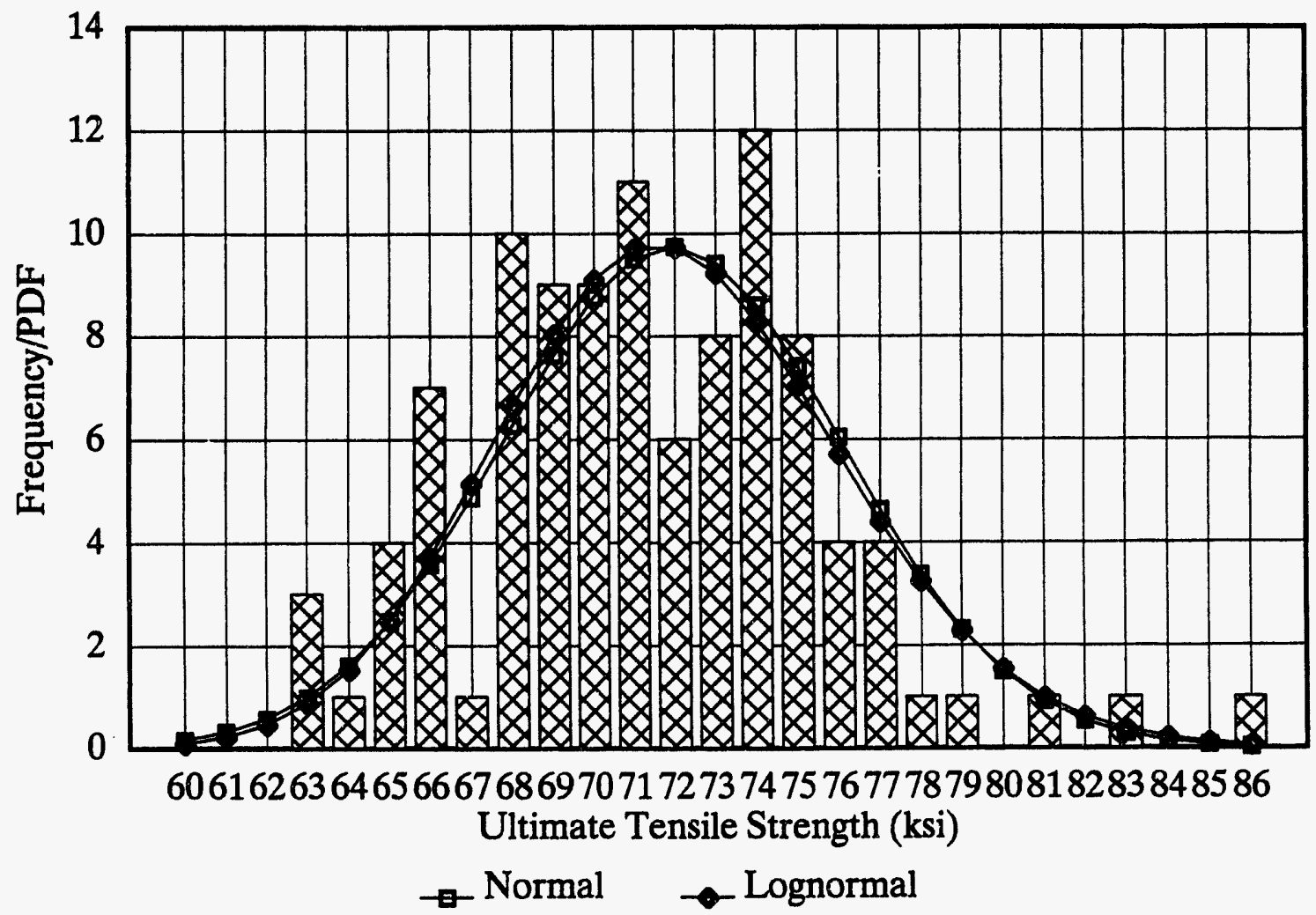

Figure 28. Normal and lognormal representations of SA-106 Grade B carbon steel ultimate tensile strength data from NUREG/CR-2137 (room temperature). 


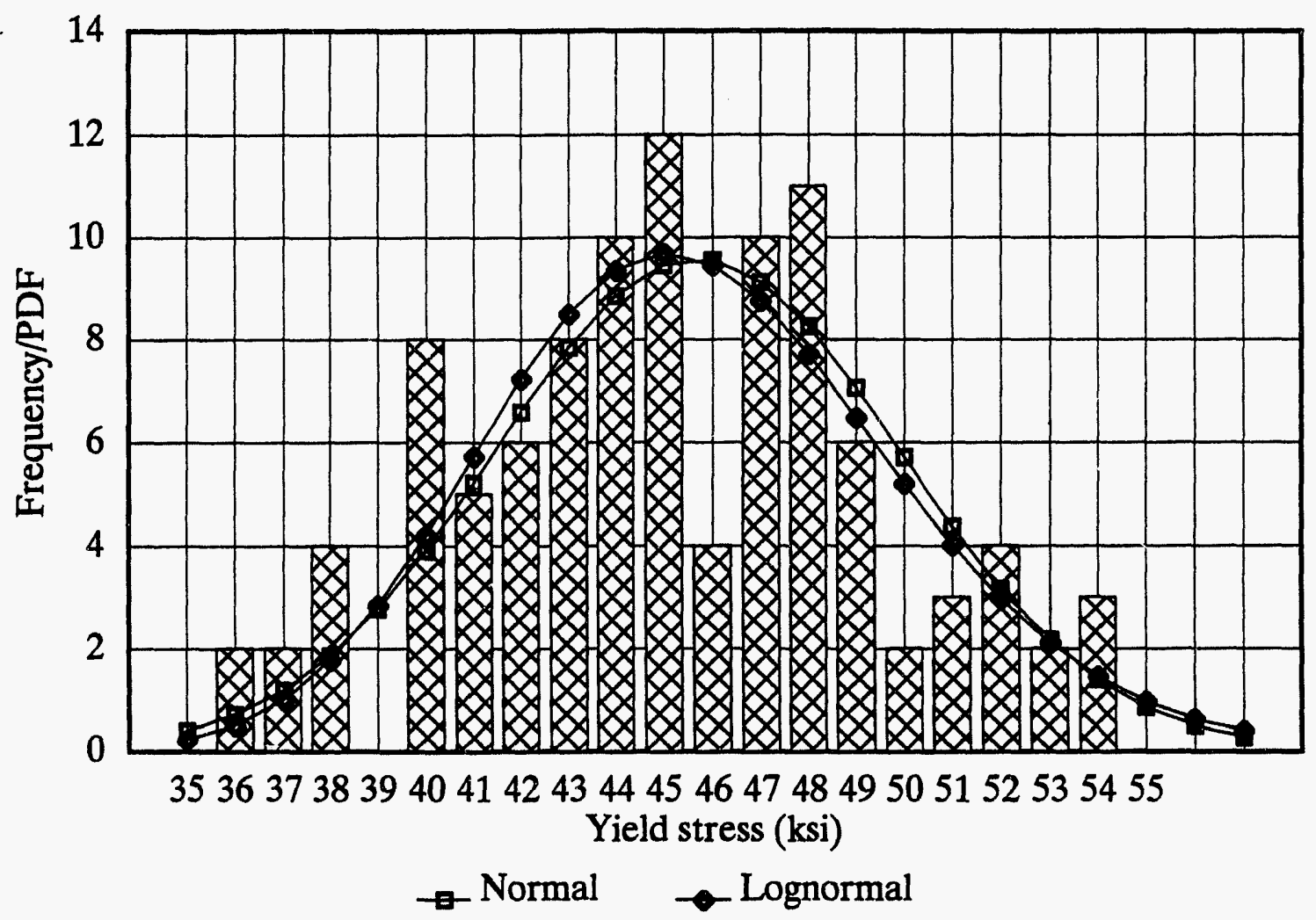

Figure 29. Normal and lognormal representations of SA-106 Grade B carbon steel yield stress data from NUREG/CR-2137 (room temperature).

of $1200^{\circ} \mathrm{F}$ or higher." From this specification, we infer that most material would be hot-rolled, not stress-relieved. The major difference in Grades $\mathrm{A}, \mathrm{B}$, and $\mathrm{C}$ is the specified carbon contents, which are $0.25,0.30$, and $0.35 \%$, respectively. Battelle Columbus Laboratories (Wilkowski et al., 1989) present data for SA-106 Grade B carbon steel pipe at three temperatures.

The data are plotted in Figures 30 and 31 (the legend SR is for the stress-relieved material). There is considerable scatter in the data, but this is to be expected from Figures 28 and 29. The room temperature data in Figures 30 and 31 lie within the bands of the data in Figures 28 and 29. The NUREG/CR-5603 values appear to be representative or conservative overall (however, when compared to the ASME/ASTM stress-relieved material property data, the NUREG/CR-5603 data are not conservative). Although NUREG/ CR-5603 does not present a value at $200^{\circ} \mathrm{F}$, data from all forms of carbon steel in Simmons and Cross (1955) show a dip in the curve at this tem- perature; consequently, this should be taken into account when choosing representative values in the room temperature to $400^{\circ} \mathrm{F}$ range.

Figures 30 and 31 demonstrate that, except for the few points for stress-relieved material, the NUREG/CR-5603 values are conservative compared to the ASTM data. We do not need to calculate survival confidences since both the NUREG/CR-5603 ultimate tensile strengths and the yield stresses are lower than the median data from other sources, and there are insufficient data to attempt to fit a curve through the data.

\subsection{SA-516 Grade 70 Carbon Steel}

While NUREG/CR-5603 and the ASME Code use SA-516 Grade 70 in the context of a plate material for tanks and vessels, it is also a piping material. For example, the fittings of the main coolant piping of currently operating B\&W 


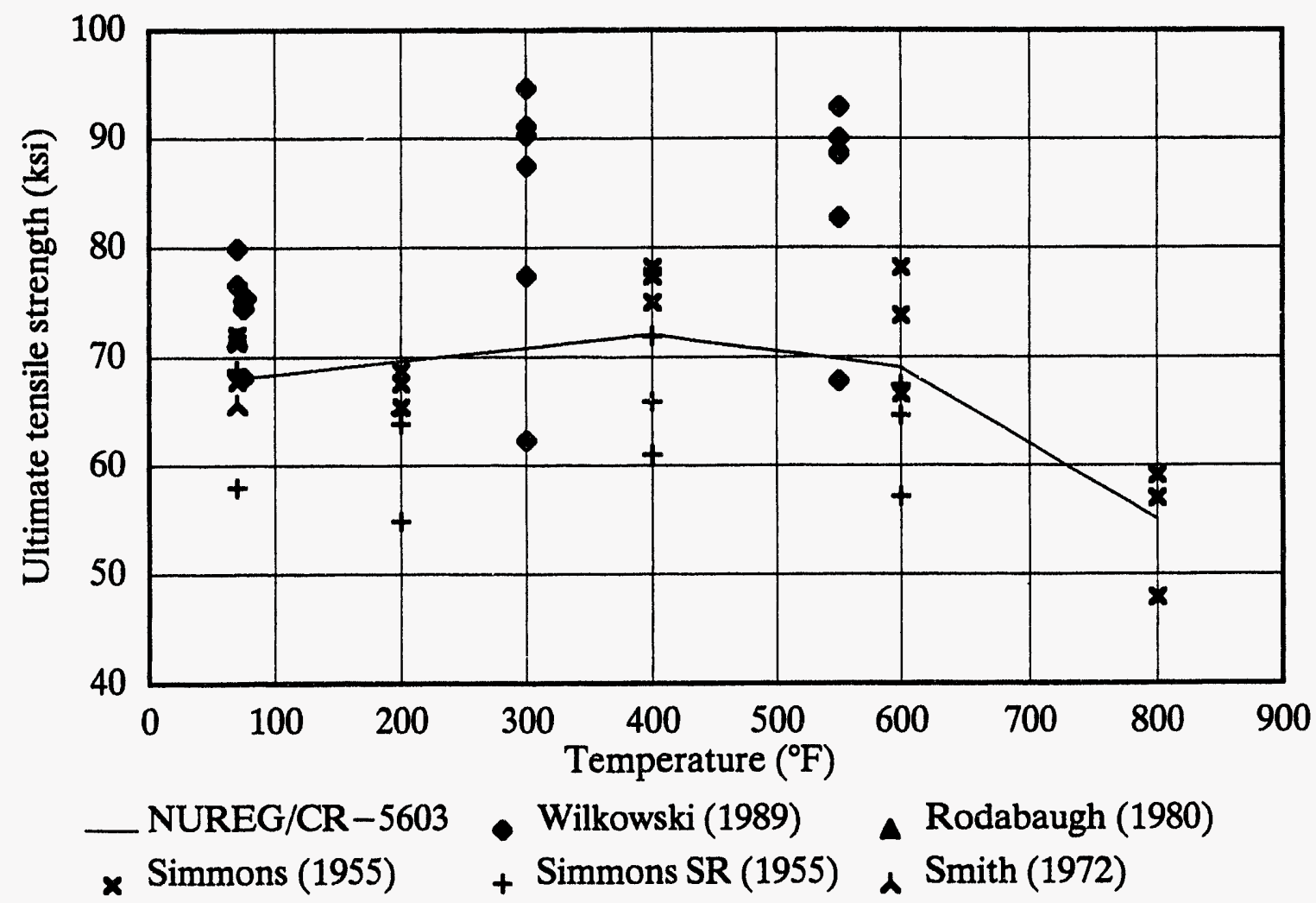

Figure 30. Ultimate tensile strength data for SA-106 Grade B carbon steel.

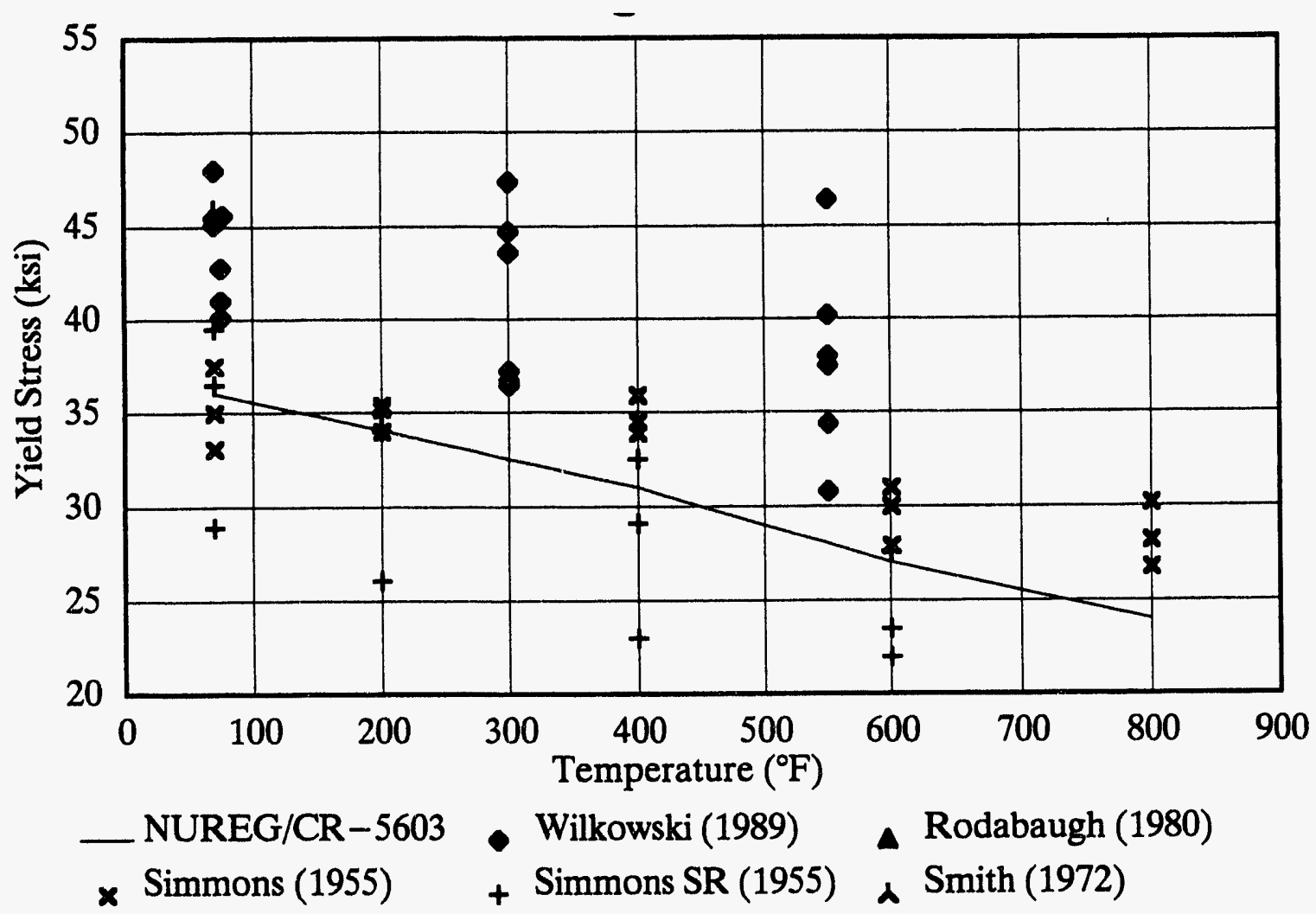

Figure 31. Yield stress data for SA-106 Grade B carbon steel. 
plants, and both the piping and the fittings of currently operating Combustion Engineering plants are made of SA-516 Grade 70 material. The Grade 70 indicates that the minimum ultimate tensile strength is $70 \mathrm{ksi}$. The carbon content is specified as 0.27 to $0.31 \%$, the minimum yield strength as $38 \mathrm{ksi}$, and the ultimate tensile strength as 70 to $90 \mathrm{ksi}$.

There is not a great deal of data on the properties of this material. The Nuclear Systems Materials Handbook (ORNL, 1988) gives equations for typical strengths of two product forms of SA-516 Grade 70 carbon steel. For normalized and tempered material,

$$
\sigma_{u}=66.104+0.083002 \mathrm{~T}
$$

$$
-1.2010 \times 10^{-4} \mathrm{~T}^{2}
$$

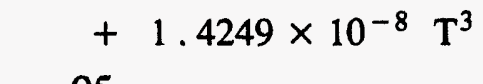

$$
\begin{aligned}
\sigma_{y}=43.340 & -0.016623 T \\
& -3.8182 \times 10^{-6} T^{2}(13)
\end{aligned}
$$

where the temperature $(\mathrm{T})$ is in ${ }^{\circ} \mathrm{F}$, and the stress is in $\mathrm{ksi}$.

Figures 32 and 33 plot comparative data from Rodabaugh and Desai (1980), Wilkowski (1989), and ORNL (1988) Equations (12 and 13) with the ASME Code ultimate tensile strength and yield stress values. The NUREG/CR-5603 values are greater than the values from the alternate sources, with the exception of the Rodabaugh and Desai yield strength value (which is an average of 52 samples) at room temperature. Some of the alternate data even lie below the ASME Code curve.

We can conclude that the NUREG/CR-5603 values appear nonconservative and would result in lower survival confidence stresses than those that would be calculated using the alternate data. From observation of the dat $t$ in Figures 32 and 33 , the best approximation might be to use the ORNL data curves.

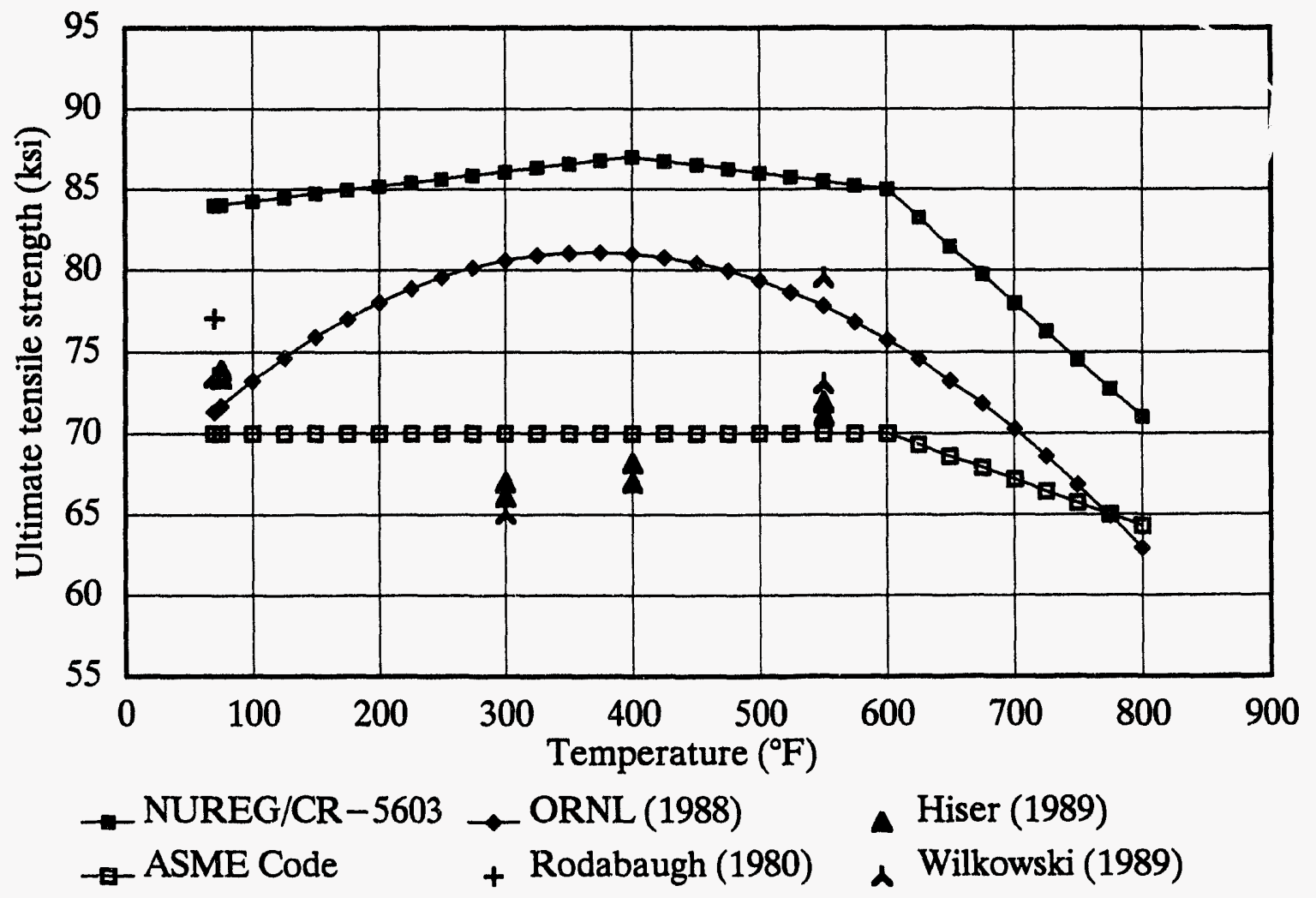

Figure 32. Ultimate tensile strength data for SA-516 Grade 70 carbon steel. 


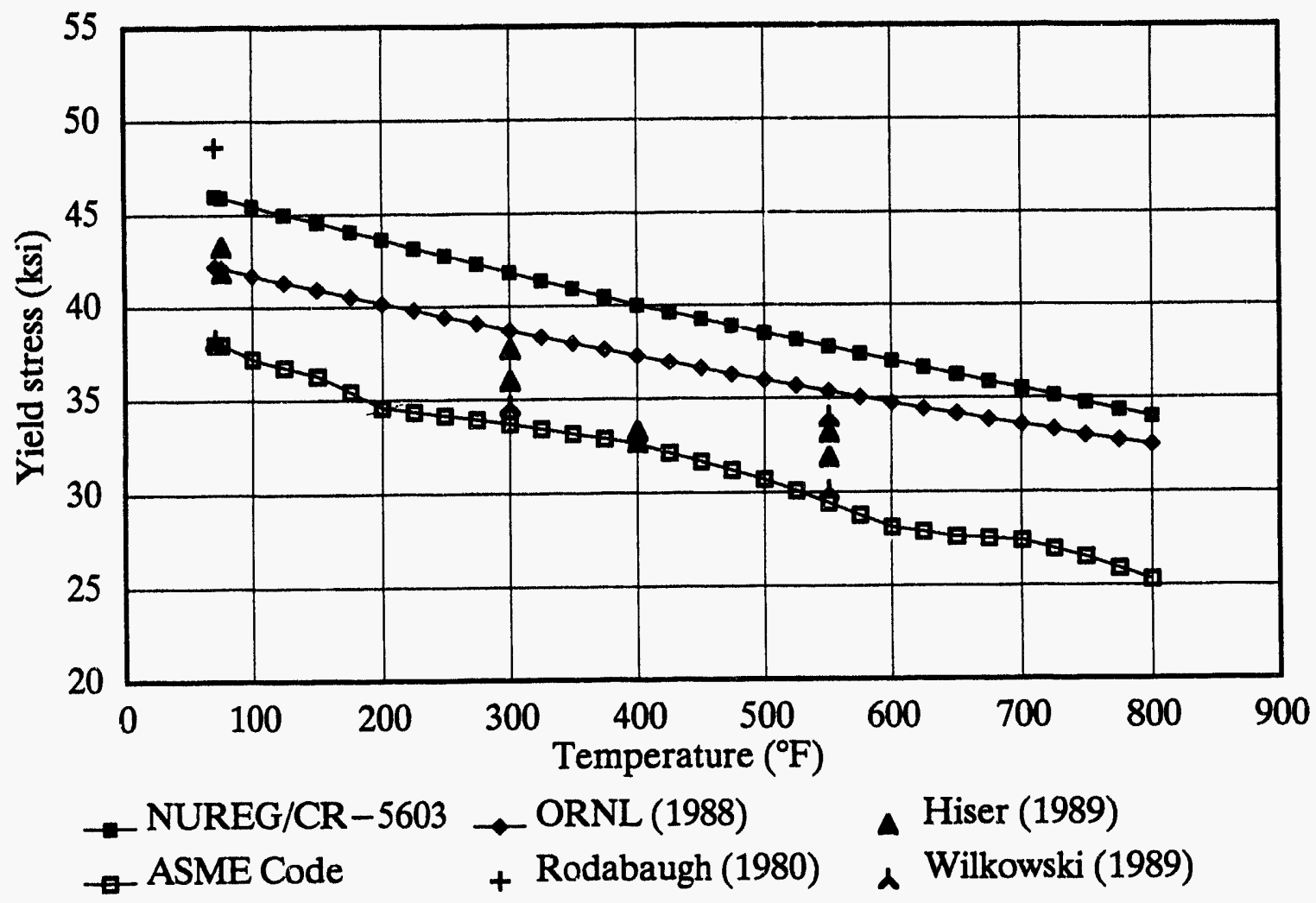

Figure 33. Yield stress data for SA-516 Grade 70 carbon steel.

\subsection{Summary}

The comparison of the NUREG/CR-5603 values to the material property data obtained from alternate sources indicates that the NUREG/ CR-5603 values are conservative and/or representative for most types of materials. However, there are two cases where the NUREG/CR-5603 values appear to be nonconservative. These are for Type 316 stainless steel and SA-516 Grade 70 carbon steel. Alternate material property data were used in Section 4 of this report for all materials except SA-106 Grade B carbon steel, for which the NUREG/CR-5603 values were used. Tables of the survival confidences for bestestimate values are presented in Attachment 2. 


\section{COMPONENT EVALUATIONS}

To achieve the goal of $90 \%$ system survival confidence in the event of an ISLOCA, each of the components in the system (piping, flanges, pumps, valves, heat exchangers) must have a survival confidence such that the product of the confidences equals $90 \%$. If the survival confidence goal for each of these five components is set for $98 \%$, then the overall system survival confidence will be about $90 \%$.

In Section 2, the methodology of NUREG/ CR-5603 defined the uncertainty in the failure stress by assigning a failure probability at the yield stress. Since the probability of failure at the yield stress is essentially zero for unflawed material, this methodology assumes that a large flaw exists in the material in a small percentage of cases. The probability of a large flaw existing increases with the amount of material, such as the length of piping or the number of welds in a component. However, this was not taken into account in NUREG/CR-5603. Although it is not based on failure probabilities, the ASME Code follows this same logic in that the same design allowable stresses are applied regardless of the size of a component or the number of welds.

In this section, the NUREG/CR-5603 methodology is applied to the components that make up the systems that will be designed for ISLOCA. Specifically, the survival confidences for components designed to $40 \%$ of the operating pressure at $350^{\circ} \mathrm{F}$ are calculated. Corrosion allowances are included, where applicable, but manufacturing tolerances are not included.

\subsection{Piping}

Calculations were performed to estimate the percent survival probability of various sizes (2- to 20 -in. nominal diameter) of carbon and stainless steel pipes. A design temperature of $350^{\circ} \mathrm{F}$ and design pressures of 410 (BWRs) and 894 (PWRs) psig (40\% of the operating pressures of 1025 and 2235 psig for current plants) were used. The minimum wall thickness for each pipe size was calculated using Equation (3) of ASME Code (ASME, 1992b) Section III NC-3641.1 and corrosion allowance values of 0.120 and 0.004 in. (BWRs) and 0.060 and 0.003 in. (PWRs) for carbon and stainless steel pipe, respectively. Based on the value of the calculated minimum wall thickness, the next higher standard pipe schedule was identified.

Three survival confidences were calculated:

1. The confidence based on the wall thickness from the ASME Code minimum wall thickness calculations.

2. The confidence based on the wall thickness of the lowest standard pipe schedule with a wall thickness greater than the calculated thickness in (1).

3. If the survival confidence in (2) was less than $99.0 \%$, the calculations were repeated for the next larger (higher) pipe schedule.

In the design of actual piping systems, piping with minimum wall thicknesses will not generally be used, but rather standard pipe schedules. Therefore, standard pipe schedules were selected from B36 [ASME (1985a, 1985b)] using the following approach. B36.10 lists a number of thicknesses for each nominal size pipe. However, only those designed by a Schedule number (for example, $20,30,40$, etc.) or by standard (STD), extrastrong (XS), or double extra-strong (XXS) designations have been chosen for the tables. For carbon steel, the approach uses the minimum thickness standard schedule from B36.10 that is greater than the minimum calculated thickness. B36.19 lists pipe schedules for stainless steels where the schedule designation is followed by an "S." For stainless steel, the approach uses standard schedules from B36.19. However, B36.19 lists no $40 \mathrm{~S}$ or $80 \mathrm{~S}$ schedules above 12 -in. nominal diameter, so B36.10 schedules are used for these larger sizes.

The calculations are summarized in Tables 12 through 17 for Types 304 and 316 stainless and 
Table 12. Survival confidences for Type 304 stainless steel BWR pipe.

\begin{tabular}{|c|c|c|c|c|c|c|c|c|c|c|c|c|c|c|}
\hline Konnel & and & carocin & $0 \mathrm{ea} \cdot 1$ & colented & Hea? & In & inned & Wall & Hoon & erval & $\mathrm{Kax}$ & Wal & Hoop & $7 \mathrm{man}$ \\
\hline$\frac{\text { Dlontr }}{(n)}$ & $\frac{\text { Denoter }}{(n)}$ & $\frac{\text { Nownee }}{(\sqrt{n})}$ & mosere & $\frac{\text { Incknese }}{\text { (n) }}$ & $\frac{601}{110}$ & $\frac{\text { Conitiones }}{\left(x^{3}\right)}$ & $\frac{P b}{6 c h}$ & $\frac{\text { Thernes }}{(n)}$ & otres & $\frac{\text { Con tinnes }}{(i)}$ & 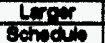 & $\frac{\text { minknese }}{(n .)}$ & $\frac{\text { trese }}{(\mathrm{a} i)}$ & $\frac{\text { conisines }}{(i)}$ \\
\hline & & & & & & & & & & & & & & \\
\hline 20 & 20.000 & 0,000 & $\$ 10$ & DEIB & 40.9 & 0.1 & Dito & 0.573 & 3.00 & $\infty 0$ & & & & \\
\hline 18 & 10.000 & 0.004 & 410 & $0 \times 1$ & 40.50 & 0.1 & 10 & 0,20 & 54 & 01,0 & 80 & 0,312 & 200 & 9.5 \\
\hline 10 & 10.000 & 0.001 & 410 & 0.000 & 40.90 & 0.1 & 10 & 0.250 & I231 & 07.7 & 20 & 0.512 & 5.60 & 20 \\
\hline 14 & 14.000 & 0.00 & 210 & 0.1772 & 40.30 & 0.1 & 10 & 0.250 & 0.14 & 0.0 & & & & \\
\hline 12 & 12.720 & 0.004 & 410 & 0.1610 & 40.30 & 0.1 & 108 & 0.120 & 3.10 & 2,4 & 870 & 0.378 & 10.6 & $\infty 2$ \\
\hline 10 & 10.70 & 0.000 & 510 & 0.1370 & 40.30 & 0.1 & I0. & 0.14 & 0.10 & 8.0 & JiD & 0.305 & 14.24 & 6.0 \\
\hline 8 & C.65 & 0.004 & 410 & 0.1107 & 0.2 & 0.1 & 100 & 0.140 & 9.7 & $9 . ?$ & & & & \\
\hline c & 0.063 & 0.004 & 410 & 0.0 .0 & 40.50 & 0.1 & $\mathrm{ES}$ & 0.100 & 31.31 & C..4 & & & & \\
\hline 4 & 4.00 & 0.00 & 410 & $0.0 \times 7$ & 40.50 & 0.1 & 8 & 0.0 .9 & 2.17 & 80 & & & & \\
\hline 3 & 3.500 & 0.004 & 410 & 0.0470 & 40.30 & 0.1 & (3) & 0.0 .0 & 81.0 & $\infty .0$ & & & & \\
\hline 2 & 2.373 & 0.004 & 410 & 0.053 & 20.00 & 0.1 & 33 & 0.0 .6 & 18.90 & 0.0 & & & & \\
\hline & & & & & & & & & & & & & & \\
\hline & & & & & & & & & & & & & & \\
\hline$E 0$ & 80.00 & 0.004 & & & & & Gio & 0.370 & E.0. & 0.0 & & & & \\
\hline 18 & 10.000 & 0.004 & & & & & 610 & 0.370 & $2 \mathrm{na}$ & 50 & & & & \\
\hline 10 & 16.000 & 0.001 & & & & & 810 & 0.576 & 31.0 & 6.0 & & & & \\
\hline 14 & 14.000 & 0.004 & & & & & 8T0 & 0.373 & 10.91 & 0.0 & & & & \\
\hline 12 & 12.750 & 0.004 & & & & & Gio & 0.376 & 16.50 & 0.0 & & & & \\
\hline 10 & 10.750 & 0.004 & & & & & 8TiD & 0.50 & 14.29 & 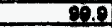 & & & & \\
\hline 8 & 0.65 & 0.004 & & & & & $8 \mathrm{TO}$ & 0.20 & 12.6 & 0.0 & & & & \\
\hline 6 & 6.625 & 0.00 & & & & & Sio & 0.20 & 11.20 & 0 & & & & \\
\hline 4 & 4.500 & 0.004 & & & & & 810 & 0.297 & 8.67 & 0.0 & & & & \\
\hline 3 & 3.500 & 0.004 & & & & & Sio & 0.210 & 7.4 & $\theta 0$ & & & & \\
\hline 2 & 2.373 & 0.004 & & & & & 8TD & 0.154 & 7.00 & 90.0 & & & & \\
\hline
\end{tabular}

Table 13. Survival confidences for Type 316 stainless steel BWR pipe.

\begin{tabular}{|c|c|c|c|c|c|c|c|c|c|c|c|c|c|c|}
\hline Nomnal & Aetul & Corrocion & $001 \%$ & Caloultad & Hoop & Enval & Etandard & Wal & Hoop & Eunal & Noxt & Wall & Hogp & Emval \\
\hline Dlenter & Diampter & Nioneres & Propecre & Thesneses & $\frac{\text { streas }}{\operatorname{tot} t)}$ & Conlisnee & Plo & $\frac{\text { mhotenese }}{(\mathrm{n})}$ & $\frac{\cos }{6031}$ & 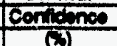 & Lerou & $\frac{\text { micknees }}{(n)}$ & etrees & Contences \\
\hline & & & & & & & & & & & & & & \\
\hline 20 & 80.000 & 0,00 & 410 & 0.267 & 4.01 & $<77.5$ & 10 & 0.250 & 40.6 & 9.0 & 870 & 0.35 & 28.60 & 5.0 \\
\hline 18 & 16.000 & 0.004 & 410 & $0.20 \mathrm{M}$ & \$B.01 & $<7.5$ & 10 & 0.230 & 3.40 & 9.2 & 20 & 0.912 & 20.93 & 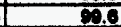 \\
\hline 10 & 16.000 & 0.004 & 410 & 0.1121 & 45.01 & $<77.6$ & 10 & 0.230 & 32.31 & 0.8 & & & & \\
\hline 14 & 14.000 & 0.009 & 410 & 0.100 & 45.01 & $<77.5$ & 10 & 0.250 & 28.14 & 6.7 & & & & \\
\hline 12 & 12.700 & 0.004 & 410 & 0.1460 & 48.01 & 57.5 & 58 & 0.165 & 30.50 & 87.0 & 100 & 0.120 & 3.10 & 84.7 \\
\hline 10 & 10.700 & 0.000 & $\$ 10$ & 0.1227 & 15.01 & $<77.8$ & $\mathrm{E}$ & 0.134 & 91.36 & 8.6 & 103 & 0.166 & 3.10 & 97.0 \\
\hline 8 & 8.63 & 0.009 & 910 & 0.1000 & 45.01 & $\leq 77.5$ & 68 & 0.100 & 91.07 & 89.7 & 108 & 0.146 & 29.97 & $\infty .3$ \\
\hline 6 & 6.60 & 0.004 & $\$ 10$ & 0.0770 & 48.01 & $<77.5$ & 58 & 0.100 & 31.31 & $\infty .0$ & & & & \\
\hline 4 & 4.500 & 0.004 & 910 & 0.0319 & 45.01 & $<77.3$ & 3 & 0.005 & 20.17 & 0.7 & & & & \\
\hline$\frac{5}{3}$ & 3.500 & 0.000 & 910 & 0.0450 & 45.01 & $<7.5$ & 58 & 0.006 & 21.08 & 90 & & & & \\
\hline$\overline{2}$ & 2.375 & 0.004 & 410 & 0.0004 & 45.01 & $<7.5$ & 58 & 0.005 & 18.03 & $\infty .0$ & & & & \\
\hline & & & & & & & & & & & & & & \\
\hline & & & & & & & & & & & & & & \\
\hline 20 & 80.00 & 0.004 & & & & & 870 & 0.378 & 8.00 & 9.0 & & & & \\
\hline 18 & 18.000 & 0.004 & & & & & 810 & 0.376 & 20.84 & 0.0 & & & & \\
\hline 16 & 16.000 & 0.004 & & & & & $8 \pi 0$ & 0.376 & 21.08 & 80.0 & & & & \\
\hline 94 & 14.000 & 0.000 & & & & & 870 & 0.375 & 18.31 & $\infty .0$ & & & & \\
\hline 12 & 12.730 & 0.004 & & & & & Sio & 0.575 & T6.50 & 20 & & & & \\
\hline 10 & 10.750 & 0.004 & & & & & $8 \pi$ & 0.86 & 14.24 & 9.0 & & & & \\
\hline 8 & 8.628 & 0.004 & & & & & 870 & 0.322 & 12.6 & 8.0 & & & & \\
\hline 6 & 6.623 & 0.004 & & & & & 810 & 0.200 & 11.24 & 5.8 & & & & \\
\hline 4 & 4.500 & 0.004 & & & & & $8 \pi 0$ & 0.227 & 8.67 & $\infty .0$ & & & & \\
\hline 3 & 3.500 & 0.001 & & & & & S10 & 0.210 & 7.4 & $\infty 0$ & & & & \\
\hline 2 & 2.376 & 0.000 & & & & & $8 \pi 0$ & 0.154 & 7.00 & $\infty .0$ & & & & \\
\hline
\end{tabular}

SA-106 Grade B carbon steel pipes. The curve fit material values from Section 3 were used for stainless steel, and the NUREG/CR-5603 values were used for carbon steel. The cast Type 304 stainless steel parameters were used since they resulted in slightly more conservative survival confidences than did the wrought parameters. Survival confidences and stresses are presented in tables in Attachment 2. No manufacturing tolerances are included in these calculations. Otherwise, they represent conservative survival confidences in that no pressure resistance is allowed for the material within the corrosion allowance.
Tables 12 through 14 show that for BWRs, STD pipe schedules will give greater than $98 \%$ survival confidence for all three materials. Using $40 \%$ of the operating pressure as the design pressure would result in 5S piping being chosen for piping up to 12 in. for Type 316 stainless steel, and up to 6-in. piping being chosen for Type 304 stainless steel. STD piping would be chosen for all carbon steel piping except for sizes 8 to 12 in., for which less than STD schedules would give $\mathbf{9 9 . 8 \%}$ survival confidences.

Tables 15 through 17 show that for PWRs, XS pipe schedules will give greater than $98 \%$ 
Table 14. Survival confidences for SA-106 Grade B carbon steel BWR pipe.

\begin{tabular}{|c|c|c|c|c|c|c|c|c|c|c|}
\hline Nonna & Ang & comenn & bon & crouled & Hose & gunn & Eind & WD & Hose & sunw \\
\hline blats & binnes & Nomenes & Promure & Thoknes & Dirse & Conictos & 700 & thone & Fin & conicence \\
\hline (n.) & (n.) & (n.) & (Di) & (n) & (ㅎiㄱ) & $(3)$ & Eonedus & (n) & (6i) & $(3)$ \\
\hline & & & & & & & & & & \\
\hline 80 & 20.000 & 0.12 & 410 & $0.5 \%$ & 30.6 & $\frac{0.1}{8.15}$ & 30 & 0.000 & cons & O29 \\
\hline$\frac{18}{9}$ & $\frac{16.000}{1.000}$ & 0.12 & $\frac{410}{410}$ & $\frac{0.3000}{0.53}$ & - & $\frac{9.1}{6.1}$ & $\begin{array}{l}\text { BID } \\
\text { sidot }\end{array}$ & $\frac{0.376}{0.37 .}$ & $\frac{30.10}{3615}$ & $\frac{10}{60}$ \\
\hline (4) & 14.000 & $\frac{.16}{0.92}$ & 410 & 0.503 & 3.1 .0 & का.1 & 20 & 0.352 & 3.34 & $\therefore 0$ \\
\hline 12 & $12,7 \cdot 0$ & 0.12 & 410 & 0.21 & 3.09 & क.1 & 30 & 0.560 & 300 & 20 \\
\hline 10 & 10.7 .0 & 0.42 & 410 & $0.2 \times \cdot 3$ & 30.60 & 0.1 & 30 & 0.507 & 2.4 & 0 \\
\hline d) & 0.0 .5 & 0.12 & 410 & 0.250 & 30.63 & 84.1 & 20 & 0.60 & 32.3 & 65 \\
\hline 6 & 6.0 .5 & 0.12 & 410 & $0.20 \%$ & 3.5 .6 & 04.1 & Giol & 02.0 & 20.0 & 30 \\
\hline 4 & 4.600 & 0.12 & 410 & 0.1603 & 3.60 & 04.1 & EID & 0.237 & 16.01 & 00 \\
\hline 3 & 3.600 & 0.12 & 410 & 0.1073 & 3.5 & 04.1 & sio & 0.270 & 77.6. & 6.0 \\
\hline 2) & $2.37 \mathrm{~J}$ & 0.12 & 410 & 0.1521 & 30.00 & 6.1 & Siol & 0.164 & 37.77 & 0.0 \\
\hline & & & & & & & 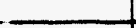 & & & \\
\hline & & & & & & & & & & \\
\hline E) & 20.009 & 0.12 & & & & & 810 & 0.573 & 0.17 & $\theta .1$ \\
\hline 18 & 16.000 & 0.12 & & & & & 810 & 0.376 & 53.16 & $02 \mathrm{~s}$ \\
\hline 10 & 16.000 & 0.12 & & & & & EiD & 0.375 & 31.13 & $\because 9$ \\
\hline रदा & 14.000 & 0.12 & & & & & gito & 0.376 & 27.11 & 0.0 \\
\hline 12 & 12.70 & 0.12 & & & & & Sto & 0.376 & 24.00 & 00 \\
\hline 10 & 10.700 & 0.12 & & & & & Sio & 0.3 .3 & 21.40 & 0.0 \\
\hline 8 & 8.60 & 0.12 & & & & & STD & 0.22 & 20.00 & 80 \\
\hline 0 & 6.0 .0 & 0.12 & & & & & SiD & 0.20 & $20<0$ & 00 \\
\hline 4 & 4500 & 0.12 & & & & & Sto & $0.2 \times 7$ & 16.00 & 00 \\
\hline 3 & 360 & 0.12 & & & & & \$10 & 0220 & 17.6. & 80 \\
\hline 2 & 2.375 & 0.12 & & & & & giD & 0.154 & 34.77 & 0.6 \\
\hline
\end{tabular}

Table 15. Survival confidences for Type 304 stainless steel PWR pipe.

\begin{tabular}{|c|c|c|c|c|c|c|c|c|c|c|c|c|c|c|}
\hline Neminal & net & conoign & Deel 1 & canded & Hoon & erval & Exdrad & wa & Hoop & ennal & Non & $\mathrm{mol}$ & Heop & grand \\
\hline$\frac{\text { Denew }}{\text { (n) }}$ & Dinoter & Anmen & Fongure & Thesnees & trate & Con:men & 10 & Thoknoes & treas & Contenes & Lex & Thenenese & tras & Conitines \\
\hline & & & & & & & & & & & & & & \\
\hline 8 & 5000 & 0.00 & 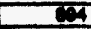 & 0.002 & 3.0 & 87 & $=-$ & 0.612 & 5.21 & Q.1 & $=--$ & 0.076 & 3.21 & \\
\hline$\infty$ & 00.000 & 0.000 & 2 & $0 . \mathrm{C}$ & $2 x$ & 27 & 40 & 0.5 & 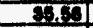 & 9.4 & $\infty$ & 0.012 & En & 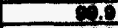 \\
\hline 10 & 11.000 & 0.00 & 9 & 0.401 & 8.6 & 2.7 & $\bar{x}$ & 0.60 & 30.24 & 87.1 & 40 & 0.02 & 2.70 & \\
\hline 10 & 16.000 & 0.00 & 1 & $0.4 \mathrm{~J}$ & 5.6 & 27 & X & 0.00 & 35.74 & 0.2 & 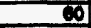 & 0.0 .0 & 2.10 & $E$ \\
\hline 12 & 12.70 & 0.00 & 6 & 0.531 & 800 & 2.7 & 870 & 0.370 & 3.07 & 0.4 & 40 & 0.400 & 0.12 & 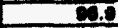 \\
\hline 10 & 10.70 & 0.003 & CA & OLES & 5.00 & 2.7 & 5 & 0.307 & 3.2 & 0.7 & gio & 0.50 & 3.5 & 0.7 \\
\hline 3 & -6.6 & 0.000 & $m$ & 0.251 & 100 & 27 & 80 & 0.200 & 8.70 & 0.0 & 30 & 0.277 & 3.29 & 9.1 \\
\hline a & 6. & 0.000 & $\mathrm{CH}$ & $0.1 \% 7$ & 200 & 627 & 8T0 & 0.20 & 34.40 & 0.0 & & & & \\
\hline 4 & 2.00 & 0.000 & 1 & $0.5 \leq 0$ & 30 & Q.7. & OTio & $0.2 \times 7$ & 10.20 & 0.0 & & & & \\
\hline 3 & 3.000 & 0.000 & D & 0.0 .3 & 2.0 & 2.7 & 108 & 0.120 & 31.10 & 0.5 & $8 \pi$ & 0.216 & 16.13 & 20 \\
\hline 2 & 2.378 & 0.000 & 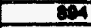 & 0.001 & 3.6 & 0.7 & 108 & 0.100 & 220 & 0.0 & & & & \\
\hline & & & & & & & & & & & & & & \\
\hline & & & & & & & & & & & & & & \\
\hline 3 & 20.00 & 0.0 .0 & & & & & $\mathbf{x}_{0}$ & 0.50 & C.23 & $<7.8$ & & & & \\
\hline 30 & 20.000 & 0.000 & & & & & $\overline{X 5}$ & 0.000 & 427 & 57.8 & & & & \\
\hline$\frac{10}{10}$ & 16.000 & 0.000 & & & & & $\ddot{\mathbf{x}}$ & 0.00 & 20 & 87.1 & & & & \\
\hline 10 & 10.00 & 0.00 & & & & & $\bar{x}$ & 0.500 & 89.74 & 00.2 & & & & \\
\hline 12 & 12.700 & 0.000 & & & & & : & 0.000 & 0.43 & 00 & & & & \\
\hline 10 & 10.70 & 0.001 & & & & & $\mathrm{XI}$ & 0.50 & 3.2 & $\omega$ & & & & \\
\hline 8 & 0.0 & 0.00 & & & & & $\mathbf{D}$ & 0.500 & 17.10 & es & & & & \\
\hline 6 & 0.03 & 0.001 & & & & & $x$ & 0.45 & I5.6 & E. & & & & \\
\hline 4 & 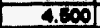 & 0.000 & & & & & $\bar{X}$ & 0.597 & 1212 & 0.0 & & & & \\
\hline $\mathbf{a}$ & $3 . \infty$ & 0.000 & & & & & 6. & 0.50 & 10.0 & 0.0 & & & & \\
\hline 3 & $2 \pi$ & 0.000 & & & & & $x$ & 0.210 & 10.11 & $\infty$ & & & & \\
\hline & & & & & & & & & & & & & & \\
\hline & & & & & & & & & & & & & & \\
\hline 30 & $=0.000$ & 0.003 & & & & & --- & 0.08 & 39.2 & 0.4 & & & & \\
\hline$\frac{30}{20}$ & 20.00 & 0.003 & & & & & $=--$ & 1.000 & 31.09 & 5.4 & & & & \\
\hline 20 & 20,0001 & 0.003 & & & & & $\infty$ & 0.012 & 2.50 & $\infty 0$ & & & & \\
\hline$\frac{18}{18}$ & 10.000 & 0.003 & & & & & 06 & 0.70 & 24.0 & $\infty .0$ & & & & \\
\hline 16 & $10, \infty 0$ & 0.003 & & & & & $\infty$ & $0.5 \%$ & 2.78 & 0.2 & & & & \\
\hline 12 & 12.730 & 0.008 & & & & & $x$ & 0.00 & 20.4 & 0.0 & & & & \\
\hline 10 & 10.700 & 0.00 & & & & & STo & 0.30 & 30.6 & 0.7 & & & & \\
\hline 6 & 8.63 & 0.003 & & & & & 870 & 0.52 & 27.0 & $\infty .7$ & & & & \\
\hline 6 & 6.0 & 0.003 & & & & & 810 & 0.20 & 24.40 & 00 & & & & \\
\hline 4 & 4.00 & 0.009 & & & & & ETD & 0.27 & 1221 & $\infty$ & & & & \\
\hline 5 & 3.000 & 0.009 & & & & & gito & 0.210 & 10.13 & 0 & & & & \\
\hline 2 & 2.375 & 0.003 & & & & & 810 & 0.13 & 15.34 & 60.0 & & & & \\
\hline
\end{tabular}

survival confidence for all three materials, with the exception of the larger sizes. Schedule 60 is needed for all sizes greater than 18 in. for carbon and Type 316 stainless steel, and for sizes greater than 16 in. for Type 304 stainless steel.
Pipe fittings purchased to the requirements of ANSI B16.9 and analyzed to the requirements of the ASME Code are assumed to be of equal strength to the same schedule of straight pipe. 
Table 16. Survival confidences for Type 316 stainless steel PWR pipe.

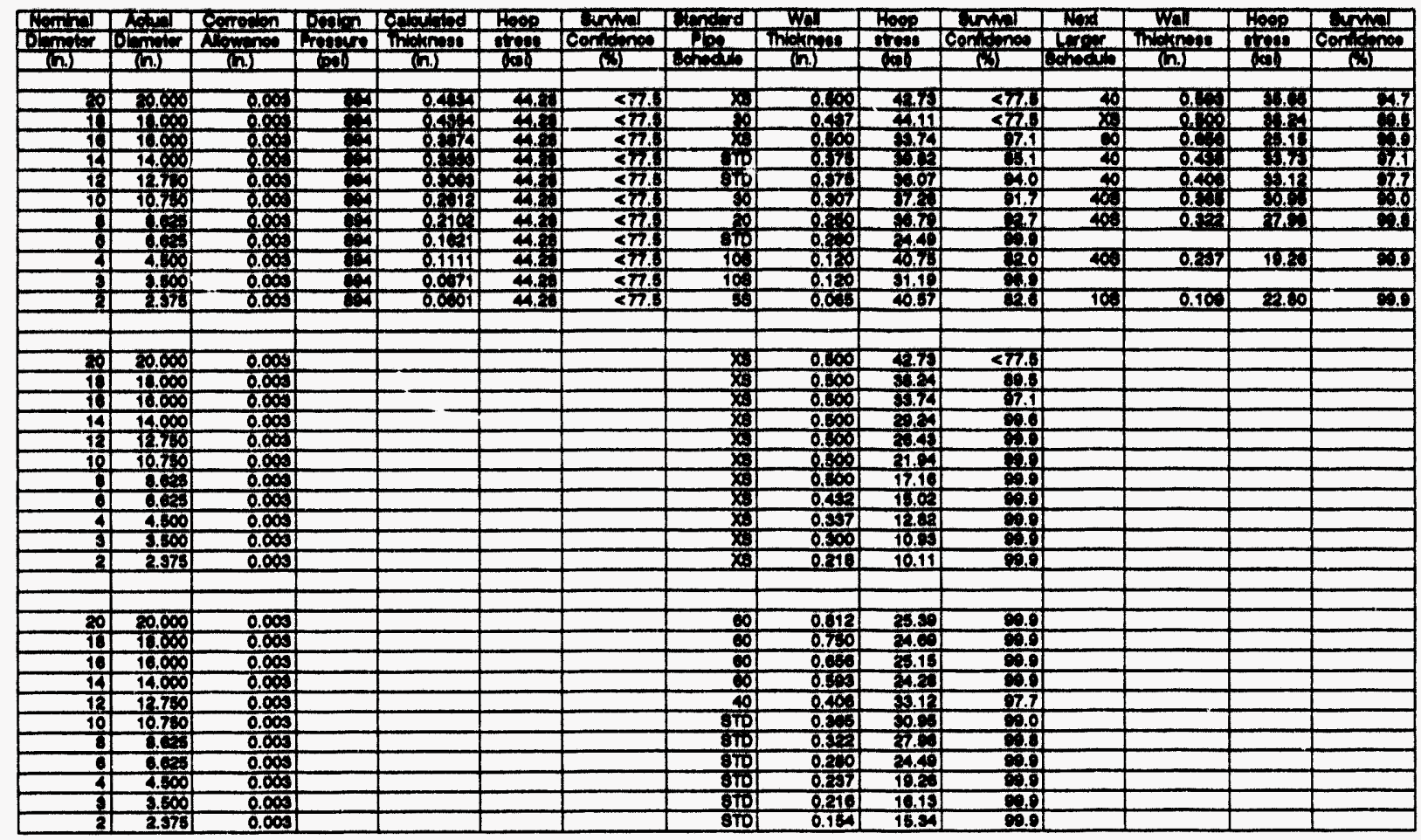

Table 17. Survival confidences for SA-106 Grade B carbon steel PWR pipe.

\begin{tabular}{|c|c|c|c|c|c|c|c|c|c|c|}
\hline Komina & Actual & Corroton & Dedon & Calculated & Hoop & Sunhal & Siendard & WUI & Hoos & Sunw \\
\hline Denetr & Damerer & Alowance & Premure & Thicknoese & Ithes & Conidence & Pro & Thichens & 8 & Cortidenes \\
\hline (n.) & (in.) & (n). & (pei) & (in.) & (6) & (3) & Echodule & (in.) & (ai) & (*) \\
\hline 801 & 5000 & 00 & & 0 & करत & $m a$ & m & तारा & रता & क0 \\
\hline 18 & 18.000 & 0.03 & $6 \%$ & 0.0 .650 & 30.10 & 0.4 & $\infty$ & $\frac{0.01 \mathrm{x}}{0.750}$ & 28.02 & 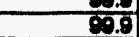 \\
\hline 10 & 16.000 & 0.00 & 64 & 0.52 .07 & 33.10 & 8.4 & 0 & 0.63 & 27.77 & 0.9 \\
\hline 14 & 14.000 & 0.0. & $6 \cdot 4$ & 0.6076 & 3.16 & 0.4 & XS & 0.000 & $35 . \leq=$ & 00 \\
\hline 12 & 12.7 .0 & 0.00 & 6 & 0.4311 & 3.10 & 0.4 & 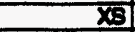 & 0.00 & 30.16 & 00 \\
\hline 10 & 10.7 .0 & 0.00 & 64 & 0.372 & 30.10 & 0.4 & $\times$ & 0.00 & 25.07 & 00 \\
\hline 8 & $6.0 \times 5$ & 0.00 & 84 & 0.3110 & 30.18 & 0.4 & Sio & 0.22 & 34.03 & 0.6 \\
\hline 6 & 8.0 .3 & 0.0. & 6 & 0.265 & 3.16 & 6.4. & 810 & 0.20 & 31.42 & 0.9 \\
\hline 4 & 4.600 & 0.00 & 64 & 0.1910 & 3.10 & 03.4 & 810 & $0.2 \times 7$ & E.10 & 0.0 \\
\hline 3 & 3.00 & 0.00 & $E \cdot 4$ & 0.1610 & 3.10 & 80.4 & STD & 0.210 & 22.64 & 6.0 \\
\hline 2 & 2.576 & 0.05 & 804 & 0.129 & 38.16 & 0.4 & 8T0 & 0.134 & 20.00 & 0.0 \\
\hline & & & & & & & & & & \\
\hline & & & & & & & & & & \\
\hline 20 & 20.000 & 0.03 & & & & & $X 9$ & 0.600 & 4850 & 91.8 \\
\hline 18 & 18.000 & 0.00 & & & & & $\overline{X S}$ & 0.500 & 45.40 & 97.7 \\
\hline 18 & 16.000 & 0.00 & & & & & $X 3$ & 0.000 & 39.40 & 00 \\
\hline 14 & 14.000 & 0.00 & & & & & X3 & 0.500 & 33.52 & 000 \\
\hline 12 & 12.7 .0 & 0.08 & & & & & $X 3$ & 0.000 & 30.15 & $\boldsymbol{\omega 0}$ \\
\hline 10 & 10.750 & 0.00 & & & & & X3 & 0.500 & 25.07 & 0.0 \\
\hline 8 & 8.035 & 0.08 & & & & & $x 3$ & 0.500 & 10.67 & $\omega 0$ \\
\hline 6 & $8.0 \times 3$ & 0.00 & & & & & XS & 0.452 & 17.07 & 0.0 \\
\hline 4 & 4.500 & 0.08 & & & & & XS & 0.357 & 15.02 & 0.8 \\
\hline 3 & 3.500 & 0.00 & & & & & $\mathrm{XS}$ & 0.300 & 14.00 & 00 \\
\hline 2 & 2.375 & 0.00 & & & & & $X S$ & 0.218 & 14.58 & 9.0 \\
\hline & & & & & & & & & & \\
\hline & & & & & & & & & & \\
\hline 20 & 20.000 & 0.08 & & & & & 40 & $0.5 \% 3$ & 39.70 & $\infty .7$ \\
\hline 18 & 10.000 & 0.00 & & & & & $X$ & 0.500 & 4.43 & 97.7 \\
\hline 16 & 10.000 & 0.03 & & & & & XS (40) & 0.500 & 38,40 & क.6.5 \\
\hline 14 & 14.000 & 0.08 & & & & & 40 & 0.438 & 30.15 & 0.8 \\
\hline 12 & 12.750 & 0.08 & & & & & STD & 0.375 & 43.00 & 60.7 \\
\hline 10 & 10.750 & 0.00 & & & & & STD & 0.53 & 37.15 & 90 \\
\hline 8 & 8.65 & 0.03 & & & & & STD & 0.322 & 34.55 & 89.9 \\
\hline 6 & 6.025 & 0.00 & & & & & STD & 0.280 & 31.42 & 09.9 \\
\hline 4 & 4.500 & 0.00 & & & & & STD & 0.237 & 20.18 & 00.0 \\
\hline 3 & 3500 & 0.08 & & & & & STD & 0.216 & 22.84 & 90 \\
\hline 2 & 2.375 & 0.08 & & & & & STO & 0.154 & 28.00 & 09.9 \\
\hline
\end{tabular}




\subsection{Flanges}

There are several styles of flange and gasket designs. The style analyzed in NUREG/CR-5603 and typical of those used in nuclear power plants is shown in Figure 34. The two flange sections are attached by a bolted joint and gasket connection. The figure shows a "raised-face" flanged joint, where the gasket is placed between the raised faces, and the bolts are torqued to a given preload. As the flange faces are drawn together, the gasket is compressed. The combined load of the bolts is equal to the load in the gasket. The gasket deflection (that is, the reduction in its thickness) equals the gasket stress (load per unit area) divided by the gasket stiffness.

The gasket shown in Figure 34 is metallic and spiral-wound with an outer compression ring, called Style CG. (Other styles may have no compression ring, an inner compression ring, or both outer and inner compression rings). The compression ring is made of solid metal and has three pur- poses: to center the gasket within the bolt ring, to prevent gasket blowout, and to act as a compression stop. The centering is accomplished by making the outer diameter of the ring equal to the bolt circle less one bolt diameter. Once the gasket has been compressed sufficiently for the flange face to contact the compression ring $(0.050$ in. in NUREG/CR-5603), the gasket can be compressed no further, and the flange faces and compression ring lock. Any further increase in the joint preload is carried almost entirely by the compression ring, so that the stress in the gasket remains very nearly constant once contact takes place.

The gasket is made by spirally winding a corrugated metal strip (with a filler material such as asbestos) over a mandrel, whose outer diameter is the desired inner diameter of the gasket. Because of its construction and materials, the gasket relaxes under load over time, such that its stress (and, therefore, the load) gradually lowers. For the case where the flange faces do not initially contact the compression ring, the bolt load must

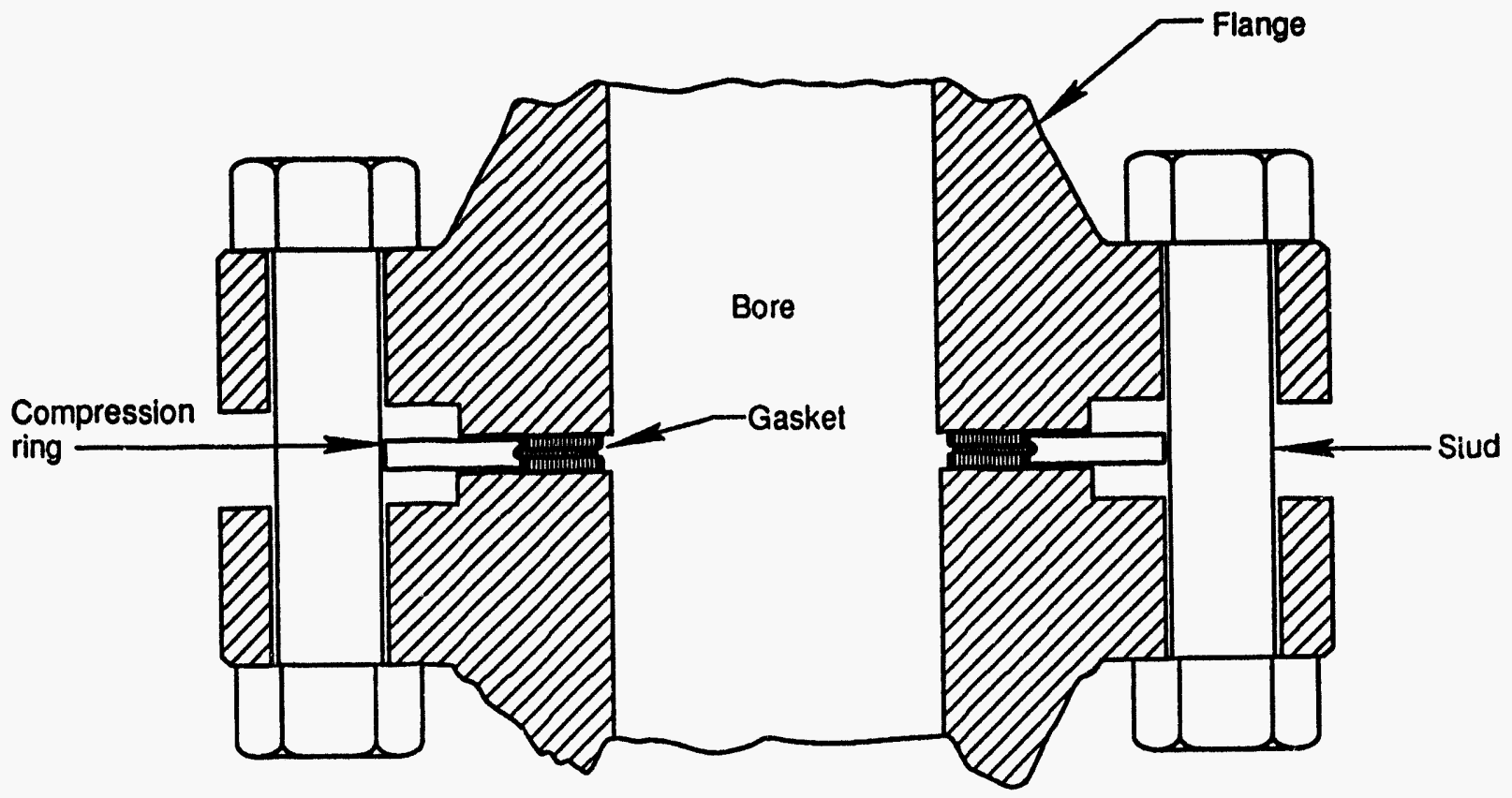

0930072

Figure 34. Raised-face flange with Style CG gasket. 
also reduce when the gasket load relaxes; consequently, the flange faces are drawn closer together, and the gasket deflection (compression) increases. For the case where the flange faces come in contact with the compression ring during the gasket relaxation, the gasket load will transfer to the compression ring after contact, and the gasket deflection will remain very nearly constant thereafter. NUREG/CR-5603 assumes that the outer $1 / 8$ in. of the gasket is ineffective in sealing, so the "effective" gasket outside diameter (OD), that is, the actual OD less $1 / 8$ in., is used to compute the gasket area.

In the past, the nomenclature for flanges was their pressure ratings, for example, $150 \mathrm{lb}, 300 \mathrm{lb}$, etc. However, flanges are now designated as Class 150 , Class 300 , etc., since there are different pressure ratings, depending on the material of construction, for each class and temperature.

4.2.1 ASME Flange Slzes. Flange sizes based on temperature and pressure are listed in Table 2 of ASME/ANSI B16.5 (ASME, 1988). The pressure ratings at $400^{\circ} \mathrm{F}$ for carbon and stainless steels are reproduced in Table 18 . At $40 \%$ of the
ABWR pressure (410 psig), Class 300 flanges would be chosen. At $40 \%$ of PWR pressures (894 psig), Class 600 flanges would be chosen with the exception of the 1.2 material in Table 18, where a Class 400 flange would be used.

\subsubsection{Methodology to Determine the GLP.}

The methodology used in this report is from NUREG/CR-5603, but since NUREG/CR-5862 is more recent and contains supplementary information, it also has been used. The more precise calculational method outlined in NUREG/ CR-5603 is followed. Although NUREG/ CR-5603 includes a methodology for leak rate calculations where gross leakage is taking place (since this is needed to evaluate operating plants), the best approach at the design stage is to size the flange and prescribe bolt preloads so that no gross leakage is allowed. In flange terminology, this means that the "gross leak pressure (GLP)," where the internal fluid pressure equals the gasket stress, is not exceeded for the desired confidence level. Thus, the leak rate calculations of NUREG/ CR-5603 are not included in this report. To ensure that gross leakage does not take place during an ISLOCA event, it is recommended that high

Table 18. B16.5 flange pressure ratings (psi).

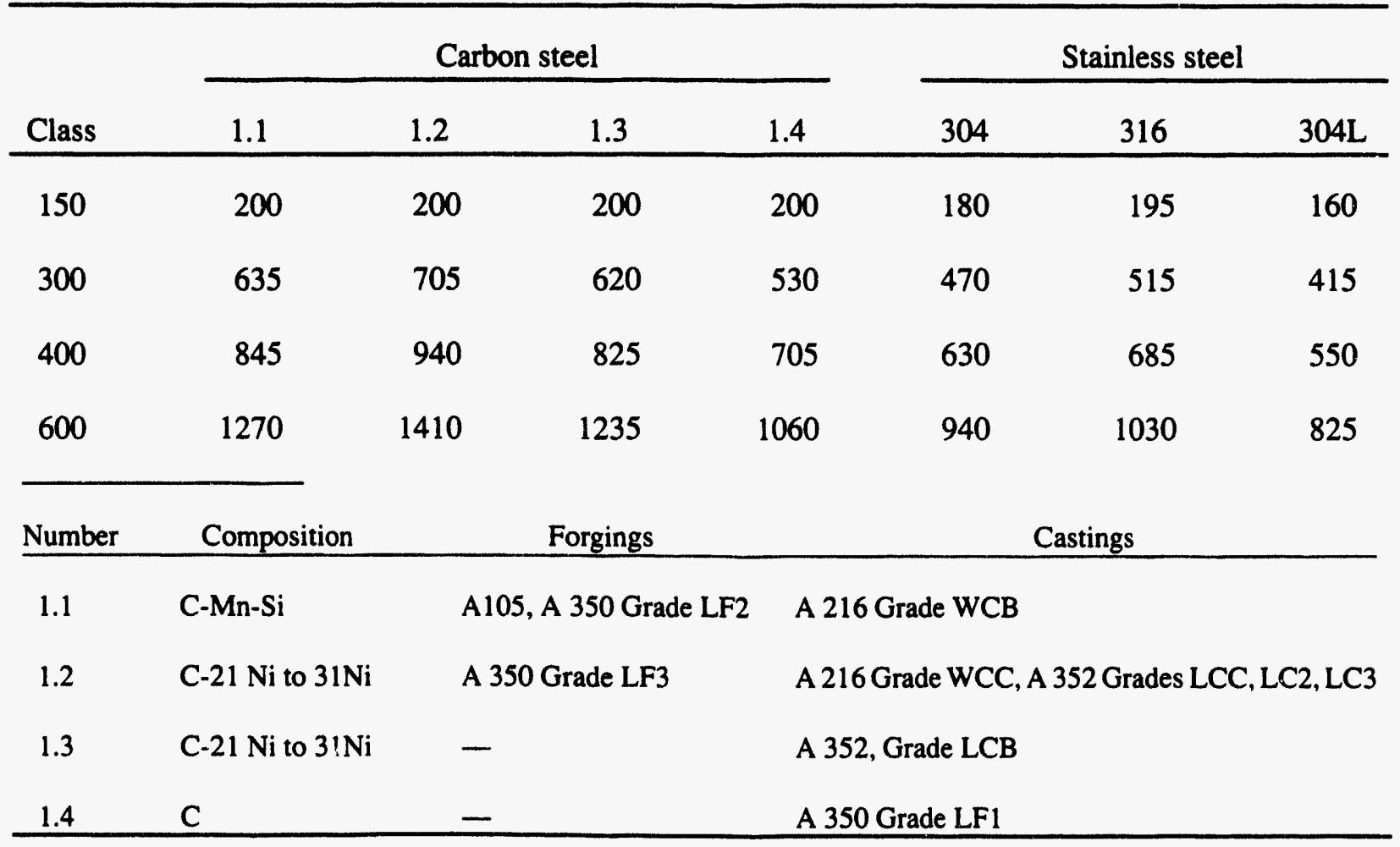


strength bolts be used in flanges, so that the bolt yield stress is not exceeded during boltup. The calculations performed for flanges in this report assume that SA-193-B7 high-strength bolts (yield stress $=111,700 \mathrm{psi} ; \mathrm{E}=29.32 \times 10^{6} \mathrm{psi}$ ) preloaded to $40,000 \mathrm{psi}$ initial stress, will be used.

When the flange bolts are preloaded, the gasket undergoes an initial compressive stress, which afterwards relaxes (a $25 \%$ relaxation in stress is assumed to be the median stress reduction). As internal pressure is applied to the flange, the pressure load is statically balanced by changes in the gasket and bolt stresses. The gasket compression is reduced as internal pressure is applied to the piping system containing the flange, and the bolt stresses may or may not increase, depending on the geometry of the flange (which controls the rotation of the flange).

The gasket deflections, both before and after relaxation, inust be calculated to determine if the flanges and compression ring lock. Locking limits the gasket defection (compression) where the flange face and compression ring come into contact (lock) to 0.050 in. (the value used in NUREG/CR-5603).

4.2.2.1. Median GLP. The initial and relaxed deflections and stresses, assuming linear behavior of both the gasket and the flange assembly, are calculated using the following equations:

$$
\begin{aligned}
& \delta_{g i}=\frac{\sigma_{b p} A_{b} N_{b}}{K_{g} A_{g}} \leq 0.050 \mathrm{in} . \\
& \sigma_{g i}=\delta_{g i} K_{g} \\
& \delta_{g r}=\delta_{g i}+f_{L} \frac{J R}{100} \frac{\sigma_{g i}}{K_{g r}} \leq 0.050 \mathrm{in} . \\
& \sigma_{g r}=\sigma_{g i}\left(1-\frac{J R}{100}\right)
\end{aligned}
$$

where

$$
\begin{aligned}
& \delta_{\mathrm{gi}}=\text { initial gasket deflection (in.) } \\
& \delta_{\mathrm{gr}}=\text { relaxed gasket deflection (in.) }
\end{aligned}
$$

$$
\begin{aligned}
\sigma_{\mathrm{gi}} & =\text { initial gasket stress (psi) } \\
\sigma_{\mathrm{gr}} & =\text { relaxed gasket stress (psi) } \\
\sigma_{\mathrm{bp}} & =\text { bolt preload stress (psi) } \\
\mathrm{A}_{\mathrm{b}} & \left.=\text { area of each bolt (in. }{ }^{2}\right) \\
\mathrm{A}_{\mathrm{g}} & \left.=\text { gasket area (in. }{ }^{2}\right) \\
\mathrm{f}_{\mathrm{L}} & =0 \text { if flange and ring contact }\left(\delta_{\mathrm{gi}}\right. \\
& =1 \text { otherwise } \\
\mathrm{N}_{\mathrm{b}}= & \text { number of bolts } \\
\mathrm{JR} & =\text { joint relaxation (\%) } \\
\mathrm{K}_{\mathrm{g}}= & \text { gasket initial stiffness (psi/in.) } \\
\mathrm{K}_{\mathrm{gr}}= & \text { gasket unloading/reloading stiff- }
\end{aligned}
$$

If the gasket deflection does not reach 0.050 in., the flanges/rings do not lock.

The median gross leak pressure is defined as the pressure at which the flange internal fluid pressure equals the stress in the gasket. The gross leak pressure (GLP) can be calculated with the aid of Figure 3-1 of NUREG/CR-5603, which is reproduced here as Figure 35 . The figure shows the ratio of the change in the gasket load to the total pressure load. For example, the pressure load goes totally into unloading the gasket with no change, in the bolt load for Class 150 flanges of sizes 12 in. or greater, while part of the pressure load goes into unloading the gasket, and the remaining fraction of the load goes into lengthening the bolts for smaller flanges. The curves in Figure 35 are approximated by

$$
\begin{gathered}
\frac{-\Delta G_{L}}{\Delta P A_{p}}=0.0547 S_{f}+0.376 \\
\left(S_{f}<12 \text { in . }\right)
\end{gathered}
$$

where

$$
\Delta G_{L}=\text { change in gasket load (lb) }
$$




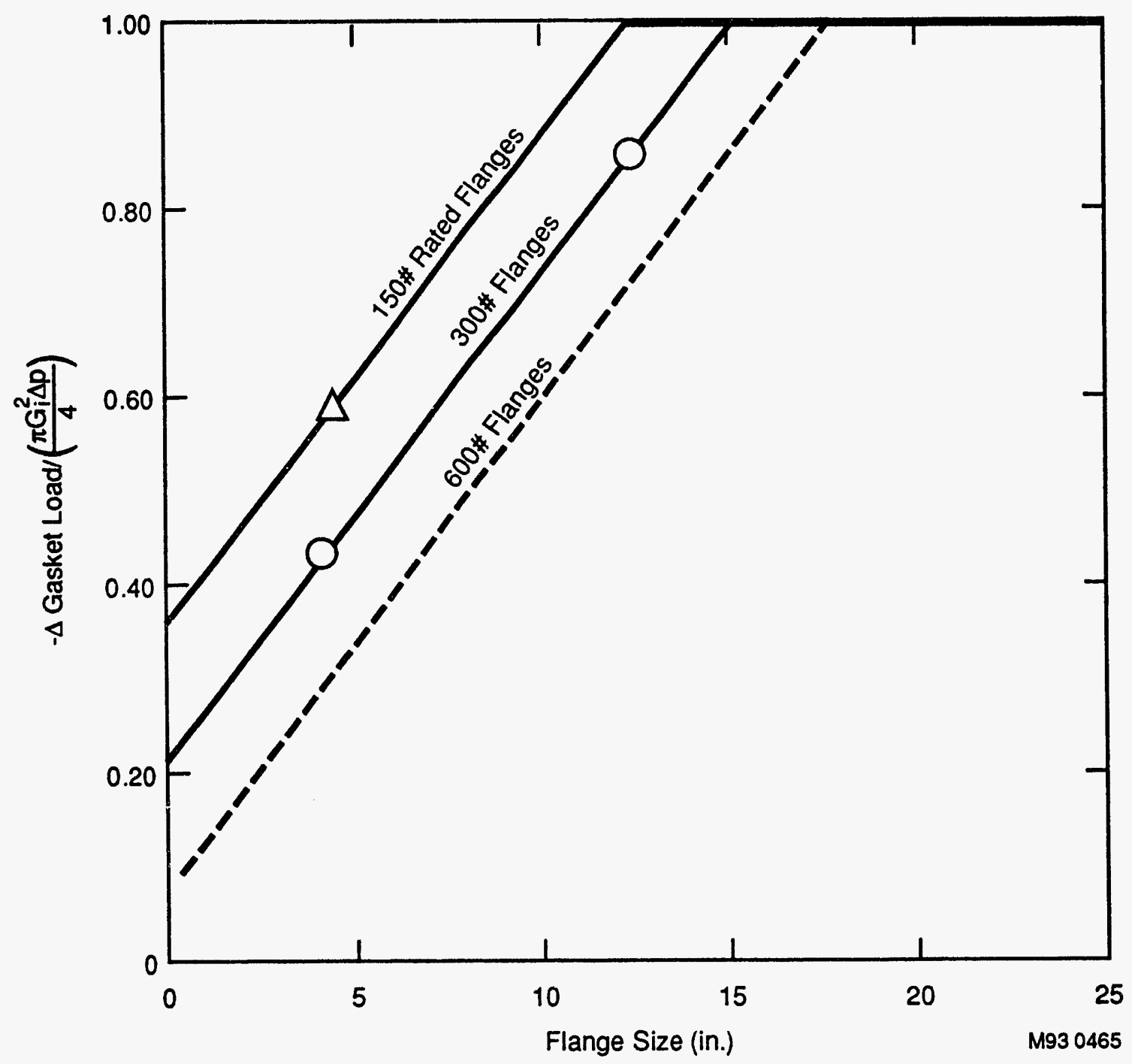

Figure 35. Fraction of pressure load transferred to gasket (Figure 3-1 of NUREG/CR-5603).

$$
\begin{aligned}
& \Delta \mathrm{P}=\text { change in system pressure (psi) } \\
& \left.A_{\mathrm{p}}=\text { pressure area (in. }{ }^{2}\right) \\
& \mathrm{S}_{\mathrm{f}}=\text { flange size (in.) }
\end{aligned}
$$

and defining $\mathrm{U}_{\mathrm{g}}$ (Class rating) as

$$
\begin{array}{rlr}
\mathrm{U}_{\mathrm{g}}(150) & =0.0547 \mathrm{~S}_{\mathrm{f}}+0.376 & \left(\mathrm{~S}_{\mathrm{f}}<12 \text { in. }\right) \\
& =1 & \left(\mathrm{~S}_{\mathrm{f}} \geq 12 \text { in. }\right) \\
\mathrm{U}_{\mathrm{g}}(300) & =0.0547 \mathrm{~S}_{\mathrm{f}}+0.214 & \left(\mathrm{~S}_{\mathrm{f}}<16 \text { in. }\right) \\
& =1 & \left(\mathrm{~S}_{\mathrm{f}} \geq 16 \text { in. }\right)
\end{array}
$$

$$
\begin{aligned}
\mathrm{U}_{\mathrm{g}}(600) & =0.0547 \mathrm{~S}_{\mathrm{f}}+0.0727 & \left(\mathrm{~S}_{\mathrm{f}}<18 \mathrm{in} .\right) \\
& =1 & \left(\mathrm{~S}_{\mathrm{f}} \geq 18 \mathrm{in} .\right)
\end{aligned}
$$

the median GLP can be calculated by the following equation:

$$
G L P=P_{L O}+\frac{\sigma_{g r}-P_{L O}}{1+U_{g} \frac{A_{p}}{A_{g}}}
$$

where $P_{L O}$, the pressure at which the flange/ring locking load is overcome, is defined by the difference in the total bolt preload and the gasket load (after relaxation): 


$$
P_{L O}=\frac{\sigma_{b p} A_{b} N_{b}-\sigma_{g r} A_{g}}{A_{p}} .
$$

Although NUREG/CR-5603 does not address the question, it would appear that the flexibility of the flange would affect unloading of the locking ring nearly identically to unloading the gasket, and, thus, the Figure 35 curves also would be applicable to unloading the locking ring. In this case, the right-hand side of Equation 20 should be divided by the factor $U_{g}$.

4.2.2.2 Uncertainty. The assumptions based on the NUREG/CR-5603 methodology described above include two major uncertainties, those for the joint relaxation and the bolt torque/initial preload; however, other parameters for which there are uncertainties have not been included, for example,

- $\quad$ Gasket stiffness

- Gasket area

- Bolt stiffness (length, area, elastic modulus)

- Bolt area

- $\quad$ Pressure area

- Initial flange/compression ring separation

- $\quad$ Figure 35 unloading curves.

In order to determine a $99 \%$ confidence GLP, we need an estimate of the uncertainty. The uncertainties in the GLP are

- Whether the flange and compression ring will lock

- The bolt preload

- The percent joint relaxation

- How much of the change in pressure load is shared by the gasket and the bolts (the value of $U_{g}$ ).
However, if we assume there is sufficient preload with high-strength bolts such that the flange is securely locked to the compression ring, most of the uncertainties no longer affect the GLP. The loss of gasket load caused by relaxation is simply transferred to the locking ring, so the only important variable is the bolt preload to be overcome.

Yahr (1985) estimates the range of the accuracy of bolt preloading from $\pm 15 \%$, with a digital torque wrench and no operator error, to $\pm 30 \%$ for a bar torque wrench under field conditions with a variability in friction. Using these percentages as the $99 \%$ confidence $(2.33 \beta)$ value, the resulting $\beta$ values are 0.060 and 0.123 (the 0.07 value used in NUREG/CR-5603 is within this range.) A $\beta_{b p}$ of 0.0915 , the midpoint of the Yahr range, will be used as the $99 \%$ confidence level for bolt preload, since this is slightly more conservative than the NUREG/CR-5603 value of 0.07 .

A joint relaxation of $25 \%$ as the median, and 0 and $50 \%$ as the $\pm 3 \beta$ uncertainties will be used. The $\beta_{\mathrm{jr}}$ for joint relaxation is computed using the GLP at $0 \%, 25 \%$, and $50 \%$ joint relaxation. In most cases, this uncertainty will be zero, since the loss of load from relaxation in the gasket will be simply transferred to the locking ring. The overall $\beta$ is computed from the square root of the sum of the squares of $\beta_{\mathrm{bp}}$ and $\beta_{\mathrm{jr}}$.

\subsubsection{Flange Size and Bolt Preload Verifi-} cation Calculations. In Section 4.2.1., we determined that for a pressure ratio of 0.4 , the designer would typically select a Class 300 flange for the ABWR, and a Class 600 flange for PWRs. Calculations were performed to determine if these size flanges with a bolt preload of 40,000 psi are adequate so that the design pressure (1025 psig for ABWRs and 2235 psig for PWRs) will not exceed the GLP with a $99 \%$ confidence.

Tables 19 and 20 summarize the calculations for GLP for Class 300 flanges subject to BWR conditions and Class 600 flanges subject to PWR conditions, respectively. High-strength bolts preloads of 40,000 psi and a 0.050 -in. gasket/ compression ring gap were used. The flange 
Table 19. BWR flange calculations for 40,000 psi bolt preload.

\begin{tabular}{|c|c|c|c|c|c|c|c|c|c|}
\hline $\begin{array}{l}\text { Flange } \\
\text { size } \\
\text { (in.) }\end{array}$ & $\begin{array}{c}\text { Number } \\
\text { of } \\
\text { bolts }\end{array}$ & $\begin{array}{l}\text { Bolt } \\
\text { area } \\
\left(\text { in. }{ }^{2}\right)\end{array}$ & $\begin{array}{c}\text { Pressure } \\
\text { area } \\
\left(\text { in. }^{2}\right)\end{array}$ & $\begin{array}{c}\text { Gasket } \\
\text { area } \\
\left(\text { in. }^{2} \text { ) }\right.\end{array}$ & \multicolumn{2}{|c|}{$\begin{array}{l}\text { Gasket } \\
\text { stiffness } \\
\text { (psi/in.) }\end{array}$} & $\begin{array}{c}\text { Gasket } \\
\text { stress } \\
@ 0 \% \\
\text { (psi) }\end{array}$ & $\begin{array}{c}\text { Gasket } \\
\text { stress } \\
\text { @ 25\% } \\
\text { (psi) }\end{array}$ & $\begin{array}{c}\text { Gasket } \\
\text { stress } \\
@ \text { 50\% } \\
\text { (psi) }\end{array}$ \\
\hline $1-1 / 2$ & 4 & 0.334 & 3.547 & 1.865 & \multicolumn{2}{|c|}{431263} & 21563 & 16172 & 10782 \\
\hline 2 & 8 & 0.2256 & 5.940 & 2.356 & \multicolumn{2}{|c|}{456480} & 22824 & 17118 & 11412 \\
\hline $2-1 / 2$ & 8 & 0.334 & 8.296 & 2.749 & \multicolumn{2}{|c|}{586094} & 29305 & 21979 & 14652 \\
\hline 3 & 8 & 0.334 & 12.566 & 4.234 & \multicolumn{2}{|c|}{380537} & 19027 & 14270 & 9513 \\
\hline 4 & 8 & 0.334 & 19.635 & 6.332 & \multicolumn{2}{|c|}{254429} & 12721 & 9541 & 6361 \\
\hline 6 & 12 & 0.3340 & 40.579 & 11.275 & \multicolumn{2}{|c|}{198477} & 9924 & 7443 & 4962 \\
\hline 8 & 12 & 0.4612 & 66.303 & 16.221 & \multicolumn{2}{|c|}{206600} & 10330 & 7748 & 5165 \\
\hline 10 & 16 & 0.6051 & 100.518 & 19.768 & \multicolumn{2}{|c|}{297242} & 14862 & 11147 & 7431 \\
\hline 12 & 16 & 0.7627 & 140.501 & 27.489 & \multicolumn{2}{|c|}{282457} & 14123 & 10592 & 7061 \\
\hline 14 & 20 & 0.7627 & 167.990 & 29.943 & \multicolumn{2}{|c|}{323574} & 16179 & 12134 & 8089 \\
\hline 16 & 20 & 0.9684 & 217.077 & 40.939 & \multicolumn{2}{|c|}{302348} & 15117 & 11338 & 7559 \\
\hline 18 & 24 & 0.9684 & 274.294 & 59.824 & \multicolumn{2}{|c|}{237965} & 11898 & 8924 & 5949 \\
\hline 20 & 24 & 0.9684 & 336.146 & 65.911 & \multicolumn{2}{|c|}{216007} & 10800 & 8100 & 5400 \\
\hline 24 & 24 & 1.4041 & 481.107 & 86.161 & \multicolumn{2}{|c|}{240258} & 12013 & 9010 & 6006 \\
\hline $\begin{array}{l}\text { Flange } \\
\text { size } \\
\text { (in.) } \\
\end{array}$ & $\begin{array}{c}\text { Liftoff } \\
\text { pressure } \\
@ 0 \% \\
\text { (psi) }\end{array}$ & $\begin{array}{c}\text { Liftoff } \\
\text { pressure } \\
@ 25 \% \\
\text { (psi) }\end{array}$ & $\begin{array}{c}\text { Liftoff } \\
\text { pressure } \\
@ \text { @ 50\% } \\
(\mathrm{psi}) \\
\end{array}$ & $\begin{array}{c}\text { GLP@ } \\
0 \% \\
\text { (psi) }\end{array}$ & $\begin{array}{c}\text { GLP@ } \\
25 \% \\
\text { (psi) }\end{array}$ & $\begin{array}{c}\text { GLP@ } \\
50 \% \\
(\mathrm{psi}) \\
\end{array}$ & $\beta_{\mathrm{jr}}$ & $\beta$ & $\begin{array}{l}99 \% \\
\text { Conf. } \\
\text { GLP } \\
\text { (psi) }\end{array}$ \\
\hline $1-1 / 2$ & 17416 & 30665 & 43914 & 20364 & 16172 & 10782 & 0.1060 & 0.1400 & 11677 \\
\hline 2 & 9586 & 16586 & 23585 & 16879 & 16879 & 11412 & 0.0652 & 0.1124 & 12997 \\
\hline $2-1 / 2$ & 14828 & 26172 & 37516 & 23624 & 21979 & 14652 & 0.0796 & 0.1213 & 16576 \\
\hline 3 & 5540 & 9779 & 14018 & 11895 & 11895 & 9513 & 0.0372 & 0.0988 & 9453 \\
\hline 4 & 3098 & 5468 & 7837 & 7207 & 7207 & 6361 & 0.0208 & 0.0938 & 5794 \\
\hline 6 & 2201 & 3472 & 4744 & 4818 & 4818 & 4818 & 0.0000 & 0.0915 & 3894 \\
\hline 8 & 1246 & 2215 & 3185 & 3725 & 3725 & 3725 & 0.0000 & 0.0915 & 3011 \\
\hline 10 & 1222 & 2182 & 3142 & 4023 & 4023 & 4023 & 0.0000 & 0.0915 & 3252 \\
\hline 12 & 817 & 1611 & 2404 & 3259 & 3259 & 3259 & 0.0000 & 0.0915 & 2634 \\
\hline 14 & 764 & 1500 & 2235 & 3136 & 3136 & 3136 & 0.0000 & 0.0915 & 2535 \\
\hline 16 & 718 & 1431 & 2143 & 3003 & 3003 & 3003 & 0.0000 & 0.0915 & 2427 \\
\hline 18 & 794 & 1443 & 2092 & 2782 & 2782 & 2782 & 0.0000 & 0.0915 & 2249 \\
\hline 20 & 648 & 1177 & 1707 & 2312 & 2312 & 2312 & 0.0000 & 0.0915 & 1369 \\
\hline 24 & 650 & 1188 & 1726 & 2376 & 2376 & 2376 & 0.0000 & 0.0915 & 1921 \\
\hline
\end{tabular}


Component Evaluations

Table 20. PWR flange calculations for 40,000 psi bolt preload.

\begin{tabular}{|c|c|c|c|c|c|c|c|c|c|c|}
\hline $\begin{array}{l}\text { Flange } \\
\text { size } \\
\text { (in.) }\end{array}$ & $\begin{array}{c}\text { Number } \\
\text { of } \\
\text { bolts }\end{array}$ & $\begin{array}{l}\text { Bolt } \\
\text { area } \\
\left(\text { in. }{ }^{2}\right)\end{array}$ & $\begin{array}{c}\text { Gasket } \\
\text { area } \\
\left(\text { in. }^{2}\right)\end{array}$ & $\begin{array}{c}\text { Pressure } \\
\text { area } \\
\text { (in. }^{2} \text { ) }\end{array}$ & \multicolumn{2}{|c|}{$\begin{array}{c}\text { Gasket } \\
\text { stiffness } \\
\text { (psi/in.) }\end{array}$} & \multicolumn{2}{|c|}{$\begin{array}{c}\text { Gasket } \\
\text { stress } \\
@ 0 \% \\
\text { (psi) }\end{array}$} & $\begin{array}{c}\text { Gasket } \\
\text { stress } \\
\text { @ 25\% } \\
\text { (psi) }\end{array}$ & $\begin{array}{c}\text { Gasket } \\
\text { stress } \\
@ \text { 50\% } \\
\text { (psi) }\end{array}$ \\
\hline $1-1 / 2$ & 4 & 0.3340 & 1.865 & 3.547 & \multicolumn{2}{|c|}{431263} & \multicolumn{2}{|c|}{21563} & 16172 & 10782 \\
\hline 2 & 8 & 0.2256 & 2.356 & 5.940 & \multicolumn{2}{|c|}{513540} & \multicolumn{2}{|c|}{25677} & 19258 & 12839 \\
\hline $2-1 / 2$ & 8 & 0.3340 & 2.749 & 8.296 & \multicolumn{2}{|c|}{659356} & \multicolumn{2}{|c|}{32968} & 24726 & 16484 \\
\hline 3 & 8 & 0.3340 & 4.234 & 12.566 & \multicolumn{2}{|c|}{428104} & \multicolumn{2}{|c|}{21405} & 16054 & 10703 \\
\hline 4 & 8 & 0.4612 & 8.247 & 17.721 & \multicolumn{2}{|c|}{306184} & \multicolumn{2}{|c|}{15309} & 11482 & 7655 \\
\hline 6 & 12 & 0.6051 & 14.726 & 37.122 & \multicolumn{2}{|c|}{322554} & \multicolumn{2}{|c|}{16128} & 12096 & 8064 \\
\hline 8 & 12 & 0.7627 & 20.654 & 61.863 & \multicolumn{2}{|c|}{317137} & \multicolumn{2}{|c|}{15857} & 11893 & 7928 \\
\hline 10 & 16 & 0.9684 & 28.459 & 91.830 & \multicolumn{2}{|c|}{391842} & \multicolumn{2}{|c|}{19592} & 14694 & 9796 \\
\hline 12 & 20 & 0.9684 & 37.797 & 130.192 & \multicolumn{2}{|c|}{368413} & \multicolumn{2}{|c|}{18421} & 13815 & 9210 \\
\hline 14 & 20 & 1.1538 & 38.448 & 159.485 & \multicolumn{2}{|c|}{411247} & \multicolumn{2}{|c|}{20562} & 15422 & 10281 \\
\hline 16 & 20 & 1.4041 & 50.621 & 207.395 & \multicolumn{2}{|c|}{383376} & \multicolumn{2}{|c|}{19169} & 14377 & 9584 \\
\hline 18 & 20 & 1.7723 & 65.299 & 268.803 & \multicolumn{2}{|c|}{385943} & \multicolumn{2}{|c|}{19297} & 14473 & 9649 \\
\hline 20 & 24 & 1.7723 & 71.975 & 330.064 & \multicolumn{2}{|c|}{420175} & \multicolumn{2}{|c|}{21009} & 15757 & 10504 \\
\hline 24 & 24 & 2.4107 & 86.161 & 481.107 & 48125 & & 24 & 63 & 18047 & 12031 \\
\hline $\begin{array}{c}\text { Flange } \\
\text { size } \\
\text { (in.) } \\
\end{array}$ & $\begin{array}{c}\text { Liftoff } \\
\text { pressure } \\
\text { @ 0\% } \\
\text { (psi) } \\
\end{array}$ & $\begin{array}{c}\text { Liftoff } \\
\text { pressure } \\
@ 25 \% \\
\text { (psi) }\end{array}$ & $\begin{array}{c}\text { Liftoff } \\
\text { pressure } \\
\text { @ 50\% } \\
\text { (psi) }\end{array}$ & $\begin{array}{c}\text { GLP@ } \\
0 \% \\
\text { (psi) } \\
\end{array}$ & $\begin{array}{c}\text { GLP@ } \\
25 \% \\
\text { (psi) } \\
\end{array}$ & & & $\beta_{\mathrm{jr}}$ & $\beta$ & $\begin{array}{l}99 \% \\
\text { Conf. } \\
\text { GLP } \\
\text { (psi) }\end{array}$ \\
\hline $1-1 / 2$ & 51264 & 90264 & 129264 & 21563 & 16172 & & & 0.1155 & 0.1474 & 11479 \\
\hline 2 & 10810 & 24794 & 38778 & 20999 & 19258 & & 339 & 0.0820 & 0.1229 & 14471 \\
\hline $2-1 / 2$ & 26952 & 64518 & 102084 & 31885 & 24726 & & 184 & 0.1100 & 0.1431 & 17728 \\
\hline 3 & 5462 & 13076 & 20690 & 14825 & 14825 & & 103 & 0.0543 & 0.1064 & 11575 \\
\hline 4 & 4130 & 10240 & 16350 & 11004 & 11004 & & 655 & 0.0605 & 0.1097 & 8526 \\
\hline 6 & 3558 & 7547 & 11537 & 9810 & 9810 & & 64 & 0.0327 & 0.0972 & 7825 \\
\hline 8 & 1223 & 3816 & 6410 & 7010 & 7010 & & 010 & 0.0000 & 0.0915 & 5666 \\
\hline 10 & 1093 & 3543 & 5992 & 7260 & 7260 & & 260 & 0.0000 & 0.0915 & 5868 \\
\hline 12 & 827 & 2660 & 4494 & 5837 & 5837 & & 837 & 0.0000 & 0.0915 & 4718 \\
\hline 14 & 991 & 2468 & 3946 & 5361 & 5361 & & 361 & 0.0000 & 0.0915 & 4333 \\
\hline 16 & 778 & 2012 & 3246 & 4544 & 4544 & & 544 & 0.0000 & 0.0915 & 3673 \\
\hline 18 & 587 & 1759 & 2931 & 4244 & 4244 & & 244 & 0.0000 & 0.0915 & 3430 \\
\hline 20 & 574 & 1719 & 2864 & 4232 & 4232 & & 232 & 0.0000 & 0.0915 & 3421 \\
\hline 24 & 501 & 1578 & 2656 & 4080 & 4080 & & 080 & 0.0000 & 0.0915 & 3289 \\
\hline
\end{tabular}


parameters were obtained from NUREG/ CR-5603. Calculations were carried out for $0 \%$ gasket relaxation, $25 \%$ gasket relaxation (the median case), and $50 \%$ gasket relaxation. The deflections were calculated using Equations 14 and 16 , and the gasket stresses were calculated using Equations 15 and 17. In all cases, the calculated initial deflections exceeded 0.050 in., so this value was used as the gasket defection. The contact (liftoff) pressures that must be overcome before the gasket starts to unload were calculated using Equation 20, and are listed in the first three columns of the lower half of the tables. The GLPs were calculated using Equation 19. The uncertainty $(\beta)$ was calculated from the square root of the sum of the squares of the bolt preload uncertainty (0.0915) and $\beta_{\mathrm{jr}}$.

Table 19 shows that for initial bolt preload stresses of 40,000 , all sizes of Class 300 flanges can be pressurized to the ABWR pressure of 1025 psig without exceeding the $99 \%$ confidence GLP. Section 3.2.1 of NUREG/CR-5603 states that a bolt preload of 30,000 psi represents a $-3 \beta$ lower bound for Class 300 and 600 flanges. A calculation using a 30,000 psi bolt preload for the 20-in. flange (which has the lowest GLP in Table 19) shows that the $99 \%$ confidence GLP was 1440 psi.

Table 20 shows that for initial bolt preload stresses of 40,000 , all sizes of Class 600 flanges can be pressurized to the PWR pressure of 2235 psig without exceeding the $99 \%$ confidence GLP. A calculation using a 30,000 psi bolt preload for the 24-in. flange (which has the lowest GLP in Table 20) shows that the $99 \%$ confidence GLP was 2446 psi.

\subsection{Valves}

Unlike piping and flanges, which more or less have standard designs, there are many different styles of valves, each of which has unique features based on the valve's function. Since for ISLOCA design we are only interested in the valve's pressure-retaining capabilities, the internals of valves are not examined in this report.
As discussed in NUREG/CR-5603, there are three areas of the valve where leakage may occur: the valve body (and bonnet), bolted connections, and packing. These areas are shown in Figure 36 (the packing is interior to the valve and cannot be seen, so only the general location is given). Figure 37 shows a typical bolted connection with a grooved flange face and gasket. The type gasket in the figure might represent a style $\mathbf{R}$ spiralwound gasket, which has no compression ring. The packing is compressed tightly around the valve stem where it exits the bonnet, as shown in Figure 38.

Valve Body: Table 21 lists the pressure ratings for valves from B16.34. The Class and pressure ratings are identical to those for flanges. Section III (NC-3521) of the ASME Code states that the valve section modulus and metal area shall not be less that $110 \%$ of the comparable piping parameters. Table NC-3521-1 of ASME Code

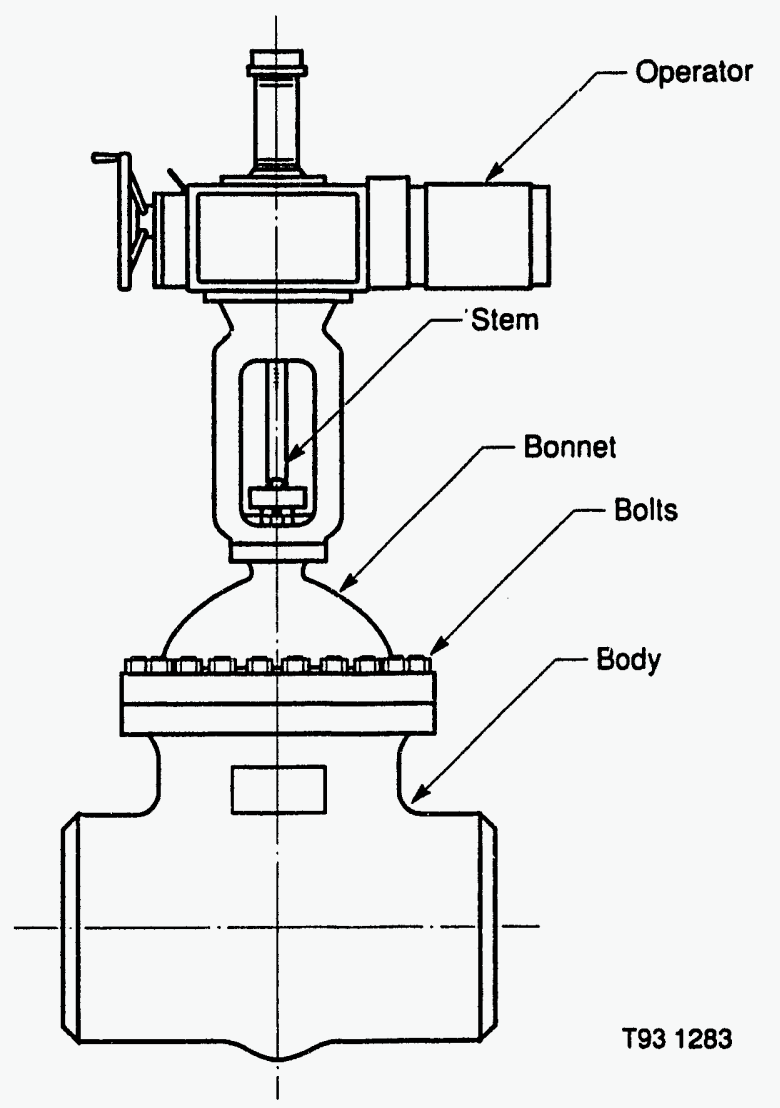

Figure 36. Bolted bonnet valve. 


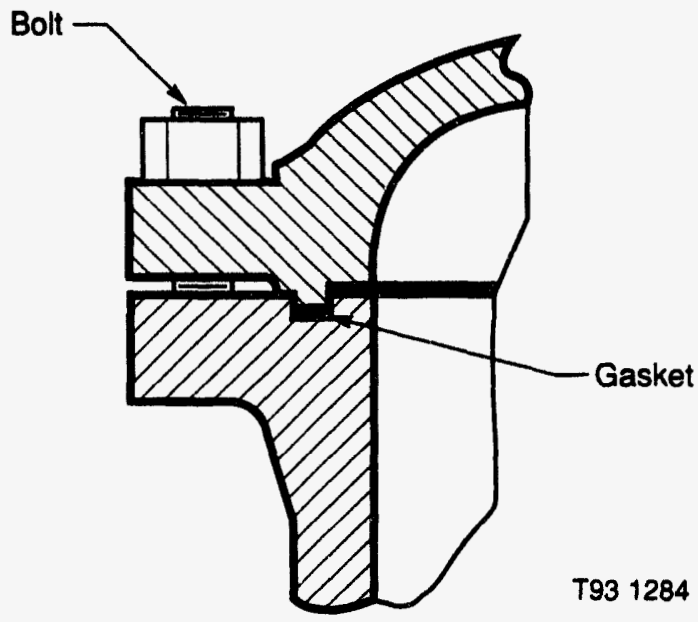

Figure 37. Valve bolted connection.

Section III allows a 1.1 factor on design pressure for Service Level B. From this we can conclude that the walls of the valve will be at least as thick as the walls of the attached piping, so the survival confidences of the valve body will be at least as great as that of the attached piping. As pointed out in the peer review panel report in Attachment 2,

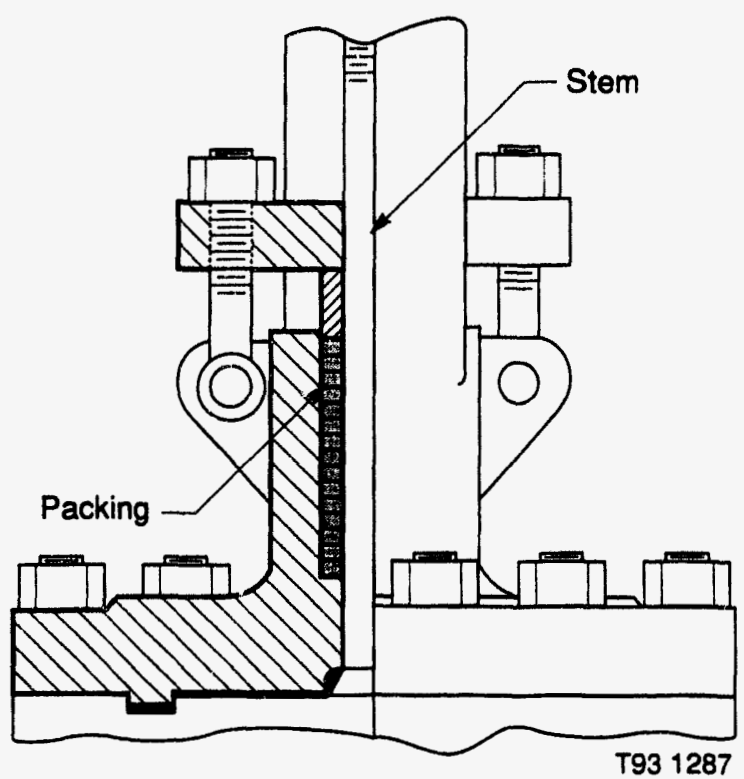

Figure 38. Packing on gate valve.

the Class 300 and 600 valves will be hydrostatically pressure tested to (or very nearly to) the ISLOCA pressure.

Table 21. B16.34 valve pressure ratings (psig) at $400^{\circ} \mathrm{F}$.

\begin{tabular}{|c|c|c|c|c|c|c|c|}
\hline \multirow[b]{2}{*}{ Class } & \multicolumn{4}{|c|}{ Carbon steel } & \multicolumn{3}{|c|}{ Stainless steel } \\
\hline & 1.1 & 1.2 & 1.3 & 1.4 & 304 & 316 & $304 \mathrm{~L}$ \\
\hline 150 & 200 & 200 & 200 & 200 & 180 & 195 & 160 \\
\hline 300 & 635 & 705 & 620 & 530 & 470 & 515 & 415 \\
\hline 400 & 845 & 940 & 825 & 705 & 630 & 685 & 550 \\
\hline 600 & 1270 & 1410 & 1235 & 1060 & 940 & 1030 & 825 \\
\hline Number & \multicolumn{2}{|c|}{ Composition } & \multicolumn{2}{|c|}{ Forgings } & \multicolumn{2}{|c|}{ Castings } & \\
\hline 1.1 & \multicolumn{2}{|c|}{$\begin{array}{l}\text { Carbon } \\
\text { C-Mn-Si }\end{array}$} & \multicolumn{2}{|c|}{ A105, A 350 Grade LF2 } & \multicolumn{2}{|c|}{ A 216 Grade WCB } & \\
\hline 1.2 & $\begin{array}{l}\text { Carbon } \\
2-1 / 2 \mathrm{Ni}\end{array}$ & & A $350 \mathrm{C}$ & 3 & $\begin{array}{l}\text { A } 216 \\
\text { A } 352 \\
\text { A } 352\end{array}$ & $\begin{array}{l}\text { NCC } \\
\text { C2 } \\
\text { C3 } 3\end{array}$ & \\
\hline 1.3 & $\begin{array}{l}\text { Carbon } \\
2-1 / 2 \mathrm{Ni}\end{array}$ & & \multicolumn{2}{|c|}{$-1-10-1$} & A 352 & $\begin{array}{c}C B \\
-\end{array}$ & \\
\hline 1.4 & \multicolumn{2}{|c|}{ Carbon } & \multicolumn{2}{|c|}{ A 350 Grade LFl } & \multicolumn{3}{|c|}{--- - - - - - - - - } \\
\hline
\end{tabular}


Bolted Connections: The recommendations for Class sizes and bolt preloads made for flanges also are applicable for valve bolted connections.

Packing: The packing leakage is expected to be minimal, since the leak area through any degraded areas of the packing material would be small.

\subsection{Pumps}

In contrast to piping and flanges, which more or less have standard designs, there are many different types of pumps, each of which has unique features. Since for ISLOCA design we are only interested in the pump's pressure-retaining capabilities, the pump internals are not examined in this report.

There are three general areas of the pump where the loss of the pressure-retaining boundary may take place: the casing, bolted connections, and seals.
Casing: The casing thickness in NC-3441 of ASME Code Section III for types A and C centrifugal pumps is

$$
\begin{array}{ll}
t=\frac{P A}{S} & \quad(\text { Type A) } \\
t=\frac{P A}{2 S} & (\text { Type C) }
\end{array}
$$

where

$$
\begin{aligned}
& \mathrm{P} \quad=\quad \text { design pressure (psig) } \\
& \mathrm{A} \quad=\quad \begin{array}{l}
\text { scroll dimension (see Figures } 39 \\
\text { and 40) }
\end{array} \\
& \mathrm{S} \quad=\quad \text { allowable stress. }
\end{aligned}
$$

The piping connected to the pump is designed to a minimum wall thickness proportional to the radius of the pipe. The type $A$ pump casing is designed to a minimum wall thickness proportional to $A$ in Figure 39, while the Type C pump is designed to a minimum wall thickness proportional to $0.5 \mathrm{~A}$ in Figure 40. Since from Figures 39

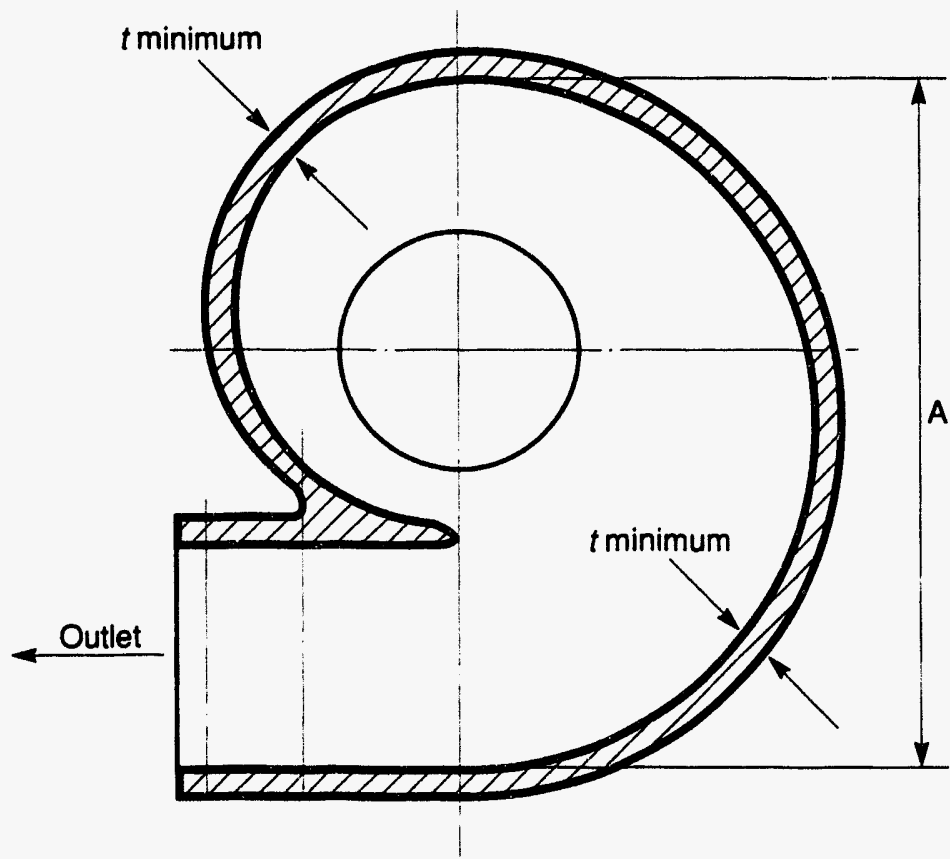

Figure 39. Type A pump.

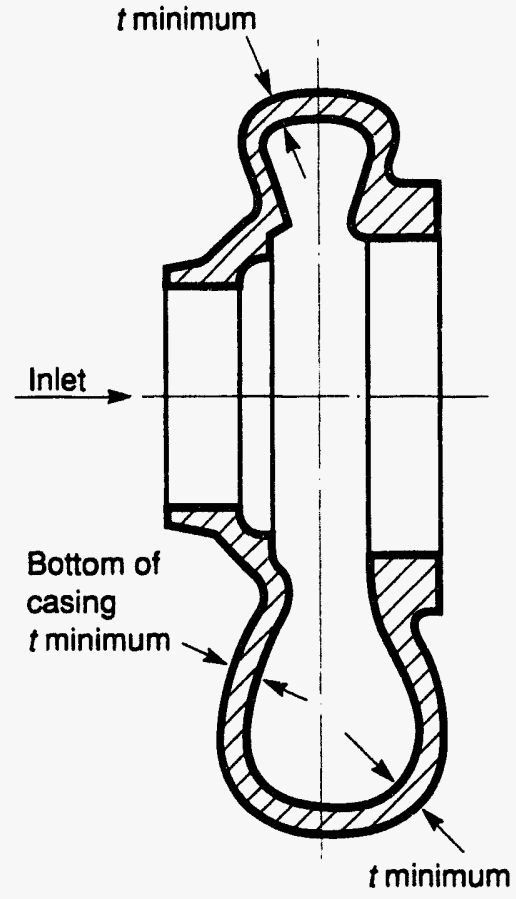

T93 1285 


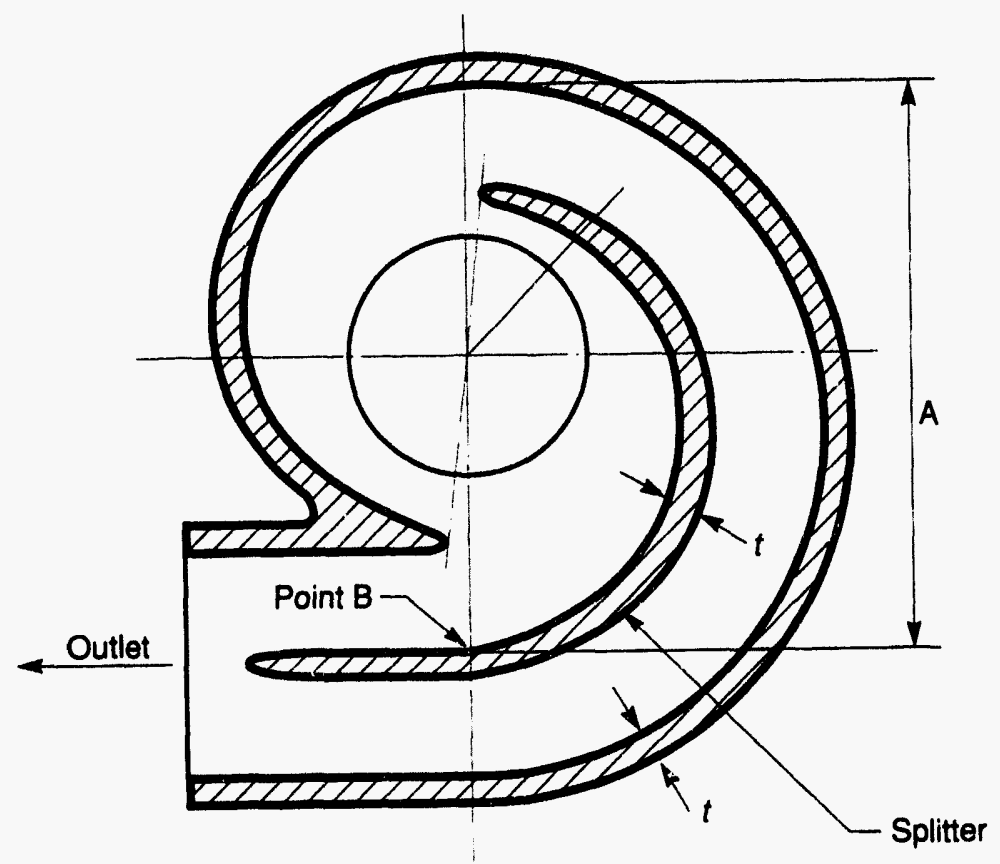

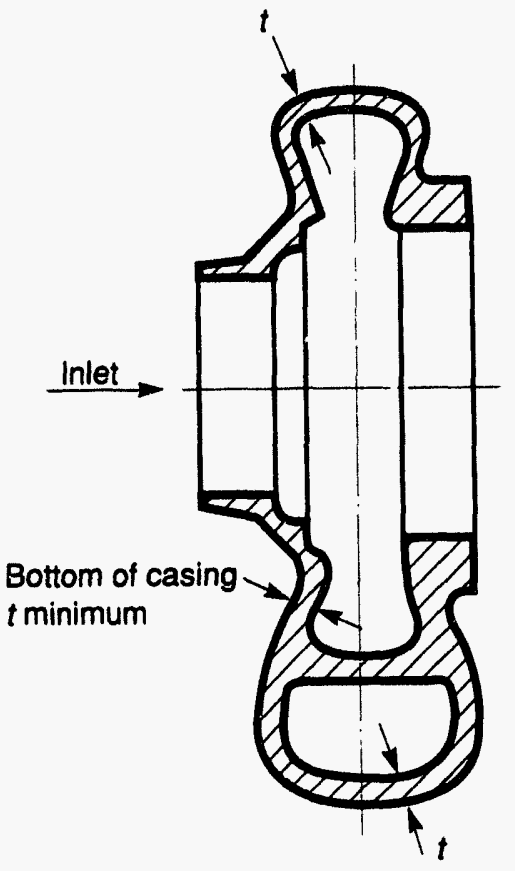

T93 1288

Figure 40. Type C pump.

and 40 the pipe radius is less than dimension $A$ in Figure 39 or $0.5 \mathrm{~A}$ in Figure 40 , the pump casing will be thicker than the adjacent pipe. Therefore, the pressure stresses in the pump casing should be less than in the adjoining piping, and the survival confidence of the pump casing will be greater than that of the adjacent piping.

Bolted Connections: The recommendations for Class sizes and bolt preloads made for flanges also are applicable for pump bolted connections.

Seals: Seals are judged to be have the highest potential for leakage of the pump subcomponents. In fact, Generic Issue 23, Reactor Coolant Pump Seal Failure, was developed to evaluate such an issue (Ruger and Luckas, 1989).

NUREG/CR-5603 recommends that a nominal leak rate of 100 to $200 \mathrm{mg} / \mathrm{sec}$ be assumed as the pump seal leakage rate under ISLOCA conditions. Since $200 \mathrm{mg} / \mathrm{s}$ is much less than $1 \mathrm{gpm}$, a leak rate of this magnitude would have a negligible affect on the total RCS fluid inventory.
Westinghouse Electric Corporation (1993) has stated that the RHR pump seal is the only AP600 component connected to the RCS not designed to have an ultimate rupture strength equal to the normal RCS operating pressure. They report that the rupture pressure of the seals with the RHR pumps operating is 670 to $700 \mathrm{psig}$, and that a seal designed to withstand full RCS pressure will likely experience abnormally fast wear during normal operation.

Based on the minimal leakage expected through the pump mechanical seals during an ISLOCA event, it appears that the Westinghouse proposal of allowing the mechanical seals to fail, but to minimize and control the leakage, is a satisfactory approach.

\subsection{Heat Exchangers}

Heat exchangers can be designed using either the shell or the tube side as the boundary for the hotter coolant. Figure 41 shows a PWR residual heat removal (RHR) system heat exchanger, which is a tube-side heat exchanger; that is, the 


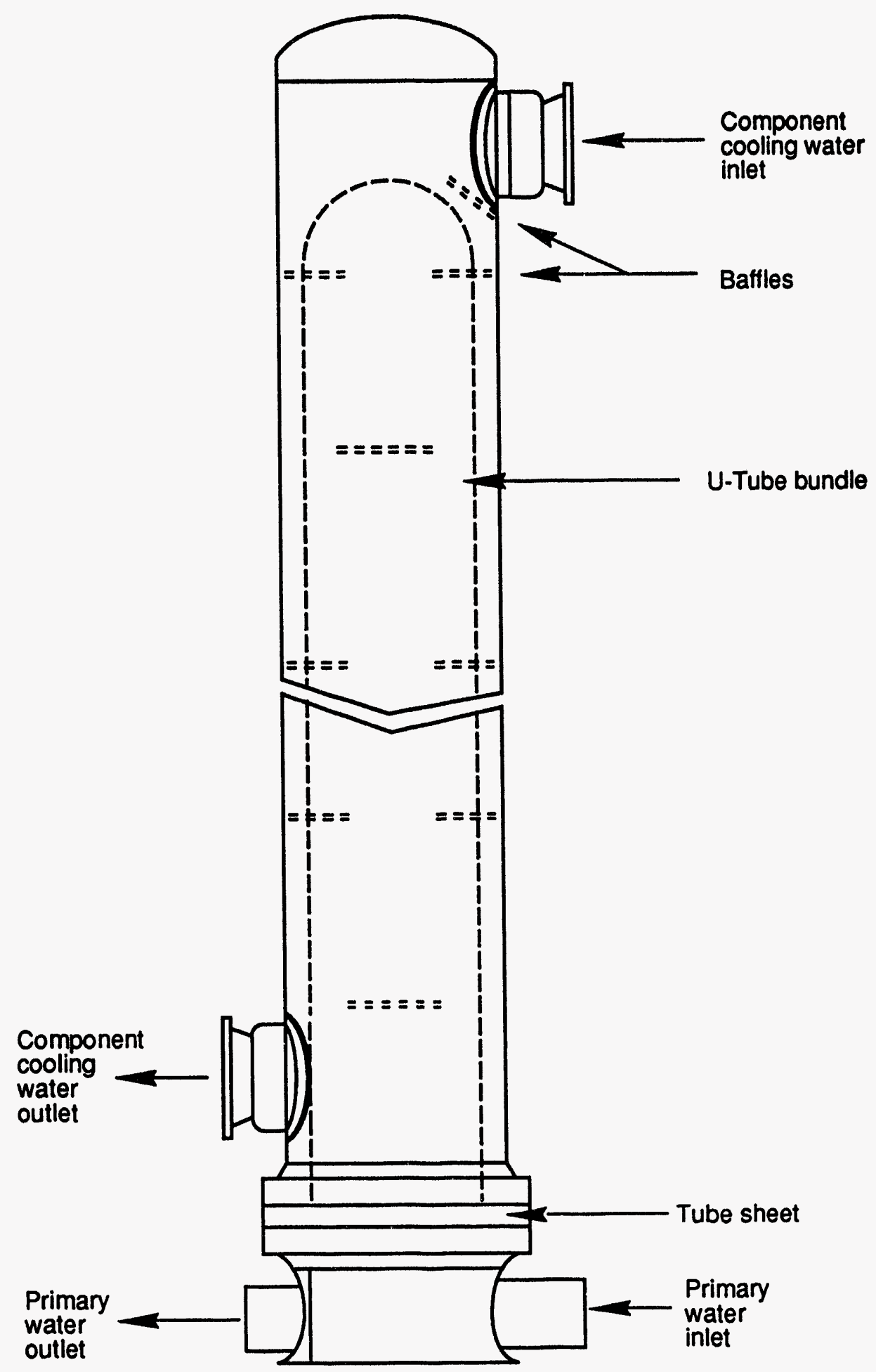

Figure 41. PWR RHR heat exchanger. 
hotter coolant flows within the tubes while the external cooling water flows exterior to the tubes but within the shell. The tubes and tubesheet separate the hotter and cooler fluids. The tubesheet is located between two bolted flanges and sealed from the flanges by gaskets on the tubesheet top and bottom; however, there are several varieties of flange and tubesheet design [TEMA (1982)]. The primary water inlet and outlet connections, the lower head, the tubesheet, and the tubes would be designed for ISLOCA pressures.

The RHR heat exchangers on BWR plants are shell-side (Public Service Electric \& Gas), with the external cooling water flowing inside the tubes and the hotter RHR coolant flowing inside the shell and external to the tubes. The design pressure is 450 psig and the design temperature is $470^{\circ} \mathrm{F}$ for both the tube- and the shell-side of the Hope Creek RHR heat exchangers.

Thus, the design of tube-side heat exchangers for ISLOCA pressures requires analysis for pressure within the tubes but not within the cylindrical shell or the upper head, while for shell-side heat exchangers the cylindrical shell and the upper head are analyzed for the ISLOCA design pressure, as well as pressure external to the tubes.

Although the ASME Code has design rules for component stress allowables, it is not detailed enough to deal with all the special features of heat exchanger design. A universally accepted code that provides minimum standards for heat exchanger design is the TEMA Standard (1982). This standard was originally designed to supplement Section VIII, Division 1, of the ASME Code. A good discussion of the rules of various heat exchanger design and construction codes can be found in Schlünder (1989).

4.5.1 Heads and Shells. The design of heat exchanger vessels with hemispherical, torispherical, and 2:1 ellipsoidal heads were investigated for ISLOCA conditions. The methodology used in this section is from NUREG/CR-5603, but since NUREG/CR-5862 is more recent and contains supplementary information, it also has been used.

\subsubsection{ASME Code Design Thicknesses.}

Cylindrical shells: The design thickness of a cylindrical shell from Section III, NC-3324.3(c) is

$$
\begin{aligned}
t & =\frac{P R_{o}}{S+0.4 P}=\frac{P(r+t)}{S+0.4 P} \\
& =\frac{P r}{S-0.6 P}
\end{aligned}
$$

and the $t / r$ ratio is

$$
\frac{t}{r}=\frac{P}{S-0.6 P}
$$

where

$$
\begin{aligned}
\mathbf{R}_{\mathbf{0}} & =\text { outside radius }=\mathrm{r}+\mathrm{t} \text { (in.) } \\
\mathbf{r} & =\text { inside radius } \\
\mathbf{t} & =\text { wall thickness (in.) } \\
\mathbf{P} & =\text { design pressure (psig) } \\
\mathrm{S} & =\text { ASME Code allowable stress. }
\end{aligned}
$$

Ellipsoidal heads: The design thickness of a 2:1 ellipsoidal head from NC-3324.6 of Section III of the ASME Code is calculated by

$t=\frac{P D}{2 S-0.2 P}$.

The thickness-to-inside-radius ratio is

$\frac{t}{r}=\frac{P}{S-0.1 P}$

where

$$
\begin{aligned}
& \mathrm{t}=\text { wall thickness (in.) } \\
& \mathbf{P}=\text { design pressure (psi) } \\
& \mathbf{D}=\text { inside diameter (in.) } \\
& \mathbf{r}=\text { inside radius (in.) }
\end{aligned}
$$


S = ASME Section III, Appendix I allowable stress (psi).

Toriapherical heads: The design thickness of a torispherical head with a hemispherical crown and a knuckle radius that is $6 \%$ of the crown radius (NC-3324.8 of Section III of the ASME Code) is calculated by

$t=\frac{0.885 P L}{S-0.1 P}$

where

$$
\begin{aligned}
& \mathrm{t}=\text { wail thickness (in.) } \\
& \mathrm{P} \quad=\text { design pressure (psi) } \\
& \mathrm{L}=\text { hemispherical crown radius (in.) } \\
& \text { S }=\text { ASME Section III, Appendix I } \\
& \text { allowable stress (psi) }
\end{aligned}
$$

and the thickness to hemispherical crown radius ratio is

$\frac{t}{L}=\frac{0.885 P}{S-0.1 P}$.

To provide an example with representative numbers, we can use the dimensions in Figure NC-3324.2-1 of Section III. In this Figure, $\mathrm{L} / \mathrm{r}$ $=1.5 \div 1.75 / 2=1.714$. Then the previous equation becomes

$$
\frac{t}{r}=\frac{1.517 P}{S-0.1 P} .
$$

Hemispherical heads: The design thickness of a hemispherical head with $t / r<0.356$ (NC-3324.7 of Section III of the ASME Code) is calculated by

$$
t=\frac{P L}{2 S-0.2 P}
$$

where

$$
\mathrm{t}=\text { wall thickness (in.) }
$$

$$
\begin{aligned}
& P=\quad \text { design pressure (in.) } \\
& L \quad=\begin{array}{l}
\text { hemispherical radius ( } r \text { in } \\
\text { NUREG/CR-5603 terminology) } \\
\text { (in.) }
\end{array} \\
& S \quad=\quad \begin{array}{l}
\text { ASME Section III, Appendix I } \\
\text { allowable stress (psi) }
\end{array}
\end{aligned}
$$

and the thickness to hemispherical crown radius ratio is

$\frac{t}{r}=\frac{P}{2(S-0.1 P)}$.

4.5.1.2 Cylindrical Shells. Table 22 lists the thickness-to-radius ratios for Type 304 stainless steel cylindrical shells at $350^{\circ} \mathrm{F}$ at various design pressure to operating pressure ratios. Hoop stresses were calculated the same as for piping for BWR and PWR conditions. Survival confidences were calculated using the Tables in Appendix B for plate material.

The hoop stresses and the survival confidences at $10^{-3}$ and $10^{-4}$ failure probability at yield stress are listed in Table 22. Survival probabilities at a pressure ratio of 0.4 (410 psi for BWRs, 894 psi for PWRs) are about 85 to $90 \%$. A pressure ratio of about 0.48 to 0.49 is needed to achieve a survival confidence of $98 \%$ (at $10^{-3}$ failure probability at yield stress), and about 0.45 at $10^{-4}$ failure probability at yield stress. Since there is less metal in heat exchangers than in pipes, a $10^{-4}$ failure probability at yield stress would seem appropriate for the shells. However, like pipes, the shells would be made of plate that would probably be chosen to the nearest $1 / 8$ in. Table 23 shows that for cylindrical shells designed for BWR conditions and constructed of plates where the thickness is divisible by $1 / 8$ in., six of the ten example thickness survival confidences are greater than $98 \%$.

Similar calculations for SA-516 Grade 70 carbon steel shells show that the survival confidences were greater than $99 \%$ for both BWR and PWR conditions.

4.5.1.3 Hemispherical Heads. Comparing Equations 24 and 30, the thickness for the head 
Table 22. Survival confidences for Type 304 stainless steel cylindrical shells at $350^{\circ} \mathrm{F}$.

\begin{tabular}{|c|c|c|c|c|c|c|c|c|}
\hline \multirow[b]{2}{*}{$\begin{array}{c}\text { Pressure } \\
\text { ratio }\end{array}$} & \multicolumn{4}{|c|}{ BWR } & \multicolumn{4}{|c|}{ PWR } \\
\hline & $\mathrm{t} / \mathrm{r}$ & $\begin{array}{c}\text { Hoop } \\
\text { stress } \\
\text { (psi) } \\
\end{array}$ & $\begin{array}{c}\text { Survival } \\
\text { conf. } \\
\left(10^{-3} @\right. \\
\left.\sigma_{y}\right)(\%) \\
\end{array}$ & $\begin{array}{c}\text { Survival } \\
\text { conf. } \\
\left(10^{-4} @\right. \\
\left.\sigma_{\mathrm{y}}\right)(\%) \\
\end{array}$ & $t / r$ & $\begin{array}{c}\text { Hoop } \\
\text { stress } \\
\text { (psi) } \\
\end{array}$ & $\begin{array}{c}\text { Survival } \\
\text { conf. } \\
\left(10^{-3} @\right. \\
\left.\sigma_{\mathrm{y}}\right)(\%) \\
\end{array}$ & $\begin{array}{c}\text { Survival } \\
\text { conf. } \\
\left(10^{-4} @\right. \\
\left.\sigma_{y}\right)(\%) \\
\end{array}$ \\
\hline 0.40 & 0.02538 & 40385 & 86.5 & 90.8 & 0.05635 & 39659 & 88.4 & 92.5 \\
\hline 0.41 & 0.02603 & 39385 & 89.0 & 93.0 & 0.05781 & 38659 & 90.7 & 94.4 \\
\hline 0.42 & 0.02667 & 38433 & 91.2 & 94.8 & 0.05927 & 37707 & 92.6 & 96.7 \\
\hline 0.43 & 0.02732 & 37525 & 92.9 & 96.2 & 0.06074 & 36799 & 94.1 & 97.1 \\
\hline 0.44 & 0.02796 & 36658 & 94.4 & 97.2 & 0.06220 & 35932 & 95.4 & 97.8 \\
\hline 0.45 & 0.02861 & 35829 & 95.5 & 98.0 & 0.06367 & 35103 & 96.4 & 98.5 \\
\hline 0.46 & 0.02925 & 35037 & 96.5 & 98.5 & 0.06514 & 34311 & 97.2 & 98.9 \\
\hline 0.47 & 0.02990 & 34279 & 97.2 & 98.9 & 0.06661 & 33553 & 97.8 & 99.2 \\
\hline 0.48 & 0.03055 & 33552 & 97.8 & 99.2 & 0.06809 & 32826 & 98.3 & 99.5 \\
\hline 0.49 & 0.03120 & 32854 & 98.3 & 99.5 & 0.06956 & 32128 & 98.7 & 99.6 \\
\hline 0.50 & 0.03185 & 32185 & 98.7 & 99.7 & 0.07104 & 31459 & 99.0 & 99.7 \\
\hline
\end{tabular}

Table 23. Survival confidences for Type 304 stainless steel shells at BWR conditions constructed of plates of thicknesses divisible by $1 / 8$ in.

\begin{tabular}{ccccccc}
\hline Radius & ASME & $\begin{array}{c}\text { Rounded } \mathrm{t} \\
\text { (in.) }\end{array}$ & $\begin{array}{c}\text { Hoop } \text { (in.) } \\
\text { (in.) }\end{array}$ & $\begin{array}{c}\text { t/r } \\
\text { stress } \\
(\mathrm{psi})\end{array}$ & $\begin{array}{c}\text { Survival } \\
\text { confidence } \\
\left(10^{-3} @\right. \\
\left.\sigma_{\mathrm{y}}\right)(\%)\end{array}$ & $\begin{array}{c}\text { Survival } \\
\text { confidence } \\
\left(10^{-4} @\right.\end{array}$ \\
\hline 6 & 0.1523 & 0.250 & 0.04167 & 24600 & 99.9 & 99.9 \\
$\left.\sigma_{\mathrm{y}}\right)(\%)$
\end{tabular}


needs to be only about half of that of the cylindrical shell $(P \ll S)$. Therefore for cylindrical shells and heads of nearly equal thickness, failure is controlled by burst of the cylindrical shell.

\subsubsection{Torispherical Heads. NUREG/} CR-5603 discusses two failure modes for dished heads: plastic collapse and knuckle buckling. For dished heads with low r/t ratios, Galletly and Aylward (1979) determined that head failure will occur because of plastic collapse rather than knuckle buckling. Galletly has defined plastic collapse as the pressure where the deflection of the crown is twice the deflection that occurs at a pressure when the material yields. This is the approach used in Appendix II (II-1430) of Section III of the ASME Code. Formulas for head collapse are also found in Langer (1964) and Shield and Drucker (1961), as mentioned in Attachment 1. However, plastic collapse by itself does not represent a failure of the head where coolant would be released, only that a certain strain level has been reached, or a lower-bound plastic hinge will form. Bennett (1987) has tested torispherical heads modeling nuclear reactor containments, and found that failure occurs first by the occurrence of knuckling buckling, and later at a higher pressure 2.4 to 3.7 times the buckling pressure. No mention is made of plastic collapse. Therefore, for design considerations for ISLOCA, plastic collapse will not be considered as a credible failure mode.

The $r / t$ ratios for vessels designed to ISLOCA pressures are lower (less than 100) than would normally be the case in existing LWRs, that is, the vessels would be thicker. Consequently, the $r / t$ ratios are lower than those used by researchers such as Radhamoham and Galletly (1979), where the $r / t$ ratios were of the order of 600 to 1500 , and Bennett (1987) where the $r / t$ ratios were of the order of 700 to 900 . In Attachment 2, Rodabaugh states that low design pressures for vessels designed to ISLOCA pressures using formulas in NUREG/CR-5603 (from Galletly) or in Langer result either from using the formulas outside their intended $r / t$ range, or from the conservatism in collapse criteria. The author believes that the latter reason causes the extreme conservatism. The
Shield and Drucker (1961) r/t ratios go as low as 71 .

Vessels designed for the higher ISLOCA pressures should be more immune to collapse. As Shield and Drucker state, "A thin-walled sharply curved knuckle region is far weaker than the main part of the spherical cap or the cylindrical portion of the vessel. On the other hand, if the torus wall is not so thin compared with the knuckle radius, the knuckle region is stiff and strong and acts somewhat like a stiffening ring at the junction of a spherical cap and cylinder. The ASME Code... apparently contains the implicit assumption that ordinarily the resistance to inward motion of the knuckl: region is adequately high. Although true for vessels designed to carry large pressure, the assumption is not valid for many storage vessels and other low-pressure containers."

NUREG/CR-5603 recommends increasing the analytically computed pressures by a factor of 1.78 (based on limited experimental data) to determine the expected mean capacities. Bennett (1987) reports a rupture pressure of 2.7 to 3.4 times the buckling pressure calculated using the BOSOR-5 Code. The NUREG/CR-5603 approach was followed in this report.

Bennett (1987) states that based on his experiments, "no truly conservative, and accurate equation has been found to predict the results of these fabricated shell experiments at this time. ... For margin-to-buckling studies, where actual containment geometry is known, a BOSOR-5 analysis or the Galletly formula using the 'worst meridian' will provide a good estimate of the buckling pressure." Consequently, the calculations in this report use the Galletly equations.

The Galletly equation for buckling of a torispherical head is

$$
P_{c r}=\frac{285 \sigma_{y}\left(1-125 \frac{\sigma_{y}}{E}\right)\left(\frac{r_{n}}{D}\right)^{0.84}}{\left(\frac{D}{t}\right)^{1.53}\left(\frac{L}{D}\right)^{1.1}}
$$

where

$$
\sigma_{y} \quad=\text { yield stress }
$$




$$
\begin{array}{ll}
\mathrm{E} & =\text { elastic modulus } \\
\mathrm{r}_{\mathrm{n}} & =\text { knuckle (torus) radius } \\
\mathrm{D} & =\text { cylinder diameter } \\
\mathrm{t} & =\text { head thickness } \\
\mathrm{L} & =\text { crown (hemispherical) radius. }
\end{array}
$$

To provide an example with representative numbers, we can use the dimensions in Figure NC-3324.2-1 of Section III, where L/D $=1.5 \div$ $1.75 / 2 \div 2=0.857$, and a knuckle radius of 0.06 of the crown radius. The results (using $\beta=0.224$ for stainless steel and 0.245 for carbon steel) are shown in Table 24. The 99\% buckling pressures are all above the ISLOCA pressure, even without applying the 1.78 factor to compute the failure pressure.

4.5.1.5 Ellipsoldal Heads. The formula for knuckle bucking from Galletly and Aylward (1979) is

$$
P_{c r}=\frac{10.4 S_{y}}{\left(\frac{D}{t}\right)^{1.25}} \text { for } 600<\frac{D}{t}<1500
$$

Calculational results are shown in Table 25 . The buckling pressures $\mathrm{p}_{\mathrm{cr}}$ were multiplied by 1.78 to obtain the estimated failure pressure, and from these the $99 \%$ survival confidence pressures were calculated. These all were above the ISLOCA pressures. However, it is assumed in NUREG/CR-5603 that in 20\% of buckling cases, a crack will develop at $P_{c r}$. For the case with the least margin, Type 304 stainless steel at BWR conditions, the survival confidence at $1025 \mathrm{psi}$ is $73.6 \%$. If failure occurs during $20 \%$ of the $26.4 \%$ of the cases where buckling occurs at 1025 psig, then failure (rupture) will occur only $5.3 \%$ of the time, and the overall survival confidence is $94.7 \%$. For the three other cases, the survival confidence is greater than $98 \%$. Since there will be

\begin{tabular}{|c|c|c|c|c|}
\hline & \multicolumn{2}{|c|}{ Type 304 plate } & \multicolumn{2}{|c|}{ SA-516 Grade 70} \\
\hline & BWR & PWR & BWR & PWR \\
\hline$t / r$ & 0.03802 & 0.08315 & 0.03562 & 0.07789 \\
\hline$r / D$ & 0.07 & 0.07 & 0.07 & 0.07 \\
\hline$D / t$ & 52.6 & 24.05 & 56114 & 25.68 \\
\hline $\mathrm{L} / \mathrm{D}$ & 0.86 & 0.86 & 0.86 & 0.86 \\
\hline$r / L$ & 0.06 & 0.06 & 0.06 & 0.06 \\
\hline$S_{y}(p s i)$ & 26,830 & 26,830 & 37,990 & 37,990 \\
\hline$E(p s i)$ & $26,800,000$ & $26,800,000$ & $28,000,000$ & $28,000,000$ \\
\hline $\mathrm{P}_{\mathrm{cr}}(\mathrm{psi})$ & 1925 & 6373 & 2342 & 7751 \\
\hline $\begin{array}{l}99 \% \text { buckling } \\
\text { confidence (psi) }\end{array}$ & 1143 & 3784 & 1391 & 4603 \\
\hline
\end{tabular}
some margin based on fabricating the head from plate that is made in 1/8-in. increments, the confidence will no doubt be greater than $98 \%$ for actual heads.

Table 24. Knuckle buckling pressures for torispherical heads at $350^{\circ} \mathrm{F}$. 
Component Evaluations

Table 25. Survival confidences for ellipsoidal heads at $350^{\circ} \mathrm{F}$.

\begin{tabular}{lccccc}
\hline & \multicolumn{2}{c}{ Type 304 plate } & & \multicolumn{2}{c}{ SA 516 Grade 70 } \\
\cline { 2 - 3 } \cline { 5 - 6 } & BWR & PWR & & BWR & PWR \\
\cline { 2 - 3 } $\mathrm{t} / \mathrm{r}$ & 0.02506 & 0.05481 & & 0.02348 & 0.05135 \\
$\mathrm{D} / \mathrm{t}$ & 79.80 & 36.49 & & 85.17 & 38.95 \\
$\mathrm{P}_{\mathrm{cr}}(\mathrm{psi})$ & 1169 & 3111 & & 1527 & 4060 \\
$1.78 \mathrm{P}_{\mathrm{cr}}$ (psi) & 2082 & 5538 & & 2718 & 7228 \\
$99 \%$ survival confidence (psi) & 1237 & 3289 & & 1614 & 4292 \\
\hline
\end{tabular}

4.5.2 Tubes. Heat exchanger tubes have the same basic geometry as pipes, that is, long circular cylinders. The requirements of pipe design are solely to sustain the internal pressure without degrading over time, and if a pipe is selected whose walls are thicker than the minimum required for the design pressure, the only drawback is the added weight and cost. However, the thermal designer desires that heat exchanger tubes be sufficiently thin to maximize heat transfer between the fluids on either side of the tubes. Thus, we might not expect large wall thickness increases over the minimum required thickness in order to reach a standard schedule as we did in the case of pipes. Furthermore, the thermal designer does not want the added thickness associated with the corrosion allowance of carbon steel tubes, so stainless steel will be assumed as the tube material for ISLOCA design.

Tubes are generally specified with a minimum thickness, and the manufacturer typically makes them slightly thicker than the minimum so that if the manufacturing process diverges slightly from the prescribed settings and the walls deviate slightly thinner, no tubes will have to be scrapped. Consequently, while the tubes may be slightly thicker than required, it appears valid for ISLOCA design purposes to assume that they will be the minimum required thickness.

The survival confidences for heat exchanger tubes can be calculated the same as for pipes.
Using the methodology for piping, the minimum survival confidences for heat exchanger tubes subject to internal pressure designed to $40 \%$ primary coolant pressure at $350^{\circ} \mathrm{F}$ are $90 \%$ for Type 304 stainless steel. However, if the minimum tube thicknesses specified in the TEMA standards are used, the minimum survival confidences for tubes up to 2 in. (under internal pressure) are higher, as shown in Tables 26 and 27. A corrosion allowance of $0.004 \mathrm{in}$. for BWRs and $0.003 \mathrm{in}$. for PWRs was used. Tubes with wall thicknesses made according to TEMA standards would have greater than $99.9 \%$ survival confidence at BWR pressures, and also for PWR pressures, with the exception of $1-$ and 1-1/4-in. tubes. The 1-in., 20 -gage tube has a survival confidence of $97.4 \%$, but the 1-1/4-in., 20-gage tube has only an $88.2 \%$ survival confidence. A 1-1/4-in., 18-gage tube has a survival confidence of greater than $99 \%$.

4.5.3 Tubesheets. Since tubesheets are basically flat plates, their primary failure modes would be from shear or bending, not from bursting, as in the case of piping. The bending and shear stresses are related to the tube hole pattern, and, therefore, are tubesheet dependent. Formulas (both bending and shear) for the minimum design thickness of tubesheets, based on the type of construction, are given in the TEMA standards.

The major concern with tubesheets is leakage at flanged joints. The recommendations on Class 


\section{Component Evaluations}

Table 26. Survival confidences for Type 304 BWR heat exchanger tubes subject to internal pressure designed to TEMA standards.

\begin{tabular}{ccccc}
\hline $\begin{array}{c}\text { Diameter } \\
\text { (in.) }\end{array}$ & Gage & $\begin{array}{c}\text { Thickness } \\
\text { (in.) }\end{array}$ & $\begin{array}{c}\text { Hoop stress } \\
\text { (psi) }\end{array}$ & $\begin{array}{c}\text { Survival confidence } \\
(\%)\end{array}$ \\
\hline $1 / 4$ & 27 & 0.016 & 9652 & 99.9 \\
$3 / 8$ & 24 & 0.022 & 9652 & 99.9 \\
$1 / 2$ & 22 & 0.028 & 9652 & 99.9 \\
$5 / 8$ & 20 & 0.035 & 9473 & 99.9 \\
$3 / 4$ & 20 & 0.035 & 11374 & 99.9 \\
1 & 20 & 0.035 & 11507 & 99.9 \\
$1-1 / 4$ & 20 & 0.035 & 19640 & 99.9 \\
$1-1 / 2$ & 16 & 0.065 & 11577 & 99.9 \\
2 & 14 & 0.083 & 11950 & 99.9 \\
\hline
\end{tabular}

Table 27. Survival confidences for Type 304 PWR heat exchanger tubes subject to internal pressure designed to TEMA standards.

\begin{tabular}{ccccc}
\hline $\begin{array}{c}\text { Diameter } \\
\text { (in.) }\end{array}$ & Gage & $\begin{array}{c}\text { Thickness } \\
\text { (in.) }\end{array}$ & $\begin{array}{c}\text { Hoop stress } \\
\text { (psi) }\end{array}$ & $\begin{array}{c}\text { Survival confidence } \\
(\%)\end{array}$ \\
\hline $1 / 4$ & 27 & 0.016 & 19255 & 99.9 \\
$3 / 8$ & 24 & 0.022 & 19820 & 99.9 \\
$1 / 2$ & 22 & 0.028 & 20115 & 99.9 \\
$5 / 8$ & 20 & 0.035 & 19940 & 99.9 \\
$3 / 4$ & 20 & 0.035 & 23956 & 99.9 \\
1 & 20 & 0.035 & 32687 & 97.5 \\
$1-1 / 4$ & 20 & 0.035 & 41417 & 79.7 \\
$1-1 / 4$ & 18 & 0.049 & 28132 & 99.6 \\
$1-1 / 2$ & 16 & 0.065 & 24801 & 99.9 \\
2 & 14 & 0.083 & 25703 & 99.9 \\
\hline
\end{tabular}

sizes and bolt preloads made for flanges also are applicable for tubesheet flanges

\subsection{Tanks}

In most if not all cases, it will probably prove impractical to design large tanks for ISLOCA pressures. Should there be cases in which tanks are designed for ISLOCA conditions, the formulas and method for vessels in Section 4.5 can be used. These show that for the cylindrical portion of the shell, a pressure ratio of between 0.45 and 0.50 is required to meet ISLOCA confidence limits for Type 304 stainless steel. A pressure ratio of 0.40 will provide $99 \%$ survival confidence for SA-516 Grade 70 carbon steel. 


\section{CONCLUSIONS AND RECOMMENDATIONS}

The NUREG/CR-5603 methodology for system rupture survival during an ISLOCA event has been applied to ALWR plants. Conditions of $350^{\circ} \mathrm{F}$ and BWR pressures of 1025 psig and PWR pressures of $2235 \mathrm{psig}$ were used. This report presents criteria such that each of the types of components in the system will achieve about a 98\% survival confidence, so that the overall system survival confidence will be about $90 \%$.

The confidence limits were determined by developing stress failure curves that used a failure stress, defined as 0.9 and 0.85 times the median ultimate tensile strength for carbon and stainless steel, respectively, as the median failure stress. The uncertainty was determined by selecting the 0.001 confidence failure stress as the median yield stress. This assumption in establishing the uncertainty is based on the probability of a large crack existing in the metal, either induced during manufacture or in operation, and is the source of several comments in the peer review panel report. There does not appear to be a straightforward way to establish the uncertainty. An alternate approach considers the operating experience in nuclear components that have been designed and operated according to the ASME Code. The alternate method of developing an uncertainty for the failure curves leads to basically the same conclusion as does the method in NUREG/CR-5603, that is, the minimum system survival confidence at 2.5 times the Level A design stress is greater than $90 \%$. This argument is based on actual operating data, and shows a better balance between the carbon and stainless steel survival probabilities than does the NUREG/CR-5603 method.

Available yield stress and ultimate tensile strength data were used to better define the material properties than the values used in NUREG/CR-5603. It is concluded that the NUREG/CR-5603 values are representative for SA-106 Grade B carbon steel, but alternate curves were developed and used in this report for stainless steels and SA-516 Grade 70 carbon steel.

A pressure ratio of 0.4 (the design pressure divided by the operating pressure) was investi- gated. The conclusions are that this pressure ratio is a suitable value for most cases. The recommended sizes for components are as follows:

- $\quad$ Pipe and pipe fittings

BWR-STD for all materials

PWR - STD up to 10 in. for all materials

SA-106 Grade B-12 in., STD; 14, 16, 20 in., Sch. $40 ; 18$ in., XS

Type $316-12$ in., Sch. 40 ; 14 to 20 in., Sch. 60

Type $304-12$ and 14 in., XS; 16 to 20 in., Sch. 60

- $\quad$ Flanges

BWR-Class 300

PWR-Class 600

Bolts-High strength with $40 \mathrm{ksi}$ preload

- $\quad$ Valves

BWR-Class 300

PWR-Class 600

- Pumps

Design for 0.4 pressure ratio

Seals-Need not design for ISLOCA but allow minimal leakage

- Heat exchangers

Cylindrical shell-Design for pressure ratio of 0.40 (SA-516 Grade 70 carbon steel), 0.45 (Type 304 stainless steel) ${ }^{\mathrm{f}}$

Heads-Design for 0.4 pressure ratio Tubes and tubesheets-Design to TEMA standards except 20 gage for 1 -in. and 18 gage for 1-1/4-in. tubes PWR.

These recommendations will satisfy the goal of $90 \%$ confidence that gross leakage will not occur to the system during an ISLOCA, but the scope of this project did not include any evaluations to assure that components such as pumps and valves will remain operable during, or fit for service after, an ISLOCA event.

f. Based on $10^{-4}$ survival confidence at yield stress. 


\section{REFERENCES}

Allegheny Ludlum (Allegheny Ludlum Steel Corporation), 1958, “Allegheny Metal 18-8," Allegheny Ludlum Blue Sheet, Pittsburgh, Pennsylvania.

ASME, 1992a, Boiler and Pressure Vessel Code, Section II (Materials), Part D-Properties, American Society of Mechanical Engineers, New York.

ASME, 1992b, Boiler and Pressure Vessel Code, Section III, Division 1, Subsection NC and Appendix I, American Society of Mechanical Engineers, New York.

ASME, 1992, Boiler and Pressure Vessel Code, Section III, Division 1, Appendix XI, American Society of Mechanical Engineers, Rules for Bolted Flange Connections for Class 2 and 3 Components and Class MC Vessels, New York.

ASME, 1988, Pipe Flanges and Flanged Fittings, B16.5, American Society of Mechanical Engineers, New York.

ASME, 1981, Valves_Flanged and Buttwelding End, B16.34, American Society of Mechanical Engineers, New York.

ASME, 1985a, Welded and Seamless Wrought Steel Pipe, ANSI B36.10M-1985, The American Society of Mechanical Engineers, New York.

ASME, 1985b, Stainless Steel Pipe, ANSI B36.19M-1985, The American Society of Mechanical Engineers, New York.

ASTM, 1982, Annual Book of ASTM Standards, Part 1, Steel-Piping, Tubing Fittings, American Society for Testing Materials, New York.

Bamford, W. H., and S. A. Swamy, 1984, "The Case for Eliminating Instantaneous Pipe Break as a Design Basis for Westinghouse Main Coolant Piping," Proceedings of the CSNI Specialist Meeting on LeakBefore-Break in Nuclear Reactor Piping, NUREG/CP-0051, pp. 56-125.

Bennett, J. G., 1987, An Assessment of Loss-of-Containment Potential Because of Knuckle Buckling for 4:1 Steel Containment Heads, NUREG/CR-4926, LA-10972-MS.

Boyer, H. E., 1987, Atlas of Stress-Strain Curves, American Society for Metals International, Metals Park, Ohio.

Brown, W. F., et al., 1992, Aerospace Structural Metals Hardbook, CINDAS/Purdue University, Hammond, Indiana.

Chopra, O. K., et al., 1991, Long-Term Embrittlement of Cast Duplex Stainless Steels in LWR Systems, NUREG/CR-4744, Volume 4, Number 2.

Chu, T.-L., et al., 1989, Interfacing Systems LOCA: Boiling Water Reactors, NUREG/CR-5124, BNL-NUREG-52141.

Galletly, G. D., and R. W. Aylward, 1979, "Plastic Collapse and the Controlling Failure Pressures of Thin 2:1 Ellipsoidal Shells Subjected to Internal Pressure," Journal of Pressure Vessel Technology 101, pp. 64-72. 
References

Galyean, W. J., et al., 1993, ISLOCA Research Program Final Report, NUREG/CR-5928, EGG-2685.

Harvey, P. D., Editor, 1985, Engineering Properties of Steel, American Society for Metals, Metals Park, Ohio.

Hays, R. A., et al., (1986), Fracture Analysis of Welded Type 304 Stainless Steel Pipe, NUREG/CR-4538, Volume 1.

Hiser, A. L., 1989, Fracture Toughness Characterization of Nuclear Piping Steels, NUREG/CR-5188.

Hiser, A. L., 1988, Tensile and J-R Curve Characterization of Thermally Aged Stainless Steels, NUREG/CR-2229.

Inside NRC, 1993, "French, German Safety Officials Set Common Goals for Advanced PWR," Inside NRC 15,15 , July 26 , pp. 1, 14-16.

Kanninen, M. F., et al., 1976, Mechanical Fracture Predictions for Sensitized Stainless Steel Piping with Circumferential Cracks, EPRI NP-192, Electric Power Research Institute, Palo Alto.

Kanninen, M. F., et al., 1982, Instability Predictions for Circumferentially Cracked Type 304 Stainless Steel Pipes under Dynamic Loadings, EPRI NP-2347, Electric Power Research Institute, Palo Alto.

Langer, B. F., 1964, PVRC Interpretive Report of Pressure Vessel Research, Section 1-Design Considerations, Bulletin 95, Welding Research Council, New York.

Manjoine, M. H., 1975, "Ductility Indices at Elevated Temperature," Journal of Engineering Materials and Technology 97, Series H, Number 2, pp. 156-161.

NRC, 1990, Evolutionary Light Water Reactor (LWR) Certification Issues and Their Relationship to Current Regulatory Requirements, SECY-90-016, United States Nuclear Regulatory Commission.

ORNL, 1988, Nuclear Systems Materials Handbook, Volume 1 Design Data, TID 26666, 37th Revision, Oak Ridge National Laboratory.

Public Service Electric \& Gas, Hope Creek Generating Station Final Safety Analysis Report, Section 5.4.

Radhamoham, S. K., and G D. Galletly, 1979, "Plastic Collapse of Thin Internally Pressurized Torispherical Shelis," Journal of Pressure Vessel Technology 101, pp. 311-320.

Rodabaugh, E. C., and Desai, K. D., 1980, Realistic Seismic Design Margins of Pumps, Valves, and Piping, NUREG/CR-2137, ORNL/Sub-2913/11.

Ruger, C. J., and W. L. Luckas, Jr., 1989, Technical Findings Related to Generic Issue 23: Reactor Coolant Pump Seal Failure, NUREG/CR-4948, BNL-NUREG-52144.

Schlünder, E. U.,1989, Heat Exchanger Design Handbook, Volume 4, "Mechanical Design of Heat Exchangers," Hemisphere Publishing Corporation, New York.

Shield, R. T., and D. C. Drucker, 1961, "Design of Thin-Walled Torispherical and Toriconical PressureVessel Heads," Journal of Applied Mechanics, pp. 292-297.

Simmons, W. F., and J. A. Van Echo, 1965, Report on the Elevated-Temperature Properties of Stainless Steels, ASTM Data Series Publication DS 5-S1 (Supplement to Publication DS 5, formerly STP 124), American Society for Testing Materials, Philadelphia. 
Simmons, W. F., and H. C. Cross, 1955, Elevated-Temperature Properties of Carbon Steels, ASTM Special Publication No. 180, American Society for Testing Materials, Philadelphia.

Simmons, W. F., and H. C. Cross, 1952, Elevated-Temperature Properties of Stainless Steels, ASTM Special Publication No. 124, American Society for Testing Materials, Philadelphia.

Smith, G. V., 1969, An Evaluation of the Yield, Tensile, Creep, and Rupture Strengths of Wrought 304, 316 , 321, and 347 Stainless Steels at Elevated Temperatures, ASTM Data Series DS 5-S2 (Supplement to Publication DS 5, formerly STP 124), American Society for Testing Materials, Philadelphia.

Smith, G. V., 1972, Elevated Temperature Static Properties of Wrought Carbon Steel, ASTM Special Technical Publication 503, American Society for Testing Materials, Philadelphia.

The Timken Roller Bearing Company, 1962, Résumé of Investigations on Steels for High Temperature High Pressure Applications 1960-1962, Canton, Ohio.

TEMA, 1982, Standards of Tubular Exchanger Manufacturers Association, Tubular Exchanger Manufacturers Association, Inc., New York.

Weiss, V., and J. G. Sessler, Editors, 1963, Aerospace Structural Metals Handbook, Volume 1: Ferrous Alloys, ASD-TDR-67-741, Air Force Materials Laboratory, Wright-Patterson Air Force Base, Ohio.

Wesley, D. A., et al., 1990, Pressure-Dependent Fragilities for Piping Components, NUREG/CR-5603, EGG-2607.

Wesley, D. A., 1992, Screening Methods for Developing Internal Pressure Capacities for Components in Systems Interfacing with Nuclear Power Plant Reactor Coolant Systems, NUREG/CR-5862, EGG-2673.

Westinghouse Electric Corporation, 1993, Response to Question 440.30, NRC Request for Additional Information, AP600.

Wilkowski, G. M., 1984, "Margins of Safety Based on Circumferentially Cracked Depth Using the Net-section Collapse Analysis," Proceedings of the CSNI Specialist Meeting on Leak-Before-Break in Nuclear Reactor Piping, NUREG/CP-0051, pp. 204-263.

Wilkowski, G. M., et al., 1989, Degraded Piping Program-Phase II, NUREG/CR-4082, BMI-2120, Volume 8.

Yahr, G. T., 1985, "Preloading of Bolted Connections in Nuclear Reactor Components," Section 2.2 of Pressure Vessel and Piping Technology-1985-A Decade of Progress, American Society of Mechanical Engineers, New York.

Yawaga, G., et al., 1984, "Stable and Unstable Growths of Circumferential Cracks in Type 304 Stainless Steel Pipes under Tensile and Thermal Loading," Proceedings of the CSNI Specialist Meeting on LeakBefore-Break in Nuclear Reactor Piping, NUREG/CP-0051, pp. 56-125. 
Peer Review Panel Report

\title{
The ALWR ISLOCA Evaluation Criteria
}

\author{
D. F. Landers
}

E. C. Rodabaugh

D. A. Wesley

July 19, 1993 
Attachment 1

TABLE OF CONTENTS

Page

1.0 INTRODUCTION . . . . . . . . . . . . . . . . A-5

2.0 BACKGROUND ........................ A-6

3.0 BASIS FOR REVIEW ..................... A-7

4.0 EVALUATION CRITERIA . . . . . . . . . . . . . . A-8

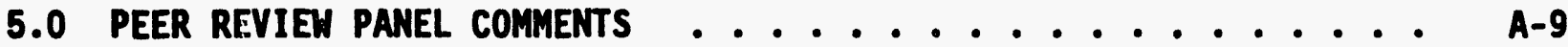

5.1 General Comments ................. A-9

5.2 Specific Comments on Technical Approach ......... A-9

5.3 Comments on NUREG/CR-5862 (Reference 1) ......... A-12

6.0 sumMary ........................ A-16

7.0 REFERENCES ....................... A-17

APPENDIX A - Significance of $P_{f}(f)=0.001$ at Sy
by E. C. Rodabaugh . . . . . . . . . . . . . A-19

APPENDIX B - Conservatism of the Median Burst . . . . . . . . A-25 Pressure for Straight Pipe by E. C. Rodabaugh

APPENDIX C - Torispherical Head . . . . . . . . . . . . . by E. C. Rodabaugh

APPENDIX D - Comments on ALWR ISLOCA Evaluation Criteria by D. A. Wesley ............. A-37 
Attachment 1

\subsection{INTRODUCTION}

The United States Nuclear Regulatory Commission staff (NRC) recommended to the Commissioners that future evolutionary Advanced Light Water Reactor (ALWR) designs reduce the possibility of a loss-of-coolant accident outside containment (ISLOCA) by designing, to the extent practicable, all systems and subsystems connected to the reactor coolant system (RCS) to an ultimate rupture strength at least equal to the full RCS pressure. The Division of Engineering, Office of Nuclear Regulatory Research (RES), working with Idaho Nuclear Engineering Laboratory (INEL), has developed evaluation criteria for addressing this issue and established a peer review panel to obtain third party input on the INEL assumptions, results and conclusions. This report provides the results of the review conducted by the peer review panel. 
Attachment 1

\subsection{BACKGROUND}

The basic goal of the NRC was to have ALWR design agents evaluate systems connected to the RCS to demonstrate that the probability of failure (burst or gross leak), is not more than 0.10 . This could be accomplished by assigning this failure probability as a goal and allowing each applicant to submit, for review, their method of compliance. However, in the spirit of standardization and in order to reduce the cost and time that would be required for the review process, NRC RES has developed a draft evaluation criteria that provides guidance to applicants on acceptable - to - NRC methods for satisfying the failure probability goal. This draft evaluation criteria is contained in NUREG/CR-5862, NUREG/CR-5603 and six INEL letter reports (References 1 through 7 ). These documents provide the basis for the review conducted by the peer review panel and the comments and conclusions contained in this report. 


\subsection{BASIS FOR REVIEY}

Dr. John $0^{\prime} B$ rien, NRC RES provided specific ground rules to the peer review panel with respect to our efforts. These are provided below:

\subsection{ISLOCA Pressures}

(a) 1025 psi for Boiling Water Reactors (BWR)

(b) 2235 psi for Pressurized Water Reactors (PWR)

\subsection{ISLOCA Temperatures}

(a) $350^{\circ} \mathrm{F}$ for both BWR and PWR

\subsection{Gross Leak Rate}

(a) Approximately 200 gallons per minute, anything less than 200 GPM is not a concern.

\subsection{Minimum Thickness $\left(t_{m}\right)$ Assumptions}

(a) Corrosion allowance is not included

(b) Manufacturing tolerances are not considered 
Attachment 1

\subsection{EYALUATION CRITERIA}

The NRC RES evaluation criteria provided in Reference 2 , is quite simple and can be summarized as follows:

Systems containing components (piping, pumps, valves, tanks, heat exchangers, etc.) subjected to the ISLOCA event satisfy the goal of having a failure probability of 0.10 or less if the component wall thickness, using ASME Section III Code Class 2 allowable stress, is based on a design pressure equal to 0.4 times the ISLOCA pressure (410 psi for BWR and 894 psi for PWR).

This simple evaluation criteria is based on the reports reviewed by the peer review panel which contain a significant amount of background documentation. 
Attachment 1

\subsection{PEER REYIFI PANEL COMMENTS}

Following are the comments of the peer review panel.

\subsection{General Comments}

(1) It is difficult to follow the overall approach utilized since details for understanding one document are provided in another without reference.

(2) The goal, as stated above, is related to system failure probabilities, however, the evaluation addresses components. One can deduce that it may be necessary to have a component probability of failure of 0.01 in order to satisfy the system goal of 0.1. If this is the case, it should be explicitly defined and the correlation explained.

(3) The evaluation criteria as expressed in Section 4.0 above is exclusive of the amount of piping or number of components. Based on this, a system with 20 feet of pipe, 1 valve and 4 pipe fittings is as acceptable as a system with 200 feet of pipe, 3 valves and 20 pipe fittings. Engineering judgement (and PRA) would suggest this is not true. The reports should address this issue and based on further peer review comments, a case may be made that sufficient conservatism exists to cover such anomalies. The same anomaly applies to tanks or vessels, size and the number of welds do not change the failure probability.

\subsection{Specific Comments on Technical Approach}

(1) While Reference 1 does not say so, the results in the section on Pipe are based on Beta established by assuming 
Attachment 1

that $\operatorname{Pr}(f)$ at $S y=0.001$ as described in Reference 2 . This, of course, is a very significant assumption and the choice of 0.001 is not adequately explained or defended.

From the data provided in Table 3 of Reference 7 , it is apparent that the probability of having A106-B material with UTS equal to Sy is essentially zero. Thus, it follows that assuming that $\operatorname{Pr}(f)$ at $S y=0.001$ implies the presence of some sort of defect in the pipe. From Appendix $A$ of this report, the following specific example is taken. For a straight pipe with a radius of 10 inches and a wall thickness of 0.3 inches an axial crack $1 / 3$ through wall (0.1 inch) must be longer than 8.7 inches for failure to occur when the pressure hoop stress equals Sy.

What is the probability of cracks of the length/depth indicated above being detected by the inspection requirements of Subsection NC and the In-Service inspection requirements of Section XI of the Code? If that question could be answered, a rational basis for the selection of $\operatorname{Pr}(f)$ at Sy would emerge. In addition there is the concern of seamless versus longitudinally welded pipe. The $\operatorname{Pr}(f)$ has been assumed the same for both. Existing experience gained from examination requirements of Section XI indicates little difference should exist. In fact, Section $X I$ has eliminated longitudinal welds from the ISI program except adjacent to butt weids. Finally, the potential of erosion/corrosion effects on carbon steel generate another concern. One can conclude that the selection of sy for determining $\operatorname{Pr}(f)$ includes a number of assumptions and variables and the amount of conservatism inherent in that selection is not apparent. 
(2) Based on the calculations provided in Appendix $B$ of this report, the evaluation criteria can be considered to underestimate the median burst pressure by about 30 percent. However, based on comparison with limited testing of SA-106 Grade B pipe performed by General Electric, the evaluation criteria could be considered appropriate.

(3) There are a number of other variables that are mentioned without assigning any value to them other than for gage length and triaxial stress effects. For these variables, cumulative reduction factors of 10 to 15 percent have been applied to the failure stress. There is some question as to whether or not triaxial stress effects is a variable of concern. Other variables that are not assigned separate reduction factors but are considered as uncertainties used to reduce the failure stress are the existence of large cracks, additional stresses (deadweight and thermal), modeling uncertainties and erosion/corrosion. In addition, the source for material properties used in the evaluation criteria is conservative by 1000 to 7000 psi as compared to ASTM or Battelle data.

(4) Another issue not discussed is pipe fittings. The position of the peer review panel is that fittings purchased to the requirements of ANSI B16.9 may be taken as equal to that of the designated matching straight pipe if the following is satisfied:

(a) Purchase orders for ANSI B16.9 fittings sha11 require evidence from the vendor that paragraph 2.2 of B16.9, as modified by footnote (1) to Table NC-3132-1 of Section III, has been complied with. 
Attachment 1

(5) Although, the peer review panel has a number of questions and concerns on straight pipe we recommend the following lower bound on acceptable pipe wall thickness:

(a) Standard weight for BWR

(b) Extra strong for PWR

\subsection{Comments on NUREG/CR-5862 (Reference 1)}

The following comments are provided using Reference 1 Table of Contents but, as can be seen, are applicable to many of the INEL documents related to the evaluation criteria.

(1) Introduction - Discussion related to some of the variables in Section 5.2 are applicable here.

(2) Section 2, Tanks and Heat Exchangers -

(a) 1st Paragraph - Certainly one would expect large tanks and some heat exchangers to have lower capacities than pipe, valves or flanges. However, small tanks and heat exchanger tubes should have capacities similar to piping and may have higher capacities than longitudinally welded pipe.

(b) 2nd Paragraph - Although higher nozzle loading may occur as a result of increased temperature it should be recognized that the load of concern, thermal expansion, is truly secondary in nature and small deformations relieve the condition. The vessel rules, for conservatism, classify thermal expansion stresses 
in the nozzle as a primary stresses. These loadings should not result in any greater uncertainty in the tank nozzle than they do in the attached pipe.

(c) Section 2.1 - See comment (b) above on nozzle loads.

(d) Section 2.2 - The approach used on torispherical heads is much too conservative. Appendix $C$ of this report provides detail comments and some comparisons between this work and Reference 9. Although the discussion in Appendix $C$ begins with the results presented in Reference 4 , the real concern is with the applicability of Equation (2-2) in this section of the NUREG report. For example, Table 22 of Reference 4 indicates a collapse pressure of $443 \mathrm{psi}$ for the BWR whose ISLOCA pressure (sort of design pressure since the sizing of the vessel is based on this pressure) is 410 psi. Since the relief valve setting would be 1.1 times design pressure $(1.1 \times 410=451 \mathrm{psi})$ the median collapse pressure of 443 psi would be exceeded. Also, hydrostatically testing the vessel at 1.5 times design pressure $(1.5 \times 410=615$ psi $)$ approaches the median collapse pressure at room temperature of $644 \mathrm{psi}$. The collapse pressures cited in Table 2 are too conservative and, as noted by one member of the peer review panel, $P_{0}=443 \mathrm{psi}$ is incredible.

(e) Section 3 - See comments in Section 5.2 (1), 5.2 (2), Appendix $A$ and Appendix $B$. 
(f) Section 4 - The work in this section is to a large degree superseded by Reference 5 . The position of the peer review panel is that ANSI B16.5 flanges be used as follows:

300 Class or higher - BWR

600 Class or higher - PWR

This is essentially in agreement with Reference 5 except we do not share the bolt pre-load concern expressed therein.

(g) Section 5 - The work in this section is superseded by Reference 6 and the peer review panel agrees with these conclusions although for different reasons. ANSI Bl6.34 valves should be used as follows:

300 Class or higher - BWR

600 Class or higher - PWR

This is based on the fact that each value body is hydrostatically tested to the following pressures:

\begin{tabular}{ccccc} 
Class & $\begin{array}{c}\text { Material } \\
\text { Group }\end{array}$ & $\begin{array}{c}\text { Test } \\
\text { Pressure } \\
\text { (PSI) }\end{array}$ & $\begin{array}{c}\text { Primary } \\
\text { Coslant } \\
\text { Pressure } \\
\text { (PSI) }\end{array}$ & $\begin{array}{c}\text { ISLOCA } \\
\text { Evaluation } \\
\text { Pressure } \\
\text { (PSI) }\end{array}$ \\
\cline { 2 - 3 } 300 & 1.1 & 1110 & 1025 & 410 \\
300 & 2.1 & 1080 & 1025 & 410 \\
600 & 1.1 & 2220 & 2235 & 894 \\
600 & 2.1 & 2160 & 2235 & 894
\end{tabular}


(h) Section 6 - Evaluation criteria is not provided. Reference 6 also addresses pumps but the discussion is limited to centrifugal pumps and little guidance is given. The basic conclusion of Reference 6 is that the basic pressure design using evaluation criteria pressures would result in wall thicknesses greater than that for the attached pipe and therefore pump casings are acceptable.

Since close tolerances are required between the casing and the impeller for efficient operation the casings are normally stiffer (thicker) than required for pressure stress. Experience with detailed pump analysis indicates the most highly stressed locations are at the cutwater tip in Type $A$ pumps and in the splitter in Type $C$ pumps neither of which would result in pressure boundary failure. The peer review panel feels that designing centrifugal pump casings to the evaluation criteria pressures is acceptable. However, as Reference 6 points out, seal leakage will occur. ALWR designs must accommodate such leakage to assure that gross leak rate criteria are complied with. With respect to positive - displacement pumps, experience and judgement indicates that these type pumps would have a higher survival rate than centrifugal pumps. One member of the peer review panel suggests shop hydrotesting of all pumps to the RCS pressure. This obviously would demonstrate acceptability.

The general consensus of the panel is that designing to 0.4 time the ISLOCA pressure for pumps should be as acceptable an approach as it is for straight pipe. 
Attachment 1

\subsection{SUMMARY}

The peer review panel is satisfied with the general approach to addressing ISLOCA presented in Reference 1 through 7 . However, a number of areas addressed in the body of ihese reports require better explanation and/or justification. Also the evaluation criteria for torispherical heads, as addressed in References 1 and 3 , is much too conservative and requires a significant amount of additional work.

In addition, the peer review panel has evaluated components not specifically addressed or, in our opinion, inadequately addressed by the reference documents and we are of the opinion that piping systems having components that meet the following minimum have $\operatorname{Pr}\left(n_{f}\right) \geq 0.9$.

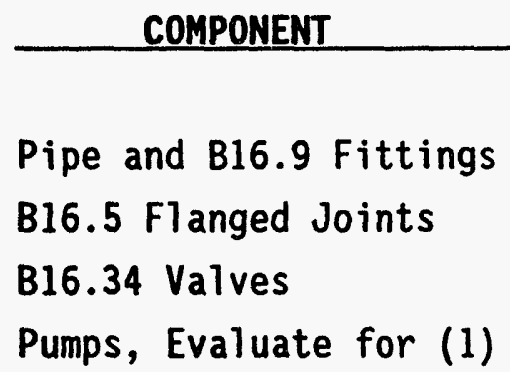

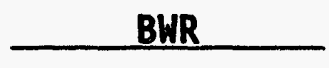

Standard Weight 300 Class 300 Class 410 PSI
PUR

Extra Strong 600 Class 600 Class 894 PSI

\section{(1) Assure Seal Leakage Satisfies Gross Leak Rate.}

One further point not addressed in Reference 1 through 7 is that of component operability. It is the opinion of the peer review panel that the evaluation criteria proposed does not assure the operability of components such as pumps and valves. This is no doubt obvious to all and is not a concern, but it should be addressed in the INEL work. 


\subsection{REFERENCES}

1. D. A. Wesley, Screening Methods for Developing Internal Pressure Capacities for Components in Systems Interfacing with Nuclear Power Plant Reactor Coolant Systems, NUREG/CR-5862, no publishing date.

2. A. G. Ware, and D. A. Wesley, Probabilistic Based Design Rules for Intersystem LOCAS in ABW Piping," no publishing date.

3. A. G. Ware, Survival Confidences for PWR ISLOCA Piping, INEL Letter Report, March 1993.

4. A. G. Ware, Vessel Analysis Using NUREG/CR-5603 and NUREG/CR-5862 Methodology for ISLOCA Design, INEL Letter Report, March 1993.

5. A. G. Ware, Flange Analysis Using NUREG/CR-5603 and NUREG/CR-5862 Methodology for ISLCCA Design, INEL Letter Report, Apri1 1993.

6. A. G. Ware, Pumps, Valve and Heat Exchanger Tube and Tubesheet Evaluation for ISLOCA Design Using NUREG/CR-5603 Methodology, INEL Letter Report, April 1993.

7. A. G. Ware, Comparison of NUREG/CR-5603 and A7ternate Materials Data for Stainless and Carbon Steels, INEL Letter Report, March 1993.

8. D. A. Wesley, T. R. Kipp, D. K. Nakaki, and H. Hadidi-Tamjed, Pressure Dependent Fragilities for Piping Components, NUREG/CR-5603. 
Attachrnent 1

\subsection{REFERENCES (Cont'd)}

9. Welding Research Council Bulletin No. 95 dated April 1964, "PVRC Interpretive Report of Pressure Vessel Research, Section 1 Design Considerations", B. F. Langer. 
Attachment 1

\section{APPENDIX A}

\section{Significance of $P_{r}(f)=0.001$ at $S_{y}$ \\ by}

E. C. Rodabaugh 
While NUREG/CR-5862 does not say so, its results in the section on "Pipe" are based on Beta established by assuming that $\operatorname{Pr}(f)$ at $S y=0.001$. This, of course, is a very significant assumption in calculating $\operatorname{Pr}(\mathrm{nf})$. Reference 2 describes how the Beta's are derived; i.e., by assuming that $\operatorname{Pr}(f)$ at $S y=0.001$. But, to me, the choice of 0.001 is not adequately explained or defended.

Figure 5 of Reference 2 was included as an indication of the sensitivity of the screening method to the selection of $\operatorname{Pr}(f)$ at $S y$. However, the "90\%" line is not correctly shown. The attached Table A shows the results of my sensitivity study for both $\operatorname{Pr}(f)$ at $S y=0.01$ and 0.0001 .

Table $A$, for $\operatorname{Pr}(n f)=0.99$, indicates that the screening method is sensitive by about 30 or $40 \%$ at $400 \mathrm{~F}$. This, I think, is not highly significant relative to the overall precision of the screening method.

By looking at Table 3 of Reference 7 , it is apparent that the probability of having A106-B material with UTS equal to Sy is essentially zero. Thus, it follows that assuming that $\operatorname{Pr}(f)$ at $S y=0.001$ implies the presence of some sort of defect in the pipe.

First, I'11 point out that pipe to A106-B must be shop hydrotested to a pressure of $0.6 *(2 * S y * t / D)$. Such shop tests are NOT sufficient to eliminate pipe with a defect such that it would fail when subjected to a pressure, $P=S y * t / r$.

What size of defect would cause the pipe to fail at $P=S y * t / r$ ? Some indication of the size of axial defect can be obtained from ASME Section $X I, H-5420$. I used the equation with $(S F)=1$ and with $S f(=$ flow stress) $=$ $(\mathrm{Su}+\mathrm{Sy}) / 2=(61.2+36) / 2=48.6 \mathrm{ksi}$. These are from Reference 2 for $\mathrm{A} 106 \mathrm{~B}$ at $100 \mathrm{~F}$. The crack sizes are: 
Attachment 1

\begin{tabular}{ccc}
$t / a$ & \multicolumn{2}{c}{$L / r$ for } \\
& $t / r=0.03 \quad t / r=0.06$ \\
4 & infinity & infinity \\
3 & 0.87 & 1.23 \\
2 & 0.32 & 0.45
\end{tabular}

The values of $t / r=0.03$ and 0.06 are representative of pipe wall thicknesses per NC-3600 for $P d=410$ and 894 , respectively. The results indicate that a crack that is $1 / 4$ through wall will not fail at $P=S y * t / r$. A crack that is $1 / 3$ or $1 / 2$ through wall will fail only if the crack length exceeds the $L / r$ indicated; $L=$ crack length.

As a specific example, consider a pipe with $r=10$ inch, $t=0.03 * 10$ $=0.3$ inch. A crack of depth 0.10 inch must be longer then $0.87 * 10=8.7$ inch for failure to occur at $P=S y * t / r$.

An obvious question is: What is the probability of cracks of the length/depth indicated above being detected by the inspection requirements of Subsection NC of the Code? If that question could be answered, a rational basis for the selection of $\operatorname{Pr}(f)$ at Sy would emerge.

There is a conceptual problem for me in that $A 106-B$ is seamless pipe; Type 304 may be seamless or longitudinally welded. Conceptlially, if I thought $\operatorname{Pr}(f)$ at $S y=0.001$ was appropriate for longitudinally welded pipe, I would tend use something like $\operatorname{Pr}(f)$ at $S y=0.0001$ for seamless pipe.

But, there are other considerations related to in-service inspection and the potential of corrosion/erosion of carbon steel pipe. There is a lot buried in the selection of $\operatorname{Pr}(f)$ at $S y$. 
Attachment 1

\section{TABLE A}

\section{SENSITIVITY TO ASSUMED Pr(f) at SY \\ "PROBABILISTIC BASED DESIGN RULES FOR INTERSYSTEM LOCAS IN \\ ABUR PIPING", MARE AND MESLEY, NOT DATED, RECEIVED FROM INEL 5/6/93}

Temp $M^{\prime} t^{\prime} 1$

For $C=\operatorname{Pr}(S)$ as indicated, the Ratios of the Stresses at assumed $\operatorname{Pr}(f)$ at Sy of 0.01 or 0.0001 to Stresses for assumed $\operatorname{Pr}(f)$ at $S y=0.001$ are:
$C=0.99$
$C=0.97$
$C=0.090$
0.0110 .0001
0.010 .0001
$\begin{array}{ll}0.01 & 0.0001\end{array}$

100 A106-B

$0.90 \quad 1.05$

$0.92 \quad 1.04$

$0.95 \quad 1.03$

400 A106-B

$0.85 \quad 1.09$

$0.88 \quad 1.07$

$0.91 \quad 1.05$

600 A106-B

$0.83 \quad 1.09$

$0.86 \quad 1.08$

$0.90 \quad 1.05$

100 TP 304

$0.89 \quad 1.06$

0.91

1.05

0.94

1.03

400 TP 304

$0.80 \quad 1.11$

0.84

1.09

$0.89 \quad 1.06$

600 TP 304

$0.78 \quad 1.13$

$0.82 \quad 1.10$

$0.88 \quad 1.07$

$C=$ confidence of survival; for $C=0.50$, ratios are all 1.00 ; i.e., the choice of $\operatorname{Pr}(f)$ at Sy does not change the median stresses. 
Attachment 1

\section{APPENDIX B}

Conservatism of the Median Burst

Pressure for Straight Pipe

by

E. C. Rodabaugh 
Attachment 1

The screening method calculates the burst pressure by the equation:

$$
P(3)=2 * S(3) * t / D i
$$

where $P(3)$ is the burst pressure, $S(3)$ is the stress by Eq. (3) of Reference 1. For A106-B at 100F, the median of $S(3)$ is $54.7 \mathrm{ksi}$.

There are sufficient burst test data on straight pipe to assert that the median burst pressure of a $4 *$ diameter length of A106-B pipe at room temperature is given by the equation:

$$
\mathrm{Pb}=2 * \mathrm{Su} * \mathrm{t} / \mathrm{Dm}
$$

where $\mathrm{Pb}=$ median burst pressure, $4 *$ diameter length

Su $=$ median UTS of A106 Grade B material

$\mathrm{Dm}=$ mean pipe diameter

At room temperature, I think $S u=72 \mathrm{ksi}$ is a good median estimate. Then, ignoring the difference between $\mathrm{Di}$ and $\mathrm{Dm}$ :

$$
\mathrm{P}(3) / \mathrm{Pb}=54.7 / 72=0.76
$$

Thus, is my opinion, the "method" is conservative by a factor of about 0.76 for the specific case of A106-B at 100F.

There are very few burst tests on straight pipe made of austenitic stainless steel; e.g., Type 304. However, those few tests plus theory (Langer, Reference 9) indicate that Eq. (B) should be multiplied by about 0.85 for estimating the median burst pressure of pipe made of 304 material. At room temperature, 304 material, I think $\mathrm{Su}=85 \mathrm{ksi}$ is a reasonable median estimate. Then, ignoring the difference between $\mathrm{Di}$ and $\mathrm{Dm}$ :

$$
P(3) / P b=57.0 /(85 * 0.85)=0.79
$$





\section{Centimeter}

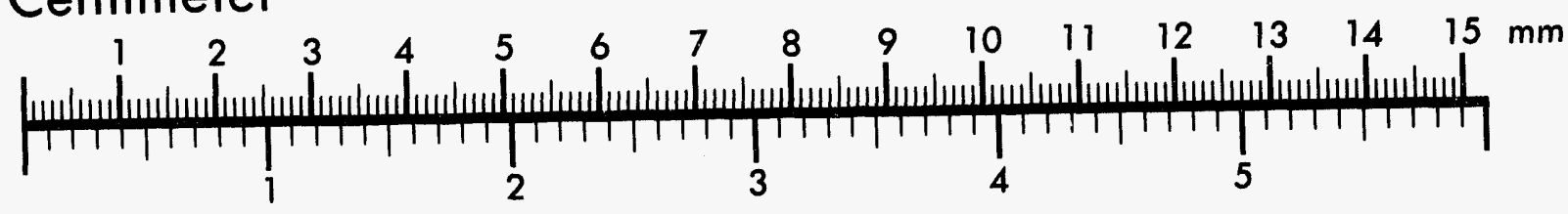
Inches
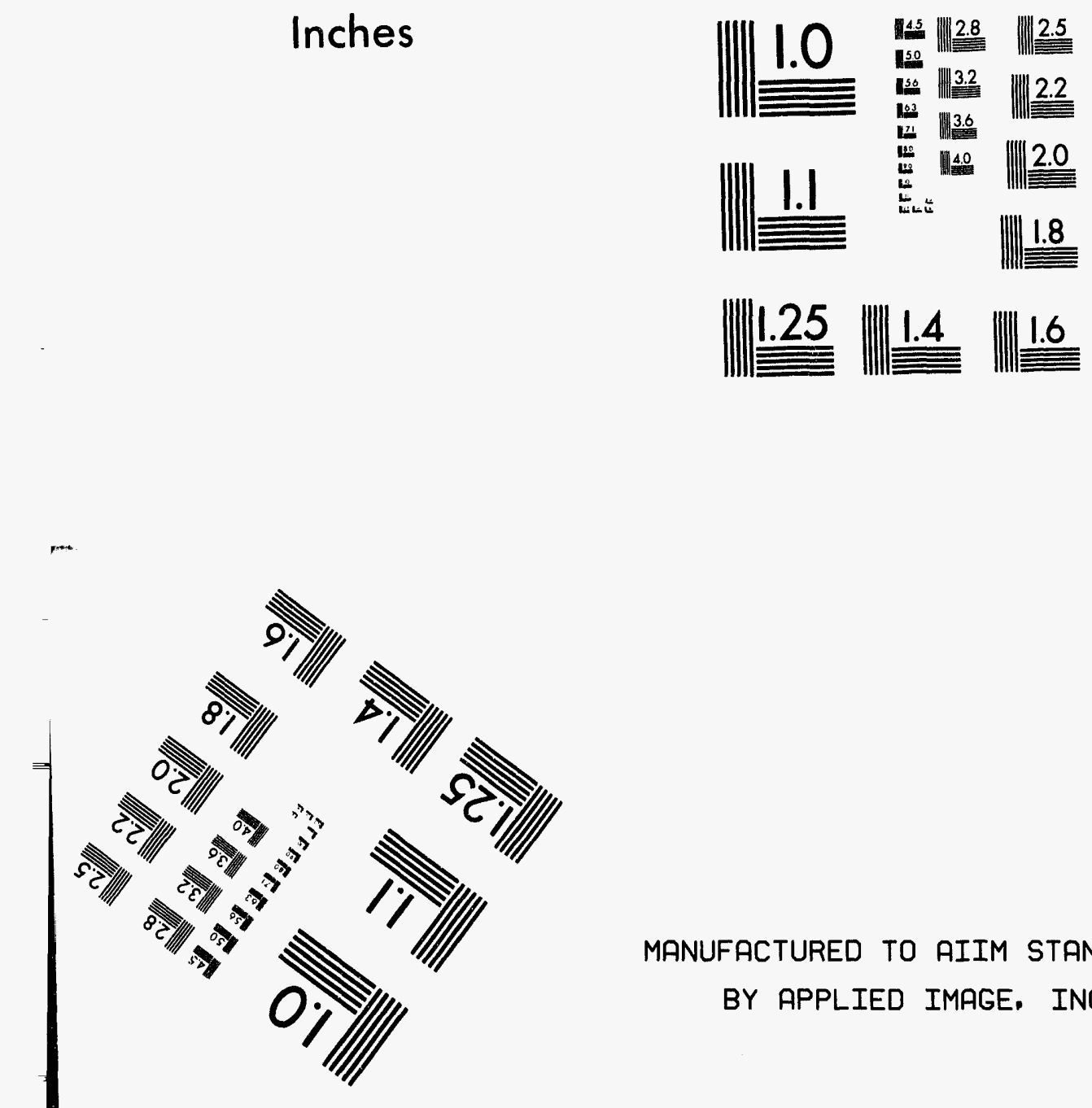

MANUFACTURED TO AIIM STANDARDS

BY APPLIED IMAGE, INC.

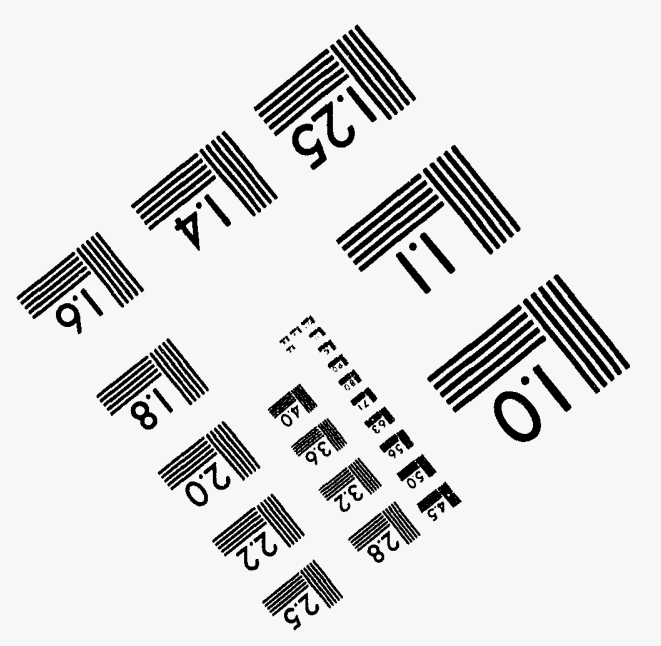



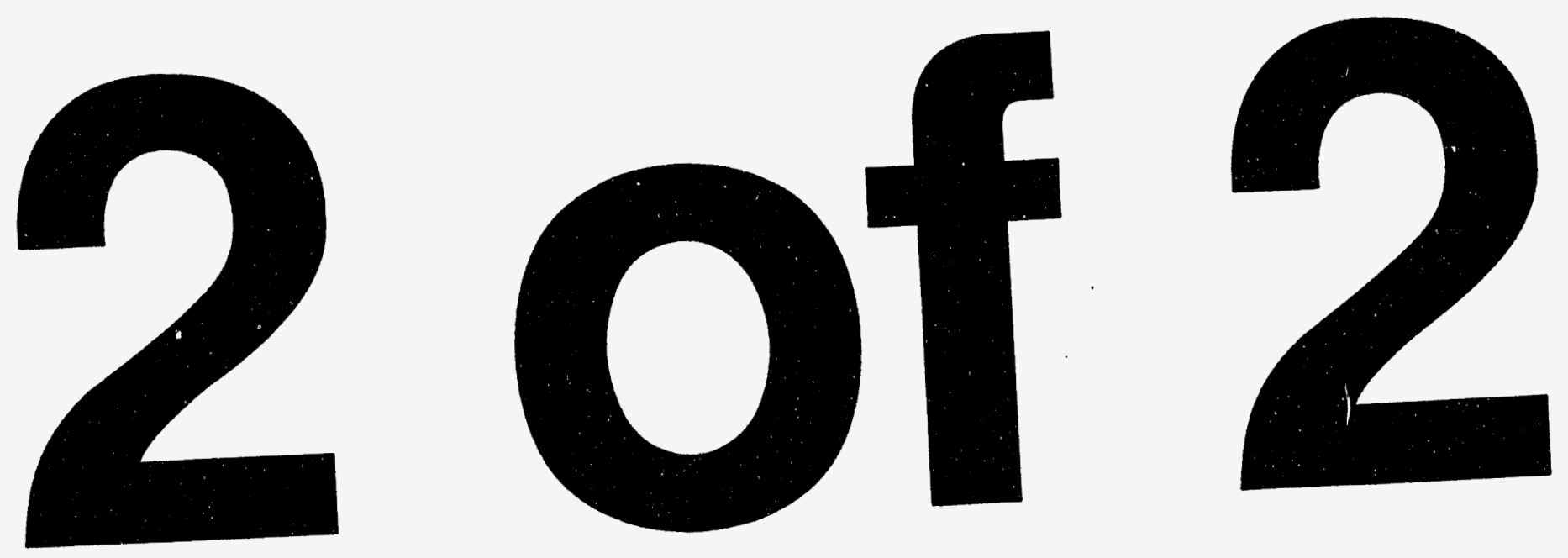
Attachment 1

I am not aware of any burst tests of straight pipe (without intentional defects) at elevated temperatures.

Langer (Reference 9) gives the equation:

$$
\mathrm{Pb}=S u * F * \ln W
$$

where $\mathrm{Pb}=$ burst pressure of a cylindrical shell (straight pipe)

$\mathrm{Su}=$ engineering UTS of pipe material

$F=[0.250 /(e+0.227) *[2.7183 / e] e$

e = true strain at maximum load in pipe material tensile test

$W$ = pipe outside diameter divided by pipe inside diameter

Noting that in $W$ is essentially equal to $2 t / D m$, Eq. (C) can be written as:

$$
\mathrm{Pb}=2 * S u^{*} \mathrm{t} / \mathrm{Dm} * \mathrm{~F}
$$

The factor $F$ depends on $e$; $e$ is not a pipe material specification property. To determine e, a tensile stress-strain curve out to the maximum load is needed. If appropriate values of e could be established, then Eq. (D) could be used to help access the median burst pressure of straight pipe at elevated temperatures. To really tie things down, it would be nice to have some burst tests on "not-intentionally-flawed" straight pipe at elevated temperatures.

In summary, the screening method under estimates the median burst pressure of a 4 diameter length of straight pipe at $100 \mathrm{~F}$ by a factor of around 0.77 ; i.e., the median burst pressure is about $30 \%$ higher than estimated by the screening method.

The 4 *diameter length qualification comes from typical burst test specimens. The test pipe is generally about four diameters in length, 
closed at each end with (often) 2:1 ellipsoidal heads. Rupture usually starts at the axial center of the pipe. (2:1 ellipsoidal heads, of the same thickness as the pipe, do NOT break). The important aspeci is that the tests are NOT tests of, say, a mile long straight pipe. If they were, then I suspect that the median failure pressure would be significantly lower than given in Eq. (B). This, of course, is related to my comment in Section $5.1(3)$ of this report. 
Attachment 1

\section{APPENDIX C}

\section{Torispherical Heads}

by

E. C. Rodabaugh 
Table 22 of Reference 4 is for torispherical heads with $L / r=1.714$, $r t / L=0.06$. These particular parameters are within the scope of NC-3324.8 and thus $(t / r)$ 's shown in Table 22 constitute valid applications of NC3324.8 .

Table 22, 400F, Po, ABWR, shows $P_{0}=443 \mathrm{psi}$. This for a design pressure of $410 \mathrm{psi!}$ This indicates that, if the relief valve is set at $1.1 * P d$, the median "collapse pressure" will be exceeded. Also, if the vessel is hydrotested to $1.5 * \mathrm{Pd}$, there is a good chance that "collapse" will occur in the test. I view Po $=443$ psi as being incredible.

Po comes from Eq. (2-2) of NUREG/CR-5862. Eq. (2-2) is based on ranges of parameters:

$$
\begin{gathered}
250<r / t<750 \\
1.5<L / r<3 \\
0.12<r t / r<0.36 \\
20 \mathrm{ksi}<\mathrm{Sy}<75 \mathrm{ksi}
\end{gathered}
$$

Noting the $(t / r)^{\prime} s$ in Table 22 ( $r / t$ ranging from 12 to 30$)$, it is apparent that Eq. $(2-2)$ is being used way outside its intended range of application; i.e., $r / t>250$. I think this is the reason for the "incredible" Po's shown in Table 22.

Langer (Reference 9), under the heading "stability under internal pressure", gives Eq. (1.3-3). He credits Eq. (1.3-3) to Shields and Drucker and intiamtes that is based on "limit analysis". Langer does not cite the range of applicability of Eq. (1.3-3); probably the Shields and Drucker paper does. However, if the range of applicability is found, it should be noted that a limit pressure, as determined by a limit analysis, may be a small fraction of the rupture pressure; e.g., 1/2 or 1/4. 


\section{Attachment 1}

The attached Table $X$ shows comparisons between Eqs. (2-2) and (1.33).

The first line of Table $X$ is a torispherical head with $L=r$ and $r t=$ $.06 * \mathrm{~L}$; which, of course, is exactly a hemispherical head. I included it to show what happens when Eqs. (2-2) and (1.3-3) are used outside their range of applicability. The gross yield and burst pressure of the head (assuming the attached cylindrical shell does not yield or burst first) are:

$$
\begin{aligned}
& P y=2 * S y * t / r=2 * 23000 * 2.245 / 100=1033 \text { psi } \\
& P u=2 * S u * t / r=2 * 54600 * 2.245 / 100=2452 \text { psi }
\end{aligned}
$$

The (median) burst pressure of $2452 \mathrm{psi}$ is a rather far cry from the 210 psi from Eq. (2-2) or the 545 psi from Eq. (1.3-3). Of course, I am mis-using Eq. (2-2) both with respect to $r / t$ and $L / r$. I suspect that I am similarly mis-using Eq. (1.3-3).

Table $X$ shows a line for $L / r=1.25$; I doubt if $L / r=1.25$ is used very much. $L / r$ between 1.5 and 2.0 are, I think, more in the range of typical torispherical heads with $r / t=0.06 * L$. Table $X$ stops at $L / r=2.00$ because that is the largest $L / r$ covered by the Code; see $N C-3324.5(d)$.

I think that Eq. (2-2) of NUREG/CR-5862 should be reviewed to see what relevance, if any, it has to pressure boundary failure of heads with $r / t$ around 20. It may also be desirable to review the Drucker and Shield paper, referenced by Langer, to see what it is based on. If (as I suspect) both Eqs. (2-2) and (1.3-3) are relevant only to heads with $r / t<250$, it may be desirable to run some appropriate analyses of heads with $r / t=20$. 
Attachment 1

\section{TABLE X}

Torispherical Heads with $L / r t=0.06, P d=$ Design Pressure

Vessel Radius $=r=100$ inch

304 material at $400 \mathrm{~F}$

$\operatorname{in}_{\text {(a) }}^{\text {int }}$ in.

100

100

125

150

175

200

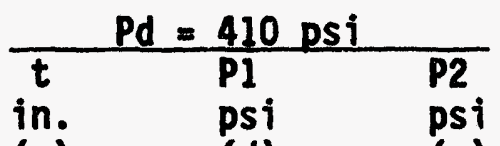

(c) (d)

2.245

1.267

2.807

3.368

3.930

4.491
210

113

284

362

445

533
228

561

577

593

609

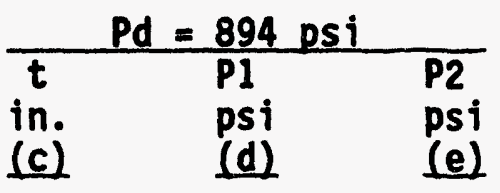

$4.911 \quad 494 \quad 1996$

$2.775 \quad 265 \quad 765$

$\begin{array}{lll}6.139 & 666 & 2017\end{array}$

$\begin{array}{rrr}7.366 & 850 & 2038 \\ 8.594 & 1045 & 2058 \\ 9.822 & 1250 & 2080\end{array}$

(a) $L$ = inside crown radius

(b) $\quad r t=$ torus radius

(c) Except for second line, $t=0.885 * P d * L /(S-0.1 P d)$

Second line, $t=P d * L /(2 * S-0.2 * P)$

$S=$ Code allowable stress for 304 at $400 \mathrm{~F},=16200 \mathrm{psi}$

(d) NUREG/CR-5862 Eq. (2-2)

Sy $=23000$ psi, ey $=0.00087$, Rs $=L$

(e) Langer (WRC Bulletin 95) Eq. (1.3-3)

Sy $=23000 \mathrm{psi}$ 
Attachment 1

APPENDIX D

Comments on ALWR ISLOCA

Evaluation Criteria

by

D. A. Wesley 


\title{
ALWR ISLOCA EVALUATION CRITERIA
}

By:

\author{
D.A. WESLEY
}

\section{INTRODUCTION}

The ALWR ISLOCA evaluation criteria developed by A.G. Ware of INEL EG\&G Idaho were based on methods developed for evaluation of existing reactors subject to ISLOCA conditions (References 1 and 2). These methods were developed to provide realistic pressure capacities for a number of components including pipe, tanks and vessels, valves, flanges and pumps. The methods were developed to provide capacities using simple analysis techniques and avoided thermal analysis of pipe lines, fracture mechanics analysis, and other analysis which might be required in a rigorous design verification. The methods developed for evaluation of existing plants included provision for possible undetected partial through wall cracks in pipe and vessels, as well as expected variability in material properties (including variation at temperatures above the system design temperature), uncertainty in strain at initiation of plastic instability, variability in initial bolt loads for a specified bolt torque, and analytical modeling uncertainty, as well as other possible sources of variability. The resulting expected leak (or burst) pressures were therefore described in probabilistic terms suitable for a probabilistic risk assessment (PRA).

Subsequent to the development of the methodology described in References 1 and 2, a considerable amount of review of the methodology and extension of these methods to the evaluation of ALWR ISLOCA conditions (References 3-8) has been completed. I believe the resulting evaluation criteria are appropriate for evaluation of ALWR ISLOCA conditions. Although based on probabilistic values, the criteria which have been presented require an absolute minimum of analysis, are easy to apply in conjunction with more rigorous design criteria, and most important, do not constrain the designer to exceed existing design conditions to implement ISLOCA modifications for those requirements which he can defend as impractical. 
Attachment 1

Although many of the methods and parameters used in References 1 and 2 are open to discussion, the overall capacities developed using these methods and material properties are considered to be representative. The decision by the USNRC staff to limit evaluation of ALWR ISLOCA conditions to $350^{\circ} \mathrm{F}$ and their finding that designing to $40 \%$ of reactor coolant pressure is adequate reduces the effects of the use somewhat different material properties or different assumed variabilities associated with a given leak or burst pressure, and makes fine tuning of the evaluation criteria less critical.

\section{MATERIALS}

The materials evaluated in References 1 and 2 were limited to those most frequently encountered in the few existing plants evaluated for ISLOCA to date. It is my understanding that ALWR will likely include similar materials. However if materials with significantly different properties, particularly brittle materials or materials other than carbon or stainless steels, are used in ALWR design, some reevaluation of the methods as well as material properties used in the current evaluation criteria would be required.

Cast Type 316 stainless steel was not explicitly considered in References 1 and 2. The evaluation conducted by INEL (Reference 6) points out that the cast Type 316 exhibits lower strength than wrought Type 316 and hence use of the Reference 1 and 2 material properties is unconservative. I agree with this conclusion. Similarly, only hot rolled SA-106 Grade B pipe was considered in References 1 and 2. Both yield and ultimate strengths for stress relieved material are less than corresponding hot rolled values over the temperature range of interest. One way to assure the applicability and limitations of the materials and their conditions used in the ALWR ISLOCA evaluation criteria is to require the designer to either note the use of the same material in his design or provide necessary adjustments in capacities to account for variations in his material conditions.

\section{PIPE AND VESSELS}

The pressure capacity of pipes and vessels in References 1 and 2 as well as subsequent INEL work is assessed based on the onset of plastic instability in the controlling membrane stress. Simplified methods for thin walled vessels which accounted for biaxial strains, strain concentrations, and variations in the material 
yield and ultimate strengths and stress strain relationships were used. Comparisons with limited experimental burst test data shows good correlation using this approach. From Reference 9 for instance, test results of Type 304 stainless steel cylinders with wall ratios $(W=\mathrm{Do} / \mathrm{Di}$ ) in the 1.2 to 1.3 range (i.e., pipe schedule 140 to 160 range) show maximum internal pressure capacities in the range of 11,000 to over 13,000 psig. Similar values are calculated using the Reference 1 and 2 methods as shown in Tables 3-1 and 2-18 of References 1 and 2 respectively. Similar correlation was seen with published data on SA 106 Grade B pipe. Thus, I believe the median capacities for burst of pipe and vessels as given in the proposed ALWR evaluation criteria are realistic.

The variabilities developed in References 1 and 2 and subsequently used in establishing the ALWR evaluation criteria included not only the variabilities associated with the materials such as variability in the yield and ultimate strengths and uncertainty in the stress-strain relation, but also some provision for uncertainty in the condition of the system being evaluated. For instance ISLOCA conditions can result in temperatures well above the design temperature of many systems under consideration. Such temperatures may result in high bending moments in the pipe, high nozzle loads in vessels, etc., in addition to the pressure induced hoop stress in the pipe or vessel. Undetected flaws may also exist in the system. In order to account for such possibilities, it was judged that a probability of failure of $10^{-3}$ at hoop yield stress would provide a reasonable estimate of overall variability. This approach eliminates the necessity of conducting thermal stress analysis of the cold lines for ISLOCA and provides a simple approach for including a great many unknowns. However, to my knowledge, there is no database to support a number of $10^{-3}$. Consequently, a parameter study using a $10^{-4}$ probability of failure at yield was conducted by INEL and the results are compared in the $10^{-3}$ INEL results.

Failure of a cylinder at a nominal hoop stress equal to yield may be implied to correspond to the existence of a partial through wall crack. For a typical wall thickness cylinder of materials under consideration here, this implies a partial through wall axial crack of the order of 3/4 of the wall thickness and several inches long. Similar results exist for a partial circumferential crack although the critical size of such cracks is much more sensitive to pipe bending moments and orientation. Clearly, such cracks should be detectable using either fabrication inspection or ISI techniques. Thus, the variability associated with assuming a $10^{-3}$ 
Attachment 1 .

or $10^{-4}$ probability may be overly conservative. However, lacking a database which would deny the existence of significant flaws and in the absence of thermal stress analysis of lines and nozzle loads, I, believe the evaluation criteria developed by INEL using the above variabilities provide a reasonable approach for evaluation of ALWRs.

The above methodology together with the NRC specified requirements for evaluation pressures, temperatures, and survival confidences leads to requirements for schedule 40 pipe for BWRS and schedule 60 or 80 for some of the larger diameter PWR piping depending on material. I believe these are prudent design conditions and should not impose undue costs on the design.

For vessels and tanks, cost penalties are expected particularly for the larger diameter vessels. Plastic collapse pressures for torispherical heads is lower than for semispherical heads which may force a greater use of semispherical heads compared to the normally less expensive torispherical. Clearly, for tanks such as flat bottomed atmospheric tanks, compliance with ISLOCA conditions will be impractical in my opinion.

The capacity of dished heads is based on analytical results from Galletly (References 10-13) using the computer program BOSOR 5 (Reference 14). Plastic collapse was defined as corresponding to deformations equal to twice the elastic deformation. Also, the results were quite sensitive to analytical modeling assumptions such as flow laws. Although the analytical results were adjusted to correlate more close!y with limited experimental data, some additional analytical studies may be warranted, particularly for thicker heads and possibly using different analytical codes and assumptions. Such investigations may show the existing methods to be conservative.

From the limited number of evaluations of heat exchangers subjected to ISLOCA conditions which I have conducted, the tubes have normally not been the controlling element, either for tube side pressure (tube burst) or for shell side pressure (tube collapse). Rather, the shell or channel burst or tube sheet gasket leak has normally controlled the capacity. Hopefully this would indicate that the heat transfer characteristics of ALWR heat exchangers will not be significantly affected by ISLOCA considerations. 
The ISLOCA evaluation of bolted flanges and bolted valve bonnets is similar and is based on PVRC gasket test data. The INEL recommendation differ in methodology only in using a larger coefficient of variation (COV $=0.15$ ) for bolt preload for a given bolt-torque based on recommendations from Yahr (Reference 15) compared to a $\mathrm{COV}=0.07$ based on Shigley's machine design which was used in References 1 and 2 . The 0.15 provides a more conservative evaluation and $I$ have no basis to judge one value more accurate than the other.

The INEL recommendations lead to Class 300 flanges for BWR and Class 600 flanges for PWR ISLOCA evaluation. This recommendation is based on maintaining ISLOCA evaluation pressures below the Gross Leak Pressure (GLP) of the gasketed flange.. I believe it is sound practice to eliminate Class 150 flanges, particularly with SA 193 Grade B8 or equivalent bolts, in applications subject to ISLOCA conditions and I support this recommendation.

\section{PUMPS}

Pump designs vary significantly for various applications and different vendors. Pump casings designed using normal design requirements would normally have wall thicknesses resulting in lower stresses than attached piping and hence a lower probability of rupture. However, an ISLOCA evaluation does not constitute the design criteria and while schedule 40 or higher pipe and Class 300 flanges or higher are included in the ISLOCA evaluation criteria for pipe, there is nothing that requires the pump designer to think in similar terms. Thus, the design criteria might permit the pump designer to come up with a casing thickness corresponding to Schedule $10 S$ piping and Class 150 flanges rather than the heavier components recommended for ISLOCA.

One possibility might be to have the pump vendor hydrotest the casing (not necessarily the seals) to ISLOCA pressure. However, in order to assure himself that he would not induce inelastic stresses which would result in a permanently deformed case, the pumps designer would probably end up with the ISLOCA pressure and temperature as the design condition with associated cost. 


\section{Attachment 1}

Noting that permanent deformation in the installed condition is acceptable from a safety consideration (although pump replacement could be required) analysis of the pump casing for ISLOCA evaluation is likely to be preferable to testing. In this case, limits on inelastic strains may be desirable as part of the ISLOCA evaluation criteria.

Bolted pump casing flanges using spiral wound gaskets can be evaluated using the same methodology as bolted pipe flanges, valve bonnets, and heat exchanger tube sheets. Some pump flanges are sealed using elastomeric seals such as silicone rubber or ethylene propylene O-rings. Leakage of this type of seal can be evaluated using simple techniques provided the residual set (and possibly increased temperature accident set) of the O-rings is included in the bolted flange opening clearance. It is my understanding designing pumps seals to withstand ISLOCA conditions would result in increased seal wear. Typically, the pumps under consideration would not be expected to have to operate during an ISLOCA event, and I would expect the amount of non-operating seal leakage during an ISLOCA would be acceptable in most instances. It is my understanding that it is the NRC staff position that consideration of ISLOCA should not result in changes to the design that could degrade normal operating performance, and I strongly support this position.

\section{REFERENCES}

1. D. A. Wesley et al., Pressure Dependent Fragilities for Piping Components, NUREG/CF-5603, EGG-2607, October 1990.

2. D. A. Wesley, Screening Methods for Developing Internal Pressure Capacities for Components in Systems Interfacing with Nuclear Power Plant Reactor Coolant Systems, NUREG/CR-5862, EGG-2673, May 1992.

3. A. G. Ware and D. A. Wesley, Probabilistic Based Assessment of Design Rules for Intersystem LOCAs in Advanced BWR Piping, ASME Pressure Vessels and Piping Conference, Denver, Colorado, PVP Volume 264, Pp. 105-120, American Society of Mechanical Engineers, New York, New York, July 1993.

4. A. G. Ware, "Survival Confidences for PWR ISLOCA Piping," Section 4 of NUREG/CR-6121.

5. A. G. Ware, "Vessel Analysis Using NUREG/CR-5603 and NUREG/CR-5862 Methodology for ISLOCA Design," Section 4.5.1 of NUREG/CR 6121. 
6. A. G. Ware, "Comparison of NUREG/CR-5603 and Alternate Materials Data for Stainless and Carbon Steels," Section 3 of NUREG/CR 6121.

7. A. G. Ware, "Flange Analysis Using NUREG/CR-5603 and NUREG/CR-5862 Methodology for ISLOCA Design, Section 4.2 of NUREG/CR61221.

8. A. G. Ware, "Pump, Valve, and heat Exchanger Tube and Tubesheet Evaluation for ISLOCA Design Using NUREG/CR-5603 Methodology, Section 4.3 , 4.4, and 4.5 of NUREG/CR-6121.

9. D. F. Landers, "PVRC Interpreting Report of Pressure Vessel Research, Section 1 - Design considerations," Welding Research Council Bulletin 95, April 1964.

10. G. D. Galletly, "Elastic and Elastic-Plastic Buckling of Internally Pressurized 2:1 Ellipsoidal shells, Transactions of the ASME, Journal of Pressure Vessel Technology, 100, November 1978, pp. 335-343.

11. G. D. Galletly and R. W. Ayiward, "Plastic Collapse and Controlling Failure Pressures of Thin 2:1 Ellipsoidal Shells Subjected to Internal pressure," Transactions of the ASME Journal of Pressure Vessel Technology, 101, February, 1979, pp. 64-71.

12. G. D. Galletly and S. K. Radhamoham, "Elastic-Plastic Buckling of Internally Pressurized this Toripherical Shells," Transactions of the ASME, Journal of Pressure Vessel Technology, 101, August 1979, pp. 216-225.

13. S. K. Radhamoham and G. D. Galletly, "Plastic Collapse of Thin Internally Pressurized Torispherical Shells," Transactions of the ASME Journal of Pressure Vessel Technology, 101, November, 1979, pp. 311-320.

14. D. Bushnell, "BOSOR-5-Program for Buckling of Elastic Plastic Shells of Revolution Including Large Deflections and Creeps," Computers and Structures, 6, 1976, pp. 221-239.

15. G.T., Yahr, "Preloading of Bolted Connections in Nuclear Reactor components," Section 2.2 of Pressure Vessel and Piping Technology-1985 A Decade of Progress, American Society of Mechanical Engineers, 1985. 
Attachment 2

\section{Survival Confidence Tables}


Attachment 2

\begin{tabular}{|c|c|c|c|c|c|c|c|c|c|c|c|c|c|c|}
\hline A & $A$ & B & c & D & $E$ & $\boldsymbol{F}$ & Q & $H$ & 1 & $J$ & $\mathbf{K}$ & L & $\mathbf{M}$ & $N$ \\
\hline 1 & Wrought Tye & 304 staints & asted & & & 68.35 & ledian UTS & & & & 0.105 & nedian fillu & estrain & \\
\hline 2 & $350 \mathrm{~F}$ & & & & & 58.40 & ledian fallu & streas & & & 64.58 & UUAEGCA & -E.003 failun & etreas \\
\hline 3 & $1.0 E-036$ & lure probal & ify & & & 25.44 & ledian yleld & streses & & & 25.12 & JUAEGCA & -5603 veld & treas \\
\hline 4 & & & & & & 0.258 & gta & & & & 0.153 & dojusted fall & ure strain & \\
\hline 5 & & & & & & & & & & & & & & \\
\hline 6 & suntival & & & ad usted & & survival & & & adjusted & & sunival & & & aciusted \\
\hline 7 & conficance & $x$ & stress & stress & & Eonfidence & $\underline{x}$ & streas & stress & & Confidence & $x$ & stress & Etreos \\
\hline 8 & 0.9000 & 3.71802 & & & & & & & & & & & & \\
\hline 9 & 0.000 & 3.00023 & 25.44000 & 25.44000 & & 0.024 & 1.43250 & 38.909313 & 36.54836 & & 0.840 & 1.03215 & 43.22951 & 39.74031 \\
\hline 10 & 0.998 & 2.87816 & 26.80854 & 28.68043 & & 0.023 & 1.42564 & 39.00311 & 36,00210 & & 0.846 & 1.02780 & 43.27603 & 39.77538 \\
\hline 11 & 0.097 & 2.74778 & 27.78634 & 27.46034 & & 0.022 & 1.41865 & 30.13251 & 38.65537 & & 0.847 & 1.02265 & 43.32427 & 30.81031 \\
\hline 12 & 0.008 & 2.65207 & 28.47997 & 20.05000 & & 0.021 & 1.41183 & 39.20132 & 36.70815 & & 0.846 & 1.01843 & 43.37140 & 39.84510 \\
\hline 13 & 0.993 & 2.57683 & 29.04487 & 20.53714 & & 0.020 & 1.40507 & 39.20005 & 36.70052 & & 0.845 & 1.01522 & 43.41847 & 39.87962 \\
\hline 14 & 0.994 & 2.51214 & 29.52537 & 28.94180 & & 0.910 & 1.303638 & 39.33739 & 38.81241 & & 0.844 & 1.01103 & 43.46536 & 39.91441 \\
\hline 15 & 0.003 & 2.45720 & 29.94578 & 29.29431 & & 0.918 & 1.39174 & 38.40474 & $30.86 \times 997$ & & 0.843 & 1.00688 & 43.51208 & 30.94855 \\
\hline 16 & 0.092 & 2.40002 & 30.32102 & 20.60778 & & 0.017 & 1.38517 & 30.47149 & 36.91504 & & 0.842 & 1.00271 & 43.558 .2 & 39.96315 \\
\hline 17 & 0.991 & 2.36502 & 30.66114 & 29.80080 & & 0.910 & 1.37800 & 39.53774 & 36.86570 & & 0.841 & 0.00658 & 43.00499 & 40.01731 \\
\hline 18 & 0.900 & 2.32035 & 30.97290 & 30.14059 & & 0.915 & 1.37200 & 39.60360 & 37.01002 & & 0.840 & 0.00446 & 43.65130 & 40.05141 \\
\hline 19 & 0.980 & 2.20037 & 31.26133 & 30.38834 & & 0.914 & 1.36581 & 39,6685 & 37.08586 & & 0.839 & 0.09030 & 43.09743 & 40.02853 \\
\hline 20 & 0.838 & 2.25713 & 31.55018 & 30.61010 & & 0.013 & 1.36046 & 39.73379 & 37.11541 & & 0.868 & 0.03627 & 43.74349 & 40.11025 \\
\hline 21 & 0.987 & 2.22021 & 31.76234 & 30.81787 & & 0.812 & 1.35317 & 30.79823 & 37.16457 & & 0.837 & 0.88200 & 43.70938 & 40.15300 \\
\hline 22 & 0.908 & 2.10729 & 32.02001 & 31.01205 & & 0.911 & 1.34624 & 39.86216 & 37.21330 & & 0.638 & 0.97815 & 43.83510 & 40.16660 \\
\hline 23 & 0.085 & 2.17000 & 32.24517 & 39.19735 & & 0.010 & 1.34078 & 39.82667 & 37.26160 & & 0.835 & 0.97411 & 43.88074 & 40.22014 \\
\hline 24 & 0.884 & 2. 14441 & 32.46020 & 31.37238 & & 0.809 & 1.33462 & 39.08888 & 37.30081 & & 0.634 & 0.07000 & 43.82621 & 40.25353 \\
\hline 25 & 0.083 & 2.12007 & 32.63338 & 31.56808 & & 0.003 & 1.32654 & 40.05163 & 37.35751 & & 0.838 & 0.80009 & 43.97150 & 40.28678 \\
\hline 28 & 0.892 & 2.00693 & 32.85867 & 31.00005 & & 0.007 & 1.32251 & 40.11383 & 37.40487 & & 0.852 & 0.88210 & 44.01672 & 40.31997 \\
\hline 27 & 0.991 & 2.07485 & 33.04611 & 31.85045 & & 0.608 & 1.31652 & 40.17578 & 37.45106 & & 0.831 & 0.05812 & 44.08187 & 40.35310 \\
\hline 28 & 0.800 & 2.05375 & 33.20023 & 31.89084 & & 0.005 & 1.31060 & 40.23730 & 37.40970 & & 0.850 & 0.05416 & 44.10635 & 40.38607 \\
\hline 20 & 0.078 & 3.00652 & 33.30905 & 32.13731 & & 0.004 & 1.30460 & 40.29840 & 37.54509 & & 0.629 & 0.05022 & 44.15164 & 40.41891 \\
\hline 30 & 0.878 & 101400 & 33.36745 & 32.27209 & & 0.003 & 1.28384 & 40.35918 & 37.59121 & & 0.828 & 0.04020 & 44.18630 & 40.45167 \\
\hline 31 & 0.077 & .00339 & 33.72955 & 32.40531 & & 0.002 & 1.20303 & 40.41003 & 37.60700 & & 0.827 & $0.0,238$ & 44.24000 & 40.48430 \\
\hline 32 & 0.078 & 1.97737 & 33.88050 & 32.53038 & & 0.001 & 1.20727 & 40.47686 & 37.68255 & & 0.628 & 0.03849 & 44.28638 & 40.51605 \\
\hline 33 & 0.975 & 1.96990 & 34.00633 & 32.05305 & & 0.000 & 1.28155 & 40.53095 & 37.7277 & & 0.825 & 0.05458 & 44.32989 & 40.54943 \\
\hline 34 & 0.874 & .94313 & 34.18673 & 32.77109 & & 0.899 & 1.27897 & 40.59672 & 37.77272 & & 0.824 & 0.96072 & 44.37400 & 40.56100 \\
\hline 35 & 0.073 & 1.0268 & 34.33050 & 32.88743 & & 0.698 & 1.27024 & 40.65764 & 37.81731 & & 0.823 & 0.02086 & 44.41814 & 40.61309 \\
\hline 36 & 0.072 & 1.91104 & 34.47052 & 32.99972 & & 0.897 & 1.20404 & 40.71634 & 37.80171 & & 0.82 & $0.02 \times 01$ & 44.46222 & 40.64618 \\
\hline 37 & 0.971 & 1.60570 & 34.60702 & 33.10004 & & 0.008 & 1.25008 & 40.77470 & 37.60583 & & 0.821 & 0.81018 & 44.50811 & 40.67828 \\
\hline 36 & 0.070 & 1.86079 & 34.74020 & 33.21557 & & 0.896 & 1.2 .5657 & 40.83262 & 37.94030 & & 0.620 & 0.81537 & 44.54962 & 40.71018 \\
\hline 39 & 0.500 & 1.800 .30 & 34.87012 & 33.31038 & & 0.894 & 1.24808 & 40.89041 & 37.89322 & & 0.810 & 0.01168 & 44.50367 & 40.74212 \\
\hline 40 & 0.508 & 1.0 .218 & 34.93720 & 33.42078 & & 0.803 & 1.24264 & 40.04778 & 38.05050 & & 0.818 & 0.00777 & 44.63713 & 40.77391 \\
\hline 41 & 0.837 & 1.83842 & 35.12148 & 33.51880 & & 0.8992 & 1.23723 & 41.00487 & 38.07058 & & 0.817 & 0.90309 & 44.68002 & 40.80503 \\
\hline 42 & 0.860 & 1.82501 & 35.24302 & 33.61650 & & 0.801 & 1.20180 & 41.08164 & $38.12 \times 38$ & & 0.816 & 0.80023 & 44.72302 & 40.83721 \\
\hline 43 & 0.005 & 1.81107 & 35.36216 & 33.71120 & & 0.800 & 1.22083 & 41.11808 & 38.16400 & & 0.815 & 0.60347 & 44.78726 & 40.86880 \\
\hline 44 & 0.004 & 1.79912 & 35.47887 & 30.80509 & & 0.869 & 1.22123 & 41.17424 & 38.20721 & & 0.814 & 0.80273 & 44.81041 & 40.00025 \\
\hline 45 & 0.800 & 1.78601 & 35.50330 & 33.89486 & & 0.888 & 1.21500 & 41.23017 & 38.24032 & & 0.813 & 0.88001 & 44.85338 & 40.93154 \\
\hline 46 & 0.862 & 1.77438 & 35.70571 & 33.86388 & & 0.887 & 1.21072 & 41.26567 & 38.29122 & & 0.812 & 0.88529 & 44.86638 & 40.86285 \\
\hline 47 & 0.861 & 1.76241 & 35.81509 & 34.07118 & & 0.688 & 1.20535 & 41.34111 & 38.33278 & & 0.811 & 0.88159 & 44.93920 & 40.89401 \\
\hline 48 & 0.000 & 1.75069 & 35.92420 & 34.15634 & & 0.886 & 1.20038 & 41.39621 & 38.37417 & & 0.810 & 0.87780 & 44.88194 & 41.02510 \\
\hline 49 & 0.030 & 1.73020 & 30.03078 & 34.24009 & & 0.624 & 1.1062 & 41.45100 & 38.41538 & & 0.800 & 0.87422 & 45.02460 & 41.08813 \\
\hline 50 & 0.838 & 1.72793 & 33.13555 & $34.52 \times 38$ & & 0.883 & 1.10012 & 41.50535 & 38.45030 & & 0.603 & 0.87055 & 45.00719 & 41.08700 \\
\hline 51 & 0.857 & 1.71680 & 36.23847 & 34.40484 & & 0.682 & 1.18504 & 41.55001 & 38.49709 & & 0.807 & 0.60689 & 45.10971 & 41.11700 \\
\hline 52 & 0.060 & 1.70004 & 38.33000 & 34.48475 & & 0.881 & 1.16000 & 41.61300 & 38.53759 & & 0.808 & 0.86025 & 45.162003 & 41.14673 \\
\hline 53 & 0.065 & 1.00340 & 30.43665 & 34.56266 & & 0.880 & 1.17400 & 41.66765 & 38.57789 & & 0.605 & 0.05962 & 45.19427 & 41.1790 \\
\hline 54 & 0.554 & 1.68404 & 36.53709 & 34.84057 & & 0.679 & 1.17000 & 41.72125 & 38.61800 & & 0.804 & $0.85 \times 00$ & 45.23644 & 41.21001 \\
\hline 55 & 0.053 & 1.07468 & 36.63467 & 34.71670 & & 0.878 & 1.16505 & 41.77449 & 38.65793 & & 0.803 & 0.65239 & 45.27853 & 41.24055 \\
\hline 56 & 0.952 & 1.60458 & 36.73032 & 34.78161 & & 0.877 & 1.16012 & 41.82758 & 38.69768 & & 0.802 & 0.84879 & 45.32054 & 41.27102 \\
\hline 57 & 0.851 & 1.68463 & 38.82440 & 34.86339 & & 0.878 & 1.15522 & 41.88041 & 38.73721 & & 0,801 & 0.84520 & 45.36247 & 41.30142 \\
\hline 38 & 0.550 & 1.64485 & 36.91730 & 34.05818 & & 0.875 & 1.15005 & 41.03299 & 38.77654 & & 0.800 & 0.84162 & 45.40433 & 41.33175 \\
\hline 59 & 0.048 & 1.06523 & 37.00990 & 35.00000 & & 0.874 & 1.14551 & 41.98650 & 38.81565 & & 0.790 & 0.83805 & 45.446111 & 41.36202 \\
\hline 60 & 0.048 & 1.62578 & 37.00030 & 35.08001 & & 0.073 & 1.14060 & 42.03747 & 38.85463 & & 0.798 & 0.83450 & 45.46760 & 41.39213 \\
\hline 61 & 0.947 & 1.61644 & 37.16348 & 36.15031 & & 0.872 & 1.13500 & 42.08938 & 38.89339 & & 0.787 & 0.85005 & 45.52091 & 41.42200 \\
\hline 62 & 0.946 & 1.00725 & 37.27663 & 35.21914 & & 0.871 & 1.13113 & 42.14113 & 38.83203 & & $0.7 \% 8$ & 0.82742 & 45.57073 & 41.45224 \\
\hline 63 & 0.845 & 1.59810 & 37.36374 & 35.28711 & & 0.670 & 1.12600 & 42.10262 & 38.97045 & & 0.795 & 0.82300 & 45.61208 & 41.48215 \\
\hline 64 & 0.044 & 1.56827 & 37.44970 & 35.35412 & & 0.860 & 1.12168 & 42.24385 & 30.00665 & & 0.794 & 0.82038 & 45.65346 & 41.51207 \\
\hline 65 & 0.043 & 1.58047 & 37.53469 & 35.42034 & & 0.868 & 1.11609 & 42.20492 & 39.04672 & & 0.793 & 0.81687 & 45.69478 & 41.54180 \\
\hline 66 & 0.842 & 1.57179 & 37.61872 & 35.46574 & & 0.607 & 1.14232 & 42.34583 & 39.08468 & & 0.792 & 0.81338 & 45.73588 & 41.57163 \\
\hline 67 & 0.241 & 1.50322 & 37.70187 & 35.35041 & & 0.868 & 1.10768 & 42.30048 & 39.12238 & & 0.791 & 0.80090 & 45.77688 & 41.60126 \\
\hline 68 & 0.940 & 1.55477 & 37.78403 & 35.61427 & & 0.865 & 1.10500 & 42.44607 & 39.15997 & & 0.790 & 0.80642 & 45.81794 & 41.63000 \\
\hline 69 & 0.090 & 1.54643 & 37.86530 & 35.67738 & & 0.084 & 1.09847 & 42.40719 & 39.19734 & & 0.780 & 0.80208 & 45.85680 & 41.66039 \\
\hline 70 & 0.038 & 1.56820 & 37.94568 & 35.73975 & & 0.868 & 1.08390 & 42.54728 & 39.23457 & & 0.788 & 0.78050 & 45.60000 & 41.68000 \\
\hline 71 & 0.837 & 1.53007 & 38.02522 & 35.80144 & & 0.862 & 1.06935 & 42.59718 & 39.27167 & & 0.787 & 0.78000 & 45.84009 & 41.71825 \\
\hline 72 & 0.836 & 1.52204 & 38.10090 & 35.86246 & & 0.861 & 1.08482 & 42.64600 & 39.30663 & & 0.788 & 0.79262 & 45.93112 & 41.74602 \\
\hline 73 & 0.035 & 1.51410 & 38.18190 & 35.82287 & & $0 . \overline{680}$ & 1.08032 & 42.600037 & 39.34537 & & 0.785 & 0.78919 & 46.02177 & 41.77782 \\
\hline 74 & 0.834 & 1.50020 & 38.25018 & 35.08200 & & 0.850 & 1.07384 & 42.74567 & 39.38180 & & 0.784 & 0.78577 & 46.06233 & 41.80714 \\
\hline 75 & 0.933 & 1.49851 & 30.33584 & 38.04172 & & 0.858 & 1.07138 & 42.79481 & 39.41844 & & 0.783 & 0.78237 & 46.10270 & 41.83621 \\
\hline 76 & 0.032 & 1.40025 & 38.41137 & 36.10023 & & 0.657 & 1.06694 & 42.84379 & 39.45477 & & 0.782 & 0.77697 & 46.14300 & 41.80530 \\
\hline 77 & 0.031 & 1.48328 & 38.48635 & 38.15812 & & 0.856 & 1.06252 & 42.89261 & 39.49096 & & 0.781 & 0.77557 & 46.18363 & 41.89440 \\
\hline 78 & 0.830 & 1.47579 & 38.58008 & 36.21548 & & 0.665 & 1.05812 & 42.94125 & 39.52702 & & 0.780 & 0.77219 & 46.22376 & 41.82334 \\
\hline 79 & 0.028 & 1.46838 & 38.63437 & 36.27229 & & 0.854 & 1.05674 & 42.88973 & 39.58293 & & 0.779 & 0.76882 & 46.26391 & 41.85222 \\
\hline 80 & 0.028 & 1.46106 & 38.70729 & 36.32848 & & 0.853 & 1.04939 & 43.03794 & 39.59862 & & 0.778 & 0.76546 & 46.303997 & 41.98102 \\
\hline 81 & 0.827 & 1.45389 & 38.77865 & 36.38420 & & 0.852 & 1.04505 & 43.08608 & 39.63425 & & 0.777 & 0.76210 & 46.34407 & 42.00094 \\
\hline 82 & 0.828 & 1.44663 & 38.85145 & 36.43945 & & 0.851 & 1.04073 & 43.13408 & 39.66974 & & 0.776 & 0.75675 & 46.38408 & 42.05858 \\
\hline 83 & 0.925 & 1.43953 & 38.92258 & 38.49414 & & 0.850 & 1.03843 & 43.18187 & 39.70510 & & 0.775 & 0.75542 & 46.42360 & 42.06717 \\
\hline
\end{tabular}


Attachment 2

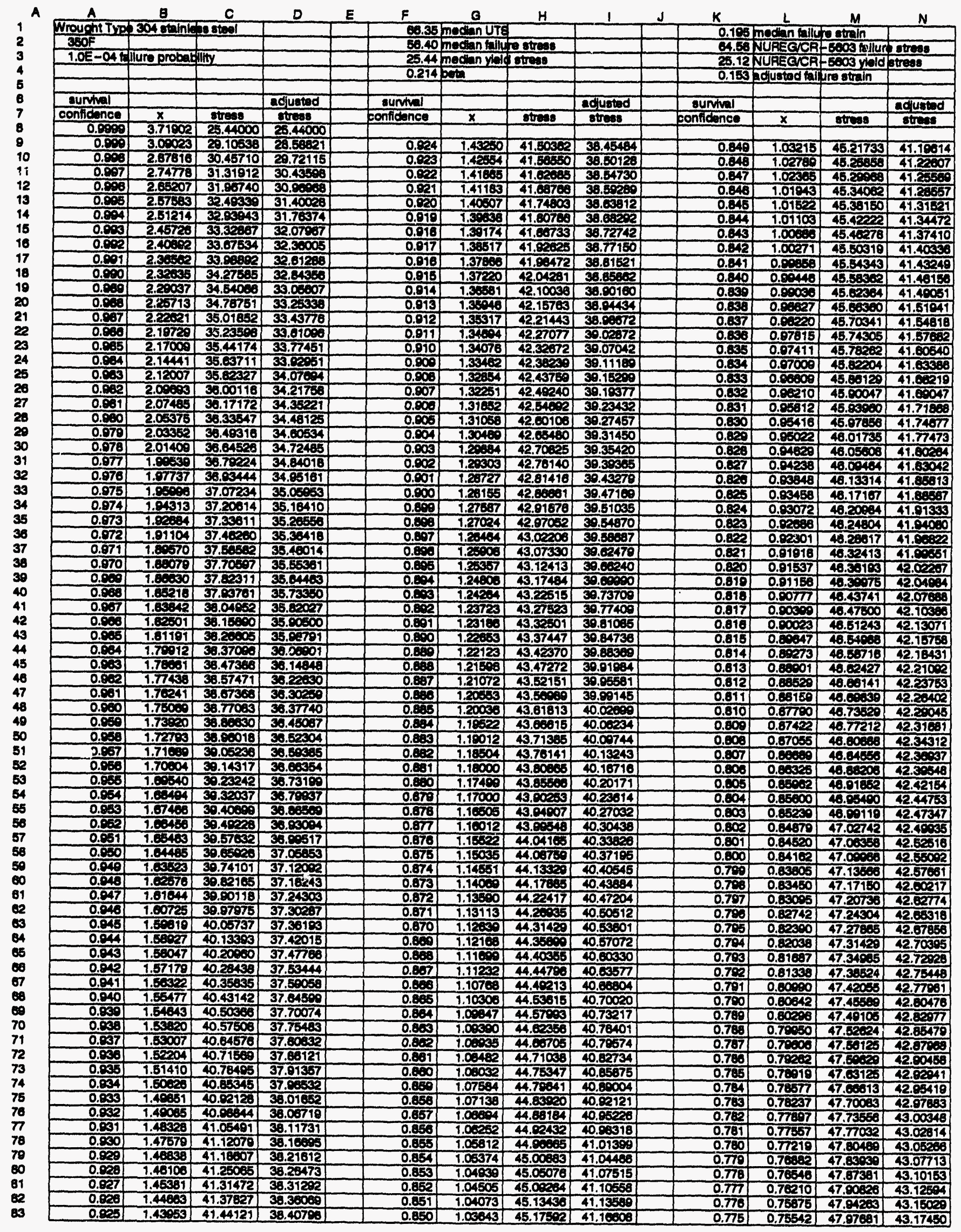

NUREG/CR-6121

B-4 





Attachment 2




Attachment 2

\begin{tabular}{|c|c|c|c|c|c|c|c|c|c|c|c|c|c|c|}
\hline A & $\mathrm{A}$ & 旦 & c & D & $\underline{E}$ & $F$ & o & $H$ & 1 & $J$ & $K$ & $L$ & $M$ & $\mathbf{N}$ \\
\hline 1 & Wrought TyP & 304 atink & 38 sted plat & & & 65.02 & median UTS & & & & 0.141 & Tredien falle & Wre strain & \\
\hline 2 & $360 \mathrm{~F}$ & & & & & 86.03 & Imedtan millu & e streses & & & & NURE GYA & -5603 tallun & streos \\
\hline 3 & $1.0 E-036$ & Ilure probal & fility & & & 26.83 & modian ylol & streses & & & 25.12 & NUREC & 50003 yield & otress \\
\hline 4 & & & & & & 0.236 & 些 & & & & 0.120 & clusted fal & Iure strain & \\
\hline 6 & sunival & & & adjuatod & & & & & & & & & & \\
\hline 7 & confidence & $x$ & otreeses & $\frac{10 j u b s}{8 t r e s s}$ & & $\frac{\text { suntual }}{\text { conficance }}$ & $x$ & & adcut & & ountual & & & adusted \\
\hline 8 & 0.0009 & 3.71802 & & & & & & sons & sines: & & & $x$ & streas & otress \\
\hline 9 & 0.809 & 3.00003 & 20.86000 & 20.83000 & & 0.924 & 1.43250 & 30.82781 & 37.80485 & & 0.840 & 1.03216 & 43.81436 & 40.95127 \\
\hline 10 & 0.009 & 2.87816 & 28.22073 & 29.00010 & & 0.023 & 1.42564 & 39.80363 & 37.85782 & & 0.648 & 1.02760 & 43.86386 & 40.08686 \\
\hline 11 & 0.097 & 2.74778 & 20.11130 & 28.84047 & & 0.022 & 1.41866 & 39.95018 & 37.01032 & & 0.847 & 1.02366 & 43.00310 & 41.02020 \\
\hline 12 & 0.008 & 2.65207 & 20.76200 & 20.4262 & & 0.021 & 1.41183 & 40.02418 & 37.80236 & & 0.846 & 1.01843 & 43.94736 & 41.05458 \\
\hline 13 & 0.003 & 2.67563 & 30.32604 & 20.60031 & & 0.020 & 1.40607 & 40.06870 & 36.01307 & & 0.843 & 1.01522 & 43.00146 & 41.00802 \\
\hline 14 & 0.004 & 2.51214 & 30.78278 & 30.20602 & & 0.010 & 1.30938 & 40.15260 & 38.00512 & & 0.644 & 1.01103 & 44.03642 & 41.12202 \\
\hline 15 & 0.003 & 2.46780 & 31.10011 & 30.64705 & & 0.810 & 1.30174 & 40.21625 & 38.11504 & & 0.043 & 1.00888 & 44.07020 & 41.1568 \\
\hline 18 & 0.002 & 2.40602 & 31.36007 & 30.06603 & & 0.017 & 1.38517 & 40.27026 & 36.16628 & & 0.842 & 1.00271 & 44.12282 & 41.10000 \\
\hline 17 & 0.001 & 2.30602 & 31.86000 & 31.23607 & & 0.916 & 1.37080 & 40.34180 & 30.21621 & & 0.841 & 0.90658 & 44.16020 & 41.22437 \\
\hline 18 & 0.00 & 2.36035 & 32.18670 & 31.40200 & & 0.918 & 1.37220 & 40.40396 & 38.20662 & & 0.840 & 0.09440 & 44.20005 & 41.25700 \\
\hline 19 & 0.090 & 2.20037 & 32.46386 & 31.72806 & & 0.914 & 1.36681 & 40.46532 & 38.31403 & & 0.830 & & 44.25260 & 41.29146 \\
\hline 20 & 0.009 & 2.26713 & 32.72203 & 31.04718 & & 0.013 & 1.35040 & 40.52000 & 38.36070 & & 0.836 & 0.06627 & 44.20001 & $\frac{41.091 .00}{41.32488}$ \\
\hline 21 & 0.697 & 2.2001 & 32.00402 & 32.15218 & & 0.912 & 1.36517 & 40.66760 & 38.41224 & & 0.857 & 0.08220 & 44.33000 & 41.35615 \\
\hline 22 & 0.090 & 2.10720 & 33.19109 & 32.34402 & & 0.911 & 1.34604 & 40.64780 & 38.46027 & & 0.036 & 0.07815 & 44.38181 & 41.39128 \\
\hline 23 & 0.0 .65 & 2.17000 & 33.40703 & 32.52700 & & 0.010 & 9.34078 & 40.70780 & 38.50797 & & 0.835 & 0.87411 & 44.42438 & 41.42435 \\
\hline 24 & 0.094 & 2.14441 & 33.01208 & 32.60000 & & 0.000 & 1.33662 & 40.76740 & 38.63541 & & 0.834 & 0.07000 & 44.46713 & 41.45728 \\
\hline 25 & 0.003 & 2.12007 & 33.80042 & 32.80456 & & 0.000 & 1.32854 & 40.62051 & 38.60243 & & 0.633 & 0.00009 & 44.60064 & 41.40000 \\
\hline 28 & 0.092 & 2.00003 & 33.00537 & 33.02138 & & 0.007 & 1.35235 & 40.68622 & 38.64910 & & 0.832 & 0.83210 & 44.55188 & 41.62278 \\
\hline 27 & 0.031 & 2.07486 & 34.17471 & 33.17180 & & 0.000 & 1.31632 & 40.04362 & 38.00502 & & 0.831 & 0.86812 & 44.59810 & 41.55344 \\
\hline 28 & 0.000 & 2.06575 & 34.36000 & 33.31000 & & 0.005 & 1.31068 & 41.00162 & 38.74150 & & 0.030 & 0.05410 & 44.63620 & 41.58700 \\
\hline 29 & 0.970 & 2.03362 & 34.51200 & 33.45409 & & 0.004 & 1.30460 & 41.00621 & 38.78732 & & 0.020 & 0.86022 & 44.67819 & $\frac{7.007033}{41.6203}$ \\
\hline 30 & 0.078 & 2.01400 & 34.67313 & 33.68670 & & 0.003 & 1.20304 & 41.11640 & 38.65278 & & 0.628 & 0.94620 & 4.72005 & 41.026204 \\
\hline 31 & 0.077 & 1.0060 & 34.0270 & 33.7170 & & 0.002 & 1.20303 & 91.17345 & 38.87797 & & 0.627 & 0.94236 & 44.76174 & 41.6461 \\
\hline 32 & 0.070 & 1.07737 & 34.97780 & 33.84278 & & 0.001 & 1.20727 & 41.23001 & 38.02281 & & 0.020 & 0.03848 & 44.60330 & 41.71601 \\
\hline 33 & 0.978 & $1.0 \mathrm{cos}$ & 35.12320 & 33.00381 & & 0.000 & 1.20150 & 41.28024 & 36.09739 & & 0.025 & 0.93468 & 44.84501 & 41.74000 \\
\hline 34 & 0.974 & 1.2413 & 35.2043 & 34.00116 & & 0.000 & 1.27667 & 41.34217 & 39.01160 & & 0.824 & 0.03072 & 44.86028 & 41.76005 \\
\hline 36 & 0.073 & 1.03094 & 35.40150 & 34.10006 & & 0.000 & 1.27024 & 41.39767 & 39.06606 & & 0.823 & 0.02609 & 44.92760 & 41.61268 \\
\hline 30 & 0.072 & 1.01104 & 35.65613 & 34.30662 & & 0.097 & 1.20404 & $41.465 \%$ & 30.00041 & & 0.022 & 0.02301 & 44.06063 & 41.84445 \\
\hline 37 & 0.071 & 1.00570 & 36.00627 & 34.41360 & & 0.000 & 1.26000 & 41.50701 & 30.14200 & & 0.621 & 0.91918 & 45.0000 & 41.87007 \\
\hline 30 & 0.070 & 1.60070 & 36.70221 & 39.51875 & & 0.603 & 1.26367 & 41.60245 & 30.180 .03 & & $0.0<0$ & 0.01637 & 48.00077 & 41.00754 \\
\hline 30 & 0.00 & 1.00030 & 36.91002 & 34.62113 & & 0.004 & 1.24000 & 41.01600 & 50.2004 & & 0.010 & 0.81158 & 46.00160 & 41.03504 \\
\hline 40 & 0.00 & 7.06210 & 33.03707 & 34.72114 & & 0.003 & 1.24604 & 41.07004 & 3.27170 & & 0.818 & 0.0077 & 45.13244 & 41.07030 \\
\hline 41 & 0.67 & $1.05 \% 2$ & 30.11543 & 34.6163 & & 0.002 & 1.23723 & 41.72400 & 30.31417 & & 0.817 & 0.00500 & 45.17311 & 42.00167 \\
\hline 42 & 0.000 & 1.6001 & 36.27115 & 34.01420 & & 0.001 & 1.23100 & 41.77003 & 30.30005 & & 0.810 & 0.00023 & 45.21360 & 42.03201 \\
\hline 43 & 0.000 & 7.01101 & 30.38460 & 36.00770 & & 0.00 & 1.22 .003 & 41.03112 & 30.30020 & & 0.816 & 0.600347 & 46.23413 & 42.0680 \\
\hline 44 & 0.0 .4 & 1.70012 & 30.46062 & 36.00012 & & 0.000 & 1.22123 & 41.6030 & 30.45007 & & 0.814 & 0.60273 & 46.2048 & 42.0967 \\
\hline 46 & 0.000 & 1.70 .01 & 33.60450 & 35.10 .79 & & 0.803 & 1.21600 & 41.03002 & 30.48147 & & 0.813 & 0.80001 & 45.33460 & 42.12563 \\
\hline 40 & 0.002 & 1.77456 & 36.71142 & 35.276062 & & 0.807 & 1.21072 & 41.0002 & 30.5278 & & 0.812 & 0.06620 & 45.37460 & 42.1570 \\
\hline 47 & 0.001 & 9.70241 & 30.81620 & $36.302 \times 2$ & & 0.080 & 1.20063 & 22.04000 & 30.56373 & & 0.8911 & 0.88160 & 45.41400 & 42.16743 \\
\hline 48 & 0.000 & 1.700 .9 & 30.01000 & 35.4400 & & 0.680 & 1.20000 & 42.00231 & 30.00455 & & 0.810 & 0.87780 & 48.45464 & 42.21810 \\
\hline 40 & 0.000 & 1.7000 & 37.06048 & 36.65007 & & 0.084 & 1.1652 & 48.1440 & 30.04517 & & 0.00 & 0.8742 & 45.40472 & 42.24600 \\
\hline 50 & 0.068 & 1.7200 & 37.12004 & 35.01101 & & 0.603 & 1.10012 & 42.10666 & 30.63560 & & 0.800 & 0.87055 & 45.53452 & 42.27092 \\
\hline $\mathbf{5 1}$ & 0.07 & 1.7160 & 37.21792 & 36.09104 & & 0.682 & 1.10604 & 42.24670 & 30.72571 & & 0.807 & 0.66000 & 4.574420 & 42.30000 \\
\hline 52 & 0.000 & 1.70004 & 37.31418 & 35.77043 & & 0.081 & 1.16000 & 42.20760 & 39.70604 & & 0.000 & 0.80625 & 45.61300 & 42.34001 \\
\hline 53 & 0.003 & 1.0640 & 37.40001 & 35.84784 & & 0.8 .0 & 9.17400 & 42.34600 & 30.80630 & & 0.006 & 0.86062 & 45.60320 & 42.37020 \\
\hline 54 & 0.034 & 1.62404 & 37.00227 & 36.20400 & & 0.870 & 1.17000 & 42.50048 & 30.84400 & & 0.004 & 0.86000 & 45.60200 & 42.40044 \\
\hline 35 & 0.063 & 1.07400 & 37.6025 & 35.00014 & & 0.078 & 1.16000 & 42.44040 & 30.68420 & & 0.803 & 0.85230 & 45.73200 & 42.43050 \\
\hline 56 & 0.852 & 1.00150 & 37.6900 & 30.07300 & & 0.877 & 1.10012 & 42.45030 & 30.92344 & & 0.800 & 0.84670 & 45.77125 & 42.40001 \\
\hline 57 & 0.851 & 9.03100 & 37.77413 & 36.14575 & & 0.878 & 1.13622 & 42.54804 & 30.00241 & & 0.601 & 0.846 & 45.81042 & 42.40050 \\
\hline 58 & 0.560 & 1.04485 & 37.66220 & 36.21751 & & 0.075 & 1.180055 & 42.69745 & 40.00117 & & 0.800 & 0.84102 & 45.64032 & 42.52051 \\
\hline 50 & 0.040 & 1.03623 & 37.04010 & 36.28622 & & 0.674 & 1.14651 & 42.64601 & 40.03973 & & 0.700 & 0.83805 & 43.86854 & 42.55036 \\
\hline$\infty$ & 0.048 & 1.62570 & 36.03400 & 36.36703 & & 0.673 & 1.14060 & 42.60562 & 40.07815 & & 0.708 & 0.83450 & 48.02735 & 42.56000 \\
\hline 81 & 0.047 & 1.61644 & 38.11047 & 36.42065 & & 0.872 & 1.13500 & 42.74436 & 40.116037 & & 0.797 & & 45.06025 & 42.60070 \\
\hline 62 & 0.946 & 1.00720 & 38.20004 & 30.40451 & & 0.671 & 1.13113 & $\$ 2.70300$ & 40.15445 & & 0.700 & 0.62742 & 40.00483 & 42.63034 \\
\hline 63 & 0.045 & 1.50610 & 38.285 .51 & 30.50152 & & 0.870 & 9.12630 & 42.84136 & 40.18232 & & 0.705 & 0.62300 & 48.04354 & 42.66384 \\
\hline 64 & 0.944 & 1.56027 & 38.38707 & 36.62750 & & 0.800 & 1.12168 & 42.66047 & 40.22009 & & 0.704 & 0.82036 & 48.08218 & 42.60835 \\
\hline 65 & 0.043 & 1.56047 & 38.44762 & 30.60280 & & 0.068 & 1.11600 & 42.03744 & 40.26752 & & 0.703 & 0.616887 & 46.12074 & 42.72780 \\
\hline 60 & 0.042 & -57170 & 38.52723 & 38.75734 & & 0.607 & 1.11232 & 42.00323 & 40.30401 & & 0.792 & 0.81338 & 40.15011 & 42.75700 \\
\hline 67 & 0.041 & 1.56322 & 38.60500 & 36.82110 & & 0.860 & 1.10768 & 43.03230 & 40.34210 & & 0.791 & & 46.19741 & 42.78632 \\
\hline 68 & 0.040 & 1.56477 & 38.68360 & 36.88405 & & 0.866 & 1.10300 & 43.00020 & 40.37915 & & 0.700 & 0.80042 & 46.23673 & 92.81666 \\
\hline 69 & 0.039 & 1.54643 & 38.76076 & 30.94627 & & 0.834 & 1.00347 & 43.12736 & 40.4 & & 0.780 & 0.80003 & 46.27367 & 42.04464 \\
\hline 70 & 0.038 & 1.53620 & 38.63665 & 37.00775 & & 0.800 & 1.000300 & 43.17434 & 40.45270 & & 0.780 & $0.7 \% 50$ & 40.31204 & 42.87375 \\
\hline 71 & 0.037 & 1.53007 & 36.01217 & 37.00657 & & 0.862 & 1.00035 & 43.22118 & 40.46027 & & 0.787 & 0.78000 & 46.35002 & 42.00270 \\
\hline 72 & 0.038 & 1.52204 & 38.60870 & 37.12871 & & 0.801 & 1.08462 & 43.2078 & 40.522570 & & 0.786 & 0.70262 & 46.36803 & 42.03160 \\
\hline 73 & 0.035 & 1.51610 & 30.00054 & 37.16827 & & 0.860 & 9.00032 & 43.31420 & 40.58102 & & 0.785 & 0.76010 & 40.42000 & 42.90058 \\
\hline 74 & 0.034 & 1.50620 & 30.13358 & 37.24715 & & 0.869 & 1.073804 & 43.30036 & 40.60001 & & 0.784 & 0.78677 & 46.46362 & 42.00030 \\
\hline 75 & 0.033 & 1.49351 & 30.20002 & 37.30643 & & 0.068 & 1.07138 & 43.40060 & 40.03500 & & 0.783 & 0.76237 & 40.50140 & 43.01800 \\
\hline 78 & 0.032 & 1.46035 & 39.27735 & 37.30010 & & 0.867 & 1.00004 & 49.46501 & 40.0 .077 & & 0.782 & 0.77097 & 46.63017 & 43.04675 \\
\hline 77 & 0.031 & 1.48628 & 30.34447 & 37.42017 & & 0.060 & 1.00232 & 43.48 & 40.70545 & & 0.781 & 0.77567 & 46.57630 & 43.07540 \\
\hline 78 & 0.030 & 1.47579 & 30.41870 & 37.47071 & & 0.055 & 1.06812 & 43.54404 & 40.74000 & & 0.780 & 0.7 & 40.61442 & 43.10401 \\
\hline 79 & 0.02 & 1.46830 & 39.48643 & 37.53271 & & 0.664 & 1.06374 & 43.56091 & 40.77240 & & 0.779 & 0.76862 & 40.65187 & 43.13240 \\
\hline 80 & 0.028 & 1.48100 & 30.66737 & 37.58810 & & 0.663 & 1.04030 & 43.63472 & 40.81158 & & 0.778 & 0.76546 & 48.60924 & 43.16000 \\
\hline 81 & 0.027 & 1.45381 & 30.62578 & 37.64302 & & 0.8652 & 1.04505 & 43.67037 & 40.84671 & & $0.7 \pi$ & 0.78210 & 46.72004 & 43.160033 \\
\hline 82 & 0.020 & 1.44063 & 39.00003 & 37.09748 & & 0.065 & 1.04073 & 43.72480 & 40.88171 & & 0.778 & 0.76875 & 46.70305 & 43.21700 \\
\hline 83 & 0.028 & 1.430033 & 30.70065 & 37.75140 & & 0.050 & 1.03643 & 4.76000 & 40.91686 & & 0.775 & 0.75642 & 46.80100 & 43.24569 \\
\hline
\end{tabular}




\begin{tabular}{|c|c|c|c|c|c|c|c|c|c|c|c|c|c|c|}
\hline A & A & $B$ & C & $D$ & 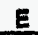 & $F$ & a & $H$ & 1 & $J$ & K & $L$ & $\mathbf{M}$ & $\mathbf{N}$ \\
\hline & Nrount Tye & 304 onlnich & sotedolat & & & 66.227 & median UTE & & & & $0.141 \mathrm{~h}$ & nedian villur & estrin & \\
\hline 2 & $360 \mathrm{~F}$ & & & & & $6.03 \mathrm{~h}$ & median billu & estrees & & & 60.26 & VUAECCA & 8.003 tillur & 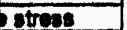 \\
\hline 3 & $1.0 E-04 E$ & Iure probule & ifiy & & & 20.83 & Inedian yolo & etrous & & & 25.12 & VUAECCA & 56003 yold & streses \\
\hline & & & & & & 0.100 & 50 & & & & 0.120 & cilusted tall & Ure strain & \\
\hline & & & & & & & & & & & & & & \\
\hline & sumval & & & adjusted & & sunval & & & aduated & & auntal & & & adfueted \\
\hline & conflidence & $x$ & atreas & atreses & & sonticence & $x$ & strese & streas & & confidence & $x$ & etroess & strees \\
\hline & 0.0000 & 3.71002 & 20.63000 & 26.63000 & & & & & & & & & & \\
\hline & 0.000 & 3.00023 & 30.38738 & 29.04862 & & 0.024 & 9.43260 & 42.10363 & 39.62407 & & 0.040 & 1.03216 & 45.67462 & 42.35070 \\
\hline 10 & 0.00 & 2.87816 & 31.60057 & 31.06604 & & 0.023 & 1.42054 & 42.26202 & 30.72034 & & 0.840 & 1.0270 & 46.71330 & 42.41000 \\
\hline 11 & 0.007 & 2.74778 & 32.51036 & 31.77520 & & 0.002 & 9.41800 & 42.30070 & 30.77620 & & 0.647 & 1.02506 & 48.73178 & 42.44500 \\
\hline 12 & 0.000 & 2.66207 & 33.14153 & 32.30200 & & 0.021 & 1.41163 & 42.30008 & 39.80014 & & 0.060 & 1.01045 & 45.70001 & 42.47407 \\
\hline 13 & 0.003 & 2.57583 & 33.04564 & 32.72744 & & 0.020 & 9.40007 & 42.42362 & 30.60473 & & 0.848 & 1.0182 & 48.62010 & 42.50410 \\
\hline 14 & 0.004 & 2.51214 & 34.07264 & 33.06622 & & 0.010 & $9.36 \cdot 63$ & 42.47030 & 30.0068 & & 0.644 & 1.01100 & 45.60023 & 42.56569 \\
\hline 15 & 0.003 & 2.46720 & 34.44402 & 33.35002 & & 0.010 & 1.30174 & 42.65675 & 30.00270 & & 0.845 & 1.0000 & 45.00412 & 42.60227 \\
\hline 10 & 0.002 & 2.40002 & 34.77620 & 33.67471 & & 0.017 & 1.36517 & 42.60112 & $30.00 \times 21$ & & 0.842 & 1.00271 & 45.04186 & 42.60113 \\
\hline 17 & 0.991 & $2.306 \times 2$ & 35.07565 & 33.22418 & & 0.016 & 1.37800 & 42.04006 & $40.050 \mathrm{~m}$ & & 0,841 & 0.0686 & 45.0794 & 42.61006 \\
\hline 18 & 0.000 & 2.320035 & 35.34946 & 34.15177 & & 0.015 & 1.37220 & $42.700 \mathrm{sa}$ & 40.00200 & & 0.640 & 0.0946 & 46.01607 & 42.64004 \\
\hline 10 & 0.600 & 2.20037 & 35.60220 & 34.36141 & & 0.014 & 9.36061 & 42.73470 & 40.12446 & & 0.860 & 0.00036 & 46.00434 & 42.67700 \\
\hline 20 & 0.000 & $2.257+3$ & 35.83730 & 34.550 .04 & & 0.013 & 9.36040 & 42.80000 & 40.10600 & & 0.658 & 0.00027 & 46.00165 & 42.70650 \\
\hline 21 & 0.067 & 2.22021 & 36.06738 & 34.73709 & & 0.012 & 1.36317 & 42.60105 & 40.20036 & & 0.637 & 0.0 .520 & 46.12601 & 42.73560 \\
\hline 22 & 0.000 & 2.10720 & 36.28446 & 34.00674 & & 0.011 & 1.34004 & 42.01475 & 40.24077 & & 0.850 & 0.97816 & 40.16862 & 42.7621 \\
\hline 23 & 0.086 & 2.17000 & 36.46030 & 35.07005 & & 0.010 & 1.34070 & 42.00730 & 40.20068 & & 0.806 & 0.07411 & 40.2027 & 42.70040 \\
\hline 24 & 0.084 & 2.14441 & 36.64617 & 35.22201 & & 0.000 & 1.33462 & 43.01057 & 40.33170 & & 0.634 & 0.97000 & 46.23000 & 42.81847 \\
\hline 25 & 0.000 & 2.12007 & 36.82321 & 35.36830 & & 0.00 & 1.36364 & 43.07130 & 40.37227 & & 0.863 & 0.0000 & 40.27600 & 42.84042 \\
\hline 26 & 0.032 & 2.00003 & 30.00232 & 35.50609 & & 0.007 & 1.32231 & 43.12265 & 40.41240 & & 0.032 & 0.02210 & 46.3127 & 42.87450 \\
\hline 27 & 0.081 & 2.07408 & 37.15441 & 35.63974 & & 0.000 & 9.31062 & 43.17403 & 40.46246 & & 0.031 & 0.05012 & 46.34028 & 42.00214 \\
\hline 28 & 0.080 & 2.00576 & 37.30000 & 35.70000 & & 0.006 & 1.31068 & 43.22464 & 40.40212 & & 0.630 & 0.8 .516 & 40.30364 & $42.6 \times 64$ \\
\hline 20 & 0.070 & 2.03562 & 37.45072 & 35.06034 & & 0.004 & 1.30469 & 43.27520 & 40.53140 & & 0.020 & 0.05022 & 40.42184 & 42.06742 \\
\hline 30 & 0.978 & 2.01400 & 37.00411 & 36.00710 & & 0.003 & 1.2684 & 03.36544 & 40.570 .2 & & 0.023 & 0.04020 & 60.46700 & 42.00400 \\
\hline 31 & 0.07 & 1.0050 & 37.74301 & 35.1200 & & 0.002 & 1.20003 & 43.37831 & 40.00002 & & 0.027 & 0.04238 & 46.40500 & $43.012 \times 5$ \\
\hline 32 & 0.970 & 1.07737 & 37.87835 & 30.23075 & & 0.001 & 1.26727 & 43.42481 & 40.04811 & & 0.020 & 0.03048 & 40.52000 & 43.00000 \\
\hline 33 & 0.976 & 1.6000 & 35.00033 & 36.33715 & & 0.000 & 1.20185 & 43.47402 & 40.6940 & & 0.025 & 0.03460 & 46.56603 & 43.00704 \\
\hline & 0.974 & 1.94313 & 36.13021 & 30.44020 & & 0.809 & 1.27687 & 43.52004 & 40.72457 & & 0.024 & 0.03072 & 46.60143 & 43.00413 \\
\hline 36 & 0.973 & 1.00034 & $30.200 \mathrm{m2}$ & 36.54027 & & 0.000 & 1.27024 & 43.67149 & 40.70237 & & 0.820 & 0.02000 & 46.63707 & 43.12123 \\
\hline 30 & 0.972 & 1.01104 & 38.37000 & 36.63750 & & 0.67 & 1.20404 & 43.61003 & 40.00000 & & 0.02 & 0.02501 & 40.67203 & 43.14620 \\
\hline 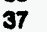 & 0.971 & 1.60570 & 38.4500 & 38.73210 & & 0.00 & 1.26000 & 43.60788 & $40.8373^{\circ}$ & & 0.621 & 0.01018 & 46.70004 & 43.17310 \\
\hline 38 & 0.070 & 1.80070 & 36.6000 & 36.62425 & & 0.6 .5 & 1.25657 & 43.71656 & 40.87440 & & 0.050 & 0.01637 & 40.74520 & 43.20103 \\
\hline 30 & 0.00 & 9.0000 & 30.72002 & 30.01300 & & $0.0 \mathrm{~d}$ & 7.2460 & 43.70310 & 40.91143 & & 0.010 & 0.01186 & 46.77667 & 43.20070 \\
\hline 40 & 0.808 & 1.06210 & 30.60523 & 37.00160 & & 0.603 & 1.24684 & 43.01020 & 40.94600 & & 0.818 & 0.0077 & 46.81300 & 43.20340 \\
\hline 41 & 0.067 & 1.03642 & 36.03517 & 37.06713 & & 0.802 & 1.20723 & 43.60722 & 40.03456 & & 0.017 & 0.00000 & 40.84 .74 & 45.2000 \\
\hline 42 & 0.60 & 9.62501 & 30.05800 & 37.17005 & & 0.601 & 1.23160 & 43.00568 & 41.00002 & & 0.810 & 0.00023 & 40.6050 .3 & 43.300 .77 \\
\hline 49 & 0.005 & 1.81101 & 30.14000 & 37.25260 & & 0.600 & 1.26063 & 43.06024 & 41.06601 & & 0.018 & 0.80047 & 48.91605 & 43.33 .077 \\
\hline 44 & 0.504 & 1.70012 & 39.23003 & 37.33235 & & 0.600 & 1.22123 & 43.00000 & 41.00003 & & 0.814 & 0.60273 & 46.06331 & 43.3014 \\
\hline 45 & 0.003 & 1.70031 & 39.35606 & 37.41000 & & 0.060 & 1.21508 & 44.04232 & 41.12827 & & 0.013 & 0.60001 & 46.00701 & 43.30700 \\
\hline 46 & $0.0 \% 2$ & 1.7745 & 39.432003 & 37.48737 & & 0.07 & 1.21072 & 44.00804 & 41.16373 & & 0.012 & 0.000 .68 & 47.002303 & 43.41505 \\
\hline 47 & 0.61 & 1.70341 & 30.62530 & 37.562250 & & 0.60 & 1.20663 & 44.133357 & 41.10600 & & 0.851 & $0.001 E 0$ & 47.0060 & 43.44007 \\
\hline 48 & 0.0 .0 & 1.75060 & 39.61743 & 37.63635 & & 0.000 & 1.20053 & 44.17860 & 41.23501 & & 0.810 & 0.07700 & 97.00130 & 43.40014 \\
\hline 49 & 0.000 & 1.5000 & 30.70767 & 37.70975 & & 0.834 & 1.10 .02 & $44.20 \times 5$ & 41.20077 & & 0.000 & 0.87462 & $47.12 \cdot 12$ & 43.40210 \\
\hline 50 & 0.060 & 1.72703 & 30.78030 & 37.77000 & & 0.0 .3 & 1.10612 & 44.20024 & 41.30038 & & 0.000 & 0.67065 & 47.1600 & 40.61011 \\
\hline & 0.007 & 1.71600 & 39.80397 & 37.6456 & & 0.0 .9 & 1.18504 & 44.31279 & 41.33767 & & 0.007 & & 47.1017 & 43.5400 \\
\hline 52 & 0.000 & $1.70 \cdot 04$ & 39.0002 & 37.01630 & & 0.681 & 1.18000 & 44.36704 & 41.37212 & & 0.000 & $0.00 \times 25$ & 47.20010 & 43.5007 \\
\hline 53 & 0.005 & 1.60340 & 40.0563 & 37.00665 & & 0.000 & 1.17400 & 44.40107 & 41.40018 & & 0.000 & & $47.2 \times 216$ & 4.60600 \\
\hline & 0.084 & 1.60404 & 40.15630 & 30.05227 & & 0.670 & 1.17000 & 44.4460 & 91.44013 & & 0.004 & 0.86000 & 47.2004 & 43.62112 \\
\hline$\$ 5$ & 0.003 & 1.07400 & 40.21637 & 38.11764 & & 0.878 & 1.16000 & 44.46054 & 41.47383 & & 0.800 & 0.05259 & 60 & 45.64071 \\
\hline 56 & 0.006 & 1.03458 & 40.20060 & 38.18100 & & 0.877 & 1.10012 & & $41.6 x$ & & 0.802 & & 97.30051 & 40.67224 \\
\hline 57 & 0.051 & 1.65463 & 40.37820 & 33.24627 & & 0.678 & 9.13 & 44.57622 & 41.54022 & & 0.801 & & 47.39729 & 43.60771 \\
\hline 88 & 0.000 & 1.04486 & 40.4 & 38.30772 & & 0.875 & 1.15035 & 9.61023 & 41.57404 & & 0.600 & 0.04162 & 47.45000 & 43.72312 \\
\hline$s$ & 0.040 & 1.03623 & 40.533381 & $38.300 \mathrm{02}$ & & 0.674 & & & 41.60707 & & 0.700 & & 47.46444 & 43.74947 \\
\hline 60 & 0.048 & 1.62670 & 40.60000 & 36.42034 & & 0.673 & 1.1 & 44.700 & 41.63000 & & 0.760 & 0.83450 & 47.40762 & 43.77300 \\
\hline 61 & 0.047 & 1.61644 & 40.8 & 38.4 & & 0.6 & & .74607 & & & 0.797 & & 47.63122 & \\
\hline 62 & 0.040 & 1.00720 & 40.73680 & 38.54860 & & 0.879 & 1.13 & 44.76835 & 41.70 & & 0.700 & 0.62742 & 47.60446 & 43.82400 \\
\hline 63 & 0.046 & 1.50619 & 40.63190 & 38.60 & & 0.870 & 1.12 & 44.85041 & 41.78 & & 0.760 & 0.82000 & 47.60762 & 43.84000 \\
\hline 64 & 0.044 & 1.60027 & $40 . x$ & & & & & & & & 0.794 & & 97.03000 & 43.87411 \\
\hline 65 & 0.043 & 1.86047 & 40.07631 & 38.72005 & & 0.600 & 1.11000 & 44.913003 & 41.00215 & & 0.703 & & 47.60302 & 43.80010 \\
\hline 60 & 0.092 & 1.57170 & 41.04500 & 36.77682 & & 0.867 & & 44.05048 & 41.63417 & & 0.702 & & 2637 & 43.92300 \\
\hline 67 & 0.821 & & & 38.83 & & & & & 41.80000 & & 0.791 & & 72075 & 43.94670 \\
\hline 68 & 0.940 & 1.65477 & 41.16456 & 38.88677 & & 0.865 & 1.10506 & 45.03790 & 41.89770 & & 0.700 & & 76203 & 43.07368 \\
\hline 60 & 0.030 & 1.34043 & 41.25202 & 38.96074 & & 0.864 & 1.00347 & 46.07804 & & & 0.780 & & 47.70038 & \\
\hline 70 & 0.038 & 7.53620 & 41.31 & 38.06 & & 0.060 & 1.00500 & 45.11175 & 41.80000 & & 0.768 & & 47.82814 & 44.02204 \\
\hline 71 & 0.037 & 1.53007 & 41.36048 & 30.04678 & & 0.602 & 1.00035 & 45.16042 & 41.09101 & & 0.767 & 0.70000 & 47.60073 & 44.04750 \\
\hline 72 & & & 41.46233 & 30.00002 & & & & & & & 0.780 & & 47.60334 & 44.07207 \\
\hline 73 & 0.935 & 1.51410 & 41.51760 & 39.150 & & 0.600 & 1.00032 & 46.24124 & 42.05405 & & 0.768 & & 47.02360 & \\
\hline 74 & 0.034 & 1.80620 & 91.56200 & 39.20163 & & 0.650 & 1.07584 & 46.238130 & 42.00491 & & 0.704 & 0.7607 & 47.03634 & 44.12102 \\
\hline 78 & 0.033 & 1.46251 & 41.04502 & 30.25201 & & 0.668 & 1.07136 & 45.32140 & 42.11584 & & 0.703 & 0.76237 & 47.00004 & 44.14534 \\
\hline 78 & 0.032 & 1.40005 & 41.70013 & 39.30103 & & 0.657 & 1.00004 & 46.30120 & 42.14000 & & 0.782 & 0.77697 & 40.02200 & 4.10000 \\
\hline 77 & 0.031 & 1.48368 & 41.77170 & 30.35136 & & 0.868 & 1.00252 & 45.40000 & 42.17675 & & 0.781 & 0.77857 & 48.06350 & 4.10400 \\
\hline 78 & 0.030 & & 41.85370 & 39.40029 & & 0.653 & & 45.44036 & 42.20713 & & 0.780 & & 48.00746 & 44.21 .20 \\
\hline 70 & 0.020 & 7.46838 & 41.86512 & 39.44875 & & 0.854 & 1.05374 & 45.47000 & 42.23738 & & 0.779 & 0.760 .2 & 40.11038 & 44.24234 \\
\hline 80 & 0.028 & 9.46108 & 41.93580 & 39.40060 & & 0.603 & 1.04039 & 45.51017 & 42.20745 & & 0.778 & 0.70650 & 48.15160 & 4.2072 \\
\hline 81 & 0.027 & 1.45381 & 42.01610 & 30.54417 & & 0.862 & 1.04605 & 46.655630 & 42.20748 & & 0.77 & & & \\
\hline 82 & 0.020 & 9.44603 & 42.07504 & 30.50120 & & 0.851 & 1.04073 & 46.50720 & 42.32735 & & 0.776 & 0.70075 & 46.21602 & 44.31454 \\
\hline 83 & 0.026 & 1.43950 & 42.13613 & 39.63787 & & 0.650 & 1.03643 & 46.63613 & 42.35712 & & 0.775 & 0.76542 & 46.24742 & 4.35345 \\
\hline
\end{tabular}


Attachment 2

\begin{tabular}{|c|c|c|c|c|c|c|c|c|c|c|c|c|c|c|}
\hline A & A & B & c & $D$ & $E$ & $F$ & a & $\mathrm{H}$ & 1 & $J$ & $K$ & 1 & $M$ & N \\
\hline 1 & $\frac{\text { Ent Type } 30}{300 F}$ & andones & 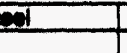 & & & $\frac{03.187}{5.371}$ & modan UTE & - & & & 0.103 & mediantilly & estrain & Streas \\
\hline 3 & $1.0 E-03 E$ & ine probal & Iity & & & 25.003 & modian ylal & Totrees & & & 26.12 & NuTe-cent & $\frac{50000}{5603 \text { yleted }}$ & $\frac{\text { buns }}{\text { btreses }}$ \\
\hline 4 & & & & & & 0.230 & sets & & & & 0.157 & Ifiusted all & tre strain & \\
\hline & & & & & & & & & & & & & & \\
\hline 6 & ounival & & & actuothd & & sunhal & & & adjuated & & eurvival & & & Acjuatod \\
\hline 7 & conlichen & $x$ & these & stress & & confidence & $x$ & treas & otreas & & soniciconce & $x$ & strees & Atrees \\
\hline 8 & 0.900 & 3.71002 & & & & & & & & & & & & \\
\hline & 0.00 & $3.000 \times 3$ & 25.60300 & 28,60300 & & 0.024 & 1.45250 & 38.26074 & 36.00761 & & 0.840 & 1.03215 & 42.00327 & 38.07662 \\
\hline 10 & $0.0 \%$ & 2.87810 & 27.22247 & 27.04601 & & 0.023 & 1.42004 & 38.36972 & 30.13620 & & 0.848 & 1.02769 & 4.13603 & 30.00040 \\
\hline 11 & 0.007 & 2.74778 & 28.07346 & 27.77488 & & 0.822 & 1.41600 & 38.42217 & 36.10460 & & 0.847 & 1.02365 & 42.17763 & 30.04004 \\
\hline 12 & 0.00 & 2.6607 & 28.71300 & 28.35063 & & 0.021 & 1.41163 & 36.40400 & 30.23240 & & 0.840 & 1.01043 & 42.21037 & 30.07746 \\
\hline 13 & 0.000 & 2.67623 & 20.23006 & 20.70200 & & 0.020 & 1.40607 & 36.54656 & 30.20000 & & 0.846 & 1.01522 & 42.20180 & 30.100201 \\
\hline 14 & 0.004 & 2.81214 & 20.67001 & 29.15511 & & 0.010 & 1.50058 & 38.60640 & 36.32707 & & 0.844 & 9.01103 & 42.30360 & 30.13400 \\
\hline 15 & 0.003 & 2.46720 & 30.00000 & 20.46033 & & 0.018 & 1.30174 & 35.60706 & 36.37363 & & 0.046 & 1.00600 & 42.34636 & 30.16613 \\
\hline 16 & $0.0 \mathrm{~m}$ & $2.400 \mathrm{c}$ & 30.41180 & 20.74834 & & 0.017 & 1.54017 & 38.72700 & 30.42014 & & 0.042 & 1.00271 & 42.36067 & 30.10010 \\
\hline 17 & 0.001 & 2.36602 & 30.72450 & 30.00675 & & 0.910 & 1,37600 & 38.78008 & 30.46 .00 & & 0.041 & 0.0030 & 42.42822 & 30.22000 \\
\hline 18 & 0.00 & 2.32003 & 31.01040 & 30.2466 & & 0.018 & 1.37220 & 38.84686 & 30.51171 & & 0.040 & 0.00440 & 42.46031 & 39.20771 \\
\hline 10 & 0.00 & 2.20037 & 31.27505 & 30.46078 & & 0.014 & 1.36681 & 36.00461 & 36.65600 & & 0.030 & 0.6006 & 42.61004 & 30.26030 \\
\hline 20 & 0.060 & 2.20713 & 31.62140 & 30.60948 & & 0.013 & 1.36040 & 38.00263 & 30.60183 & & 0.638 & 0.96027 & 42.65171 & 30.31000 \\
\hline 21 & 0.507 & 2.2621 & 31.73242 & 30.65077 & & 0.812 & 1.36317 & 39.02078 & 36.64630 & & 0.607 & 0.06220 & $42.50 \times 2$ & 30.34041 \\
\hline$\ddot{20}$ & 0.000 & 2.1070 & 31.0000 & 31.05002 & & 0.911 & 1.340 .04 & 30.07823 & 30.60057 & & 0.650 & 0.07818 & 42.60337 & 39.37974 \\
\hline 23 & 0.0 .0 & 2.17000 & 32.17804 & 31.20010 & & 0.810 & 1.34070 & 30.13620 & 30.73443 & & 0.056 & 0.97411 & 42.67406 & 30.41001 \\
\hline 24 & 0.0 .4 & 2.14441 & 32.37101 & 31.30000 & & 0.000 & 1.33462 & 30.10200 & 36.77605 & & 0.634 & 0.07000 & 42.71460 & 30.44015 \\
\hline 25 & 0.0 .3 & 2.12007 & 32.65018 & $31.561 \mathrm{OO}$ & & 0.000 & 1.32054 & 30.24036 & 36.62120 & & 0.635 & 0.00000 & 42.73404 & 30.47016 \\
\hline 20 & 0.0 .2 & 2.0603 & 32.73054 & 31.00000 & & 0.007 & 1.52601 & 30.30428 & 38.60410 & & 0.632 & 0.06210 & 42.70 .23 & 30.80010 \\
\hline 27 & 0.001 & 2.07460 & 32.00705 & 31.80040 & & 0.000 & 1.316 .2 & 30.36001 & 30.00000 & & $0.6 \sqrt{31}$ & 0.05012 & 42.83640 & 30.50000 \\
\hline 26 & 0.000 & 2.0 .576 & 33.07190 & 31.04020 & & 0.000 & 1.31060 & 30.41515 & 36.94021 & & 0.650 & 0.03416 & 42.87603 & 30.60075 \\
\hline 20 & 0.070 & 2.03362 & $33.2 \times 033$ & 32.00001 & & 0.004 & 1.30460 & 39.47000 & $3 . .9124$ & & 0.620 & 0.03022 & 42.01644 & 30.560037 \\
\hline 30 & 0.078 & 2.01400 & 33.30313 & 32.10000 & & 0.003 & 1.2004 & 30.52453 & 37.03500 & & 0.62 & 0.04620 & 42.03027 & 30.01803 \\
\hline 31 & 0.077 & 1.5 .300 & 33.65094 & 32.31210 & & 0.002 & 1.20303 & 30.57600 & 37.07460 & & 0.027 & 0.04238 & 42.00400 & 30.64637 \\
\hline 32 & 0.070 & $1.97 \mathrm{rs7}$ & 33.67301 & 32.42046 & & 0.001 & 1.26727 & 30.05207 & 37.11577 & & 0.820 & 0.03648 & 43.03450 & 30.67774 \\
\hline 33 & 0.070 & 1.060 & 33.01251 & 32.54000 & & 0.000 & 1.20168 & 39.66023 & 37.15673 & & 0.00 & 0.03458 & 43.07480 & 30.70713 \\
\hline 34 & 0.074 & 1.04313 & 35.04713 & 32.64009 & & 0.0 .0 & 1.27697 & 39.73000 & 37.10744 & & 0.624 & 0.03072 & 43.11347 & 30.75020 \\
\hline 35 & 0.073 & $1.60 \times 4$ & 34.0700 & 32.75476 & & 0.00 & 1.21024 & 39.70034 & 37.23702 & & 0.03 & 0.02000 & 43.15278 & 30.7036 \\
\hline 30 & 0.072 & 1.01104 & 34.20031 & 32.80752 & & 0.697 & 1.20404 & 30.046 & 37.27003 & & 0.022 & 0.02301 & 43.10000 & 30.70411 \\
\hline 37 & 0.971 & 1.0670 & 34.32002 & 32.05715 & & 0.60 & 1.5000 & 30.00730 & 37.31707 & & 0.021 & 0.01010 & 43.23110 & $30.0 \times 30$ \\
\hline 36 & 0.070 & 1.0 .070 & 34.45046 & $33 . \cos 41$ & & 0.805 & 1.5657 & 30.04027 & 37.35700 & & 0.620 & 0.01537 & 43.27001 & 30.06212 \\
\hline 30 & 0.000 & 1.0000 & 34.60034 & 33.14016 & & 0.004 & 9.2400 & 40.00100 & 37.30711 & & 0.010 & 0.91160 & 43.30000 & 50.0000 \\
\hline 40 & 0.50 & 1.0 .218 & 34.6 .007 & 33.24100 & & 0.03 & 1.245 & 40.00620 & 37.4560 & & 0.010 & 0.00777 & 43.3472 & 30.0000 \\
\hline 41 & 0.0 .57 & 1.62 & 34.7004 & 33.332 .07 & & 0.0 .3 & 1.2350 & 40.10368 & 37.4760 & & 0.017 & 0.0050 & 43.50 .042 & 30.050 .21 \\
\hline 48 & 0.900 & $1.0 \times 01$ & 34.00710 & 33.46003 & & 0.001 & 1.23160 & 40.18460 & 37.51400 & & 0.810 & 0.00003 & 45.42460 & \\
\hline 43 & 0.0 .3 & 1.61101 & 36.01632 & 30.00074 & & 0.000 & 1.20 .03 & 40.20012 & 37.86231 & & 0.615 & 0.60347 & $43.40 \times 62$ & 30.0047 \\
\hline 44 & 0.0 .4 & 1.7012 & 36.12121 & 33.60127 & & 0.0 .0 & 1.22120 & 40.23547 & 37.00011 & & 0.814 & 0.0273 & 4.60102 & $40.0 \times 563$ \\
\hline 45 & $0.0 \times 3$ & 1.70 .1 & 36.22510 & 33.07412 & & 0.00 & 1.21000 & 40.30660 & 37.6202 & & 0.013 & 0.86001 & 43.54014 & 40.05174 \\
\hline 40 & 0.0 .2 & 1.7760 & 35.32000 & 33.70 .67 & & 0.607 & 1.21072 & 40.36340 & 37.00094 & & 0.012 & & 43.57640 & 40.0700 \\
\hline 47 & 0.601 & 1.76241 & 36.46000 & 33.03465 & & 0.60 & 9.20053 & 40.40400 & 37.7044 & & 0.011 & 0.00150 & $43.610 \%$ & 40.10007 \\
\hline 46 & $0.0 \% 0$ & 1.700 .9 & 36.65511 & 33.01601 & & 0.003 & 1.20050 & 40.45451 & 37.74100 & & 0.610 & 0.07700 & 4.60340 & 40.15310 \\
\hline 40 & 0.050 & 1.7000 & 36.62101 & $33.0 \cdots 0$ & & 0.024 & 1.1632 & 40.5034 & 37.77010 & & 0.000 & 0.8742 & 43.60246 & 40.10407 \\
\hline 80 & 0.096 & 1.72103 & 36.71652 & 34.00402 & & 0.0 .3 & 1.10012 & 40.8624 & 37.81621 & & 0.003 & 0.87066 & 43.75030 & $\$ 0.1010$ \\
\hline 51 & 0.96 & 1.7160 & 35.60074 & 34.15000 & & 0.6 .2 & 1.10604 & 40.00000 & 37.60312 & & 0.007 & 0.00000 & $\overline{513}$ & 40.21033 \\
\hline 52 & 0.000 & 1.70004 & 33.00150 & 34.21 & & 0.001 & 1.16000 & 40.04024 & 37.80978 & & 0.000 & 0.00650 & 43.00070 & 40.24734 \\
\hline 63 & 0.03 & $1.6 .3+0$ & 35.6016 & 34.26312 & & 0.0 .0 & 1.17400 & 40.60730 & 37.02021 & & 0.000 & 0.6062 & 4.04532 & 40.27010 \\
\hline 64 & 0.0 .54 & 1.6 .04 & 30.00000 & 34.36562 & & 0.670 & 1.17000 & 40.74633 & 37.0004 & & 0.004 & 0.05000 & 43.00001 & 40.30270 \\
\hline 8 & 0.830 & 1.07400 & 30.10057 & 34.4201 & & 0.07 & & 40.7000 & 201 & & 0.003 & 50 & 43.01602 & 40.33000 \\
\hline 80 & 0.0 .2 & 1.60160 & 30.25402 & 34.4 & & 0.67 & 1.16012 & 40.84040 & & & 0.602 & 879 & 43.06067 & 677 \\
\hline 87 & 0.531 & 1.06403 & 30.34002 & 34.55018 & & 0.070 & 1.15022 & 40.68778 & 38.0 & & 0.601 & 0.84620 & $43 . \cos 24$ & 6317 \\
\hline 68 & 0.030 & 1.6446 & 30.42403 & 34.02450 & & 0.675 & & 40.03460 & & & 0.600 & 0.04162 & 44.05004 & 40.41251 \\
\hline 50 & 0.040 & 1.05 .23 & 30.50035 & 34.6 & & 0.074 & 9.14051 & 40.03161 & 33. & & 0.700 & 0.86005 & 4.00717 & 5078 \\
\hline$\infty$ & 0.040 & 1.02570 & 36.56857 & 34.7 & & 0.673 & 1.14000 & 41.02627 & 38.1 & & 0.703 & 0.03480 & 44.10412 & \\
\hline 01 & 0.947 & 1.01044 & 30.0097 & 34.8 & & 0.672 & & 41.07470 & & & 0.797 & & & 40.40407 \\
\hline 62 & 0.040 & 9.60725 & 30.74802 & 34.87000 & & 0.071 & 1.13113 & 41.12000 & 38.2 & & 0.700 & c सर2742 & & 40.52100 \\
\hline$\infty$ & 0.045 & 9.56010 & 36.62751 & 34.04160 & & 0.070 & 1.11 & 41.10703 & 38.28120 & & 0.765 & & 44.21404 & 4600 \\
\hline 64 & 0.094 & 9.56027 & 39.00515 & 35.00274 & & 0.000 & & 41.21233 & & & 0.704 & & 44.25140 & 40.57400 \\
\hline 65 & 0.043 & 1.56047 & 30.03101 & 36.0 & & 0.000 & 1.11600 & 41.23640 & 38.36016 & & 0.703 & 0.81007 & 44.20000 & 018 \\
\hline$\infty$ & & & $37.05 \mathrm{~m}$ & 35.12240 & & 0.607 & & 41.30401 & 38.38445 & & 0.702 & 0.81330 & 44.32460 & 2865 \\
\hline 67 & 0.9 & 1.0002 & 37.13263 & 35.181110 & & 0.800 & & 41.34828 & & & 0.791 & & 44.30100 & 40.05334 \\
\hline & 0.040 & 1.53477 & 37.20000 & 35.23 & & 0.663 & 1.10300 & 41.30441 & 38.45252 & & 0.700 & 0.60012 & 44.39740 & 8206 \\
\hline 6 & 0.030 & 1.64043 & 37.20002 & 35.20658 & & 0.004 & & & 38.48620 & & 0.760 & & 44.43377 & 40.70001 \\
\hline 70 & 0.030 & 9.63200 & 37.36223 & 35.30 & & 0.003 & 1.00000 & 41.48403 & 38.5 & & 0.769 & 0.70600 & 44.47000 & 3510 \\
\hline 71 & 0.097 & 1.65007 & 37.42460 & 35.40 & & 0.002 & 1.00035 & 41.52602 & 38.63347 & & 0.787 & 0.7000 & 44.60022 & 40.76163 \\
\hline 72 & $0.0 \times 3$ & 1.62204 & 37.46502 & 35.4 & & 0.601 & 1.00462 & 41.57300 & 38.56687 & & 0.760 & $0.70 \times 2$ & 44.34256 & 40.76000 \\
\hline 73 & 0.035 & 1.51410 & 37.5650 & 35.51803 & & 0.000 & 1.00032 & 41.61725 & 30.62007 & & 0.785 & 0.70019 & 44.57847 & 40.81 \\
\hline 74 & 0.034 & 1.50020 & 37.03688 & 35.57389 & & 0.60 & 1.07534 & 41.60130 & 38.65314 & & 0.784 & 0.70 .77 & 44.61448 & 40.64000 \\
\hline 75 & 0.053 & 1.46851 & 37.70451 & 36.62738 & & 0.683 & 1.07138 & 41.70510 & 38.60600 & & 0.783 & 0.70207 & 44.60031 & 40.80000 \\
\hline 76 & 0.052 & 1.40003 & 37.77278 & 35.6 & & 0.667 & 1.00004 & 41.74603 & & & 0.782 & 0.77697 & & 40.60318 \\
\hline$\pi$ & 0.031 & 1.40328 & 37.64033 & 36.7 & & 0.800 & & 41.700232 & & & 0.781 & 0.77507 & 44.72205 & \\
\hline 78 & 0.050 & 1.47670 & 37.00731 & 3.7 & & 0.860 & 1.06012 & 41.83600 & 36.7 & & 0.780 & 0.77210 & 44.75775 & 40.94545 \\
\hline 79 & 0.00 & 1.46838 & 37.97368 & 36.65604 & & 0.054 & 1.05374 & 41.87025 & 36.61681 & & 0.770 & 0.76082 & 44.70330 & 40.07145 \\
\hline & 0.020 & 1.46100 & 38.00037 & 35.66700 & & 0.053 & 1.04030 & 41.9223 & 38.84085 & & 0.778 & 0.76546 & 44.82003 & 40.00730 \\
\hline 81 & 0.027 & 1.75381 & 38.10464 & 35.95852 & & 0.6 .2 & 1.04505 & 41.06328 & 38.68104 & & 0.77 & 0.76210 & 44.66450 & 41.02334 \\
\hline 82 & 0.000 & 1.446 .03 & 38.10010 & 35.9607 & & 0.661 & 1.04073 & 42.00000 & 30.01310 & & 0.778 & 0.76075 & 44.00000 & 41.04022 \\
\hline & 0.65 & 1.45033 & 38.23320 & 30.03831 & & 0.0 .0 & $1.00 \sin$ & 42.00075 & 30.04502 & & 0.775 & 0.73542 & 44.03532 & 41.07400 \\
\hline
\end{tabular}


Attachment 2

\begin{tabular}{|c|c|c|c|c|c|c|c|c|c|c|c|c|c|c|}
\hline A & A & B & C & D & $\mathbf{E}$ & $F$ & 0 & $H$ & 1 & $J$ & K & $L$ & $M$ & $\mathbf{N}$ \\
\hline 1 & Cot Type 30 & stinleas & 01 & & & 63.187 & Thedien UTE & & & & 0.163 & medien thilu & $\sqrt{\text { re strain }}$ & \\
\hline 2 & $360 \mathrm{~F}$ & & & & & 8.3 .71 & medien falle & sotries & & & 04.58 & NUAECCA & E003 tallur & stress \\
\hline 3 & $1.0 E-04 E$ & Ilure probut & Itity & & & 25.693 & medien yole & Itreas & & & 25.12 & NUAEबCA & -6603 yold & treas \\
\hline 4 & & & & & & 0.109 & bot & & & & 0.137 & goluatod bil & Hre otrain & \\
\hline 8 & & & & & & & & & & & & & & \\
\hline 6 & survin & & & acluoted & & surval & & & aduoted & & survial & & & cousted \\
\hline 7 & conficance & $x$ & streas & theses & & sontidence & $x$ & streas & strees & & conficonce & $x$ & stress & streses \\
\hline 8 & $0.0 \%$ & 3.71002 & 23.60300 & 25.80000 & & & & & & & & & & \\
\hline 9 & 0.00 & 3.00003 & 20.0246 & 20.80010 & & 0.024 & 1.45500 & 40.65080 & 37.81480 & & 0.849 & 1.05215 & 43.80352 & 40.20008 \\
\hline 10 & 0.003 & 2.87810 & 30.860 .97 & 29.05608 & & 0.023 & 1.4 .5 .54 & 40.00501 & 37.85091 & & 0.848 & 1.02760 & 43.00049 & 40.31726 \\
\hline 11 & 0.007 & 2.74778 & 31.36002 & 30.50002 & & 0.02 & 1.41806 & 40.60063 & 37.86064 & & 0.847 & 1.023 .6 & 43.93702 & 40.34413 \\
\hline 12 & 0.00 & 2.0607 & 31.02162 & 30.00042 & & 0.021 & 1.41183 & 40.71527 & 37.83978 & & 0.840 & 1.01845 & 43.07341 & 40.370 .0 \\
\hline 13 & 0.06 & 2.67883 & 32.40288 & 31.39418 & & 0.000 & 1.40007 & 40.70230 & 37.86060 & & 0.645 & 7.0162 & 4.00078 & 40.39780 \\
\hline 14 & 0.004 & 2.51214 & 32.81027 & 31.72710 & & 0.910 & 1.30238 & 40.65204 & 38.02121 & & 0.84 & 1.01100 & 44.04694 & 40.42410 \\
\hline 18 & 0.003 & $2.467 \mathrm{CO}$ & 33.16343 & 32.01627 & & 0.018 & 9.50174 & 40.87600 & 38.00140 & & 0.843 & 1.00683 & 44.08109 & 40.45087 \\
\hline 16 & 0.02 & $2.400 \cdot 2$ & 33.48146 & 32.27274 & & 0.017 & 1.36517 & 40.02078 & 38.10132 & & 0.842 & 1,00271 & 44.11769 & 40.47703 \\
\hline 17 & 0.091 & 2.30 .2 & 33.76707 & 32.30580 & & 0.010 & 1.37800 & 40.09108 & 38.14094 & & 0.841 & 0.0003 & 44.15505 & 40.50328 \\
\hline 18 & 0.000 & 2.320 .53 & 34.02022 & 32.71408 & & 0.015 & $1,37 \mathrm{rep}$ & 41.03505 & 38.16010 & & 0.840 & 0.09446 & 44.16935 & $40.52 \times 48$ \\
\hline 10 & 0.900 & 2.20007 & 34.20027 & 32.00078 & & 0.014 & 1.30301 & 41.03462 & 38.21000 & & 0.850 & 0.00038 & 44.22491 & 40.65688 \\
\hline 20 & 0.093 & 2.25713 & 34.40347 & 33.00230 & & 0.013 & 1.35018 & 41.13674 & 38.25760 & & 0.858 & 0.0 .627 & 44.26041 & 40.58160 \\
\hline 21 & 0.637 & 2.22 .21 & 34.70334 & 33.25721 & & 0.012 & 1.36317 & 41.18663 & 38.2051 & & 0.657 & 0.08020 & 44.20577 & 40.00732 \\
\hline 22 & 0.03 & 2.19700 & 34.00070 & 33.41622 & & 0.011 & 1.34694 & 41.23000 & 38.3338 & & 3.830 & 0.07815 & 44.33000 & 40.03332 \\
\hline 23 & 0.035 & 2,17000 & 35.08733 & 33.53459 & & 0.910 & 1.34078 & 41.28093 & 38.37158 & & 0.855 & 0.97411 & 44.30012 & 40.65007 \\
\hline 24 & 0.044 & 2.1441 & 35.20474 & 33.70671 & & 0.09 & 1.33402 & 41.33660 & 38,40008 & & 0.854 & 0.07000 & 44.40113 & 40.68471 \\
\hline 25 & 0.023 & 2.12007 & 36.43354 & 33.84010 & & 0.000 & 1.36034 & 41.35002 & 30.44621 & & 0.863 & 0.00000 & 44.43690 & 40.71023 \\
\hline 28 & 0.025 & 2.00 .03 & 35.50476 & 33.96620 & & 0.007 & 1.36251 & 41.45501 & 38.48507 & & 0.852 & 0.60210 & 44.47078 & 40.73670 \\
\hline 27 & 0.031 & 2.07465 & 36.74028 & 34.00001 & & 0.008 & 1.31052 & 41.40673 & 36.51072 & & 0.851 & 0.05812 & 44.50352 & 40.78112 \\
\hline 28 & 0.000 & 2.0 .578 & 35.89757 & 34.20344 & & 0.008 & 1.31068 & 41.56210 & 36.65600 & & 0,830 & 0.93416 & 44.54011 & 40.78842 \\
\hline 20 & 0.070 & 2 men & 30.04032 & 34.32144 & & 0.804 & 1.30400 & 41.88012 & 38.56217 & & $(8.89$ & 0.05022 & 44.57455 & 40.81161 \\
\hline 30 & 0.070 & 2.01400 & 30.17797 & 34.46024 & & 0.003 & 1.20084 & 41.62767 & 38.62904 & & 0.668 & 0.9462 & 44.00693 & 40.83674 \\
\hline 31 & 0.97 & 1.0 .50 & 30.31003 & 34.53621 & & 0.002 & $1.2 \times 003$ & 41.07634 & 38.60500 & & 0.627 & 0.04238 & 44.04318 & 40.83176 \\
\hline 32 & 0.070 & 1.07137 & 30.430 .33 & $34.65 \times 11$ & & 0.001 & $1.207 \mathrm{C7}$ & 41.72240 & 38.60005 & & 0.60 & 0.05848 & 44.67733 & $40.8 \% 072$ \\
\hline 33 & 0.076 & 1.903 & 30.59490 & 34.7340 & & 0.000 & 1.23165 & 41.76031 & 38.73420 & & 0.825 & 0.03458 & 44.71163 & 40.91170 \\
\hline 34 & 0.974 & 1.04513 & 58.68513 & 34.82003 & & 0.00 & 1.27007 & 41.81889 & 38.70012 & & 0.024 & 0.05072 & 44.74540 & 40.05043 \\
\hline 35 & 0.073 & 1.0 .24 & 39.00055 & 34.0200 & & $0 . \cdots 3$ & 1.27024 & 41.86000 & 3.00578 & & 0.603 & 0.2608 & 44.77029 & 40.99117 \\
\hline 30 & 0.972 & 1.01104 & 30.01631 & 35.01183 & & 0.097 & 1.23404 & 41.00311 & 38.8302 & & 0.02 & 0.02301 & 44.81313 & 40.06880 \\
\hline 37 & 0.91 & 1.6570 & 37.00 .07 & 35.0013 & & 0.803 & 1.20008 & 41.06584 & 38.67240 & & 0.821 & 0.01018 & 44.84681 & 41.01043 \\
\hline 38 & 0.970 & 1.6000 & 37.13 .54 & 35.18400 & & 0.800 & 1.25657 & 41.0002 & 38.80040 & & 0.00 & 0.01637 & 4.80003 & 41.03480 \\
\hline 30 & 0.00 & $1.6 \times 00$ & 37.24200 & 35.20002 & & 0.604 & 1.24 .00 & 42.04440 & 53.94003 & & 0.670 & 0.01150 & 44.91591 & 41.00038 \\
\hline 40 & 0.53 & 1.0 .218 & 37.34657 & 35.34760 & & $0.00 \mathrm{~s}$ & 1.26894 & 42.00 .01 & 3.91501 & & 0.818 & 0.0077 & 44.94731 & 41.00370 \\
\hline 41 & 0.07 & $1.0 \times M^{2}$ & 57.44062 & 36.6204 & & $0 . \% 2$ & $9.207 \mathrm{Cx}^{2}$ & 42.13407 & 30.0073 & & 0.817 & $0.005 \times 9$ & 44.00009 & 41.10000 \\
\hline 42 & 0.00 & 1.8 .01 & 77.3518 & 35.60059 & & 0.091 & 1.20180 & 42.17046 & $39.0403 x$ & & 0.810 & 0.00023 & 46.01360 & 41.13217 \\
\hline 45 & 0.50 & 1.01101 & 37.04177 & 36.67079 & & 0.000 & 1.20003 & $42.25 \times 31$ & 30.07360 & & 0.815 & 0.8047 & 45.04707 & 41.15050 \\
\hline 44 & 0.54 & 1.2012 & 37.76 .34 & 35.0 .60 & & 0.600 & 1.2212 & 42.20003 & 50.10030 & & 0.074 & 0.60273 & 45.00013 & 41.16043 \\
\hline 48 & 0.0 .0 & $1.7 \ldots 1$ & $57 . \cdots 07$ & 36.72452 & & 0.683 & $1.21 \mathrm{GJ}$ & 42.31003 & $30.13 \%: 3$ & & 0.813 & 0.6501 & 45.11304 & 41.20458 \\
\hline 40 & 0.0 .2 & 9.7743 & 57.010:4 & 36.70318 & & 0.0 .7 & 9.25072 & 42.36577 & 30.17141 & & 0.012 & 0.8850 & 45.14509 & 41.28634 \\
\hline 47 & 0.0 .31 & 1.7 .241 & 53.00010 & $35.0 \times 44$ & & 0.65 & 1.200 .3 & $42.3 \cdots 2$ & 39.20050 & & 0.011 & 0.83169 & 45.17870 & 41.20218 \\
\hline 48 & 0.00 & 1.7000 & 30.0000 & $36.05 \times 3$ & & 0.603 & 1.2005 & 42.45094 & 30.2057 & & 0.810 & 0.87700 & 45.21148 & 41.27397 \\
\hline 40 & 0.00 & .700 & 38.1000 & $36.0 \times 04$ & & 0.04 & 1.10 .2 & 42.48278 & 30.20768 & & 0.000 & 0.87402 & 45.24413 & 41.20070 \\
\hline 80 & 0.53 & $1.7 \mathrm{nx}$ & 3.20707 & 36.00484 & & 0.083 & 1.10012 & 42.56 .63 & 30.2007 & & 0.608 & 0.670 .5 & 45.27672 & 41.32338 \\
\hline $\mathbf{6 1}$ & 0.97 & $1.71 \ldots$ & 33.35005 & 3.12970 & & 0.02 & 1.18504 & 42.59700 & 30.35004 & & 0.007 & 0.0 .609 & 45.30024 & 41.34701 \\
\hline 62 & 0.00 & 1.70 .04 & 3.43170 & 5.1000 & & 0.691 & 1.10000 & 42.00000 & $39.3 \times 210$ & & 0.800 & 0.80325 & 45.34100 & 41.37051 \\
\hline 80 & 0.53 & 1.0340 & 33.31207 & 3.23411 & & 0.680 & 1.17400 & 42.85170 & 30.30337 & & 0.006 & 0.860 .2 & 46.37391 & 41.30500 \\
\hline 64 & 0.5 .4 & 9.6704 & 50.00118 & 30.31624 & & 0.80 & 1.17000 & 42.60347 & 39.42445 & & 0.004 & 0.80000 & 45.40014 & 41.41735 \\
\hline $\mathbf{8 3}$ & $0.6 .3]$ & 1.076 & 30.0000 & 30.37060 & & 0.678 & 1.10005 & 42.73485 & 39.45650 & & 0.000 & 0.86209 & 45.45031 & 41.44070 \\
\hline 60 & 0.0 .5 & 1.0968 & 30.74670 & 3.43400 & & 0.877 & 1.10012 & 42.77650 & 39.46000 & & 0.600 & 0.84870 & 45.47041 & $41.40 \times 09$ \\
\hline 67 & 0.031 & 1.0 .103 & 39.82134 & $30.4 \% 31$ & & 0.670 & $1.15 \times 22$ & 42.81744 & 30.51600 & & 0.801 & 0.84520 & 45.60245 & 41.46722 \\
\hline 68 & 0.000 & 1.6400 & 38.60300 & $30,560<0$ & & 0.675 & 1.15036 & 42.86837 & 39.54700 & & 0.000 & 0.84102 & 45.53442 & 41.51040 \\
\hline 80 & 0.040 & 1.05623 & 38.6037 & 30.0060 & & 0.874 & 1.14551 & 42.80000 & 30.57723 & & 0.700 & 0.83805 & 45.56632 & 41.53362 \\
\hline$\infty$ & 0.046 & 1.02078 & 30.04184 & 30.60258 & & 0.873 & 1.14000 & 42.06607 & 39.60738 & & 0.708 & 0.63450 & 45.50008 & 41.55682 \\
\hline 61 & 0.047 & 1.6104 & 39.11309 & 36.71762 & & 0.872 & 1.13690 & $4 . \overline{80004}$ & 39.03731 & & 0.707 & 0.85005 & 45.62923 & 41.57030 \\
\hline$\infty$ & 0.040 & 1.00725 & 30.18307 & 36.77975 & & 0.871 & 1.13113 & 43.02020 & 39.60715 & & 0.706 & 0.82742 & 45.60144 & 41.000242 \\
\hline 60 & 0.045 & $1.50 \cdot 10$ & 39.23688 & 38.0256 & & 0.870 & 1.12009 & 43.06050 & 39.60083 & & 0.795 & 0.82300 & 45.60200 & 41.02525 \\
\hline 84 & 0.044 & $1.60 \% 7$ & $39.302 \times 3$ & 36.67804 & & 0.600 & 1.12168 & 4.10011 & 30.72633 & & 0.794 & 0.62038 & 45.72455 & 41.64610 \\
\hline 63 & 0.043 & 1.88047 & 30.30027 & 38.93015 & & 0.863 & 1.11000 & 43.13979 & 39.75572 & & 0.793 & 0.81687 & 45.75605 & 41.87030 \\
\hline 60 & 0.042 & 1.57170 & 30.45741 & 38.98160 & & 0.807 & 1.11232 & 43.17833 & 39.78501 & & 0.782 & 0.81338 & 45.76739 & 41.60355 \\
\hline 67 & 0.841 & $1.5 \times 2$ & 39.59380 & 37.05245 & & 0.803 & 1.10768 & 43.21805 & 39.81412 & & 0.701 & 0.80090 & 45.81868 & 41.71617 \\
\hline 68 & 0.940 & 1.6347 & $39.50 \times 38$ & 37.06205 & & 0.808 & 1.10003 & 43.25784 & 30.84312 & & 0.790 & 0.80342 & 45.84005 & 41.73870 \\
\hline 60 & 0.050 & 1.04043 & 39.60421 & 37.13224 & & 0.884 & 1.00947 & 43.20881 & 39.87185 & & 0.760 & 0.80206 & 45.83100 & 41.76120 \\
\hline 70 & 0.038 & 1.06820 & 39.71828 & 37.18124 & & 0.800 & 1.00500 & 43.33565 & 39.80067 & & 0.788 & 0.70050 & 45.01224 & 41.78380 \\
\hline 71 & 0.007 & 1.86007 & 39.78168 & 37.2603 & & 0.802 & 1.08035 & 43.37435 & 30.02020 & & 0.787 & 0.70008 & 45.94820 & 41.80018 \\
\hline 72 & 0.038 & 1.66004 & 30.84440 & 37.27768 & & 0.881 & 1.08482 & 43.41291 & 30.86778 & & 0.780 & 0.70202 & 45.97420 & 41.82053 \\
\hline 73 & 0.035 & 1.61410 & 30.00831 & 37.32403 & & 0.600 & 1.00032 & 43.45125 & 30.08611 & & 0.785 & 0.70919 & 48.00619 & 41.85002 \\
\hline 74 & 0.034 & 1.50000 & 30.80794 & 37.37184 & & 0.060 & 1.07564 & 43.48946 & 40.01433 & & 0.784 & 0.78677 & 46.05607 & 41.87320 \\
\hline 75 & 0.035 & 1.46351 & $40 . \overline{02878}$ & 37.41860 & & 0.850 & 1.07138 & 43.52753 & 40.04243 & & 0.783 & 0.76237 & 48.00079 & 41.806 \\
\hline 76 & $0.0 \times 2$ & 1.40005 & 40.08005 & 37.48407 & & 0.857 & 1.00604 & 43.56540 & 40.07042 & & 0.782 & 0.77607 & 46.09753 & 41.91754 \\
\hline$\pi$ & 0.031 & 1.40320 & 40.14663 & 37.50044 & & 0.858 & 1.06252 & 43.00325 & 40.00831 & & 0.781 & 0.77657 & 46.12820 & 41.80972 \\
\hline 78 & 0.050 & 1.47570 & 40.20757 & 37.55438 & & 0.853 & 1.08812 & 43.64091 & 40.12608 & & 0.780 & 0.77210 & 46.15888 & 41.86178 \\
\hline 79 & 0.6 & 1.40838 & 40.26007 & 37.30097 & & 0.854 & 1.06374 & 43.67842 & 40.15373 & & 0.770 & 0.76802 & 48.18941 & 41.86378 \\
\hline 80 & 0.028 & 1.48108 & 40.32003 & 37.04200 & & 0.853 & 1.04939 & 43.71571 & 40.18122 & & 0.778 & 0.70548 & 40.21987 & 42.00572 \\
\hline 81 & 0.627 & 1.46381 & 40.38133 & 37.68648 & & 0.052 & 1.04505 & 43.75605 & 40.20865 & & 0.777 & 0.78210 & 40.25034 & 42.02767 \\
\hline 82 & 0.00 & 1.44603 & 40.43825 & 37.72971 & & 0.851 & 1.04073 & 43.70003 & 40.23507 & & 0.778 & 0.75076 & 46.20075 & 42.04057 \\
\hline 83 & 0.025 & 1.43053 & 40.49481 & 37.77240 & & 0.850 & 1.00843 & 43.82700 & 40.26318 & & 0.775 & 0.76342 & 48.31090 & 42.07134 \\
\hline
\end{tabular}

NUREG/CR-6121

B-10 
Attachment 2

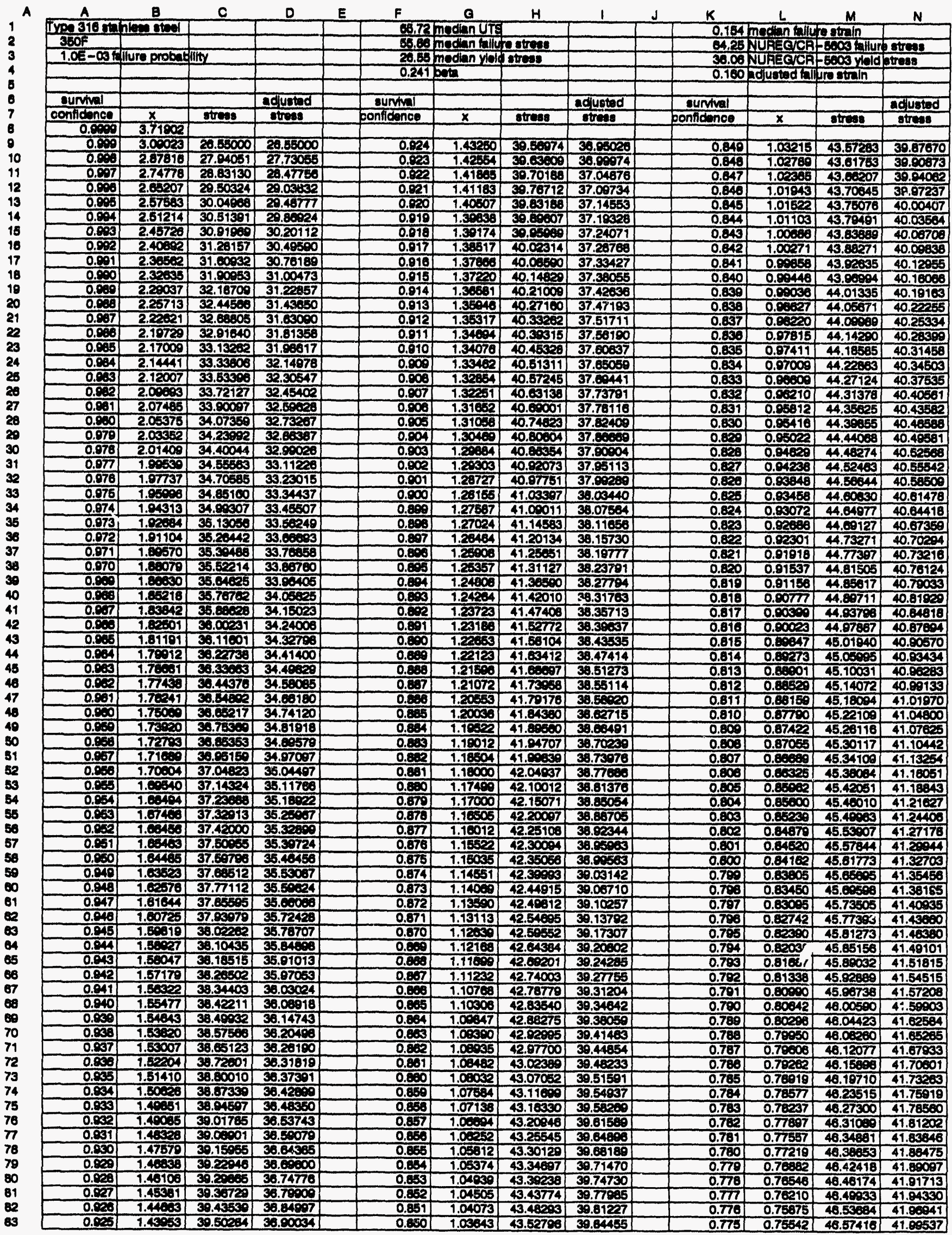




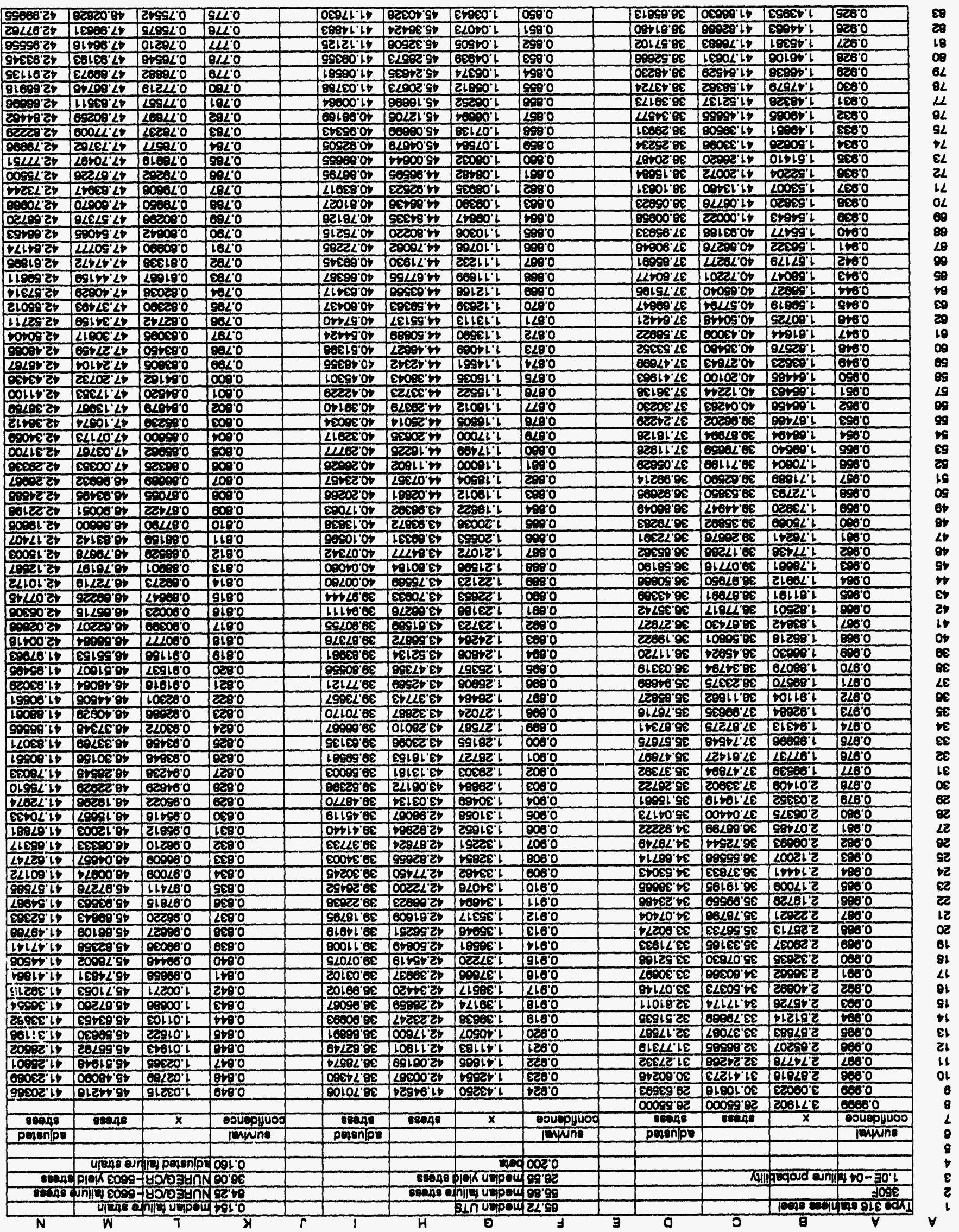


Attachment 2

\begin{tabular}{|c|c|c|c|c|c|c|c|c|c|c|c|c|c|c|}
\hline A & A & $\mathbf{B}$ & C & D & E & $\boldsymbol{F}$ & $\mathbf{G}$ & $\mathrm{H}$ & 1 & \rfloor & $\mathbf{K}$ & $L$ & $\mathbf{M}$ & $\mathbf{N}$ \\
\hline 1 & $3 A-108 \mathrm{Gr}$ & carbon ste & & & & 64.25 & median fallu & estress & & & 0.088 & median fallu & e stuain & \\
\hline 2 & $350 \mathrm{~F}$ & & & & & 37.89 & median yield & stress & & & 64.25 & NUAEGCA & -5003 ballur & stress \\
\hline 3 & $1.0 E-00 k$ & lure probal & ilty & & & 0.171 & beta & & & & 37.89 & NURECICA & -5003 yield & streas \\
\hline 4 & & & & & & & & & & & 0.089 & adiusted fall & yre strain & \\
\hline 5 & & & & & & & & & & & & & & \\
\hline 6 & suntivel & & & adjusted & & \begin{tabular}{|l} 
survival \\
\end{tabular} & & & adjusted & & survival & & & adjusted \\
\hline 7 & confidence & $x$ & Stress & stueas & & confidence & $x$ & stress & gtress & & confidence & $x$ & stress & stress \\
\hline 8 & 0.9099 & 3.71902 & & & & & & & & & & & & \\
\hline 9 & 0.900 & 3.000023 & 37.88788 & 37.68788 & & 0.224 & 1.43250 & 50.29931 & 40.28888 & & 0.849 & 1.03215 & 53.83195 & 51.12233 \\
\hline 10 & $0.0 \% 3$ & 2.87816 & 39.28650 & 39.10302 & & 0.923 & 1.42654 & 50.35919 & 48.33684 & & 0.848 & 1.02789 & 53.00118 & 51.15310 \\
\hline 11 & 0.097 & 2.74778 & 40.17188 & 39.86841 & & 0.022 & 1.41865 & 50.41853 & 48.38450 & & 0.847 & 1.02365 & 53.84027 & 51.18389 \\
\hline 12 & 0.096 & 2.05207 & 40.83449 & 40.43476 & & 0.921 & 1.41183 & 50.47734 & 48.43183 & & 0.846 & 1.01943 & 63.87919 & 51.21448 \\
\hline 13 & 0.895 & 2.57563 & 41.37012 & 40.89241 & & 0.820 & 1.10507 & 50.53579 & 48.47872 & & 0.845 & 1.01522 & 54.01805 & 51.24501 \\
\hline 14 & 0.894 & 2.51214 & 41.82297 & 41.27234 & & 0.919 & 1.30838 & 50.60353 & 49.52516 & & 0.844 & 1.01103 & 54.05675 & 51.27541 \\
\hline 15 & 0.093 & 2.45728 & 42.21715 & 41.61277 & & 0.918 & 1.39174 & 50.65008 & 48.57128 & & 0.843 & 1.00683 & 54.00369 & 51.30568 \\
\hline 16 & $0.8 \% 2$ & 2.400 .92 & 42.59743 & 41.80950 & & 0.917 & 1.38517 & 50.70790 & 48.61696 & & 0.842 & 1.00271 & 54.13568 & 51.33582 \\
\hline 17 & 0.001 & 2.36002 & 42.85306 & 42.17678 & & 0.916 & 1.37888 & 50.78436 & 48.66225 & & 0.841 & 0.99858 & 54.17191 & 51.38582 \\
\hline 18 & 0.090 & 2.32035 & 43.17248 & 42.42042 & & 0.815 & 1.37220 & 50.82044 & 48.70723 & & 0.840 & 0.89448 & 54.21007 & 51.39577 \\
\hline 19 & 0.899 & 2.200037 & 43.43882 & 42.64460 & & 0.914 & 1.38581 & 50.67598 & 48.75175 & & 0.839 & 0.90030 & 54.24808 & 51.42559 \\
\hline 20 & 0.080 & 2.25713 & 43.68633 & 42.85273 & & 0.913 & 1.35946 & 50.93123 & 48.78603 & & 0.838 & 0.88627 & 54.28002 & 51.45534 \\
\hline 21 & 0.897 & 2.22621 & 43.91783 & 43.04703 & & 0.912 & 1.35317 & 50.98602 & 48.83892 & & 0.837 & 0.98220 & $54.32 \times 80$ & 51.48497 \\
\hline 22 & 0.089 & 2.10729 & 44.13547 & 43.22041 & & 0.911 & 1.34094 & 51.04035 & 48.88343 & & 0.838 & 0.97815 & 54.35142 & 51.51446 \\
\hline 23 & 0.825 & 2.17009 & 44.34115 & 43,40154 & & 0.910 & 1.34078 & 51.09429 & 48.92681 & & 0.635 & 0.87411 & 54.30907 & 51.54389 \\
\hline 24 & 0.834 & 2.14441 & $44.53 \times 22$ & 43.58457 & & 0.800 & 1.33462 & 51.14795 & 48.03955 & & 0.834 & 0.97000 & 54.43337 & 51.57318 \\
\hline 25 & 0.893 & 2.12007 & 44.72100 & 43.71855 & & 0.808 & 1.32654 & 51.20113 & 49.01210 & & 0.833 & 0.86609 & 54,47360 & 51.60238 \\
\hline 20 & 0.802 & 2.00093 & 44.89914 & 45.86732 & & 0.807 & 1.32251 & 51.25393 & 49.05432 & & 0.832 & 0.86210 & 54.51076 & 51.63147 \\
\hline 27 & 0.081 & 2.07485 & 45.00802 & 44.00371 & & 0.808 & 1.31652 & 51.30344 & 49.09330 & & 0.831 & 0.05812 & 54.54786 & 51.60052 \\
\hline 28 & 0.800 & 2.05375 & 45.23178 & 44.14417 & & 0.005 & 1.31058 & 51.35858 & 49.13705 & & 0.830 & 0.05410 & 54.58470 & 51.88043 \\
\hline 20 & 0.079 & 2.03352 & 45.38844 & 44.27438 & & 0.004 & 1.30460 & 51.41029 & 49.17928 & & 0.829 & $0 . \sqrt{5022}$ & 54.62157 & 51.71821 \\
\hline 30 & 0.978 & 2.01400 & 45.53944 & 44.39973 & & 0.003 & 1.20684 & 51.48172 & 49.22006 & & 0.828 & 0.04629 & 54.65827 & 51.74603 \\
\hline 31 & 0.977 & 1.00539 & 45.68523 & 44.52084 & & 0.802 & 1.29303 & 51.51288 & 49.28118 & & 0.827 & 0.24238 & 54.63402 & 51.77552 \\
\hline 32 & 0.878 & 1.97737 & 45.82617 & 44.63742 & & 0.001 & 1.28727 & 51.56360 & 49.30168 & & 0.826 & 0.83848 & 54.73129 & 51.80405 \\
\hline 33 & 0.975 & 1.9509 & 45.86275 & 44.75048 & & 0.800 & 1.29155 & 51.81404 & 49.34193 & & 0.825 & 0.93458 & 54.76779 & 51.83259 \\
\hline 34 & 0.074 & 1.24313 & 46.09517 & 44.86000 & & 0.899 & $1.2,387$ & 51.68418 & 49.38191 & & 0.824 & 0.93072 & 54.80394 & 51.86085 \\
\hline 35 & 0.073 & 1.82034 & 46.22370 & 44.80 .022 & & 0.898 & 1.27024 & 51.71302 & 49.42158 & & 0.823 & 0.02686 & 54.84011 & 51.88912 \\
\hline 36 & 0.072 & 1.91104 & 48.34870 & 45.00944 & & 0.897 & 1.28404 & 51.76344 & 49.46105 & & 0.822 & 0.82301 & 54.87621 & 51.91733 \\
\hline 37 & 0.971 & 1.89570 & 46.47039 & 45.16024 & & 0.896 & 1.23908 & 51.81286 & 49.50027 & & 0.821 & 0.91018 & 54.91215 & 51.94540 \\
\hline 38 & 0.970 & 1.88070 & 46.58808 & 45.26760 & & 0.805 & 1.25357 & 51.88149 & 49.53916 & & 0.820 & 0.81537 & 54.94782 & 51.07334 \\
\hline 30 & 0.000 & 1.80030 & 46.70452 & 45.36278 & & 0.894 & 1.24800 & 51.81018 & 49.57794 & & 0.819 & 0.91158 & 54.86372 & 52.00120 \\
\hline 40 & 0.068 & 1.85218 & 48.81738 & 45.45568 & & 0.893 & 1.24264 & 51.05847 & 49.61638 & & 0.818 & 0.80777 & 55.01935 & 52.02911 \\
\hline 41 & 0.007 & 1.80842 & 46.82762 & 45.54630 & & 0.802 & 1.23723 & 52.00854 & 49.65464 & & 0.817 & 0.80309 & 55.05491 & 52.05687 \\
\hline 42 & 0.000 & 1.82501 & 47.03531 & 45.83488 & & 0.891 & 1.23188 & 52.05430 & 49.69264 & & 0.818 & 0.80023 & 55.08031 & 52.08449 \\
\hline 43 & 0.865 & 1.81101 & 47.14075 & 45.72149 & & 0.600 & 1.22653 & 52.10174 & 49.73038 & & 0.815 & 0.89647 & 55.12572 & 52.11212 \\
\hline 44 & 0.004 & 1.70912 & 47.24393 & 45.80018 & & 0.889 & 1.22123 & 52.14697 & 49.76782 & & 0.814 & 0.89273 & 55.16098 & 52.13881 \\
\hline 45 & 0.0 .3 & 1.70 .01 & 47.34508 & 45.68014 & & 0.888 & 1.21500 & 52,19560 & 49.80528 & & 0.813 & 0.88901 & 55.16000 & 52.16097 \\
\hline 46 & 0.002 & 1.77438 & 47.44414 & 45.97036 & & 0.897 & 1.21072 & 52.24274 & 49.84245 & & 0.812 & 0.86520 & 55.23117 & 52.19435 \\
\hline 47 & 0.081 & 1.70261 & 47.54131 & 48.04097 & & 0.086 & 1.20553 & 52.28910 & 49.87828 & & 0.811 & 0.88159 & 55.20311 & 52.22158 \\
\hline 48 & 0.000 & 9.75000 & 47.03605 & 46.12803 & & 0.685 & 1.20038 & 52.33533 & 49.91600 & & 0.810 & 0.87700 & 55.30008 & 52.24875 \\
\hline 49 & 0.059 & 1.7300 & 47.73050 & 46.20466 & & 0.884 & 1.19522 & 52.38134 & 49.85252 & & 0.800 & 0.87422 & 55.35578 & 52.27387 \\
\hline 50 & 0.053 & 1.72703 & 47.00234 & 46.27902 & & 0.863 & 1.10012 & 52.42702 & 49.88878 & & 0.808 & 0.87055 & 55.37050 & 52.30201 \\
\hline 51 & 0.057 & 1.71690 & 47.81207 & 46.35374 & & 0.882 & 1.18504 & 52.47258 & 50.02492 & & 0.807 & 0.60889 & 55.40516 & 52.32900 \\
\hline 52 & 0.838 & 1.70004 & 48.00161 & 48.42009 & & 0.881 & 1.18000 & 52.51779 & 50.08079 & & 0.608 & 0.86525 & 55.43004 & 52.35675 \\
\hline 53 & 0.030 & 1.69340 & 46.06999 & 46.49772 & & 0.880 & 1.17489 & 52.56278 & 50.09647 & & 0.805 & 0.85902 & 55.47405 & 52.38353 \\
\hline 54 & 0.564 & 1,6894 & 48.17505 & 46.56793 & & 0.879 & 1.17000 & 52.60763 & 50.13203 & & 0.804 & 0.85000 & 55.50039 & 52.41020 \\
\hline 55 & 0.853 & 1.67468 & 48.25077 & 46.63702 & & 0.878 & 1.16505 & 52.65217 & 50.16733 & & 0.803 & 0.85209 & $55.542 \times 5$ & 52.43602 \\
\hline 58 & 0.832 & 1.60458 & 48.34316 & 48.70497 & & 0.877 & 1.16012 & $52.60 \times 55$ & 50.20250 & & 0.802 & 0.84879 & 55.57634 & 52.46351 \\
\hline 57 & 0.851 & 1.05403 & 48.42320 & 48.77187 & & 0.878 & 1.15522 & 52.74071 & 50.23747 & & 0.801 & 0.84620 & 55.61005 & 52,40005 \\
\hline 58 & 0.850 & 1.64485 & 48.50031 & 46.83783 & & 0.875 & 1.15035 & 52.78463 & 50.27225 & & 0.800 & 0.84162 & 55.64409 & 52.51652 \\
\hline $5 ?$ & 0.949 & 1.03523 & 49.50614 & 48.00278 & & 0.874 & 1.14551 & 52.82832 & 50.30884 & & 0.700 & 0.83805 & 55.07800 & 52.54292 \\
\hline 60 & 0.048 & 1.62576 & 48.68485 & 46.86879 & & 0.873 & 1.14000 & 52.87186 & 50.34130 & & 0.789 & 0.83450 & 55.71276 & 52.50919 \\
\hline 61 & 0.847 & 1.61644 & 48.74244 & 47.02306 & & 0.872 & 1.13500 & 52.91517 & 50.37557 & & 0.797 & 0.63005 & 55.74058 & 52.50547 \\
\hline 62 & 0.948 & 1.60725 & 48.81807 & 47.00211 & & 0.871 & 1.13113 & 52.05833 & 50.40971 & & 0.780 & 0.82742 & 55.78022 & 52.82181 \\
\hline 63 & 0.945 & 1.50818 & 48.89473 & 47.15355 & & 0.670 & 1.12630 & 53.00128 & 50.44365 & & 0.795 & 0.82390 & 55.81379 & 52.64769 \\
\hline 64 & 0.944 & 1.59027 & 48.06934 & 47.21419 & & 0.860 & 1.12168 & 53.04395 & 50.47740 & & 0.794 & 0.82038 & 55.84738 & 52.87377 \\
\hline aE & 0.043 & 1.58047 & 49.04305 & 47.27391 & & 0.888 & 1.11698 & 53.08849 & 50.51103 & & 0.703 & 0.81687 & 55.68090 & 52.60080 \\
\hline 68 & 0.942 & 1.57179 & 49.11587 & 47.333096 & & 0.867 & 1.11232 & 53.12688 & 50.54452 & & 0.792 & 0.81338 & 55.81425 & 52.72568 \\
\hline 67 & 0.041 & 1.56322 & 49.18787 & 47.39131 & & 0.880 & 1.10788 & 53.17103 & 50.57782 & & 0.791 & 0.80980 & 55.84752 & 52.75150 \\
\hline 68 & 0.940 & 1.55477 & 48.25697 & 47.44891 & & 0.885 & 1.10306 & 53.21304 & 50.61100 & & 0.790 & 0.80642 & 55.88081 & 52.77734 \\
\hline$\infty$ & 0.830 & 1.54643 & 49.32924 & 47.50581 & & 0.834 & 1.08847 & 53.25481 & 50.64397 & & 0.789 & 0.80206 & 56.01333 & 52.80303 \\
\hline 70 & 0.838 & 1.53620 & 49.39909 & 47.56202 & & 0.863 & 1.00380 & 53.29342 & 50.67652 & & 0.788 & 0.79950 & 58.04707 & 52.82873 \\
\hline 71 & 0.837 & 1.53007 & 49.46738 & 47.61759 & & 0.862 & 1.06035 & 53.33789 & 50.70054 & & 0.787 & 0.76000 & 56.08003 & 52.85429 \\
\hline 72 & 0.038 & 1.52204 & 49.53533 & 47.67254 & & 0.861 & 1.08482 & 53.37921 & 50.74213 & & 0.788 & 0.78262 & 58.111302 & 52.87987 \\
\hline 73 & 0.035 & 1.51410 & 49.00200 & 47.72002 & & 0.800 & 1.08032 & 53.42023 & 50.77453 & & 0.785 & 0.78918 & 56.14503 & 52.90537 \\
\hline 74 & 0.834 & 1.50008 & 49.60912 & $47.7 \mathrm{E003}$ & & 0.850 & 1.07534 & 53.46121 & 50.80880 & & 0.784 & 0.78577 & 58.17676 & 52.03002 \\
\hline 75 & 0.833 & 1.46651 & 46.73406 & 47.83383 & & 0.858 & 1.07138 & 53.50188 & 50.83893 & & 0.783 & 0.78237 & 56.21142 & 52.05812 \\
\hline 78 & 0.832 & 1.40005 & 40.80013 & 47.88844 & & 0.857 & 1.06094 & 53.54260 & 50.87095 & & 0.782 & 0.77897 & 56.24400 & 52.88145 \\
\hline$\pi 7$ & 0.831 & 1.48523 & 49.80461 & 47.85847 & & 0.858 & 1.00252 & 53.58307 & 50.00283 & & 0.781 & 0.77557 & 56.27679 & 53.00678 \\
\hline 78 & 0.830 & 1.47579 & 49.82349 & 47.00000 & & 0.855 & 1.05812 & 53.62338 & 50.83458 & & 0.780 & 0.77210 & 56.30932 & 53.03194 \\
\hline 79 & 0.025 & 1.40838 & 49.99177 & 46.04102 & & 0.854 & 1.05374 & 53.66354 & 50.96621 & & 0.779 & 0.76882 & 58.34178 & 53.05708 \\
\hline 80 & 0.928 & 9.46100 & 50.05436 & 48.09146 & & 0.853 & 1.04939 & 53.70346 & 50.89763 & & 0.778 & 0.78546 & 56.37413 & 53.08211 \\
\hline 81 & 0.827 & 1.75381 & 50.11643 & 48.14148 & & 0.852 & 1.04505 & 53.74332 & 51.02000 & & 0.777 & 0.76210 & 56.40052 & 53.10718 \\
\hline 82 & 0.388 & 1.44683 & 30.17707 & 48.19103 & & 0.851 & 1.04073 & 53.78302 & 51.06024 & & 0.778 & 0.75875 & 56.43863 & 53.13217 \\
\hline 83 & 0.025 & 1.43953 & 50.23891 & 48.24008 & & 0.850 & 1.03843 & 53.62256 & 51.09135 & & 0.775 & 0.75542 & 56.47090 & 53.15703 \\
\hline
\end{tabular}


Attachment 2

\begin{tabular}{|c|c|c|c|c|c|c|c|c|c|c|c|c|c|c|}
\hline $1^{A}$ & $\frac{A}{\sqrt{A-106 G} \text {. }}$ & $\frac{B}{3 \text { carbon ste }}$ & $c$ & D & $E$ & $F$ & G & $H$ & 1 & 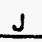 & $\mathbf{K}$ & & $\mathbf{M}$ & $\mathrm{N}$ \\
\hline $\begin{array}{l}1 \\
2\end{array}$ & $\frac{8 A-108 \text { Gr. }}{350 F}$ & 3 carbon ate & & & & & & & & & \multirow{2}{*}{\multicolumn{4}{|c|}{$\begin{array}{l}0.088 \text { median rallure strain } \\
64.25 \text { NuAEC/CR- } 5803 \text { tallure stress }\end{array}$}} \\
\hline 3 & $1.0 E-04 t$ & ture probet & Iility & & & 37.89 & median yiles & $\frac{10 \text { otress }}{\text { of stress }}$ & & & & & & \\
\hline 4 & & & & & & 0.142 & both & & & & 0.088 & dilusted fall & ithre strain & Istress \\
\hline 6 & sunvel & & & & & & & & & & & & & \\
\hline & confidence & $x$ & stress & $\frac{0 u}{\text { stress }}$ & & confidence & $x$ & stress & $\frac{\text { acjusted }}{\text { stress }}$ & & $\begin{array}{l}\text { survival } \\
\text { confidence }\end{array}$ & & & $\frac{\text { aduetad }}{\text { strests }}$ \\
\hline & 0.0909 & 3.71802 & 37.68768 & 37.89788 & & & & 80038 & & & & $x$ & stress & stress \\
\hline & 0.999 & 3.00023 & 41.42729 & 40.94115 & & 0.924 & 1.43250 & 52.42530 & 49.88749 & & 0.848 & 1.03215 & 55.48283 & 52,3961 \\
\hline 10 & 0.008 & 2.87816 & 42.69409 & 42.01662 & & 0.823 & 1.42554 & 52.47724 & 50.02863 & & 0.848 & 1.02789 & 55.52641 & 52.42428 \\
\hline 11 & 0.897 & 2.74778 & 43.48208 & 42.68948 & & 0.822 & 7.41865 & 52.52862 & 50.06939 & & 0.847 & 1.02365 & 55.55686 & 52.45031 \\
\hline 12 & 0.998 & 2.65207 & 44.08734 & 43.18910 & & 0.921 & 1.41183 & 52.57953 & 50.10975 & & 0.846 & 1.01943 & 55.50317 & 52.47622 \\
\hline 13 & 0.995 & 2.57583 & 44.56734 & 43.59065 & & 0.920 & 1.40507 & 52.63004 & 50.14979 & & 0.845 & 1.01522 & 55.62643 & 52.50208 \\
\hline 14 & 0.994 & 2.51214 & 44.97232 & 43.82828 & & 0.919 & 1.39838 & 52.68007 & 50.18944 & & 0.844 & 1.01103 & 55.65854 & 52.52782 \\
\hline 15 & 0.993 & 2.45728 & 45.32424 & 44.22104 & & 0.818 & 1.39174 & 52.72978 & 50.22881 & & 0.843 & 1.00686 & 55.68251 & 52.55340 \\
\hline 16 & 0.982 & 2.40892 & 45.63650 & 44.48024 & & 0.917 & 1.388517 & 52.77901 & 50.28780 & & 0.842 & 1.00271 & 55.72535 & 52.57609 \\
\hline 17 & 0.091 & 2.36562 & 45.91803 & 44.71347 & & 0.918 & 1.37868 & 52.62783 & 50.30845 & & 0.841 & 0.99858 & 55.75805 & 52.60438 \\
\hline 18 & 0.090 & 2.32035 & 46.17486 & 44.92587 & & 0.815 & 1.37220 & 52.87632 & 50.34483 & & 0.840 & 0.89446 & 55.79000 & 52.62974 \\
\hline 19 & 0.889 & 2.29037 & 46.41143 & 45.12120 & & 0.914 & 1.36581 & 52.92433 & 50.38282 & & 0.839 & 0.00038 & 55.82318 & 52.65498 \\
\hline 20 & 0.838 & 2.25713 & 46.63108 & 45.30228 & & 0.913 & 1.35946 & 52.97209 & 50.42050 & & 0.838 & 0.88627 & 55.65562 & 52.68017 \\
\hline 21 & 0.987 & 2.22621 & 46.83630 & 45.47725 & & 0.912 & 1.35317 & 53.01943 & 50.45803 & & 0.837 & 0.88220 & 55.88792 & 52.70525 \\
\hline 22 & 0.088 & 2.10729 & 47.02908 & 45.62976 & & 0.911 & 1.34604 & 53.00637 & 50.48513 & & 0.838 & & & 52.73021 \\
\hline & 0.965 & 2.17009 & 47.21112 & 45.77928 & & 0.910 & 1.34078 & 53.11297 & 50.53195 & & 0.635 & 0.97411 & 55.95218 & $\frac{2 x .0011}{52.75512}$ \\
\hline 24 & 0.084 & 2.14441 & 47.38363 & 45.82077 & & 0.909 & 1.33462 & 53.15031 & 50.56866 & & 0.834 & 0.97009 & 55.98413 & 52.77991 \\
\hline 25 & 0.063 & 2.12007 & 47.54772 & 46.05522 & & 0.908 & 7.32854 & 53.20523 & 50.60483 & & 0.853 & & 56.01595 & 52.80459 \\
\hline 28 & 0.082 & 2.09093 & 47.70425 & 46.18335 & & 0.807 & 1.32251 & 53.25082 & 50.64082 & & 0.832 & 0.86210 & 56.04770 & 52.82822 \\
\hline 27 & 0.081 & 2.07485 & 47.85409 & 46.30588 & & 0.808 & 1.31652 & 53.29615 & 50.67660 & & 0.831 & 0.95812 & 58.07930 & 52.85380 \\
\hline 28 & 0.030 & 2.05375 & 47.99772 & 46.42321 & & 0.905 & 1.31068 & 53.34113 & 50.71200 & & 0.830 & 0.95416 & 56.11004 & 52.87828 \\
\hline 29 & 0.879 & 2.03352 & 48.13583 & 46.53594 & & 0.804 & 1.30469 & 53.36577 & 50.74731 & & 0.828 & 0.95022 & 56.14235 & 52.90280 \\
\hline 30 & 0.978 & 2.01400 & 48.26885 & 48.64442 & & 0.003 & 1.28684 & 53.43015 & 50.78231 & & 0.628 & 0.84629 & 56.17370 & 52.82690 \\
\hline 31 & 0.977 & 1.89530 & 48.39723 & 48.74901 & & 0.802 & 1.28303 & 53.47426 & 50.81708 & & 0.827 & 0.94238 & 58.20480 & 52.85108 \\
\hline 32 & 0.978 & 1.97737 & 48.52125 & 46.84890 & & 0.901 & 1.28727 & 53.51802 & 50.85158 & & 0.820 & 0.93848 & 56.23605 & 52.97520 \\
\hline 33 & 0.975 & 1.95000 & 48.64138 & 46.94771 & & 0.900 & 1.28155 & 53.56152 & 50.89505 & & 0.625 & 0.03458 & 56.26720 & 52.99933 \\
\hline 34 & 0.974 & 1.04313 & 48.75780 & 47.04234 & & 0.809 & 1.27587 & 53.60475 & 50.91991 & & 0.824 & 0.83072 & 56.29808 & 53.02323 \\
\hline 35 & 0.973 & 1.82684 & 48.87074 & 47.13400 & & 0.808 & 1.27024 & 53.64763 & 50.05368 & & 0.823 & 0.92686 & 58.32603 & 53.04713 \\
\hline 38 & 0.972 & 1.81104 & 48.88053 & 47.22319 & & 0.897 & 1.28484 & 53.69032 & 50.98720 & & 0.022 & 0.92301 & 56.35975 & 53.07008 \\
\hline 37 & 0.871 & 1.89570 & 49.08737 & 47.30985 & & 0.806 & 1.25000 & 53.73273 & 51.02007 & & 0.821 & 0.81818 & 58.30041 & 53.09471 \\
\hline 38 & 0.970 & 1.68079 & 49.19143 & 47.39419 & & 0.805 & 1.25357 & 53.77480 & 51.05377 & & 0.820 & 0.91537 & 56.42004 & 53.11833 \\
\hline 39 & 0.899 & 1.86630 & 49.20277 & 47.47820 & & 0.804 & 7.24808 & 53.61675 & 51.08677 & & 0.819 & 0.91156 & 56.45148 & 53.14183 \\
\hline 40 & 0.968 & 9.85218 & 49.39173 & 47.55630 & & 0.803 & 1.24204 & 53.85835 & 51.11940 & & 0.818 & 0.00777 & 56.48187 & 53.16547 \\
\hline 41 & 0.867 & 1.86842 & 49.48835 & 47.63455 & & 0.802 & 1.23723 & 53.80975 & 51.16204 & & 0.817 & 0.00390 & 56.51220 & 53.18893 \\
\hline 42 & 0.868 & 1.82501 & 48.58270 & 47.71083 & & 0.891 & 1.23188 & 53.94087 & 51.18437 & & 0.818 & 0.80023 & 58.54230 & 53.21227 \\
\hline 43 & 0.865 & 1.81191 & 48.67504 & 47.78544 & & 0.800 & 1.22653 & 53.28172 & 51.21647 & & 0.815 & 0.60647 & 56.57200 & 53.23562 \\
\hline 44 & 0.984 & 1.79912 & 48.76536 & 47.85838 & & 0.889 & 1.22123 & 54.02237 & 51.24841 & & 0.814 & 0.89273 & 58.60260 & 53.25885 \\
\hline 45 & 0.863 & 1.78631 & 49.85386 & 47.82890 & & 0.888 & 1.21590 & 54.06282 & & & 0.813 & 0.88001 & 58.63257 & 53.28186 \\
\hline 46 & 0.892 & $1.77 \div 0$ & 49.84054 & 47.90971 & & 0.867 & 1.21072 & 54.10308 & 51.31170 & & 0.812 & 0.88529 & 56.66250 & 53.30500 \\
\hline 47 & 0.081 &. .16241 & 50.02552 & 48.08822 & & 0.883 & 1.20553 & 54.14297 & 51.34311 & & 0.811 & 0.88159 & 58.69229 & 53.32800 \\
\hline 48 & 0.800 & 1.75060 & 50.10888 & 48.13537 & & 0.885 & 1.200 & 54.18274 & 51.37433 & & 0.81 & & 56.72201 & 53.35105 \\
\hline 49 & 0.959 & 1.73920 & 50.12070 & 48.20127 & & 0.864 & 1.19522 & 54.22231 & & & 0.809 & 0.87422 & 56.75166 & 53.37395 \\
\hline & 0.958 & 1.72793 & 50.27111 & 48.20509 & & 0.883 & 1.10012 & 54.28161 & 51.43620 & & 0.808 & 0.87055 & 56.78125 & 53.39678 \\
\hline 51 & 0.857 & 1.71639 & 50.34899 & 48.32945 & & 0.882 & 1.185 & 54.30077 & 51.48601 & & 0.807 & & 58.81078 & 53.41958 \\
\hline 52 & 0.058 & 1.70604 & 50.42785 & 48.39188 & & 0.881 & 9.18000 & 54.35908 & 51.49740 & & 0.8 & 0.82325 & 4015 & 53.44225 \\
\hline & 0.055 & 1.66540 & 50.50391 & 48.456 & & 0.880 & 1.17409 & 54.37834 & 51.52772 & & 0.805 & 0.85902 & 56.86947 & 53.46487 \\
\hline & 0.954 & 1.68494 & 50.57900 & 48.51349 & & 0.879 & 1.170 & 54.416 & 51.557 & & 0.804 & & & 53.46743 \\
\hline 55 & 0.053 & 1.67466 & 50.65200 & 82 & & 0.878 & & 54.4 & & & 0.803 & & 56.92700 & 53.50994 \\
\hline & 0.852 & 1.63458 & 50.72562 & 48.6 & & 0.877 & & 54.4 & 51.61780 & & 0.802 & 0.84878 & 58.85701 & 53.53239 \\
\hline & 0.051 & 1.65463 & 50.79721 & 48.6 & & 0.878 & & 54.5 & 51.647 & & & & & 53.55479 \\
\hline & 0.050 & 1.64485 & 50.86782 & 521 & & 0.8 & & 54.5 & & & 0.800 & 0.84 & 57.01505 & 53.57713 \\
\hline 5 & 0.949 & 1.635 & 50.03737 & 48.8 & & 0.874 & & & 51.70642 & & 0.789 & 0.8 & & 53.50042 \\
\hline & 0.048 & 1.62578 & 51.00503 & 48.85587 & & 0.873 & 1.14000 & 54.1 & & & 0.78 & 0.85 & 57.07273 & 53.62150 \\
\hline & 0.947 & 1.81644 & 51.07349 & 48.9 & & 0.87 & & 54.6 & 51.7 & & 0.78 & & 57.10152 & 53.64376 \\
\hline$\theta$ & 0.846 & 1.60725 & 51.14020 & & & 0.871 & & & & & 0.798 & 0.82742 & 57.13015 & 53. \\
\hline & 0.945 & 1.59819 & 51.20605 & 48.0 & & 0.870 & 9.12 & 54.75500 & & & 0.7 & & 5872 & 53.68783 \\
\hline & 0.844 & 1.56927 & 51.27097 & 794 & & 0.860 & 9.12168 & 54.7 & 51.8 & & 0.794 & & & 53.70084 \\
\hline & 0.943 & 1.58047 & & & & 0.8 & & & & & 0.793 & 0.81687 & 57.21582 & 53.73178 \\
\hline & 0.942 & 1.57170 & 51.3 & 80 & & 0.867 & 1.112 & 3453 & 51.8 & & 0.782 & & 57.24419 & 53.75363 \\
\hline & 0.941 & 1.56322 & 51.4 & & & 0.868 & & & & & 0.791 & & 7249 & 53.77541 \\
\hline & 0.840 & & & & & & & 54.8 & & & 0.780 & 0.80642 & 57.30081 & 53.79720 \\
\hline & 0.039 & & & & & 0.864 & & 54.97256 & 51.8 & & 0.789 & 0.8 & & \\
\hline 70 & 0.038 & 1.53820 & 51.64422 & 48.3 & & 0.863 & 1.09390 & 55.00825 & & & 0.78 & & & 53.84054 \\
\hline & 0.937 & 1.53007 & 51.70389 & & & 0.86 & & 55.0 & 52. & & 0.787 & & 57.38519 & 53.86210 \\
\hline & 0.936 & & 51.76289 & & & 0.80 & & 55.0 & & & 0.786 & 0.78262 & 57.41323 & 53.88367 \\
\hline & 0.035 & 1.51410 & 51.82130 & 48.5 & & 0.860 & 1.08032 & 55.11446 & & & 0.785 & 0.78919 & 57.44121 & 53.90518 \\
\hline 74 & 0.934 & & 51.87804 & 48.5 & & 0.859 & 1.07584 & 55.14954 & 52.13 & & 0.784 & 0.7857 & 57.46912 & 53.92863 \\
\hline & 0.933 & 1.49851 & & & & 0.8 & & 55.1 & 52.15794 & & 0.783 & 0.78237 & 57.49688 & 53.94796 \\
\hline 76 & 0.932 & & & 4364 & & 0.857 & 9.06694 & 55.21830 & 52.18509 & & 0.782 & 0.77897 & 57.52465 & 53.86930 \\
\hline 77 & 0.023 & 1.48328 & 52.04884 & 49.68814 & & 0.856 & 1.06252 & 55.253307 & 52.21212 & & 0.781 & & 57.56243 & 53.98005 \\
\hline 78 & 0.930 & 1.47579 & 52.10 & 49.73220 & & 0.855 & & & 52.26 & & 0.780 & 0.77210 & 57.58007 & 54.01188 \\
\hline & 0.820 & & & & & 0.854 & 1.053 & 55.322202 & 52.26585 & & $0.77 \theta$ & 0.76882 & 57.60764 & 54.03305 \\
\hline & 0.928 & 1.46100 & 52.21316 & 48.81895 & & 0.853 & & 55.35711 & & & 0.778 & & 57.63514 & 54.05416 \\
\hline 81 & 0.027 & 1.45381 & 52.26089 & 49.86160 & & 0.8 & 1.04505 & & & & 0.777 & & 57.68265 & 54.07520 \\
\hline 82 & 0.926 & 1.44863 & 52.32029 & 49.80405 & & 0.851 & 1.04073 & 55.42524 & 52.34554 & & 0.778 & 0.7 & 57.69009 & 54.09835 \\
\hline & 0.825 & 1.43953 & 52.37307 & 49.94596 & & 0.850 & 1.03643 & 55.45610 & 52.37180 & & 0.775 & & 57.71 & 73 \\
\hline
\end{tabular}

NUREG/CR-6121

B-14 
Attachment 2

\begin{tabular}{|c|c|c|c|c|c|c|c|c|c|c|c|c|c|c|}
\hline A & A & B & C & D & $E$ & $F$ & G & $H$ & 1 & $J$ & K & L & $\mathbf{M}$ & $\mathbf{N}$ \\
\hline 1 & SA-510 Cr. & O carbon st & & & & $81.05 \mathrm{~h}$ & median UTS & & & & 0.0411 & median tailur & e gtrain & \\
\hline 2 & $350 \mathrm{~F}$ & & & & & 72.85 & nedian fallú & 3 otreas & & & 77.89 & NURECYCA- & -5.03 ballun & stress \\
\hline 3 & $1.0 E-038$ & llure probedill & & & & 37.09 & nedian yield & stress & & & 40.91 & NUREC/CR & -5603 yield & tress \\
\hline 4 & & & & & & 0.211 & set & & & & 0.039 & Qjuste : killy & yrestrain & \\
\hline 5 & & & & & & & & & & & & & & \\
\hline 6 & survival & & & adjusted & & suntual & & & aciusted & & suntival & & & aclustad \\
\hline 7 & confidence & $x$ & stress & atreas & & confidence & $x$ & strees & stress & & conffdence & $x$ & streas & stress \\
\hline 8 & 0.9090 & 3.71002 & & & & & & & & & & & & \\
\hline 9 & 0.09 & 3.00023 & 37.80000 & 37.05000 & & 0.024 & 1.43250 & 53.00653 & 52.97839 & & 0.849 & 1.03215 & 58.68288 & 57.35515 \\
\hline 10 & 0.808 & 2.87816 & 39.72948 & 39.05340 & & 0.023 & 1,42554 & 53.28779 & 53.05174 & & 0.848 & 1.02769 & 58.71583 & 57.40349 \\
\hline 11 & 0.997 & 2.74778 & 40.83821 & 40.71032 & & 0.922 & 1.41885 & 54.00638 & 53.12444 & & 0.847 & 1.02365 & 58.76824 & 57.45164 \\
\hline 12 & 0.098 & 2.65207 & 41.87175 & 41.50322 & & 0.021 & 1.41163 & 54,14428 & 33.18249 & & 0.848 & 1.01843 & 53.82002 & 57,48000 \\
\hline 13 & 0.095 & 2.57583 & 42.34789 & 42.14533 & & 0.020 & 1.40507 & 54.22100 & 53.26000 & & 0.845 & 1.01522 & 58.67292 & 57.54748 \\
\hline 14 & 0.004 & 2.51214 & 42.22113 & 42.68697 & & 0.018 & 1.30238 & 54.20024 & 53.3385 & & 0.844 & 1.01103 & 53.02502 & 57.50517 \\
\hline 15 & 0.003 & 2.45726 & 43.42130 & 43.16275 & & 0.018 & 1.39174 & 54.37441 & 53.40027 & & 0.843 & 1.00683 & 58.97002 & 57.64267 \\
\hline 18 & 0.092 & 2.40302 & 43.80009 & 43.58420 & & 0.817 & 1.38517 & 54.44688 & 53.47002 & & 0.842 & 1.00271 & 59.02861 & 57.60090 \\
\hline 17 & 0.991 & 2.36502 & 44.20052 & 43.90503 & & 0.916 & 1.37063 & 54.52478 & 53.54823 & & 0.841 & 0.0958 & 50.08010 & 57.73710 \\
\hline 18 & 0.000 & 2.35035 & 44.05805 & 44.31314 & & 0.915 & $1.37 \mathrm{ec0}$ & 54.59017 & 53.61609 & & 0.840 & 0.90448 & 59.13151 & 57.78414 \\
\hline 18 & 0.009 & 2.29037 & 44.97841 & 44.63438 & & 0.914 & 1.30581 & 54.07297 & 53.68508 & & 0.869 & $0.900 \mathrm{se}$ & 59.18271 & 57.83008 \\
\hline 20 & 0.088 & 2.25713 & 45.20515 & 44.03312 & & 0.913 & 1.35040 & 54.74022 & 53.75292 & & 0.638 & 0.90 .27 & 50.20303 & 57.87775 \\
\hline 21 & 0.097 & 2.22021 & 45.50178 & 45.21271 & & 0.912 & 1.36317 & 54.81890 & 53.85001 & & 0.837 & 0.99620 & 50.28475 & 57.92432 \\
\hline 22 & 0.003 & 2.10729 & 45.87003 & 45.47571 & & 0.911 & 1.3469 & 54.09111 & 59.86003 & & 0.836 & 0.07815 & 59.33546 & 57.97070 \\
\hline 23 & 0.835 & 2.17009 & 46.13514 & 45.72438 & & 0.910 & 1.34070 & 54.00277 & 53.05600 & & 0.835 & 0.97411 & 50.30000 & 58.01700 \\
\hline 24 & 0.034 & 2.14441 & 46.38094 & 45.80034 & & 0.009 & 1.33462 & 55.03406 & 54.01801 & & 0.834 & 0.97009 & 59.43651 & 58.00310 \\
\hline 25 & 0.903 & 2.12007 & 46.02400 & 46.16508 & & 0.008 & 1.32054 & 55.10474 & 54.00385 & & 0.833 & 0.80009 & 59.48672 & 58.10901 \\
\hline 28 & 0.0 .2 & 2.0000 & 46.853203 & 46.3005 & & 0.907 & 1.32251 & 55.17494 & 54.14633 & & $0.8 \times 2$ & 0.80210 & 50.53635 & 58.15484 \\
\hline 27 & 0.031 & 2.07485 & 47.07214 & 46.00530 & & 0.008 & 1.31652 & 55.24475 & 54.21305 & & 0.831 & 0.95312 & 59.58090 & 58.20053 \\
\hline 28 & 0.980 & 2.06375 & 47.2029 & 48.80202 & & 0.005 & 1.31058 & 55.31407 & 54.27700 & & 0.850 & 0.85416 & 50.65673 & 58.24813 \\
\hline 29 & 0.979 & 2.05552 & 47.46465 & 46.09255 & & 0.004 & 1.30400 & 55.38000 & 54.34049 & & 0.829 & 0.00022 & 50.68638 & 58.29148 \\
\hline 30 & 0.978 & 2.01400 & 47.6793 & 47.17500 & & 0.003 & 1.29884 & 55.45134 & 54.40561 & & 0.028 & 0.04 .29 & 50.73500 & 58.33675 \\
\hline 31 & 0.977 & 1.0955 & 47.86843 & 47.35652 & & 0.002 & 1.20003 & 55.51009 & 54.46037 & & 0.827 & 0.04238 & 50.78523 & 58.38182 \\
\hline 32 & 0.978 & 1.97737 & 48.03068 & 47.52354 & & 0.001 & 1.28727 & 55.56094 & 54.52005 & & 0.820 & 0.08848 & 50.83447 & 58.42001 \\
\hline 33 & 0.975 & 1.85908 & 48.22781 & 47.08933 & & 0.800 & 1.28155 & 55.65411 & 54.59057 & & 0.825 & 0.83458 & 59.830375 & 58.47183 \\
\hline 34 & 0.974 & 1.24313 & 48.30947 & 47.85011 & & 0.899 & 1.27587 & 55.72089 & 54.65212 & & 0.824 & 0.03072 & 59.85257 & 59.51643 \\
\hline 35 & 0.973 & 1.00094 & $48.5 \times 620$ & 48.00022 & & 0.898 & 1.27024 & 55.78715 & 54.71320 & & 0.823 & 0.02006 & 50.00143 & 58.58105 \\
\hline 38 & 0.972 & 1.91104 & 48.72047 & 48.15810 & & 0.897 & 1.26404 & 55.85314 & 54.77401 & & 0.822 & 0.92001 & 60.05020 & 58.00580 \\
\hline 37 & 0.971 & 1.80570 & 48.86653 & 48.30099 & & 0.808 & 1.25003 & 55.01874 & 54.83445 & & 0.621 & 0.91018 & 60.07670 & 58.64033 \\
\hline 38 & 0.870 & 1.80079 & 49.04085 & 46.45014 & & 0.805 & 1.23357 & 55.83583 & 54.80941 & & 0.820 & 0.01537 & 60.12710 & 58.69403 \\
\hline 30 & 0.09 & 1.80050 & 49.18009 & 48.590 .2 & & 0.694 & 1.24003 & 30.04675 & 54.05421 & & 0.810 & 0.91158 & 00.17548 & 58.75020 \\
\hline 40 & 0.988 & 1.85218 & 49.33775 & 48.72789 & & 0.803 & 1.24294 & 58.11315 & 50.01353 & & 0.818 & 0.00777 & $60.2 \times 65$ & 58.78220 \\
\hline 41 & 0.867 & 1.88842 & 49.48128 & 48.80200 & & 0.692 & 1.20723 & 50.17728 & 55.07257 & & 0.817 & 0.90599 & 60.27173 & 58.86008 \\
\hline 42 & 0.080 & 1.82501 & 49.62156 & 46.89504 & & 0.691 & 1.23183 & 50.24100 & 55.13125 & & 0.816 & 0.00023 & 60.31059 & 58.60978 \\
\hline 43 & 0.865 & 1.81191 & 49.75890 & 49.12137 & & 0.800 & 1.22633 & 50.30432 & 55.18954 & & 0.815 & 0.80847 & 60.56749 & 88.91347 \\
\hline 44 & 0.984 & 1.79912 & 49.80651 & 49.24697 & & 0.889 & 1.22123 & 50.30735 & 55.24758 & & 0.814 & 0.00273 & 60.41517 & 58.95603 \\
\hline 45 & 0.000 & 1.78351 & 50.02540 & 49.37011 & & 0.888 & 1.21508 & 56.43010 & 55.30531 & & 0.813 & 0.88001 & 60.46234 & 59.00009 \\
\hline 46 & 0.002 & 1.77488 & 50.15478 & 49.49078 & & 0.887 & 1.21072 & 56.49253 & 55.30278 & & 0.812 & 0.88520 & 60.51014 & 58.04362 \\
\hline 47 & 0.001 & 1.76241 & 50.28160 & 49.60915 & & 0.883 & 1.20553 & 56.55449 & 55.41077 & & 0.811 & 0.88159 & 60.55742 & 59.06675 \\
\hline 48 & 0.060 & 1.75000 & 50.40065 & 49.72630 & & 0.865 & 1.20053 & 50.61625 & 55.47053 & & 0.810 & 0.87790 & 60.60481 & 59.12000 \\
\hline 49 & 0.839 & $1.73 \% 20$ & 50.52803 & 49.85943 & & 0.884 & 1.1062 & 58.67772 & 55.53313 & & 0.809 & 0.87422 & 60.65172 & 50.17275 \\
\hline 50 & 0.058 & 1.72703 & 50.04003 & 49.95161 & & 0.883 & 1.10012 & 56.73877 & 55.58928 & & 0.808 & 0.87055 & 60.60373 & 50.21562 \\
\hline 51 & 0.857 & 1.71689 & 50.76721 & 50.08173 & & 0.892 & 1.18504 & 56.79003 & 55.64527 & & 0.807 & 0.88089 & 60.74584 & 59.25840 \\
\hline 52 & 0.033 & 1.70004 & 50.68503 & 50.17018 & & 0.881 & 1.18000 & 56.86012 & 55.70087 & & 0.808 & 0.83325 & 60.70234 & 50.30008 \\
\hline 53 & 0.855 & 1.60540 & 50.00005 & 50.27874 & & 0.860 & 1.17490 & 56.82020 & 55.75810 & & 0.805 & 0.85002 & 60.83005 & 59.34346 \\
\hline 54 & 0.654 & 1.68484 & 51.11079 & 50.38171 & & 0.879 & 1.17000 & 58.80029 & 55.81134 & & 0.604 & 0.85600 & 60.88546 & 59.38580 \\
\hline 55 & 0.858 & 1.67463 & 51.22184 & 50.46508 & & 0.878 & 1.16505 & 57.03898 & 55.86809 & & 0.803 & $0.852 \times 9$ & 60.23188 & 50.422817 \\
\hline 56 & 0.852 & 1.68458 & 51.33117 & 50.50082 & & 0.877 & 1.16012 & 57.00920 & 55.92088 & & 0.802 & 0.84879 & 60.07820 & 50.47030 \\
\hline 57 & 0.851 & 1.65463 & 51.43888 & 50.68705 & & 0.878 & 1.15522 & 57.15838 & 55.97408 & & 0.801 & 0.84520 & 61.02444 & 50.51252 \\
\hline 58 & 0.850 & 1.644 .5 & 51.54520 & 50.78594 & & 0.875 & 1.15035 & 57.21715 & 56.02800 & & 0.800 & 0.84162 & 61.07057 & 59.55453 \\
\hline 50 & 0.840 & 1.05523 & 51.64909 & 50.88339 & & 0.874 & 1.14551 & 57.27565 & 56.08274 & & 0.789 & 0.83805 & 61.11662 & 59.50651 \\
\hline 60 & 0.048 & 1.62576 & 51.75338 & 50.97949 & & 0.873 & 1.14069 & 57.33363 & 58.13000 & & 0.789 & 0.83450 & 61.16244 & 59.63825 \\
\hline 61 & 0.947 & 1.61644 & 51.85528 & 51.07424 & & 0.872 & 1.13500 & 57.39188 & E6.18958 & & 0.797 & 0.83095 & 61.20829 & 59.68002 \\
\hline 62 & 0.848 & 1.00725 & 51.85509 & 51.16783 & & 0.871 & 1.13113 & 57.44979 & 56.24288 & & 0.793 & 0.82742 & 61.25303 & 50.72158 \\
\hline 63 & 0.945 & 1.59819 & 52.05546 & 51.20025 & & 0.870 & 1.12630 & 57.50730 & 58.20549 & & 0.795 & 0.82350 & 61.29946 & 59.76305 \\
\hline 64 & 0.244 & 1.58927 & 52.15357 & 51.35140 & & 0.860 & 1.12168 & 57.56451 & 56.34801 & & 0.794 & 0.82038 & 61.34503 & 59.60455 \\
\hline 65 & 0.843 & 1.58047 & 52.25055 & 51.44147 & & 0.868 & 1.11699 & 57.62154 & 56.40036 & & 0.793 & 0.81697 & 81.38050 & 59.84505 \\
\hline 68 & 0.042 & 1.57179 & 52.34639 & 51.53046 & & 0.837 & 1.11232 & 57.67837 & 50.45253 & & 0.792 & 0.81338 & 61.43575 & 59.88715 \\
\hline 67 & 0.041 & 1.56322 & 52.44118 & 51.61846 & & 0.886 & 1.10768 & 57.73490 & 50.50441 & & 0.791 & 0.80090 & 61.48000 & 59.82825 \\
\hline 68 & 0.040 & 1.55477 & 52.53481 & 51.70537 & & 0.865 & 1.10308 & 57.79124 & 58.55010 & & 0.780 & 0.80842 & 61.52009 & 59.89938 \\
\hline 69 & 0.009 & 1.54643 & 52.62739 & 51.70128 & & 0.834 & 1,08347 & 57.84727 & 58.60751 & & 0.780 & 0.80298 & 61.57105 & 60.01030 \\
\hline 70 & 0.938 & 1.53820 & 52.71891 & 51.87619 & & 0.803 & 1.00090 & 57.00310 & 58.05874 & & 0.783 & 0.79030 & 61.81604 & 60.05125 \\
\hline 71 & 0.037 & 1.83007 & 52.80047 & 51.80000 & & 0.802 & 1.03935 & 57.05875 & 58.70978 & & 0.787 & 0.79008 & 81.66000 & 60.00188 \\
\hline 72 & 0.858 & 1.50204 & 52.80007 & 52.04530 & & 0.861 & 1,09482 & 58.01420 & 56.70064 & & 0.786 & 0.70262 & 01.70500 & 00.13274 \\
\hline 73 & 0.935 & 1.51410 & 52.09781 & 52.12350 & & 0.800 & 1.00032 & 58.00034 & 58.81121 & & 0.785 & 0.78919 & 81.75028 & 60.17341 \\
\hline 74 & 0.034 & 1.50026 & 53.07550 & 52.20098 & & 0.050 & 1.07584 & 58.12429 & 56.66160 & & 0.784 & 0.78577 & 61.79489 & 60.21309 \\
\hline 75 & 0.033 & 1.49851 & 53.10250 & 52.26752 & & 0.858 & 1.07138 & 56.17004 & 58.91180 & & 0.783 & 0.78237 & 61.85028 & 60.25435 \\
\hline 78 & 0.852 & 1.49065 & 53.24854 & 52.36725 & & 0.857 & 1.00094 & 58.23300 & 58.80181 & & 0.782 & 0.77897 & 61.86067 & 60.29474 \\
\hline 77 & 0.031 & 1.48328 & 53.33370 & 52.44616 & & 0.856 & 1.08252 & 58.28797 & 57.01165 & & 0.781 & 0.77557 & 61.02810 & 60,33515 \\
\hline 78 & 0.830 & 1.47570 & 53.41810 & 52.52435 & & 0.835 & 1.05812 & 58.34213 & 57.06130 & & 0.780 & 0.77219 & 81.97231 & 00.37535 \\
\hline 79 & 0.29 & 1.46838 & 53.50173 & 52.60181 & & 0.854 & 1.05374 & 58.36811 & 57.11078 & & 0.779 & 0.70002 & 02.01841 & 60.41545 \\
\hline 80 & 0.028 & 1.46108 & 53.58447 & 52.67843 & & 0.853 & 1.04930 & 58.44978 & 57.15602 & & 0.778 & 0.76540 & 82.00042 & 60.45547 \\
\hline 81 & 0.027 & 1.45381 & 53.66655 & 52.75443 & & 0.852 & 1.04505 & 58.50334 & 57.20001 & & 0.777 & 0.76210 & 62.10446 & 80.40550 \\
\hline 82 & 0.828 & 1.44603 & 53.74790 & 52.82979 & & 0.851 & 1.04073 & 58.55671 & 57.25791 & & 0.776 & 0.75675 & 02.14839 & 80.53544 \\
\hline 83 & 0.825 & 1.43053 & 53.82858 & 52.80441 & & 0.850 & 1.05843 & 58.60000 & 57.30603 & & 0.775 & 0.75542 & 62.10210 & 60.57517 \\
\hline
\end{tabular}


Attachment 2

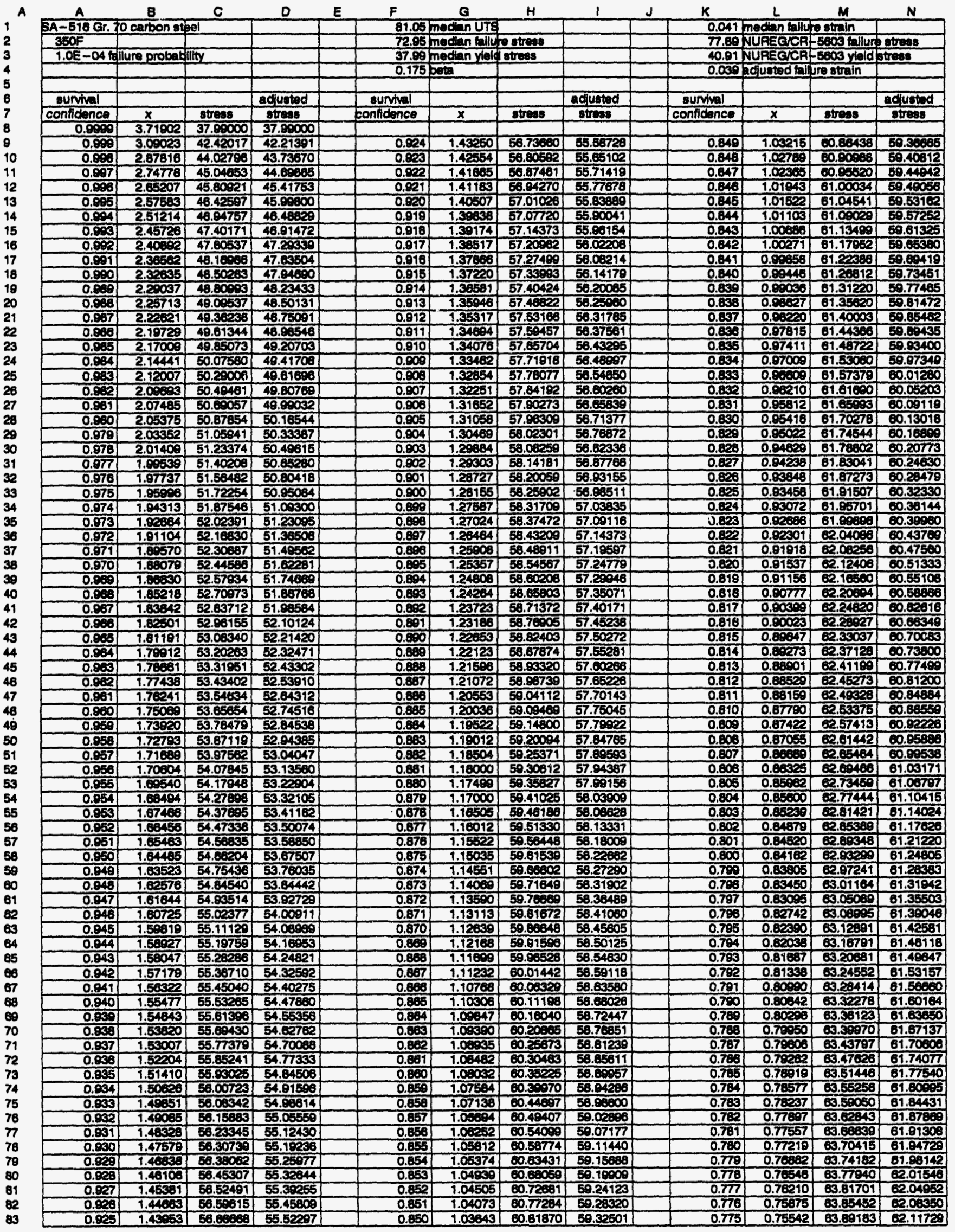

NUREG/CR-6121

B-16 

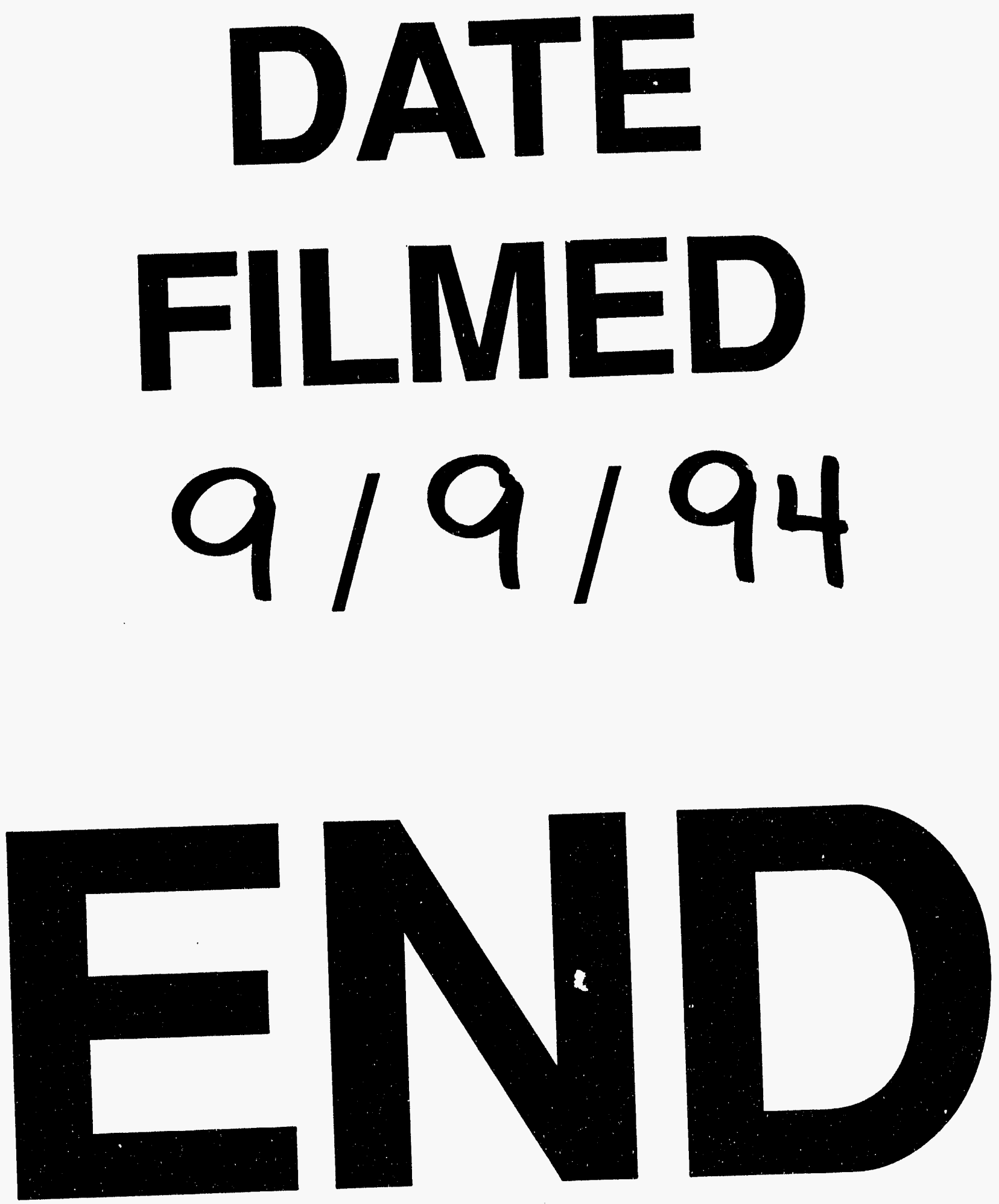
